Edited by: Anna Belehaki, Mike Hapgood and Juergen Watermann

\title{
The ESPAS e-infrastructure: Access to data from near-Earth space
}

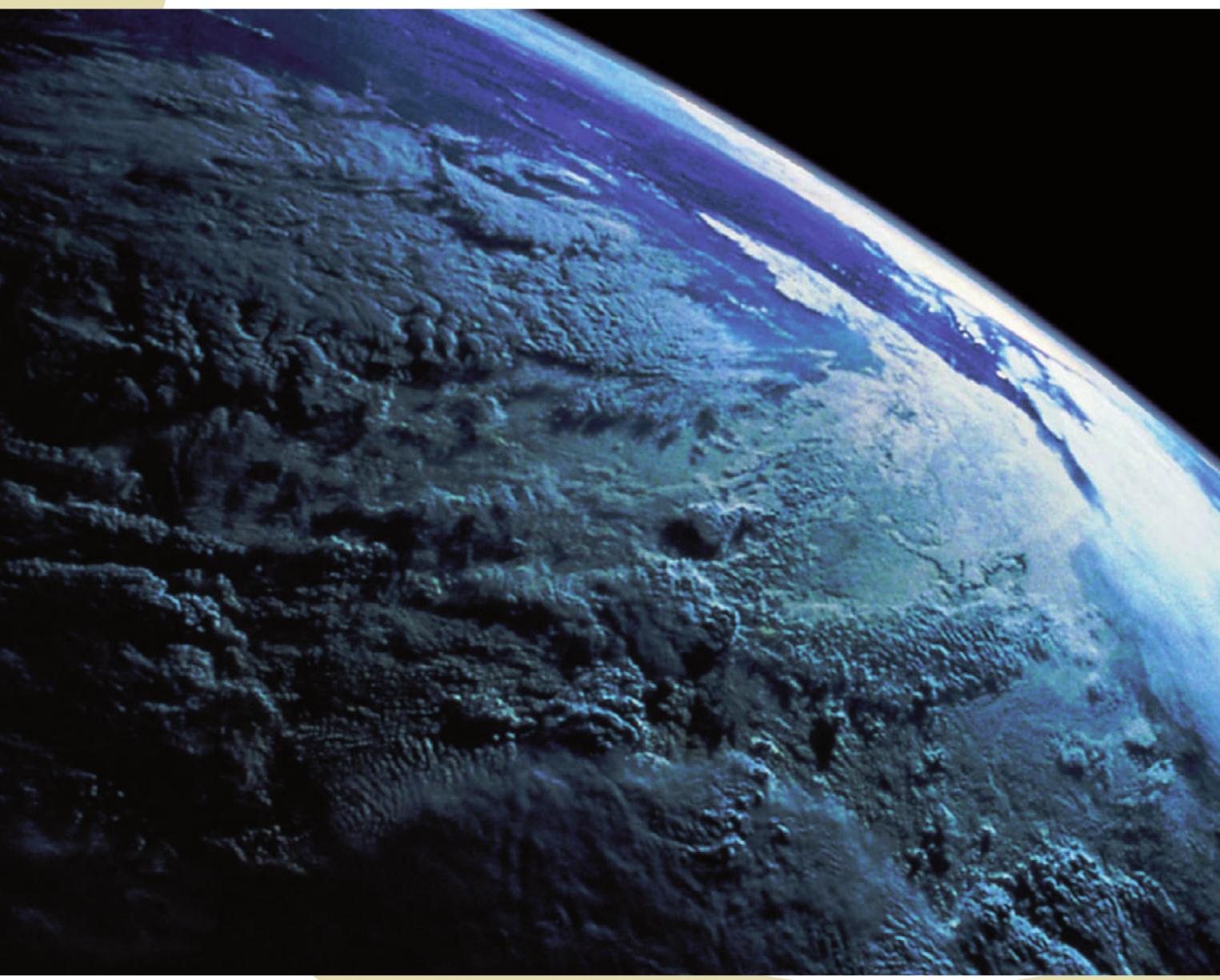

(․) espas 


\section{The ESPAS e-infrastructure: Access to data from near-Earth space}


This work is published in open access under the terms of the Creative Commons Attribution License (http://creativecommons.org/licenses/by/4.0), which permits unrestricted use, distribution, and reproduction in any medium, provided the original work is properly cited.

http://www.edp-open.org

ISBN 978-2-7598-1949-2

DOI: $10.1051 / 978-2-7598-1949-2$

(C) EDP Science, 2017 - www.edpsciences.org 


\section{Acknowledgements}

The ESPAS project is funded through EU-FP7 under grant agreement 283676. The publication of the ESPAS e-book is co-funded by the OpenAIRE FP7 post-grant Open Access Pilot and the National Observatory of Athens. Authors are grateful to the "Laboratorio grafica \& immagini" of the Istituto Nazionale di Geofisica e Vulcanologia for its precious work in designing the ESPAS corporate material and logo. 



\section{Contents}

\section{Introduction}

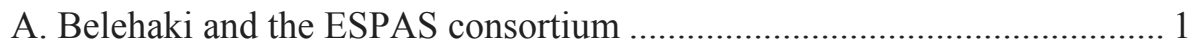

2. Space physics ontology for ESPAS

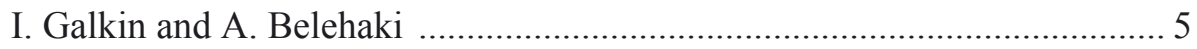

\section{ESPAS observation collections}

M. Hapgood and A. Belehaki ................................................................... 11

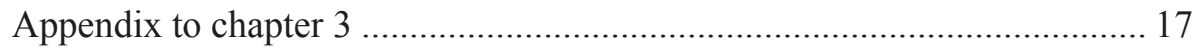

3.1 Fabry-Pérot interferometer and CMAT2 model

P. Guio, A. Aruliah, A. Aylward, A. Bushell and E. Henley ........................ 29

3.2 Cluster and DEMETER satellite data in ESPAS

F. Darrouzet, J. De Keyser and P. Décréau .................................................. 47

3.3 Calibrated and corrected POES/MEPED energetic particle observations

T. Asikainen 
3.4 Ground and space based GNSS ionosphere monitoring data in ESPAS

J. Berdermann, M. Hoque, M. Kriegel

and N. Jakowski for the ESPAS consortium

3.5. Ground base ionospheric radio sounding: Basic principles and application

B. Zolesi

3.6 Ionospheric modeling results in ESPAS

I. Tsagouri 91

3.7. Ionospheric data assimilation in ESPAS

M.J. Angling, S. Elvidge, N. Jackson-Booth and R.W. Penney. 103

\subsection{Incoherent and coherent scatter radars}

I. Häggström

4. ESPAS interoperability

A. Belehaki, N. Manola and M. Hapgood

\subsection{The ESPAS data model}

S. James, S. Ventouras and A. Charisi

Appendix to chapter 4.1 


\subsection{ESPAS Services}

A. Charisi, A. Lebesis and N. Manola....................................................... 137

\section{ESPAS functionalities for the end-user}

A. Belehaki, A. Charisi, S. James, M. Hapgood, S. Ventouras, I. Galkin, A. Lembesis and J. Berdermann.

\subsection{How to access data through ESPAS}

I. Tsagouri, A. Charisi and F. Darrouzet ................................................... 149

\section{Summary}

M. Hapgood, A. Belehaki and the ESPAS consortium 



\section{Introduction}

Anna Belehaki ${ }^{1}$ and the ESPAS consortium ${ }^{2}$

1. National Observatory of Athens, Greece

2. https://www.espas-fp7.eu/trac/wiki/PublicPages/ESPASConsortium

Near-Earth space is the region that extends from the middle atmosphere up to the outer radiation belts. This region is of significant interest because of its potentially undesired effects on human life and on technological systems, whose understanding, modeling and prediction require continuous scientific exploration and advances. Consequently, a number of observing systems have been set up to acquire observations from the near-Earth space, producing a wealth of diverse types of data which still need to be homogenized and organized in order to become widely accessible.

The exploitation of multi-instrument data from a large number of distributed observing sites is the requirement for accurate predictions of the near-Earth space environment. As the near-Earth space is part of the complex Sun-Earth system, supporting data from the Sun, the interplanetary medium but also from the upper and lower layers of the atmosphere, are needed to drive near-Earth prediction models. In space physics, predictions are made via physical, semi-empirical or empirical models. The models are fed with actually observed properties (e.g., measured solar wind speed and density) or with typical values for specific environmental properties (e.g., average speed and density of the slow solar wind during solar minimum), and the model output provides values which can be compared to other properties derived from observations (e.g., local or global geomagnetic activity index). A comprehensive comparison between model results and observed data enables the community to distinguish between models with good and with poor performance under certain geophysical conditions. Space physics models with good predictive capabilities may be used to forecast accurately the state of the space environment and to enable the end user communities to mitigate the effects of major disturbances on humans and technological systems. Results obtained from model runs depend to a large extent on the boundary conditions. Sometimes the problem can be solved by specifying boundary conditions over the entire globe and running the model on a global scale. However, specification of global boundary conditions requires data from many observational sites. Ionospheric total electron content (TEC) maps are a typical example for the dependency of maps on global data coverage in order to be realistic.

This specific need has led the space science community to work intensively for the development of systems that can facilitate data discovery and processing.

- The Inter-university Upper atmosphere Global Observation NETwork (IUGONET) has been implemented by Japanese universities and institutes and aims at providing new research platforms, metadata database and analysis software tools, to facilitate the use and distribution of the long-term observation data for upper atmospheric physics (Hayashi et al., 2013). In addition to the open 
search service based on the metadata database, IUGONET provides: automatic data download; data analysis without regard to the file format of the data; parallel display of different types of data; utilization of various analysis functions (e.g., frequency analysis, filtering); output into an ASCII file or image files. The generated metadata are archived as XML files for interoperability with other metadata databases and future expandability. As the base of the metadata format, IUGONET selected the Space Physics Archive Search and Extract (SPASE) data model/metadata format (Merka et al., 2008), that has been modified to best match the upper atmosphere data, to create the IUGONET common metadata format.

- The Automated Multi Dataset Analysis (AMDA) is provided by the Centre de Données de la Physique des Plasmas (CDPP) supported by CNRS, CNES, Observatoire de Paris and Université Paul Sabatier, Toulouse (Jacquey et al., 2010). AMDA is a web-based facility for online analysis of space physics time series data coming from either its local database or distant ones. AMDA offers functionalities to access and analyze multi-point and multi-instrument data in a transparent way by the user. More precisely, AMDA provides functionalities for: performing search of events; performing automated and semi-automated characterization of events; extracting sub-database from an input timetable; performing basic data treatment in order to provide to the user data ready to use with her/his favorite software. AMDA provides direct access to data from distant databases in a transparent way and includes a connection layer compliant with the SPASE standards.

- The HELiophysics Integrated Observatory (HELIO) has been developed in the framework of an EU-FP7 research infrastructure project (Bentley et al., 2010). HELIO adopts the concept of distributed network of services that addresses the needs of a broad community of researchers in heliophysics. It coordinates access to the resources needed by the community, and provides services to mine and analyze the data. HELIO has been developed as a set of independent services. Several ways are provided to access them. The services can be used individually, within a workflow or scripting language, or through the HELIO Front-End web user interface. HELIO provides the scientist with an operational scenario for heliophysical data handling (Perez-Suarez et al., 2012). It relieves the user from the burden of data source identification and data integration, as its web interface makes it possible to place complex searches on multiple data repositories relevant to heliospheric data in a unified, user-transparent way. This facilitates research, and creates a favorable operational environment for knowledge discovery.

- The Integrated Space Weather Analysis System (iSWA) is a U.S. Government Computer Server that provides access to space weather data products and tools for both real-time as well as historical analysis. Users are provided with the capability to specify and/or forecast the large scale and local space environment. Certain data products may be in experimental or evaluation phases of development. iSWA is customer configurable and adaptable for use as a powerful decision making tool, providing mission managers and decision-makers with personalized "quick look" 
space weather information, detailed insight into space weather forecasts, and tools for historical impact analysis. iSWA data management is based on a comprehensive data model that drives the system and it is supported by the Cygnet software.

Driven from these developments and in order to reach further advances in the discovery and uniform access to data, the European Commission has funded the NearEarth space data infrastructure for e-science (ESPAS) project from Framework Programme 7. ESPAS is a data e-infrastructure facilitating discovery and access to observations and model predictions of the near-Earth space environment (Belehaki et al., 2016). ESPAS provides a one-stop shop for researchers and users of research results who wish to exploit multi-instrument multi-point science data for analysis. ESPAS offers two major advantages:

(a) its basic functionalities are based on the exploitation of metadata; consequently the data reside at the node of the provider, and therefore both the data integrity and their distribution policy are protected.

(b) the adopted data model and the domain ontology developed to standardize the metadata and data offer homogeneous and easy discovery of data offered by ESPAS.

These basic advantages pave the way for easier use of key Research Infrastructures that have registered their data in ESPAS. EISCAT, the European Incoherent SCATter Scientific Association, is one representative example. EISCAT is a major European research infrastructure with radar facilities in Northern Scandinavia and at Svalbard. The current radars operate normally, for funding reasons, in campaign mode, with data-taking periods of some hours to several days. The incoherent scatter radar technique is the most powerful ground-based tool to conduct research on the whole atmosphere and ionosphere. The basic observed properties are the derived narrow field profiles of plasma properties. To get a better understanding of the physics the data represent, it is often needed to gather data from other instruments to complete the picture in several dimensions like time, space and depth of physical properties. The functionalities of ESPAS are able to investigate what data is available and suitable for this by giving lists of available complementing observations covering the same time periods, nearby or overlapping locations, with direct links to the data. This allows also a wealth of additional properties, describing the ionosphere and neutral atmosphere, to be derived. On the other hand, ESPAS will also significantly increase the user base of EISCAT. The EISCAT data is normally available in the Madrigal database, but to use it efficiently it is needed to be rather familiar with the technique. ESPAS enables the data to be visible and searchable for other communities in a heterogeneous way. In the long run, this can open up new funding possibilities for the radars enabling extended operations over longer times bringing the science further with increased speed.

In this book, we provide the basic concept applied for the development of the ESPAS platform and examples demonstrating its functionality. More specifically, in Section 2 we provide an analytical description of the space physics ontology for ESPAS. In Section 3 we present the data whose registration is tested in the ESPAS 
platform giving emphasis on the scientific exploitation of these data to resolve key near-Earth space physics problems. In Section 4 we present the interoperability concept of ESPAS focusing on the data model and on the internal services developed to offer the discovery and access. Finally, in Section 5 we present some basic use cases to provide examples to the reader for the functionalities of the ESPAS platform. The book is completed with a conclusion section.

\section{References}

Belehaki, A., S. James, M. Hapgood, S. Ventouras, I. Galkin, A. Lembesis, I. Tsagouri, A. Charisi, L. Spogli, J. Berdermann, I. Häggström (2016), The ESPAS eInfrastructure: Access to Data From Near-Earth Space, Advances in Space Research, Available online 17 June 2016, ISSN 0273-1177, http://dx.doi.org/10.1016/j.asr.2016.06.014.

Bentley, R. D., Csillaghy, A., Aboudarham, J., Jacquey, C., Hapgood, M. A., Bocchialini, K., Messerotti, M., Brooke, J., Gallagher, P., Fox, P., Hurlburt, N., Roberts, D. A., Duarte, L. Sanchez, "HELIO: The Heliophysics Integrated Observatory", Advances in Space Research, Volume 47, Issue 12, p. 2235-2239, 2010 [DOI: 10.1016/j.asr.2010.02.006]

Pérez-Suárez, D., S. A. Maloney, P. A. Higgins, D. S. Bloomfield, P. T. Gallagher, G. Pierantoni, X. Bonnin, B. Cecconi, V. Alberti, K. Bocchialini, M. Dierckxsens, A. Opitz, A. Le Blanc, J. Aboudarham, R. B. Bentley, J. Brooke, B. Coghlan, A. Csillaghy, C. Jacquey, B. Lavraud and M. Messerotti, "Studying Sun-Planet Connections Using the Heliophysics Integrated Observatory (HELIO)", Solar Physics, Vol 280, Issue 2, pp 603-621, 2012

Hayashi, H., Y. Koyama, T. Hori, Y. Tanaka, S. Abe, A. Shinbori, M. Kagitani, T. Kouno, D. Yoshida, S. UeNo, N. Kaneda, M. Yoneda, N. Umemura, H. Tadokoro, T. Motoba, and IUGONET project team, "Inter-university Upper Atmosphere Global Observation NETwork (IUGONET)", Data Sci. J., 12, WDS179WDS184, link, 2013.

Jacquey, C., V., Génot, E. Budnik, R. Hitier, M. Bouchemit, M. Gangloff, M., A. Fedorov, B. Cecconi, N. André, B. Lavraud, C. Harvey, F. Dériot, D. Heulet, E. Pallier, E. Penou, J.L. Pinçon, AMDA, Automated Multi-Dataset Analysis: A WebBased Service Provided by the CDPP, in "The Cluster Active Archive", Astrophysics and Space Science Proceedings, pp 239-247, ed. by H. Laakso, E. Taylor, M. E. Escoubet, C. Philippe, 10.1007/978-90-481-3499-1_16, http://dx.doi.org/10.1007/978-90-481-3499-1_16, Springer Netherlands, 2010.

Merka, J., T. W. Narock, A. Szabo, Navigating through SPASE to heliospheric and magnetospheric data, Earth Sci Inform (2008) 1:35-42, DOI 10.1007/s12145-0080004-5 


\title{
2. Space physics ontology for ESPAS
}

\author{
Ivan Galkin ${ }^{1}$ and Anna Belehaki ${ }^{2}$
}

1. University of Massachusetts Lowell, Space Science Laboratory, Lowell, USA

2. National Observatory of Athens, Institute of Astronomy, Astrophysics, Space Applications and Remote Sensing, Greece

The major challenge that ESPAS project had to face was the standardization of metadata describing inhomogeneous data files. To make this possible, ESPAS had to use a data model capable to describe all hierarchies and procedures involved in the chain of observation acquisition and archiving, and to find all correspondences between the different classes of the data model and the physical parameters describing the near-Earth space environment. The space physics ontology of ESPAS is a vocabulary of keywords used by the data providers to characterize the physical content of their observations. The ESPAS data portal manages this vocabulary of Space Physics keywords to narrow down data searches to observations of specific physical content. Such content-targeted search is an ESPAS innovation provided in addition to the commonly practiced data selection by time, location, and instrument. The ESPAS Space Physics ontology is the cornerstone of the domain-specific data search functions. The ontology is organized in several hierarchies of keywords connected to each other via a "broader-narrower" relationship. Understanding the ontology hierarchies is critical for efficient data search and discovery in ESPAS.

The ESPAS Ontology leverages several existing domain vocabularies developed for space physics over the years. In particular, definitions of SPASE data model (King et al., 2010) built for NASA Heliophysics Data Environment (HPDE) were heavily reused and further augmented with the ground-based measurement language and wave science dictionaries (Shing, 2010). By attributing terminology from other data models, ESPAS simplified an important task of cross-walking metadata in various collaborative space data environments (Galkin et al., 2015).

However, SPASE has been designed as a resource-centric project, reflecting the HPDE focus on a comprehensive account of all Space Physics data resources and lesser interest in the detail of their content description. In contrast, ESPAS was coined to become observation-centric, structured, extremely detailed, and equipped with modern day tools for manipulating metadata compliant with the Earth Science ISO standards for geographic information, in particular the Observation and Measurement (O\&M) standard 19156 (ISO, 2011).

The expanding scope and growing detail of relevant ESPAS subdomains demanded a studious effort to restructure the wealth of existing terminology. It is only with the use of ISO O\&M standard that we could bring the systematic arrangement to otherwise plain linear list of terms and nicknames found in the heterogeneous space data environments. Critically instrumental to the task, the ISO O\&M views the near-Earth domain through the prism of its founding concepts of Observation, Observed Property, and Process. 


\subsection{Observation, Observed Property, and Process}

In the ISO O\&M standard, it is the Observed Property that describes the underlying naturally-occurring physical phenomenon of interest to scientists. Then, Observation is a human-initiated act that results in evaluation of the intended phenomenon property by means of particular Process, a combination of data acquisition and computation steps (ISO, 2011). This important distinction in the O\&M architecture greatly helps the task of building ESPAS Ontology, as all required terms of the Observed Property vocabulary are directly associated with physical concepts and relationships specific to the near-Earth space and are free from cluttering definitions of various Process-related attributes such as system of coordinates, vector projections, dimensions, units, etc. This important aspect of ESPAS Ontology is further illustrated by comparison of the Observed Property to Process Capability.

\subsection{Observed Property vs Process Capability}

O\&M standard makes a clear, important distinction to separate the Observed Property (as occurring naturally) from the Process Capability (that describes specific and usually limited capability of the sensors or models to evaluate the property). For example, one of the common Observed Properties of the ionospheric plasma is its bulk velocity that naturally exists as a vector quantity everywhere in the $3 \mathrm{D}$ volume of the Earth's ionosphere. However, the bulk velocity can be observed with various spatial coverages, completeness of the vector representation, choices of coordinate system and units, background assumptions, approximations, limitations, etc. For example, certain high-frequency ionosondes can detect velocity of the bottomside ionospheric plasma under assumption that the plasma is drifting across the sky over the observatory location as a single entity. In this case, the Process Capability points to the Observed Property "drift velocity of electrons", but defines that its dimensionality is 0D.Point (rather than the natural 3D.Volume), along with descriptions of simplifications and other assumptions used in the process of computing the velocity.

The ESPAS search engine uses the vocabulary of Observed Properties rather than the Process Capabilities. Therefore, when a user searches for "drift velocity of electrons", ESPAS retrieves several Observation Collections produced by incoherent scatter radars, coherent radars, ionosondes, with a variety of Process Capabilities associated with different sensors in their instrument categories. The relationship between Observed Property, Process Capability and Observations is further illustrated in Fig. 2.1 showing key constituents of the O\&M data model tailored and 
implemented in ESPAS.

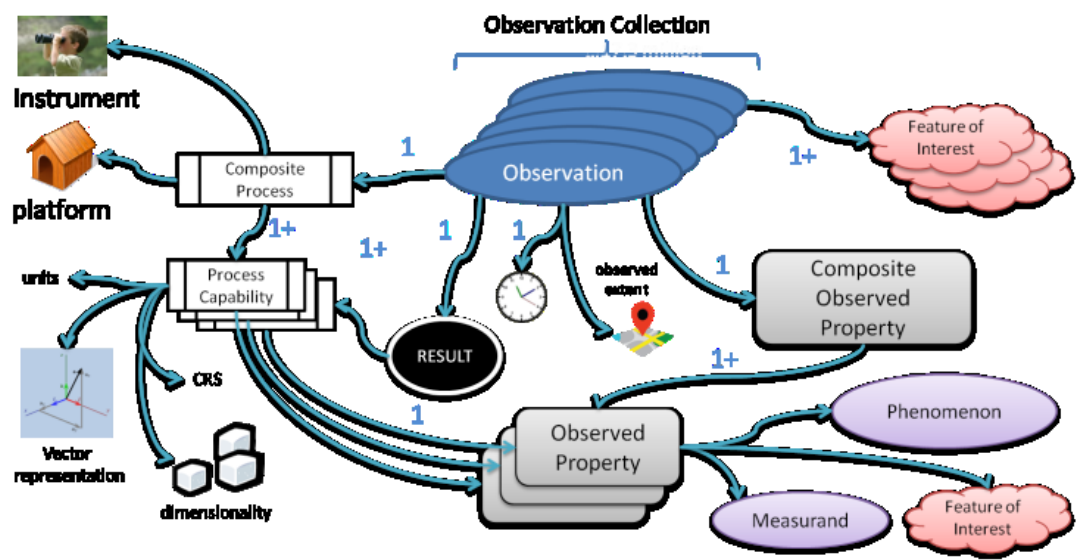

Figure 2.1: Relationship between Observation, Observed Property, and Process Capability

\subsection{Observed Property vocabulary}

A large number of Observed Properties are defined in various Space Physics vocabularies, ranging from particle fluxes to critical frequencies of plasma layers. Given the overwhelming variety of observations managed by ESPAS, it is grossly inefficient to present scientists with an alphabetically sorted list of all registered Observed Properties.

For a more structured approach to select the Observed Property criteria for the content-targeted data searches in ESPAS, the Observed Property vocabulary is built as a set of hierarchies describing various aspects of the properties. While some of the resulting definitions are quite elaborate, especially in the category of wave phenomena, all Observed Properties have two defined components: Phenomenon and Measurand.

def. Phenomenon: (not to be confused with Event): underlying physical phenomenon for which the Observation provides an estimate of its property value.

def. Measurand: measurable quantity of the Observed Property, whose value is estimated in Observation.

ESPAS provides hierarchical lists of Observed Properties sorted by their Phenomenon and Measurand aspects so as to allow rapid access to the search criteria (Fig.2.2).

Wave phenomena require significantly more elaborate description due to their nature; a truly comprehensive definition must include information about physical processes responsible for wave generation, propagation, and interaction with underlying media. Once the corresponding elements were added to ESPAS 
Ontology, resulting complete description of the wave phenomenon allowed unprecedented capability to formally register many popular wave terms in circulation, including standard URSI ionogram-derived characteristics (Piggott and Rawer, 1978). Table 2.1 exemplifies the ESPAS ontology record for foF2, O-wave critical frequency of F2 layer in the ionosphere.

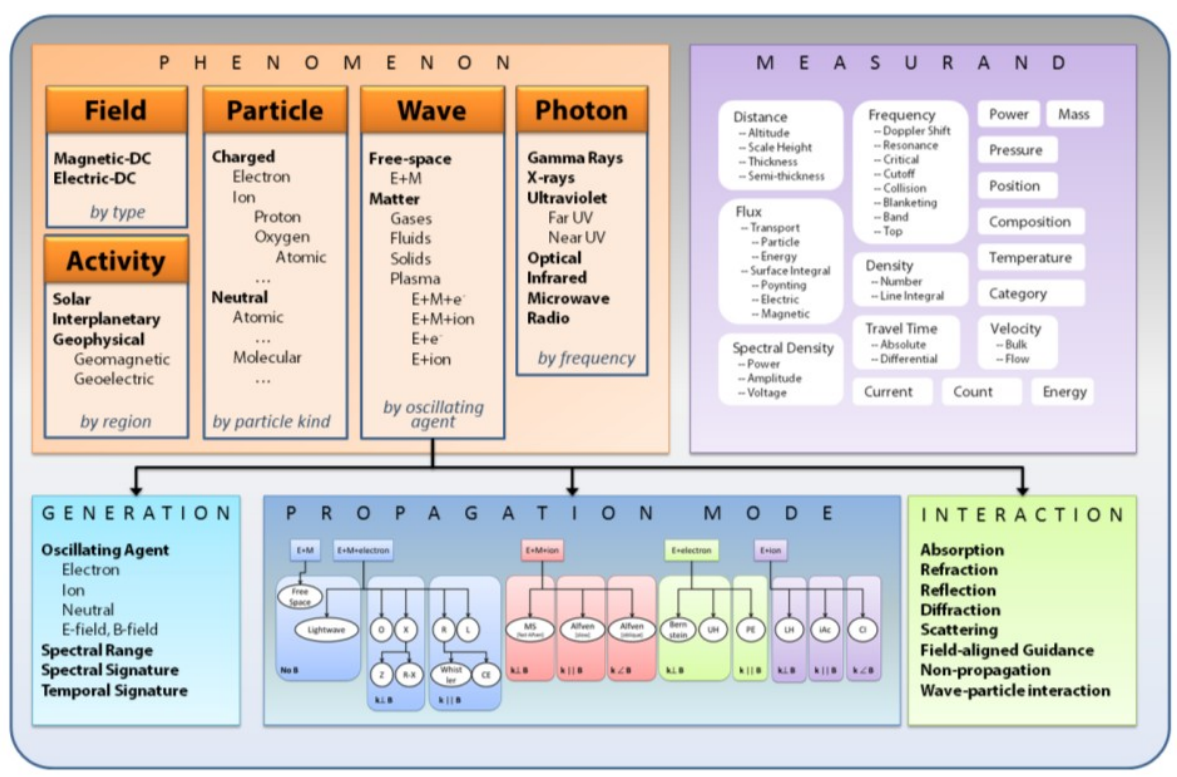

Figure 2.2: Phenomenon and Measurand Vocabularies

Table 2.1: ESPAS Ontology Definition of foF2

\begin{tabular}{|c|l|l|}
\hline Tree \# & \multicolumn{1}{|c|}{ Tree Name } & \\
\hline \multirow{4}{*}{1} & Phenomenon & Wave. Electromagnetic. Plasma. Electron \\
\cline { 2 - 3 } & Oscillating Agent & Electron, E-Field, B-Field \\
\cline { 2 - 3 } & Spectral Range & HF \\
\cline { 2 - 3 } & Propagation Mode & O \\
\cline { 2 - 3 } & Interaction & Reflection, Refraction \\
\hline 2 & Measurand & Frequency. Critical \\
\hline 3 & Feature of Interest & $\begin{array}{l}\text { Earth. NearSurface. Ionosphere. F-Region. } \\
\text { F2-layer }\end{array}$ \\
\hline
\end{tabular}

\subsection{Summary and Outlook}

Development of the ESPAS Ontology was deemed necessary in order to help the process of unification of ESPAS data resources into, ultimately, a new system that 
contributes the near surface plasma environment of the Earth to the global view of all the different Heliophysics domains as a connected system. Adopting ISO 19100 standard series for the founding ESPAS data model has led to an important opportunity to accommodate the disparate space physics vocabulary terms across all data providers using key ISO definitions of the Observed Property and Process Capability. This unification process led to an emerging capability of searching the entire collection of ESPAS data by content, as opposed to more commonly practiced searches by time, location, event, or geospace context.

The ESPAS Ontology is especially important to the Wave community, whose data resources, given the complexity of wave phenomena and lack of intuitive interpretation of observational data, remained unfathomable to the world of Heliophysics. With recognition of the waves as the key mechanism of energy transfer between domains and important role of wave data providers in ESPAS (from IESCAT, SuperDARN, DIAS, GIRO, and RPI projects), the compatible ontology of wave phenomena and observed properties is a major contribution to the task of systematic domain unification.

Ultimately, ESPAS is strategically placed between Space and Earth sciences, thus bridging modern e-Science technologies from ISO Geoscience community with the wealth of Space Physics knowledge from the outer space community. Future efforts will likely be directed towards further integration of the Space and Earth domains of information science via crosswalks between major models and ontologies for a one-stop data service for all connected Heliophysics domains.

\section{References}

ISO 19156:20111 Observations and measurements, http://www.iso.org/iso/catalogue detail.htm?csnumber=32574, OGC Observations and measurements Schema, http://www.opengeospatial.org/standards/om

Fung, S.F. (2010), "The Virtual Wave Observatory (VWO): A Portal to Heliophysics Wave Data," Radio Science Bulletin, No. 332, March 2010, pp. 89-102.

Galkin, I. A.; Fung, S. F.; Benson, R. F.; Heynderickx, D.; Ritschel, B.; King, T. A.; Roberts, D. A.; Hapgood, M. A.; Belehaki, A. (2015) "Crosswalking near-Earth and space physics ontologies in SPASE and ESPAS”, AGU Fall Meeting 2015, Paper IN23D-1752.

King, T., J. Thieman, and D. A. Roberts, "SPASE 2.0: A Standard Data Model for Space Physics", Earth Sci Inform (2010), 3:67. doi 10.1007/s12145-010-0053-4

Piggott W. R. and K. Rawer, Editors, "U.R.S.I. Handbook of lonogram Interpretation and Reduction", World Data Center A for Solar-Terrestrial Physics Report UAG-23. and 23A, Boulder CO (1978).

Shing, F., The Virtual Wave Observatory (VWO): A Portal to Heliophysics Wave Data, The Radio Science Bulletin; 332, 89-102, 2010 https://ntrs.nasa.gov/search.jsp?R=20110007272 



\title{
3. ESPAS observation collections
}

\author{
Mike Hapgood ${ }^{1}$ and Anna Belehaki ${ }^{2}$ \\ 1. RAL Space, STFC Rutherford Appleton Laboratory, Oxfordshire, United \\ Kingdom
}

2. National Observatory of Athens, Institute of Astronomy, Astrophysics, Space Applications and Remote Sensing, Greece

ESPAS seeks to improve access to data on the natural environments that exist in the near-Earth space environment: the upper atmosphere of the Earth and the regions of space close to the Earth. These environments have been the focus of scientific study since the middle of the nineteenth century, but gained impetus throughout the twentieth century following the clear demonstration of a correlation between processes on the Sun, e.g. sunspots, and processes in Earth's upper atmosphere, e.g. geomagnetic storms (Maunder, 1904). That impetus was reinforced by the development of measurement techniques throughout the twentieth century, firstly methods for remotely sensing the upper atmosphere and then in-situ measurements, when these became possible through use of sounding rockets and satellites from about 1950 onwards. In addition, a number of key scientific developments enabled progress in understanding how energy from the Sun could significantly influence the near- Earth space environment. These include the recognition of plasma physics (ionised gas) as a distinct state of matter (Langmuir, 1928), the subsequent development of magnetohydrodynamics (Alfvén, 1942), the discovery of the solar wind (Biermann, 1951, Parker, 1958) and the recognition that magnetic reconnection plays a key role in transferring energy from the solar wind to the neat-Earth space environment (Dungey, 1961). These developments provided the wonderful discovery posited by Kelvin (1892) to enable science to explain how the Sun could deliver enough energy to Earth to cause geomagnetic storms. These developments enabled a golden age of discovery in this discipline, traditionally called solar-terrestrial physics, starting in 1950s and continuing into the 1970s. During this period, scientists sketched out our high-level understanding of the science. In particular, we know now that the Sun emits a continuous, but highly variable, flow of plasma that we call the solar wind. This flows around the Earth's magnetic field, confining it to a cavity that is compressed on the sunward side (dayside) and drawn out into a long tail on the anti-sunward side (nightside). This cavity defines the magnetosphere, the region of near-Earth space that is dominated by the Earth's magnetic field and home to many plasma phenomena, including the energisation of ions and electrons to produce the aurora (Figure 3.1), the ring current and the radiation belts, together with a wide range of plasma waves. These phenomena are largely driven by energy inflows from the solar wind, particular magnetic reconnection at the boundary between the solar wind and 
the magnetosphere, but also contributions from other boundary processes such as the Kelvin-Helmholtz instability. The magnetosphere is magnetically coupled to the ionosphere - the ionised component of the upper atmosphere produced by solar EUV emissions acting on the thermosphere, the neutral component of the upper atmosphere. Thus energy from the magnetosphere flows into the ionosphere, e.g. via electric currents, where it is dissipated through ion-neutral collisions leading to acceleration and heating of the thermosphere. This energy flow drives a wealth of

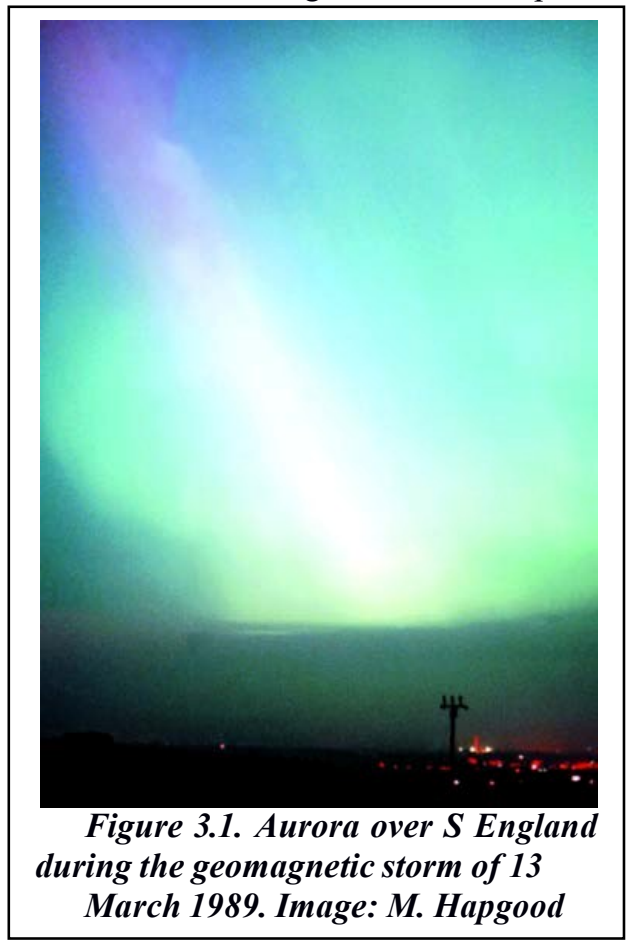

processes in both the ionosphere and thermosphere, leading to both local and global perturbations of both components of the upper atmosphere. The variations in the solar wind, especially the large eruptions that we call coronal mass ejections, can drive major perturbations of conditions in the magnetosphere and upper atmosphere. These major perturbations are traditionally characterised via the large electric currents that they produce in the ionosphere; these currents have long been observed as strong magnetic variations on Earth's surface and given the name of "geomagnetic storms" or, more generally, "geomagnetic activity".

Some of these perturbations can in turn modify processes in the magnetosphere. For example, one of the key inflows from the solar wind is the transport of momentum from the solar wind to the polar thermosphere. When that inflow temporarily stops, e.g. due to the onset of solar wind conditions unfavourable for magnetic reconnection, the polar thermosphere retains its momentum and will release some of it back to the magnetosphere. This "flywheel" effect can enable a geomagnetic storm to continue for a few hours after the end of inflow from the solar wind. This is one example of the feedback from the ionosphere to the magnetosphere that makes near-Earth space a truly complex environment, one which still provides many challenges for science (Figure 3.2).

This scientific picture of near-Earth space is made even more complex by other energy flows from the Sun besides the solar wind. The Sun produces bursts of ions and electrons at energies thousands and even millions of times higher than 
in the solar wind. These bursts (known as solar energetic particle events, or more popularly, as radiation storms) can penetrate deep into the magnetosphere and atmosphere, even down the Earth's surface for the highest energies. They can produce additional ionisation in the upper and middle atmosphere changing some properties of the ionosphere and also affecting atmospheric ion chemistry. They can also create a significant radiation hazard for humans in space and on high-flying aircraft. The Sun also produces occasional bursts of EUV and X-rays, known as solar flares. These can produce additional ionisation in the upper atmosphere, again changing some properties of the ionosphere.

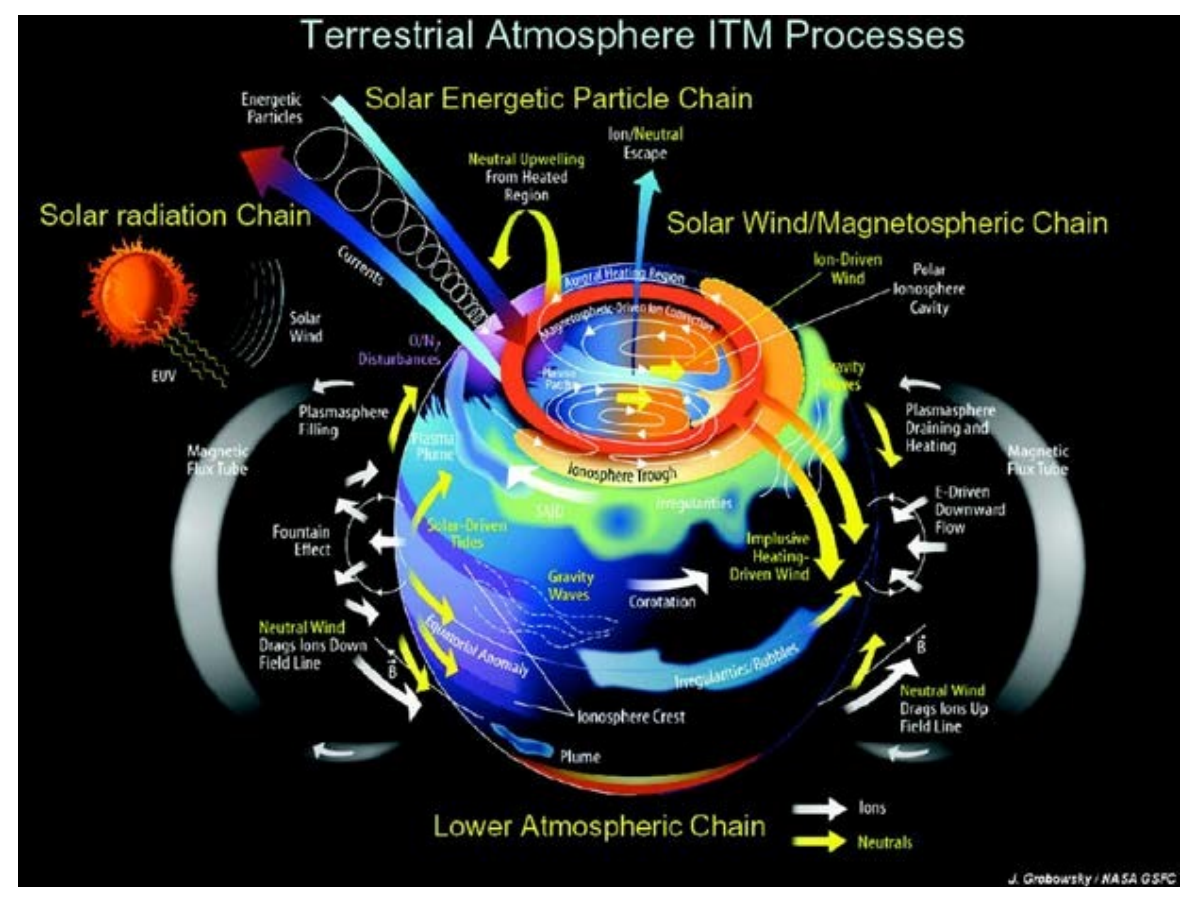

Figure 3.2. Schematic showing the complexity of physical processes occurring where near-Earth space meets the upper atmosphere of our planet. Image courtesy NASA.

As outlined above we have a good high-level understanding of the science of near-Earth space, thanks to the discoveries made in the second half of the twentieth century. So this is now an area of science where the challenge is to broaden and deepen that understanding to the point that we can deliver knowledge that is truly useful to people who have to work in and with the near-Earth space environment. These include most obviously people working with systems in space, but also people using radio systems that send signals through the upper 
atmosphere and people working with systems affected by magnetic and radiation effects propagating from space down through the atmosphere and reaching right to the Earth's surface. So this area of science is expanding beyond its roots in astronomy and becoming an environmental science where we seek a detailed scientific understanding that allows us to make reliable forecasts of future conditions over a wide range of timescales.

But this science retains its value for astronomy. Near-Earth space is now an accessible natural laboratory where we can observe many astrophysically important processes in exquisite detail and learn lessons that can be applied to more distant environments across the solar system and the wider universe. For example, Earth's magnetosphere is an excellent place to make in-situ observations of collisionless plasma processes such as reconnection, whilst the ionosphere is, by far, the most accessible place to explore both how cosmic plasmas are modified by collisions with neutrals and how plasmas change in the transition from collision-dominated to collisionless regimes (a transition that plays a key role in the dynamics of the ionosphere).

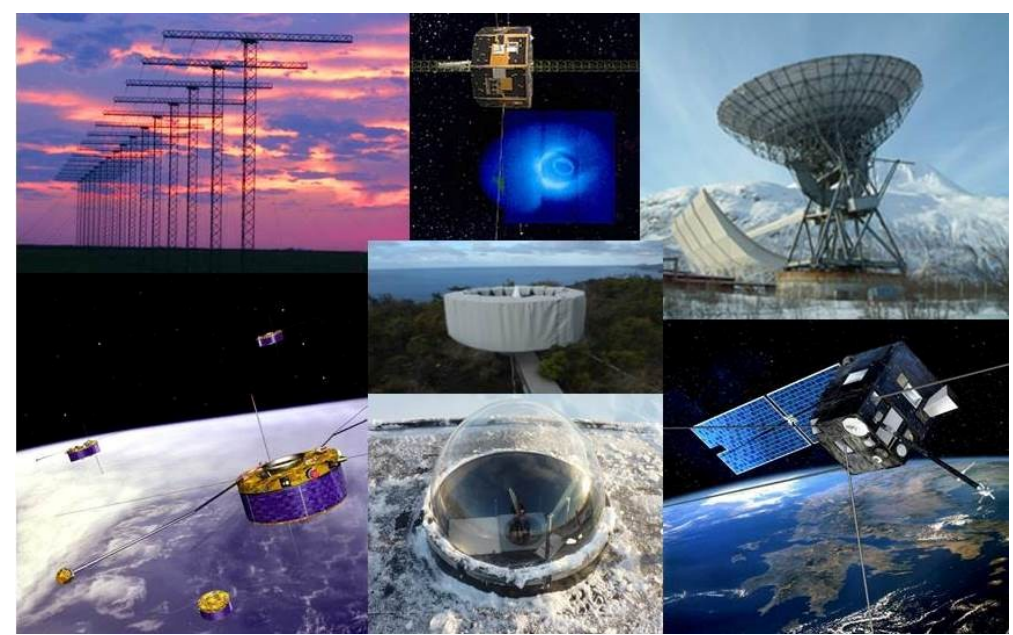

Figure 3.3. Some of the sources of data for ESPAS. Clockwise from top left: a SuperDARN radar antenna near Saskatoon, Canada; NASA's IMAGE satellites observing the plasmasphere; the EISCAT radar antennae near Tromso; CNES's DEMETER satellite; a Fabry-Perot Inteferometer protected from weather by an observing dome; and ESA's four Cluster satellites. Centre: a GNSS monitoring antenna.

To pursue all these scientific objectives we need data on conditions across nearEarth space - measurements of the magnetic and electric fields, the charged particles and the neutral atmosphere that exist across these regions. As indicated above, 
some of these data are collected by satellite-borne instruments, many making insitu measurements of the local environment, but also some making remote sensing measurements using a mixture of optical and radio techniques. But we also have a wealth of ground-based data, again some making in-situ observations of the magnetic field variations and radiation fluxes that penetrate our atmosphere, but also many optical and radio systems that can remotely sense conditions in space above the Earth.

Scientists working today in this field require access to a wide range of these datasets. The days are long gone when most progress was made by groups analysing data only from their own instruments. Today there is a strong emphasis on combining data from a variety of sources in order to obtain a broader understanding of the science under study and to set that research in the context of wider conditions across near-Earth space (and sometimes of the driving conditions on the Sun and in the solar wind). Thus scientists in this field require the ability to find and obtain a wide range of relevant datasets. This sets the context for the establishment of ESPAS infrastructure. The project has sought to provide a platform that allows users to search over a range of different archives to find data that will assist their research, and having found it to then enable the user to access those data (Figure 3.3). In particular, the platform should provide a homogeneous and easily understood interface to all these different datasets. This was a major challenge because of the diversity of the types of datasets and also the ways in which the datasets are organised at different archives.

In this chapter, we provide a description of the data collections registered in ESPAS, we describe the experiments operated to obtain the observations through which the data are derived, and the methodologies and modeling techniques applied to analyse all different data sets, showing also some science cases. An overall view of the observation collections whose registration is successfully tested in ESPAS, is given in the full list presented in Tables 1-3 of Appendix 1.

\section{References}

Alfvén, H. (1942) Existence of electromagnetic-hydrodynamic waves. Nature 150, 405-406. doi: 10.1038/150405d0

Biermann, L. (1951) Kometenschweife und solare Korpuskularstrahlung. Zeitschrift für Astrophysik 29, 274-286. ADS:1951ZA....29..274B.

Dungey, J.W. (1961) Interplanetary Magnetic Field and the Auroral Zones. Phys. Rev. Lett. 6, 47-48. doi: 10.1103/PhysRevLett.6.47

Kelvin, W. T. (1892) President's address, 1892-93. Proc. R. Soc. 52, 299-325. doi:10.1098/rspl.1892.0077

Langmuir, I. (1928) Oscillations in ionized gases, Proc. Natl. Acad. Sci. U.S.A. 14, 627-637. doi:10.1073/pnas.14.8.627 



\section{Appendix 1}

An overall view of the observation collections whose registration is successfully tested in ESPAS.

Table 1: Near-Earth space datasets from ground-based experiments and related applications

\section{Radars}

1. 1 Coherent Radar

\begin{tabular}{|c|c|}
\hline SuperDARN & $\begin{array}{l}\text { Observed Properties } \\
\text { Electric potential [resolution: } 40 \text { x } 40 \text { grid, } 2 \text { minutes } \\
\text { cadence] } \\
\quad \text { MLT grid - SuperDARN (ULEIC) } \\
\circ 49 \text { Spherical harmonic coefficients - SuperDARN } \\
\quad \text { (ULEIC) } \\
\quad \text { Associated information - SuperDARN (ULEIC) }\end{array}$ \\
\hline \multicolumn{2}{|c|}{1.2 Incoherent Scatter Radar } \\
\hline EISCAT & $\begin{array}{l}\text { Observed Properties } \\
\text { [coverage: sporadic, } 1000 \mathrm{~km} \text { range, resolution: few } \mathrm{Km}^{3}, 1 \\
\text { minute] } \\
\text { - Line-of-sight profiles (Standard ISR and derived parameters) } \\
\quad-E I S C A T \text { ISR (EISCAT) }\end{array}$ \\
\hline \multicolumn{2}{|l|}{ 2. Receivers } \\
\hline \multicolumn{2}{|l|}{2.1 GNSS } \\
\hline NOA GNSS & $\begin{array}{l}\text { Observed Properties } \\
\text { [receiver location: Athens, Greece] } \\
\text { Raw data (RINEX files) } \\
\quad-\text { Athens GNSS (NOA) } \\
\text { - } \quad \text { TEC } \\
\quad \text { Local estimates - Athens GNSS (NOA) }\end{array}$ \\
\hline GFZ GNSS & $\begin{array}{l}\text { Observed Properties } \\
\text { [sample rate } 1 \mathrm{~Hz}(1 \mathrm{~h} \text {-files per station)] } \\
\text { Raw data (RINEX files) - CHAMP: High rate GPS ground } \\
\text { tracking data (GFZ - ISDC) }\end{array}$ \\
\hline INGV GNSS & $\begin{array}{l}\text { Observed Properties } \\
\left.\text { [receiver location: Chania (Greece }-35.51^{\circ} \mathrm{N}, 24.02^{\circ} \mathrm{E}\right) \text { ] } \\
\text { Raw data (RINEX files) [time resolution: } 60 \mathrm{~min} \text { (since June } \\
\text { 2007)] - CHA1 GPS RINEX data (INGV) } \\
\text { Scintillation indices [time resolution: } 15 \mathrm{~min} \text { ] - CHA1 GPS } \\
\text { Scintillation and TEC Parameters (INGV) } \\
\text { TEC } \\
\text { - Local estimates [time resolution: } 60 \text { min (since 2007)] } \\
\text { - CHA1 GPS Scintillation and TEC raw data (INGV) } \\
\text { - CHA1 GPS Scintillation and TEC Parameters (INGV) }\end{array}$ \\
\hline
\end{tabular}




\begin{tabular}{|c|c|}
\hline DLR GNSS & 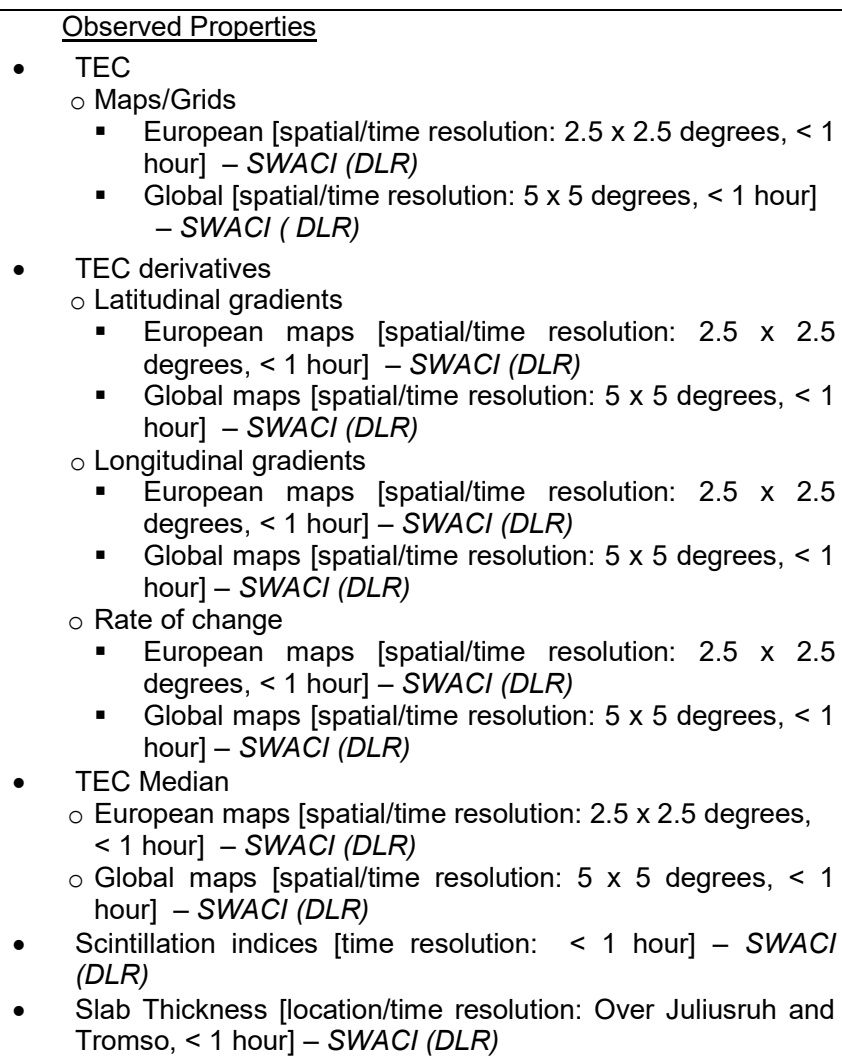 \\
\hline \multicolumn{2}{|l|}{ 2.2 Beacon } \\
\hline SGO Beacon & $\begin{array}{l}\text { Observed Properties } \\
\left.\text { [height range } 0-700 \mathrm{~km} \text {, latitudes: } 60^{\circ}-70^{\circ} \mathrm{N}\right] \\
\text { Electron density } \\
\text { O Tomography reconstructed matrix } \\
\text { - Chapman regularization } \\
\text { - Finnish lonospheric tomography (SGO - Uoulu) } \\
\text { - IRI regularization } \\
\text { - Finnish lonospheric tomography (SGO - Uoulu) }\end{array}$ \\
\hline \multicolumn{2}{|l|}{ 3. Sounders } \\
\hline \multicolumn{2}{|l|}{ 3.1 lonosonde } \\
\hline Athens Digisonde & $\begin{array}{l}\text { Observed Properties } \\
\text { [range: } 500 \mathrm{~km} \text { around Athens, time resolution: } 15 \text { min (or } \\
\text { higher under special campaigns)] } \\
\text { - lonograms } \\
\text { ○ Raw data - Athens Digisonde Data (NOA) } \\
\text { O Images - Athens Digisonde Data (NOA) } \\
\text { lonospheric characteristics (autoscaled) }\end{array}$ \\
\hline
\end{tabular}




\begin{tabular}{|c|c|}
\hline & $\begin{array}{l}\text { - Athens Digisonde Data (NOA) } \\
\text { - } \quad \text { Electron density (profiles) } \\
\text { - Athens Digisonde Data (NOA) } \\
\text { - } \quad \text { lonospheric plasma drifts } \\
\circ \quad \text { Skymaps - Athens Digisonde Data (NOA) } \\
\circ \quad \text { Drift velocities (data files and daily plots) } \\
\quad-\text { Athens Digisonde Data (NOA) }\end{array}$ \\
\hline DIAS network & 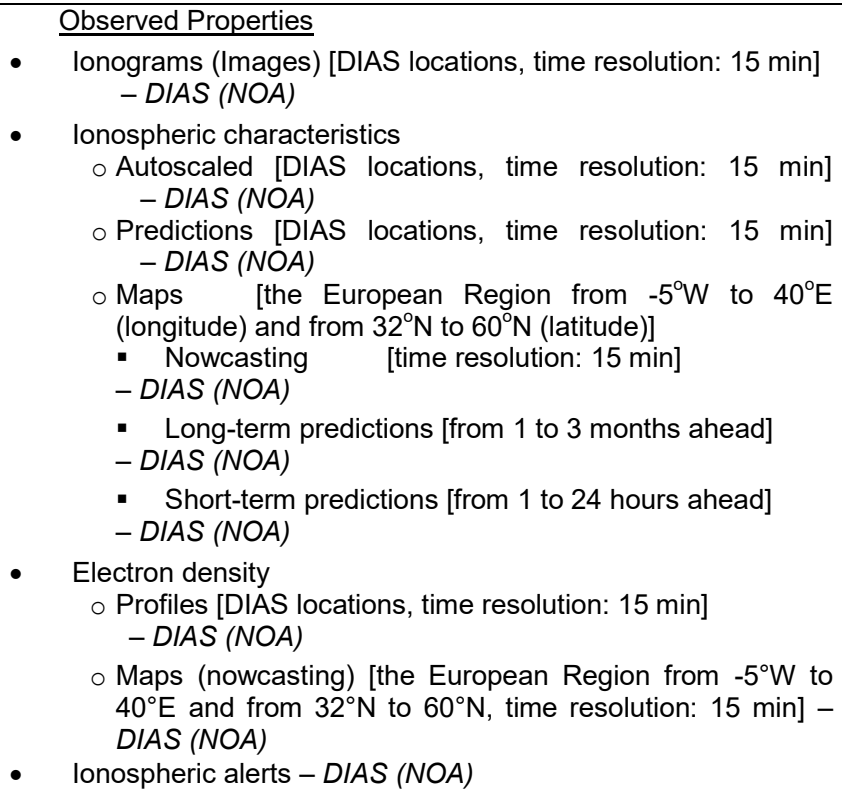 \\
\hline Rome Digisonde & $\begin{array}{l}\text { Observed Properties } \\
\left.\text { [digisonde location: Rome }\left(41.8^{\circ} \mathrm{N}, 12.5^{\circ} \mathrm{E}\right)\right] \\
\text { - Ionograms [time resolution: } 15 \mathrm{~min}(\text { from 1998)] } \\
\circ \quad \text { Raw data - Rome raw lonograms - DPS4 (INGV) } \\
\circ \quad \text { Images - Rome lonogram images - DPS4 (INGV) } \\
\text { Ionospheric characteristics (Autoscaled) [time resolution: } 15 \\
\text { min (from 1998)] } \\
\quad-\text { Rome ionogram autoscaled data - DPS4 (INGV) } \\
\quad \text { - Rome lonogram images - DPS4 (INGV) } \\
\text { Electron density (Profiles) [time resolution: } 1 \text { hour] - Rome } \\
\text { ionogram autoscaled data - DPS4 (INGV) }\end{array}$ \\
\hline Rome AIS.INGV & $\begin{array}{l}\text { Observed Properties } \\
\text { [ionosonde location: Rome }\left(41.8^{\circ} \mathrm{N}, 12.5^{\circ} \mathrm{E}\right) \text {, time resolution: } \\
15 \text { min (from 2005)] } \\
\text { - Ionograms } \\
\quad \text { O Raw data - Rome raw lonograms - AIS.INGV (INGV) } \\
\quad \text { Images - Rome lonogram images - AIS.INGV (INGV) } \\
\text { Ionospheric characteristics (Autoscaled) } \\
\quad-\text { Rome ionogram autoscaled data - AIS.INGV (INGV) }\end{array}$ \\
\hline
\end{tabular}




\begin{tabular}{|c|c|}
\hline & $\begin{array}{l}\text { - Rome lonogram images - AIS.INGV (INGV) } \\
\text { - Electron density (Profiles) } \\
\text { - Rome ionogram autoscaled data - AIS.INGV (INGV) }\end{array}$ \\
\hline Gibilmanna AIS.INGV & 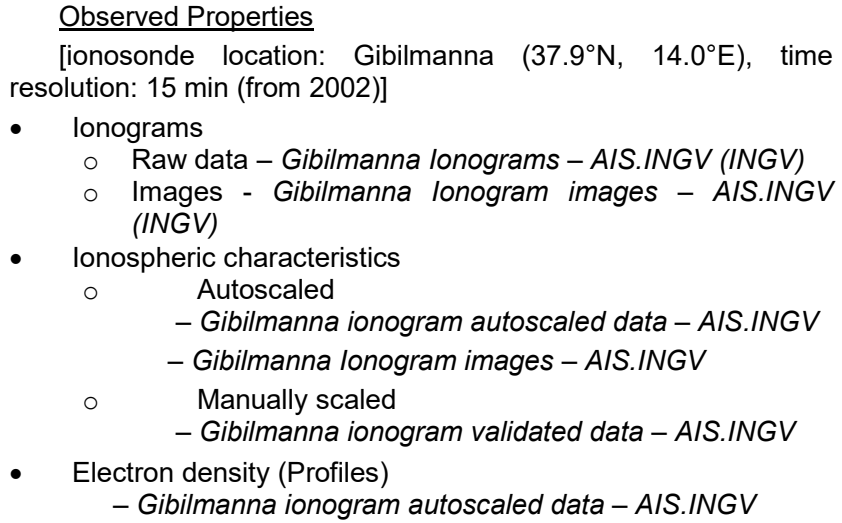 \\
\hline GIRO & 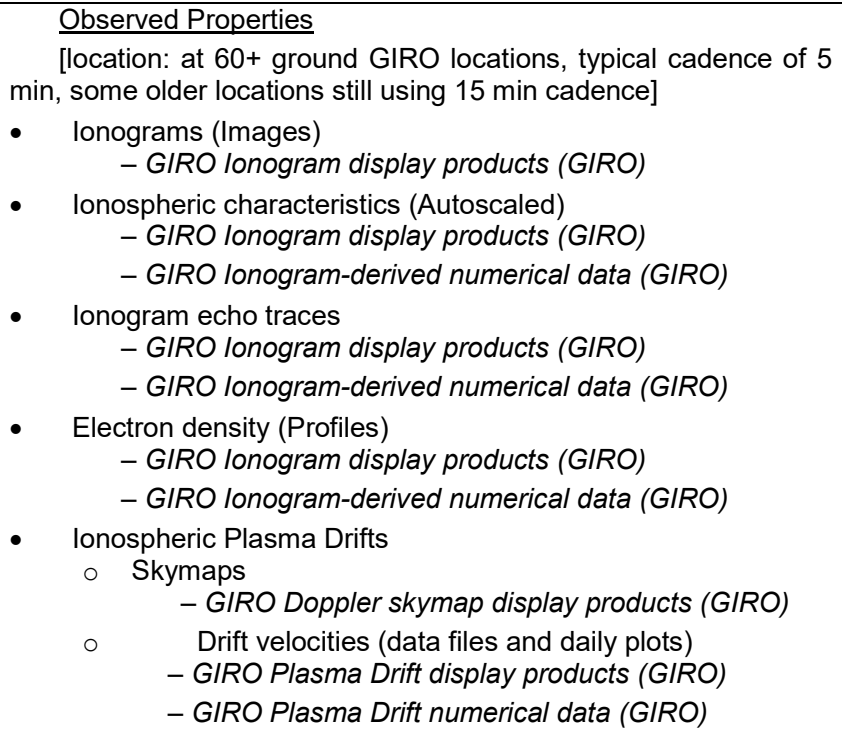 \\
\hline SGO lonosonde & $\begin{array}{l}\text { Observed Properties } \\
\left.\text { [ionosonde location: at } 67^{\circ} 22^{\prime} \mathrm{N}, 26^{\circ} 38^{\prime} \mathrm{E}\right] \\
\text { lonograms } \\
\circ \quad \text { Raw data } \\
\quad-\text { lonosonde of } S G O \text { (SGO - Uoulu) } \\
\quad \quad \text { Matrices [Time resolution: } 1 \text { hour (since 1957)] } \\
\quad-\text { lonosonde of SGO (SGO - Uoulu) } \\
\text { lonospheric characteristics [Time resolution: } 10 \text { min (since } \\
\text { 2005) and } 1 \text { min (since } 2007)] \\
\quad \text { - lonosonde of SGO (SGO - Uoulu) }\end{array}$ \\
\hline
\end{tabular}




\begin{tabular}{|c|c|}
\hline $\begin{array}{l}\text { Warsaw } \\
\text { Ionosonde }\end{array}$ & 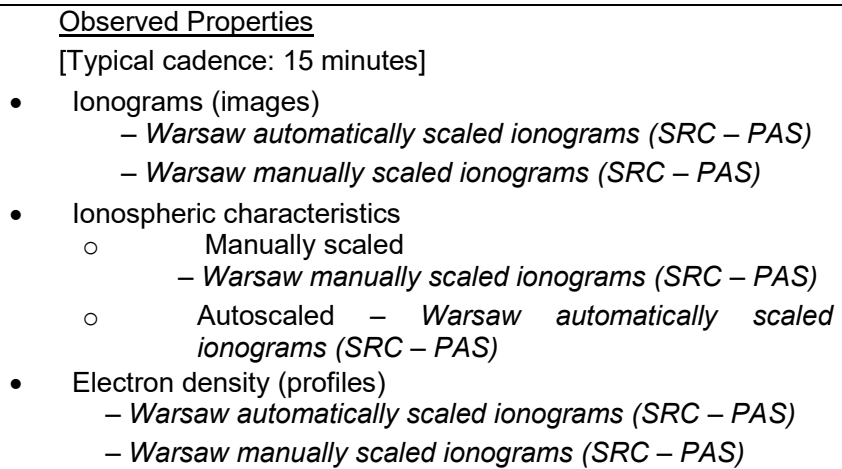 \\
\hline Hornsund lonosonde & $\begin{array}{ll}\text { Observed Properties } \\
\text { [Typical cadence: } 15 \text { minutes] } \\
\text { lonograms (images) } \\
\text { - Hornsund automatically scaled ionograms (SRC - PAS) } \\
\text { - } \quad \text { lonospheric characteristics (autoscaled) } \\
\text { - Hornsund automatically scaled ionograms (SRC - PAS) } \\
\text { - Electron density (profiles) } \\
- \text { Hornsund automatically scaled ionograms (SRC - PAS) }\end{array}$ \\
\hline \multicolumn{2}{|l|}{ 3.2 Dynasonde } \\
\hline EISCAT Dynasonde & $\begin{array}{l}\text { Observed Properties } \\
\text { [Time resolution: } 6 \text { minutes }] \\
\text { Standard vertical sounding and derived parameters } \\
- \text { Dynasonde (EISCAT) }\end{array}$ \\
\hline \multicolumn{2}{|c|}{ 3.3 Oblique Sounding } \\
\hline Inskip - Rome & $\begin{array}{l}\text { Observed Properties } \\
\text { [Time resolution: } 15 \text { minutes (Available dates under special } \\
\text { campaigns)] } \\
\text { - lonograms (Raw files) } \\
\quad-\text { Oblique ionograms Inskip-Rome (INGV) }\end{array}$ \\
\hline Inskip - Chania & $\begin{array}{l}\text { Observed Properties } \\
\text { [Time resolution: } 15 \text { minutes (Available dates under special } \\
\text { campaigns)] } \\
\text { - lonospheric characteristics (MUF, fmin) (manually scaled) } \\
\quad-\text { Observed Maximum Usable Frequencies - of the radio } \\
\text { link Inskip-Chania (INGV) }\end{array}$ \\
\hline \multicolumn{2}{|c|}{ 4. Ground-based Magnetometers } \\
\hline DTU array & $\begin{array}{l}\text { Observed Properties } \\
\text { [Spatial resolution: locally fixed }(200-1000 \mathrm{~km} \text { distance in } \\
\text { Greenland), time resolution: } 1-20 \text { seconds] } \\
\text { - Geomagnetic field (vector - variations) } \\
\quad-D T U \text { ground magnetometer array (DTU) }\end{array}$ \\
\hline NORMAG & $\begin{array}{l}\text { Observed Properties } \\
\text { [magnetometer locations: } 14 \text { sites in Norway, time resolution: } \\
10 \text { seconds averages (since 1986)] }\end{array}$ \\
\hline
\end{tabular}




\begin{tabular}{|c|c|}
\hline & $\begin{array}{l}\text { - Geomagnetic field (vector - variations) } \\
\text { - NORMAG - TGO magnetometer array (TGO) }\end{array}$ \\
\hline INGV & 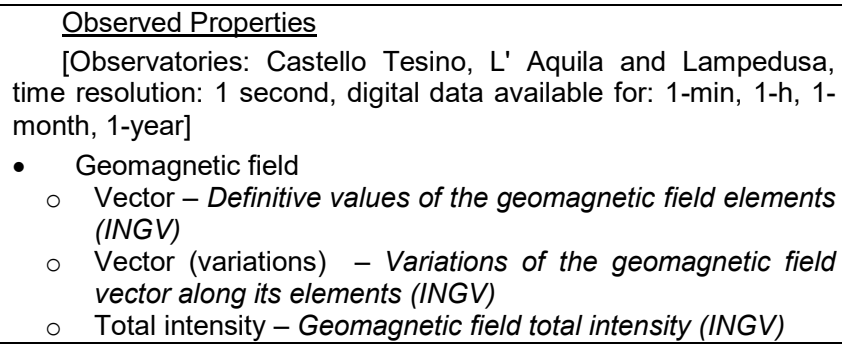 \\
\hline IMAGE & $\begin{array}{l}\text { Observed Properties } \\
\text { [magnetometer locations: } 30 \text { stations, time resolution: } 10 \\
\text { seconds] } \\
\text { - Geomagnetic field (vector - variations) } \\
\quad \text { - IMAGE magnetometer network (FMI) }\end{array}$ \\
\hline $\begin{array}{c}\text { Finish } \\
\text { magnetometer chain }\end{array}$ & $\begin{array}{l}\text { Observed Properties } \\
\text { Geomagnetic field (pulsation) } \\
\quad \text { - Finnish pulsation magnetometer chain (SGO-Uoulu) }\end{array}$ \\
\hline \multicolumn{2}{|l|}{ 5. Riometers } \\
\hline Finnish network & $\begin{array}{l}\text { Observed Properties } \\
\text { [European high latitudes, time resolution: } 1 \text { minute absorption } \\
\text { values from widebeam }\left(60^{\circ}\right) \text { riometers at fixed frequencies }(30.0 \text {, } \\
32.4,51.4 \mathrm{MHz} \text { ) calculated from } 10 \mathrm{~s} \text { raw data] } \\
\begin{array}{l}\text { Ionospheric absorption } \\
\quad-\text { Finnish riometer network (SGO-Uoulu) }\end{array}\end{array}$ \\
\hline \multicolumn{2}{|c|}{ 6. Neutron Monitors } \\
\hline Oulu NM & $\begin{array}{l}\text { Observed Properties } \\
\text { [time resolution: } 1 \text { minute] } \\
\text { Cosmic ray } \\
\text { ○ Cosmic ray (Count rate) - Oulu NM cosmic ray (SGO - } \\
\text { Uoulu) } \\
\text { o Barometric Pressure - Oulu NM cosmic ray (SGO - Uoulu) }\end{array}$ \\
\hline \multicolumn{2}{|r|}{ 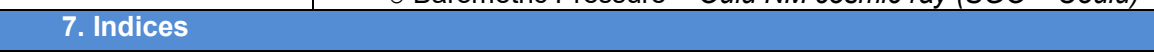 } \\
\hline \multicolumn{2}{|c|}{$\begin{array}{l}\text { Observed Properties } \\
\text { - Solar indices (International Sunspot number) } \\
\text { - International Sunspot number (ROB) }\end{array}$} \\
\hline \multicolumn{2}{|l|}{ 8. FPls } \\
\hline $\mathrm{UCL}$ & $\begin{array}{l}\text { Observed Properties } \\
\text { [FPIs: time series with some spatial coverage (8 points around } \\
\text { a circle centred on the FPI, SCANDI: time series and spatial } \\
\text { coverage (variable nos of points in a } 500 \mathrm{~km} \text { radius circle)] } \\
\text { - Thermospheric neutral wind (Vector) } \\
\quad-\text { FPls (UCL) } \\
\text { - Thermospheric temperature } \\
\quad-\text { FPls (UCL) }\end{array}$ \\
\hline
\end{tabular}


Table 2: Near-Earth space datasets from space based experiments and related applications

\begin{tabular}{|c|c|}
\hline \multicolumn{2}{|c|}{ 1. Radio Occultation Data } \\
\hline CHAMP & 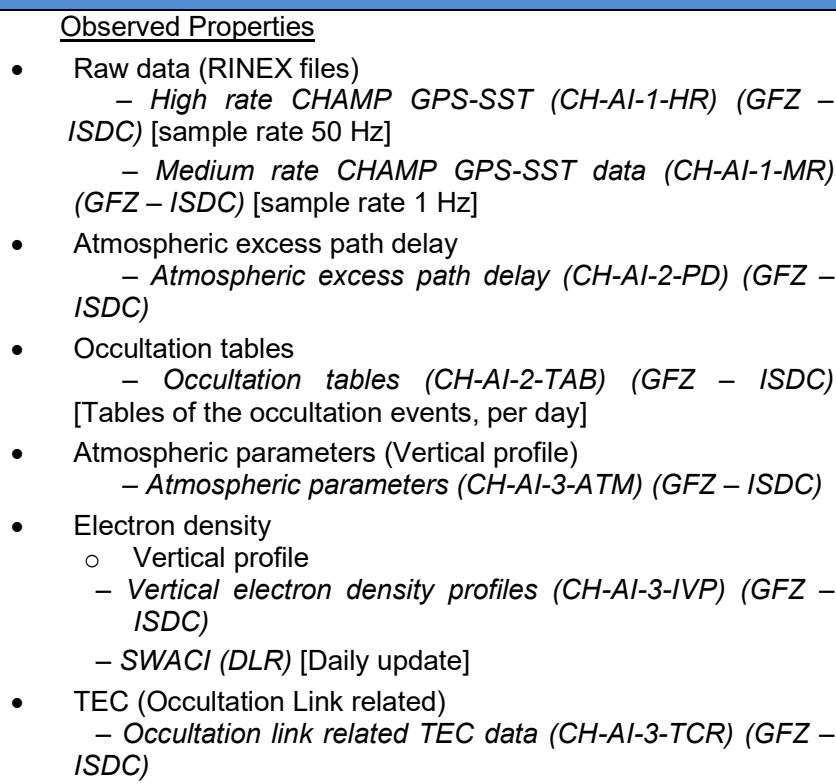 \\
\hline TerraSAR-X & $\begin{array}{l}\text { Observed Properties } \\
\text { Raw data } \\
- \text { TerraSAR-X GPS-SST occultation data (TSX-OCC-1- } \\
H R)(G F Z-I S D C) \text { [sample rate of } 0.02 \mathrm{sec}(=50 \mathrm{~Hz})] \\
- \text { TerraSAR-X GPS-SST occultation data (TSX-OCC-1- } \\
\text { MR) (GFZ - ISDC) [sample rate of } 1.0 \mathrm{sec} \text { ] }\end{array}$ \\
\hline & 2. Solar data \\
\hline SOHO/LASCO & $\begin{array}{l}\text { Observed Properties } \\
\text { - Coronographic white-light images (Outer solar corona } \\
\text { images) } \\
\quad-S O H O / L A S C O(R O B)\end{array}$ \\
\hline SOHO/EIT & $\begin{array}{l}\text { Observed Properties } \\
\text { Coronal EUV images (Full disk images) } \\
\quad-\text { SOHO/EIT (ROB) }\end{array}$ \\
\hline PROBA2/SWAP & $\begin{array}{l}\text { Observed Properties } \\
\text { [FOV }=54^{\prime}, \text { spatial resolution } 3.16 ", \text { Wavelength }=17 \mathrm{~nm} \text {, } \\
\text { temporal cadence } \sim 2 \text { min] } \\
\text { - Coronal EUV images (Full disk images) } \\
\quad-P R O B A 2 / S W A P(R O B)\end{array}$ \\
\hline
\end{tabular}




\begin{tabular}{|c|c|}
\hline PROBA2/LYRA & $\begin{array}{r}\text { Observed Properties } \\
\text { UV and EUV solar irradiance } \\
-P R O B A 2 / L Y R A(R O B)\end{array}$ \\
\hline \multicolumn{2}{|c|}{ 3. Plasma Sounding/Monitoring } \\
\hline IMAGE/RPI & 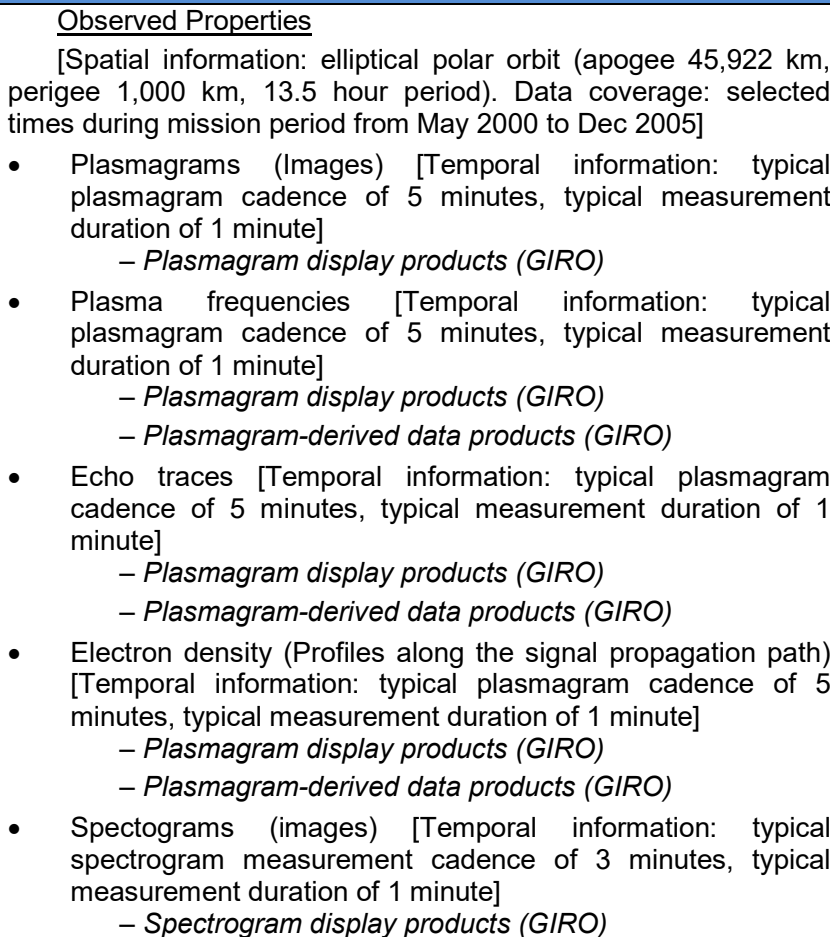 \\
\hline CLUSTER/WHISPER & $\begin{array}{l}\text { Observed Properties } \\
\text { [Space locations: magnetosphere and solar wind, Frequency } \\
\text { range: } 2-80 \mathrm{kHz} \text {, Frequency resolution: } 163 \mathrm{~Hz} \text {, Density range: } \\
0.05-80 \mathrm{~cm}^{-3}, \text { Time resolution: } 2 \text { seconds] } \\
\begin{array}{l}\text { - Electron density } \\
\quad-\text { CLUSTERWHISPER density (BISA) }\end{array}\end{array}$ \\
\hline $\begin{array}{l}\text { CLUSTER/Cluster } \\
\text { Active Archive }\end{array}$ & $\begin{array}{l}\text { Observed Properties } \\
\text { [Coverage: } 2001 / 02 \sim 50 \% \text { from } 2003 \% \sim 100 \% \text {. Cadence is } \\
\text { typically at spin resolution ( 4 s) with some instruments } \\
\text { (particularly fields) providing much higher sampling rates. Duration } \\
\text { of the mission } \sim 10 \text { years] } \\
\text { - Magnetic field } \\
\quad \text { - Cluster Active Archive }(E S A-C A A) \\
\text { - Electric field } \\
\quad-\text { Cluster Active Archive (ESA - CAA) } \\
\text { - Magnetic waves } \\
\quad-\text { Cluster Active Archive }(E S A-C A A)\end{array}$ \\
\hline
\end{tabular}




\begin{tabular}{|c|c|}
\hline & $\begin{array}{l}\text { - } \quad \text { Electric waves } \\
- \text { Cluster Active Archive (ESA - CAA) } \\
\text { - } \quad \text { Plasma electrons and ion composition } \\
\quad \text { few eV to } 10 \mathrm{keV} \\
- \text { Cluster Active Archive (ESA - CAA) } \\
\quad 40 \mathrm{keV} \text { to few hundred keV } \\
- \text { Cluster Active Archive (ESA - CAA) }\end{array}$ \\
\hline ACE/SWEPAM & $\begin{array}{l}\text { Observed Properties } \\
\text { [Interplanetary medium: L1 point, Daily files, Time resolution: } 1 \\
\text { minute, Data latency: } 5 \text { minutes] } \\
\text { - } \quad \text { Solar wind proton density } \\
\quad \text { - ace_swepam_1m (DH consultancy) } \\
\text { - Bulk speed } \\
\quad \text { - ace_swepam_1m (DH consultancy) } \\
\text { - Ion temperature } \\
\quad \text { - ace_swepam_1m (DH consultancy) }\end{array}$ \\
\hline ACE/MAG & $\begin{array}{l}\text { Observed Properties } \\
\text { [Interplanetary medium: L1 point, Daily files, Time resolution: } 1 \\
\text { minute, Data latency: } 5 \text { minutes] } \\
\text { - IMF components } \\
\quad-\text { ace_mag_1m (DH consultancy) } \\
\text { - IMF total field strength } \\
\quad-\text { ace_mag_1m (DH consultancy) }\end{array}$ \\
\hline DEMETER & $\begin{array}{l}\text { Observed Properties } \\
\text { [Spatial information: Geographical longitude range: }-180: 180 \\
\text { degrees, Geographical latitude range: }-60: 60 \text { degrees, Temporal } \\
\text { information: July 2004 - December } 2010 \text { (each map is one month } \\
\text { average)] } \\
\text { - Particle density } \\
\circ \quad \text { Electron (maps) - Demeter maps (NOA) } \\
\circ \quad \text { lon (maps) - Demeter maps (NOA) } \\
\text { Particle temperature } \\
\circ \quad \text { Electron (maps) - Demeter maps (NOA) } \\
\circ \quad \text { lon (maps) - Demeter maps (NOA) } \\
\text { - Drift velocity (maps) - Demeter maps (NOA) }\end{array}$ \\
\hline Magion-3 & 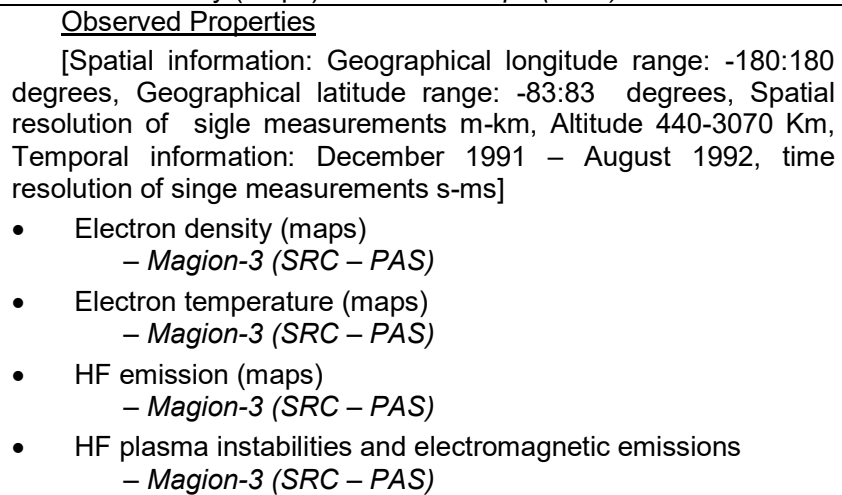 \\
\hline
\end{tabular}




\begin{tabular}{|l|l|}
\hline $\begin{array}{l}\text { FORMOSAT- } \\
\text { 3/COSMIC }\end{array}$ & $\begin{array}{l}\text { Observed Properties } \\
\text { [Spatial information: Geographical longitude range: -180:180 } \\
\text { degrees, Geographical latitude range: -85:85 degrees, 2000-2500 } \\
\text { osculation points per day which correspond to 200 km spatial } \\
\text { resolution, Temporal information: January 2007 till now, 2 h - 1 } \\
\text { day time resolution] } \\
\text { E Electron density (profiles) - COSMIC (SRC-PAS) }\end{array}$ \\
\hline 4. Energetic particle data & $\begin{array}{l}\text { Observed Properties } \\
\text { NOAA/POES:MEPED }\end{array}$ \\
& $\begin{array}{l}\text { [Averaged fluxes at 102 min orbit period resolution, including } \\
\text { and orbit plane MLT orientation, from 11 NOAA/POES } \\
\text { satellites since 1979] } \\
\text { Energetic particle fluxes } \\
\text { Electrons (corrected and calibrated) (From 30 keV to 2.5 } \\
\text { MeV) - NOAA/POES MEPED (Uoulu) } \\
\text { Protons (corrected and calibrated) (30 keV upwards) - } \\
\text { NOAA/POES MEPED (Uoulu) }\end{array}$ \\
\hline
\end{tabular}

Table 3 Models

\begin{tabular}{|c|c|}
\hline \multicolumn{2}{|l|}{ Models } \\
\hline $\begin{array}{l}\text { International } \\
\text { Reference lonosphere } \\
\text { (IRI) }\end{array}$ & $\begin{array}{l}\text { Modelled Properties } \\
\text { - foF2 (global grids) } \\
\quad-\text { IRI foF2 grids - CCIR F peak model } \\
\text { This collection contains the global grids ( } 0 \text { to } 360 \text { degrees in } \\
\text { longitude and - } 90 \text { to } 90 \text { degrees in latitude) of the foF2 critical } \\
\text { frequency predicted by IRI (International Reference lonosphere) } \\
\text { model using the CCIR (Comite Consultatif International des } \\
\text { Radiocommunications) F peak model. The foF2 predictions were } \\
\text { obtained through the IRI-2012 version of the model available for } \\
\text { online computations at http://irimodel.org. The grids are provided } \\
\text { with hourly time resolution in ASCll format. }\end{array}$ \\
\hline $\begin{array}{l}\text { International } \\
\text { Reference lonosphere } \\
\text { (IRI) }\end{array}$ & $\begin{array}{l}\text { Modelled Properties } \\
\text { foF2 (global grids) } \\
\quad-\text { IRI foF2 grids - URSI F peak model } \\
\text { This collection contains the global grids ( } 0 \text { to } 360 \text { degrees in } \\
\text { longitude and - } 90 \text { to } 90 \text { degrees in latitude) of the foF2 critical } \\
\text { frequency predicted by IRI (International Reference lonosphere) } \\
\text { model using the URSI (International Union of Radio Science) F } \\
\text { peak model. The foF2 predictions were obtained through the IRI- } \\
2012 \text { version of the model available for online computations at } \\
\text { http://irimodel.org. The grids are provided with hourly time } \\
\text { resolution in ASCII format. }\end{array}$ \\
\hline $\begin{array}{l}\text { Simplified } \\
\text { lonospheric Regional } \\
\text { Model Updated in real- }\end{array}$ & - $\quad \frac{\text { Modelled Properties }}{\text { foF2 (grids for the European region) }}$ \\
\hline
\end{tabular}




\begin{tabular}{|c|c|}
\hline time (SIRMUP) & $\begin{array}{l}\text { - DIAS SIRMUP nowcasting maps of foF2 } \\
\text { This collection contains the ionospheric maps of the foF2 } \\
\text { critical frequency provided by DIAS for the European region (from - } \\
5 \text { to } 40 \text { degrees } \mathrm{E} \text { in longitude and from } 34 \text { to } 60 \text { degrees } \mathrm{N} \text { in } \\
\text { latitude). The maps are based on the Simplified lonospheric } \\
\text { Regional Model Updated in real-time (SIRMUP) with autoscaled } \\
\text { ionospheric parameters obtained by DIAS Digisondes. The maps } \\
\text { are provided as images (PNG format) as well as numerical grids } \\
\text { (ASCIl format). }\end{array}$ \\
\hline $\begin{array}{l}\text { Simplified } \\
\text { lonospheric Regional } \\
\text { Model Updated in real- } \\
\text { time (SIRMUP) }\end{array}$ & $\begin{array}{l}\text { Modelled Properties } \\
\text { - } \mathrm{M}(3000) \mathrm{F} 2 \text { (grids for the European region) } \\
\text { - DIAS SIRMUP nowcasting maps of M(3000)F2 } \\
\text { This collection contains the ionospheric maps of the } \\
\mathrm{M}(3000) \mathrm{F} 2 \text { propagation factor provided by DIAS for the European } \\
\text { region (from }-5 \text { to } 40 \text { degrees } \mathrm{E} \text { in longitude and from } 34 \text { to } 60 \\
\text { degrees } \mathrm{N} \text { in latitude). The maps are based on the Simplified } \\
\text { lonospheric Regional Model Updated in real-time (SIRMUP) with } \\
\text { autoscaled ionospheric parameters obtained by DIAS Digisondes. } \\
\text { The maps are provided as images (PNG format) as well as } \\
\text { numerical grids (ASCIl format). }\end{array}$ \\
\hline $\begin{array}{l}\text { Electron Density } \\
\text { Assimilative Model } \\
\text { (EDAM) }\end{array}$ & $\begin{array}{l}\text { Modelled Properties } \\
\text { [Derived electric potential on a } 40 \times 40 \text { grid evenly spaced on a } \\
\text { pole-centered MLT-latitude grid such that at midnight and noon, } \\
\text { dawn and dusk the grid extends to } 50 \text { degrees latitude, Cadence: } \\
2 \text { minutes] } \\
\text { - Electron density (3D grids) - EDAM (UBIRM) }\end{array}$ \\
\hline CMAT2 & $\begin{array}{ll} & \text { Modelled Properties } \\
\text { - } & \text { Neutral parameters (3D grids) - CMAT2 (UCL) } \\
\text { - } \quad \text { lonospheric parameters - CMAT2 (UCL) }\end{array}$ \\
\hline
\end{tabular}





\title{
3.1 FABRY-PÉROT INTERFEROMETER AND CMAT2 MODEL
}

\author{
P. Guio ${ }^{1}$, A. Aruliah ${ }^{1}$, A. Aylward ${ }^{1}$, A. Bushell ${ }^{2}$ and E. Henley ${ }^{2}$
}

\begin{abstract}
University College London (UCL) has conducted research on the upper atmosphere of the arctic auroral regions since the 1960s, contributing with both observational and modelling studies. In terms of observations, UCL has designed and built its own Fabry-Pérot Interferometer (FPI) instruments and deployed a network of these in Northern Scandinavia since the beginning of the 1980s. Meanwhile on the modelling side, UCL has developed so-called General Circulation Model (GCM) of the upper atmosphere/ionosphere coupled system, originally for the Earth, leading to the current CMAT2, but also for several other solar system bodies like Mars, the gas giants Jupiter and Saturn, and the latter's largest moon Titan, and a Jupiter-type exoplanet. This paper describes the contribution of UCL to the ESPAS project, with data from the FPI, and CMAT2, and work on the preliminary result of an ESPAS use case study in conjunction with the Met Office to compare FPI and CMAT2 data.
\end{abstract}

\subsubsection{Introduction}

An important aspect of ESPAS is the development of an ontology for space physics. The ontology consists of a collection of well-structured, hierarchical organisation of controlled vocabulary that captures the general to particular relationships between domain concepts [Galkin, 2015]. In the framework of the ESPAS ontology, the Fabry-Pérot Interferometer (FPI) is an instrument ${ }^{1}$ while CMAT2 is a computation. They both provide observations from the thermosphere, one of the ESPAS feature of interest. A set of observations is called a collection. This paper is organised in the following way. We provide first some basic knowledge of the upper atmosphere, necessary to understand the FPI measurement, then we introduce the concepts behind FPI measurements, and the specific FPI instruments designed at University College London (UCL). We then give a brief overview of the principles behind the CMAT2 model and its capabilities, and finally we illustrate

\footnotetext{
${ }^{1}$ Department of Physics and Astronomy, UCL, Gower Street, London, WC1E 6BT, United Kingdom; email: p.guio@ucl.ac.uk

${ }^{2}$ Met Office, Fitzroy Road, Exeter, EX1 3PB, United Kingdom

${ }^{1}$ References to ESPAS ontology vocabulary are emphasised
} 
how FPI and CMAT2 data have been used in the ESPAS use case study UC4c [ESPAS, 2012].

\subsubsection{The upper atmosphere}

The Earth atmosphere has four structured layers extending from the ground to roughly $600 \mathrm{~km}$. These layers are characterised by how the atmospheric gas temperature $T$ varies with respect to height. It is useful to introduce the lapse rate $\gamma$, the rate at which atmospheric temperature decreases with increasing altitude and defined as the opposite of the temperature gradient $\gamma=-\nabla T$. The adiabatic lapse rate $\gamma_{a}$ is the lapse rate for a parcel of air moving upward or downward without exchanging heat with its surroundings. When $\gamma<\gamma_{a}$, the atmosphere is stable, when $\gamma>\gamma_{a}$, thermal instability causes convection and vertical mixing. The left panel of Fig. 3.1.1 provides an overview of the temperature profile and the different associated atmospheric layers. The thermosphere and the stratosphere are characterised by a positive temperature gradient and are mostly stable layers while the mesosphere and the troposphere are layers prone to vertical mixing and turbulence. The middle panel shows the number density of the daytime ionosphere characterised by two ionisation maxima. The daytime ionosphere is mainly created by photo-ionisation of the atmosphere by solar radiation and sustained by complex processes leading to photo-chemical equilibrium in the lower altitude, the so-called E-region with the lower density maximum, and diffusive equilibrium in the upper F-region with the second density maximum. The right panel shows the neutral density profile decreasing as a function of increasing height as a result of hydrostatic equilibrium. For a thorough discussion of the physics of the upper atmosphere and ionosphere, the reader is referred to Rees [1989].

\subsubsection{Airglow and aurora}

The energy required for both airglow and aurora originates from the Sun as depicted in Fig. 3.1.2a. Daytime UV radiation excites atoms of oxygen $\mathrm{O}$ and nitrogen atoms $\mathrm{N}$ and molecules $\mathrm{N}_{2}$. These excited particles can either return to their ground (un-excited) state and release a photon in the process or bump into other atoms and molecules, exciting them or creating other molecules via chemical reaction. The production of hydroxyl radicals $\mathrm{OH}$, nitric oxide $\mathrm{NO}$ and molecular oxygen $\mathrm{O}_{2}$ release light or airglow in a process known as chemiluminescence.

In a related but different process the more well-known (and spectacular) Northern lights, or aurorae result when beams of magnetospheric energetic electrons hit and directly excite the oxygen atoms of the upper atmosphere.

The photonic emission depends on the available input energy and the atmosphere composition and density, thus different emissions dominate at different heights as seen in Fig. 3.1.2b.

The dominant emissions in the thermosphere are from OI. The green line emission at $557.7 \mathrm{~nm}$ is usually the most obvious as seen in Fig. 3.1.2b, and corresponds to the decay or transition

$$
\mathrm{O}\left({ }^{1} \mathrm{~S}\right) \rightarrow \mathrm{O}\left({ }^{1} \mathrm{D}\right)+\mathrm{h} \nu(2.22 \mathrm{eV})
$$




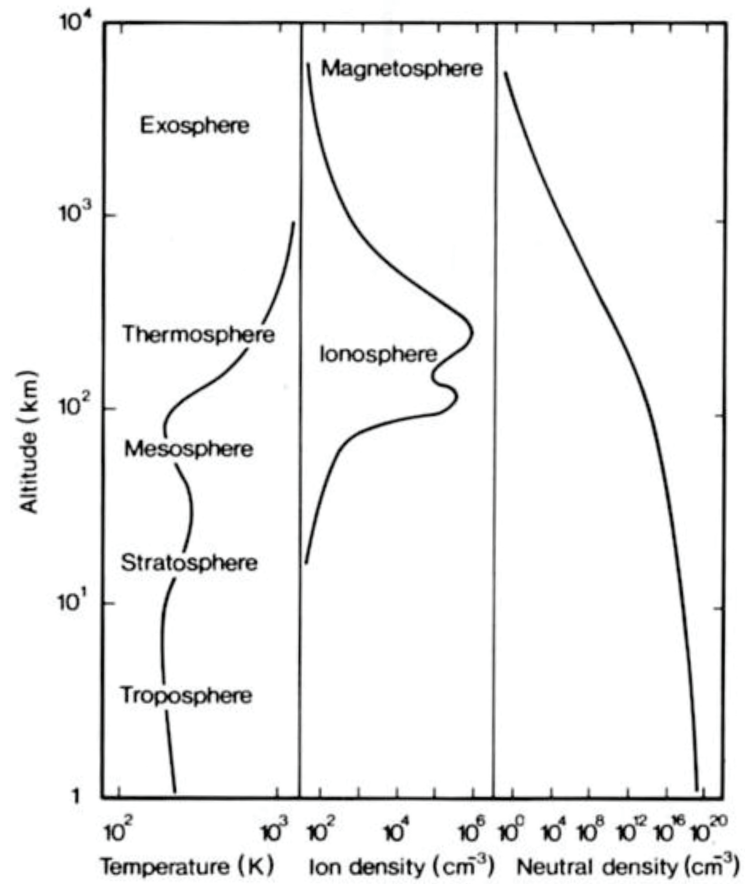

Fig. 3.1.1. From left to right, the vertical structure of the temperature of the atmosphere, and the density of the ionosphere and the atmosphere [Rees, 1989].

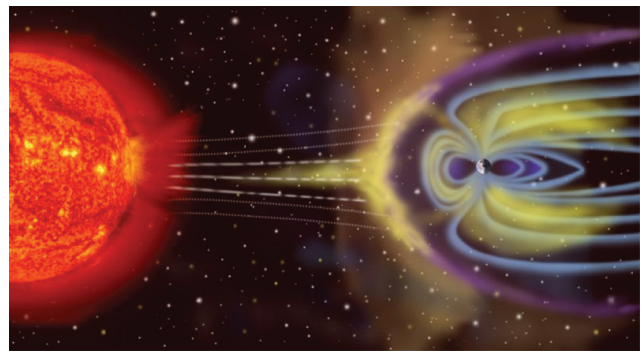

(a)

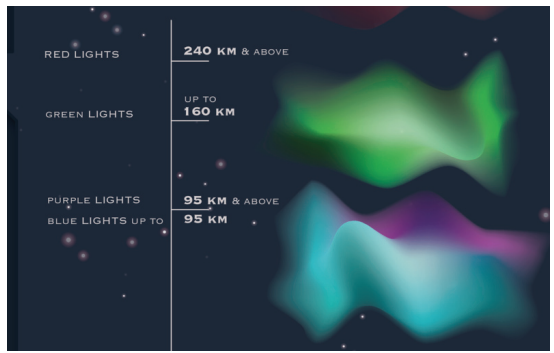

(b)

Fig. 3.1.2. (a) Sketch of the solar wind and radiation hitting the Earth, and its effect on the Earth upper atmosphere confined in the Earth magnetic field. (b) Illustration of the colours and the height distribution of airglow emissions.

where the excited state $\mathrm{O}\left({ }^{1} \mathrm{~S}\right)$ has a lifetime of $0.91 \mathrm{~s}$, i.e., the time for the number of atoms in the excited state to decay by $1 / e$. The red line emission at $630.0 \mathrm{~nm}$ takes place higher in the thermosphere (top of Fig. 3.1.2b), and corresponds to the decay

$$
\mathrm{O}\left({ }^{1} \mathrm{D}\right) \rightarrow \mathrm{O}\left({ }^{3} \mathrm{P}\right)+\mathrm{h} \nu(1.97 \mathrm{eV}),
$$


Table 1. Summary of the different excitation processes for $\mathrm{O}\left({ }^{1} \mathrm{D}\right)$

\begin{tabular}{|ll|}
\hline Electron impact (photo electron collision) & $\mathrm{O}+\mathrm{e}_{\mathrm{ph}} \rightarrow \mathrm{O}\left({ }^{1} \mathrm{D}\right)+\mathrm{e}_{\mathrm{ph}}$ \\
\hline Dissociative recombination & $\mathrm{O}_{2}^{+}+\mathrm{e}_{\mathrm{th}} \rightarrow \mathrm{O}+\mathrm{O}\left({ }^{1} \mathrm{D}\right)$ \\
\hline Photo dissociation & $\mathrm{O}_{2}^{+}+\mathrm{h} \nu \rightarrow \mathrm{O}+\mathrm{O}\left({ }^{1} \mathrm{D}\right)$ \\
\hline Cascade & $\mathrm{O}\left({ }^{1} \mathrm{~S}\right) \rightarrow \mathrm{O}\left({ }^{1} \mathrm{D}\right)+\mathrm{h} \nu$ \\
\hline \multirow{2}{*}{ Chemistry } & $\mathrm{N}\left({ }^{2} \mathrm{D}\right)+\mathrm{O}_{2} \rightarrow \mathrm{NO}+\mathrm{O}\left({ }^{1} \mathrm{D}\right)$ \\
& $\mathrm{N}^{+}+\mathrm{O}_{2} \rightarrow \mathrm{NO}^{+}+\mathrm{O}\left({ }^{1} \mathrm{D}\right)$ \\
\hline
\end{tabular}

Table 2. Summary of the different excitation processes for $\mathrm{O}\left({ }^{1} \mathrm{~S}\right)$

\begin{tabular}{|ll|}
\hline Electron impact (photo electron collision) & $\mathrm{O}+\mathrm{e}_{\mathrm{ph}} \rightarrow \mathrm{O}\left({ }^{1} \mathrm{~S}\right)+\mathrm{e}_{\mathrm{ph}}$ \\
\hline Collisional deactivation & $\mathrm{N}_{2}\left(\mathrm{~A}^{3} \Sigma_{\mathrm{u}}^{+}\right)+\mathrm{O} \rightarrow \mathrm{N}_{2}+\mathrm{O}\left({ }^{1} \mathrm{~S}\right)$ \\
\hline Dissociative recombination & $\mathrm{O}_{2}^{+}+\mathrm{e}_{\mathrm{th}} \rightarrow \mathrm{O}+\mathrm{O}\left({ }^{1} \mathrm{~S}\right)$ \\
\hline Photo dissociation & $\mathrm{O}_{2}^{+}+\mathrm{h} \nu \rightarrow \mathrm{O}+\mathrm{O}\left({ }^{1} \mathrm{~S}\right)$ \\
\hline & $\mathrm{O}+\mathrm{O}+\mathrm{M} \rightarrow \mathrm{O}_{2}^{*}+\mathrm{M}$ \\
Chemistry & $\mathrm{O}_{2}^{*}+\mathrm{O} \rightarrow \mathrm{O}_{2}+\mathrm{O}\left({ }^{1} \mathrm{~S}\right)$ \\
& $\mathrm{N}+\mathrm{O}_{2}^{+} \rightarrow \mathrm{NO}^{+}+\mathrm{O}\left({ }^{1} \mathrm{~S}\right)$ \\
\hline
\end{tabular}

where the excited state $\mathrm{O}\left({ }^{1} \mathrm{D}\right)$ has a much longer lifetime of $110 \mathrm{~s}$ and is thus defined as meta stable. This long lifetime allows the airglow to be observable through the night. More importantly, there is time for the excited oxygen atoms to be thermalised and assume the velocity and temperature of the ambient gas. Thus the Doppler shift and broadening of the emission is representative of the winds and temperature of the thermosphere at around $240 \mathrm{~km}$ altitude.

The mechanisms to produce the excited states $\mathrm{O}\left({ }^{1} \mathrm{D}\right)$ and $\mathrm{O}\left({ }^{1} \mathrm{~S}\right)$ in the first place are summarised in Tables 1 and 2. A thorough description of these mechanisms can be found in Witasse et al. [1999].

\subsubsection{Neutral winds and temperatures measurement}

Optical methods (using FPIs and rockets) are the only way to measure thermospheric neutral winds and temperatures directly. In situ measurements are unfeasible, as the height range required is too high for balloons, and generally too low for satellites (which burn up when below $\sim 200 \mathrm{~km}$ ).

Remote measurement of the airglow characteristics by FPIs can be restricted to latitude and narrow altitude range defined by the height profile of the emission being observed [Vlasov et al., 2005]. FPI measurements are also limited by clear and dark skies owing to light scattering by clouds, and the weakness of auroral and airglow emissions when compared with sunlight.

In addition, the van Rhijn and atmospheric extinction effects require extra data cali- 
bration to allow direct comparison between zenith and off-zenith intensities [Herrero and Meriwether, 1980]. The Doppler shift of the emission lines then give the background velocity of the gas.

Prior to FPI, measurements were only possible by rockets with glowing chemical releases which were tracked from the ground, providing good vertical and latitudinal coverage but restricted temporal coverage to the rocket trajectories of a few tens of minutes.

The neutral winds measured by the FPIs and those modelled by CMAT 2 are not always a good match, but modelled winds do not account for small scale structure in time and space [Aruliah et al., 2005] and inertia of the thermosphere. There are also discrepancies between the winds measured by FPIs and those derived from radar measurements such as EISCAT [Griffin et al., 2004]. The optically measured winds can vary from winds derived from radar measurement by up to $100 \%$, and the temperatures by $100 \mathrm{~s}$ of $\mathrm{K}$. This does not mean the radar measurements are more accurate than FPIs as the calculation of neutral-ion coupling used to derive winds from radar measurements is based on many assumptions [Davis et al., 1995].

\subsubsection{Fabry-Pérot interferometer}

\subsubsection{The Fabry-Pérot Etalon}

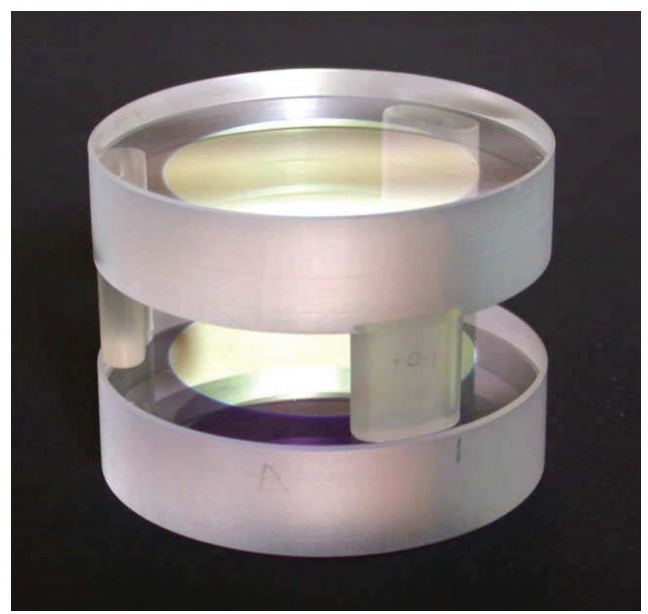

(a)

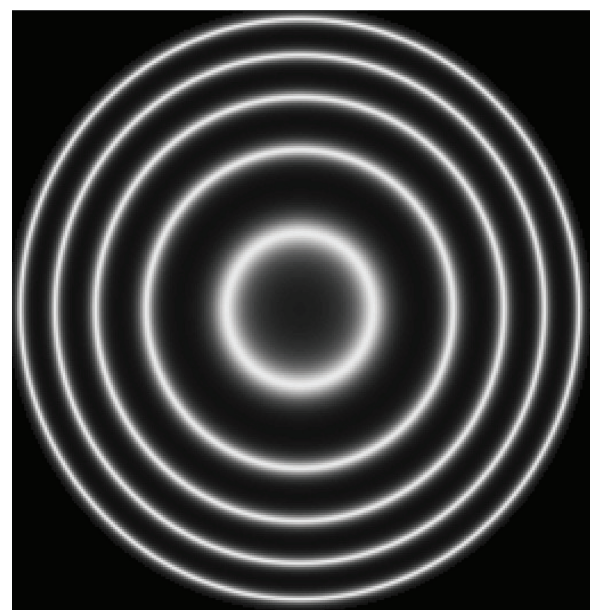

(b)

Fig. 3.1.3. (a) Fabry-Pérot etalon. (b) Interference pattern measured by the etalon.

Fig. 3.1.3a shows an example of a Fabry-Pérot etalon. A Fabry-Pérot interferometer or etalon is typically made of either a transparent plate with two reflecting surfaces, or a cavity formed by two perfectly parallel and flat highly reflecting mirrors (with reflectivity $R \sim 90 \%$ ). More precisely, the former is an etalon and the latter is an interferometer. 
The transmission spectrum as function of wavelength exhibits peaks of large transmission corresponding to resonances in the etalon. Fig. 3.1.3b shows the typical pattern of concentric interference fringes produced when the etalon is illuminated by a monochromatic light.

In the $19^{\text {th }}$ century, the royal astronomer George Biddell Airy described mathematically the interference between waves of equal inclination between parallel reflecting surfaces as a function of the phase change $\Delta \Phi$ of the light wave between successive reflections. This function now referred to the Airy distribution gives the transmitted intensity (or transmittance) $I_{t}$ as function of phase change $\Delta \Phi$.

$$
I_{t}(\Delta \Phi)=\frac{1}{1+F \sin ^{2}(\Delta \Phi / 2)}
$$

where $F$ is known as the coefficient of finesse and defined as $F=4 R /\left(1-R^{2}\right)$, where $R$ is the reflectance of the surfaces. It can be seen that maximum transmission $\left(I_{t}=1\right)$ occurs when $\Delta \Phi=(2 \pi) n$ where $n$ is an integer. In absence of absorption, the reflectance $I_{r}$ is the complement of the transmittance, i.e. $I_{t}+I_{r}=1$, and the maximum reflectivity is given by $I_{r}=1-1 /(1+F)$.

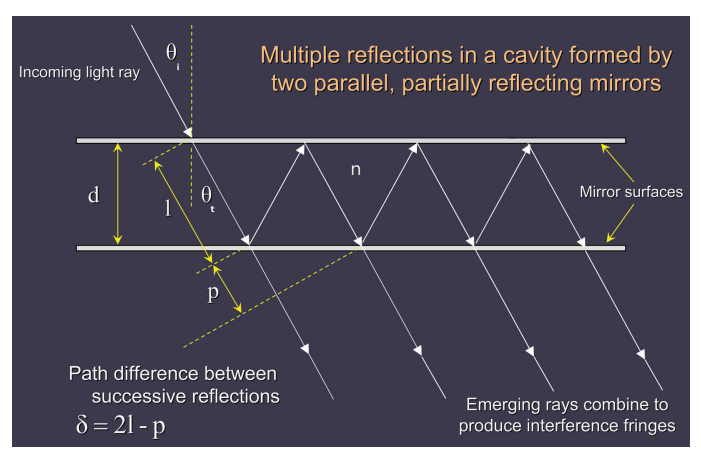

(a)

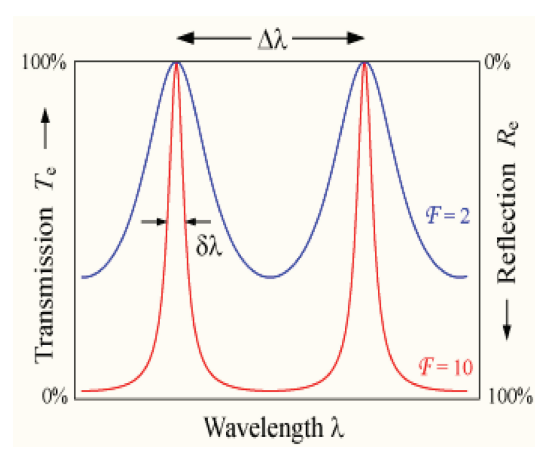

(b)

Fig. 3.1.4. (a) Principle of multiple reflections of the etalon. (b) The Airy function for two different values of finesse $\mathcal{F}=2$ and 10 .

In the end of the $19^{\text {th }}$ century, Fabry and Pérot investigated the Airy distribution for high surface reflectance $R$ and conceived the etalon.

Fig. 3.1.4a sketches the geometry of multiple reflections of the etalon creating the interference. It is easy to see that the optical path difference $\delta=2 l-p$ is given by $\delta=2 n d \cos \theta_{t}$, where $n$ is the refractive index and $\theta_{t}$ is the transmitted angle. For the etalon $n=1$ and $\theta_{i}=\theta_{t}=\theta$, and the phase change $\Delta \Phi$ for a given wavelength $\lambda$ is given as function of the optical path difference by the relation

$$
\Delta \Phi=\frac{2 \pi}{\lambda} d \cos \theta
$$

The wavelength separation between two adjacent transmission peaks $\Delta \lambda$ is called the free spectral range (FSR) and is given by $\Delta \lambda=\lambda^{2} /(2 n d)$, defined by the plate separation 
d. The FSR $\Delta \lambda$ gives information about the largest resolved Doppler shift, and large finesse $\mathcal{F}$ defined by - but not to be confused with the coefficient of finesse $F$ -

$$
\mathcal{F}=\frac{\Delta \lambda}{\delta \lambda} \approx \pi \frac{\sqrt{R}}{1-R},
$$

which results in sharper fringes but requires large $R . \delta \lambda$ is called the full-width halfmaximum (FWHM). There is always a trade off when choosing the plate separation $d$. Small FSR will give greater accuracy as seen in Fig. 3.1.4b, but must be large enough to fit the whole spectral profile onto the detector while being greater than the largest possible Doppler shift.

\subsubsection{UCL's FPI setup and monitoring}

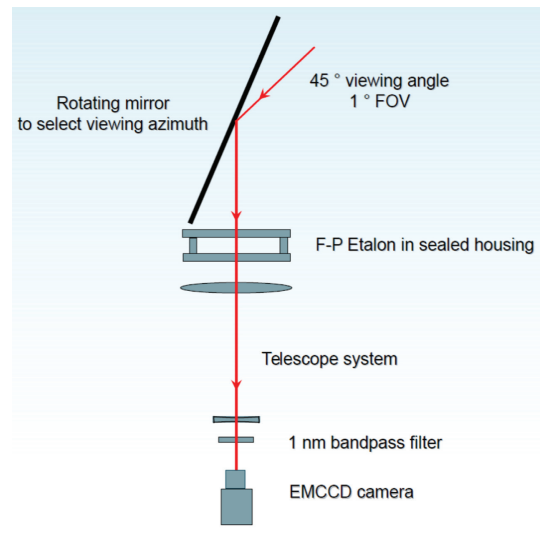

(a)

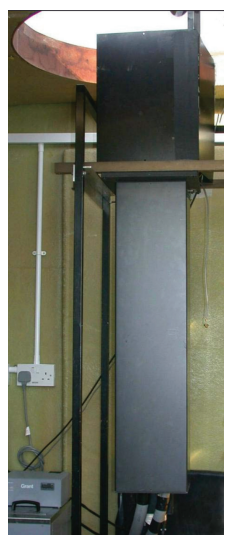

(b)

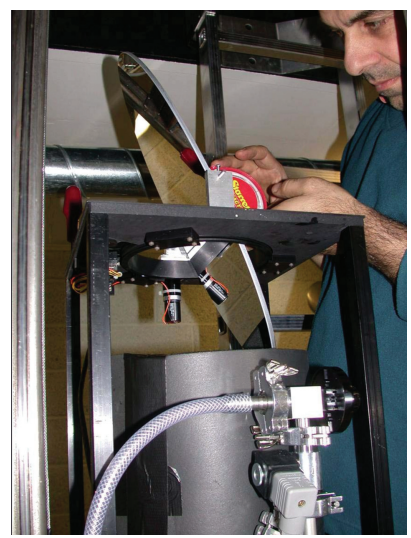

(c)

Fig. 3.1.5. Sketch (a) and view (b) of the FPI built by UCL. (c) Careful adjustment of the angle of the scanning mirror.

UCL's FPIs observe through a rotating mirror which in turn selects the azimuthal (cardinal) viewing directions. The off-zenith look directions are fixed for each instrument. The elevation angle for mainland instruments (see Fig. 3.1.7) is $45 \mathrm{deg}$, and $30 \mathrm{deg}$ for the instrument deployed on Svalbard. After bouncing off the mirror, incident light then passes through the Fabry-Pérot etalon, and enters a Galilean telescope with effective focal length of $1.2 \mathrm{~m}$, then travels through a $1 \mathrm{~nm}$ band pass filter before detection on an electron multiplying charge-coupled device (EMCCD) sensor where the image is digitised (see Fig. 3.1.5). The instrument has an approximate height of $\sim 2 \mathrm{~m}$ and a weight of $\sim 80 \mathrm{~kg}$.

Fig. 3.1.6a shows a screenshot of the main window of the monitoring system of UCL's FPI. The image with the concentric rings on the left is from the EMCCD sensor. In order to improve the signal-to-noise ratio, the intensity of the pixels is integrated along circles centred on the interference pattern, to produce the line on the right. The Doppler shift (or position) and the broadening (or width) of the fringe (with respect to a baseline value 


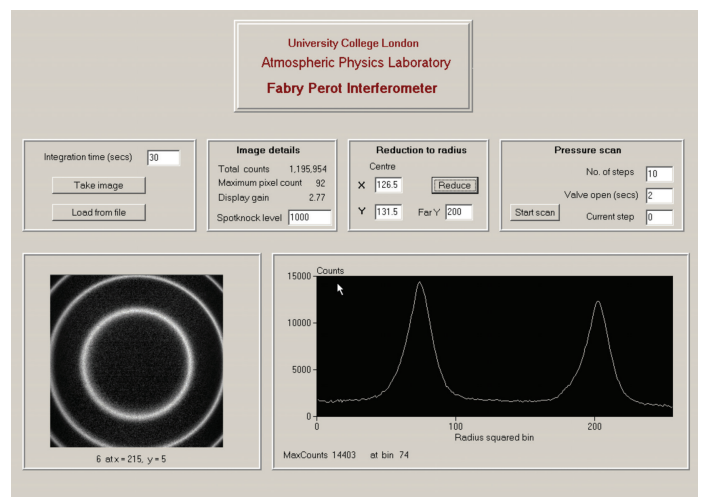

(a)

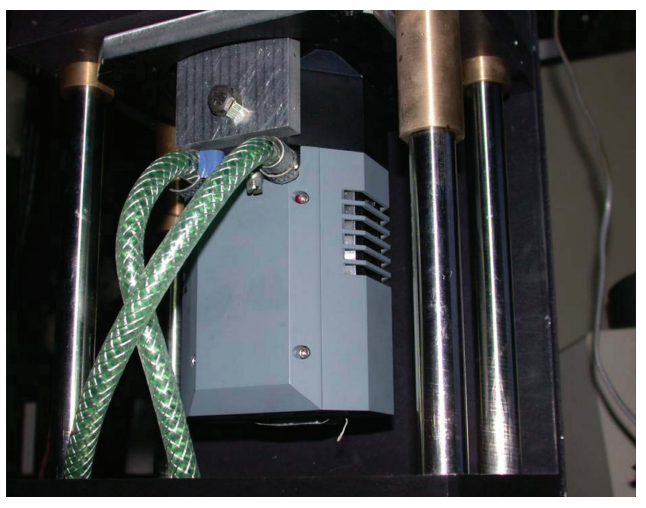

(b)

Fig. 3.1.6. (a) Screenshot of the monitoring system of UCL's FPI. (b) The EMCCD sensor of the UCL FPI.

obtained from a calibration lamp) is then analysed using an inversion method to provide respectively the wind velocity along the line-of-sight and the temperature representative of the region of the height of the emission layer. The analysis also provides error estimates of the calculated velocity, which are typically of the order of $\Delta V \sim$ tens $\mathrm{m} / \mathrm{s}$. The typical exposure time for the red line is between $10-30 \mathrm{~s}$ and less for the green line [Aruliah et al., 2005].

Current research focuses on small scale structure of the auroral dynamics [Aruliah et al., 2005] and is therefore looking for the highest possible time resolution. This can be achieved thanks to the highly sensitive and low noise EMCCD sensor.

The flux of photon is measured in Rayleighs $(R)$, equivalent to the following column emission rate

$$
1 \mathrm{R} \equiv 10^{10} \text { photons } \mathrm{m}^{-2} \text { column }{ }^{-1} \mathrm{~s}^{-1} .
$$

A night sky typically has a photon flux of $\sim 250 \mathrm{R}$ while an aurora can reach flux values as large as $1000 \mathrm{kR}$.

UCL FPIs have a $15 \mathrm{~cm}$ aperture and a $\sim 1 \mathrm{deg}$ field of view (FOV). Therefore the number of photons collected at the front of the instrument is of the order of $\sim 4200$ photons $\mathrm{s}^{-1}$ per $1 \mathrm{R}$ of sky illumination. For our detector with dimensions $\left(506 \times 506\right.$ pixels), this is equivalent to $\sim 0.02$ photons pixel $\mathrm{s}^{-1}$ per $\mathrm{R}$, implying $\sim 5$ photons pixel s ${ }^{-1}$ for a typical night sky! And due to various losses from the interferometer filter, glass surface and other factors, this count is further reduced. The EMCCD sensor seen in Fig.3.1.6b can cope with this low flux as it is a digital camera technology capable of detecting single photon events whilst maintaining high quantum efficiency (low noise). All UCL FPIs have EMCCD cameras, with the best sensitivity EMCCDs for the FPI and Scanning Doppler Imager (SCANDI) at Svalbard. The EMCCDs have improved the time resolution by up to a factor of five compared to conventional CCDs, resulting in excellent measurements of atmosphere gravity and meso-scale structures with only 10 s exposures [Ford et al., 2007]. 


\subsubsection{FPI deployment in Northern Scandinavia}

UCL's FPIs are currently deployed on three platforms in northern Scandinavia, as seen in Fig. 3.1.7. These locations are (i) the Kiruna Esrange Optical Platform Site (KEOPS) $(67.8 \mathrm{~N}, 20.4 \mathrm{E})$ at the ESRANGE scientific rocket and balloon facility near Kiruna, Sweden, (ii) the Pittiövaara Observatory (67.4N,26.6E) in Sodankylä, Finland, (iii) the Kjell Henriksen Observatory (KHO) $(78.1 \mathrm{~N}, 16.0 \mathrm{E})$ by the EISCAT Svalbard radar (ESR), near Longyearbyen, Svalbard archipelago. Note it has been at the above location since Nov. 2007, and in Adventdalen (78.2N,15.6E) near Longyearbyen prior to this. Note the Svalbard FPI location is within the polar cap.

In terms of ESPAS ontology, there are four instruments deployed at these three platforms: (i) two instruments in Kiruna (red and green lines), (ii) one instrument in Sodankylä (red line), and (iii) one instrument in Longyearbyen (both green and red lines). These four instruments represent five acquisitions in operation: (i) three red lines in Kiruna, Sodankylä and Longyearbyen, and (ii) two green lines in Kiruna and Longyearbyen.

For each acquisition system, neutral horizontal winds are derived along the main cardinal pointing directions (north, east, south, west). There are also custom direction modes, designed to have beam intersections with remote EISCAT stations. There is also an additional FPI, called SCANDI. This is a wide FOV $\left(140^{\circ}\right)$ FPI also designed and built at UCL, and deployed at KHO near Longyearbyen. SCANDI provides a complete allsky field of winds, temperatures and $630.0 \mathrm{~nm}$ emission intensities divided into up to 91 sectors of the sky [Aruliah et al., 2010]. SCANDI data are not available through the ESPAS project.

\subsubsection{CMAT2}

UCL has a long history of planetary atmosphere models: CMAT2 [Harris, 2001, Harris et al., 2002] is the latest General Circulation Model (GCM) for Earth in a long line of UCL models originally meant for studying the upper atmosphere. The thermosphere modelling started in 1980, was soon coupled to the high latitude F-region ionosphere, and then included the plasmasphere and lower ionosphere molecular ions region. Later the lower boundary was taken down through the middle atmosphere, and in CMAT2 reaches down to the top of the troposphere. An extended description of the equations behind such GCMs can be found in Schunk [1996].

CMAT2 was completely tidied up and re-written in Fortran 90, and is becoming more versatile and supports a larger altitude range and variable spatial and time resolutions.

CMAT2 is three-dimensional (latitude, longitude, pressure level coordinates) and is time-dependent. It solves finite difference equations of the momentum, energy and continuity equations for ion and neutral components. In assuming hydrostatic equilibrium, it can use pressure for the vertical coordinate. This assumption results in considerable simplification when solving the equations. The grid resolution is reasonable for global and meso-scale behaviour but causes inaccuracies for fine horizontal grid resolutions and filters out vertically propagating acoustic waves [Jacobson, 2005]. The integration in time is done with an explicit scheme (Euler forward) which means that spatial grid and time 


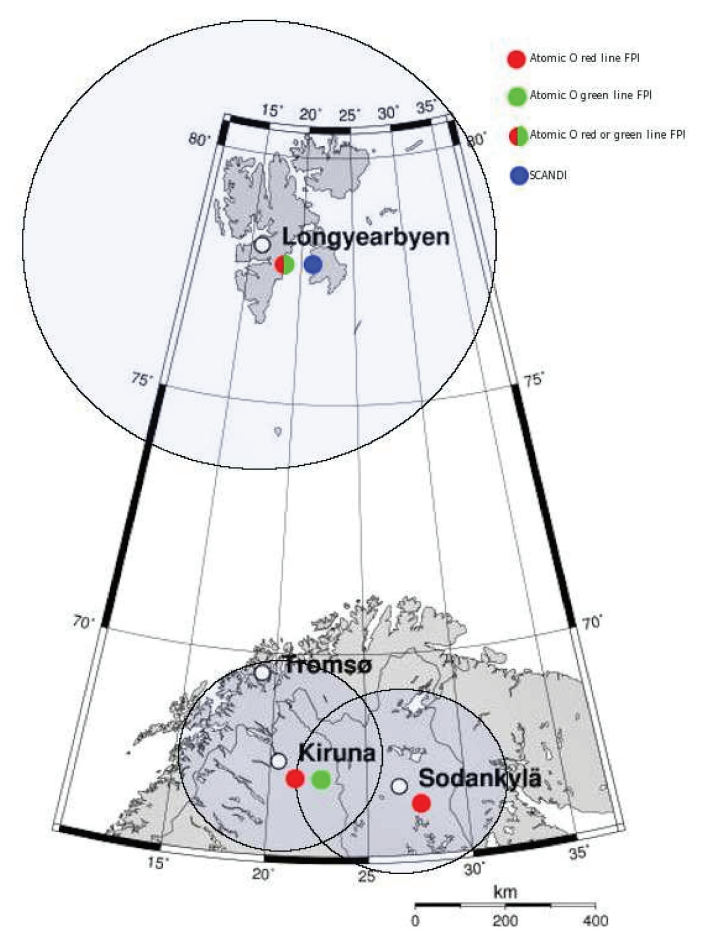

Fig. 3.1.7. Map of the location of UCL's FPIs network in northern Scandinavia. Shaded circles around the sites location represent the field of view of the instrument [Ronksley, 2016].

integration has to be treated carefully keeping in mind the Courant condition for the finite difference equations.

CMAT2 covers heights between $80-500 \mathrm{~km}$ for the thermosphere, and $110-10000 \mathrm{~km}$ for the ionosphere and plasmasphere. The typical resolution is $2 \mathrm{deg}$ in latitude, $18 \mathrm{deg}$ in longitude, $1 / 3$ scale height in pressure, and $30-60 \mathrm{~s}$ in time.

CMAT2 includes three major neutral constituents $\left(\mathrm{O}+\mathrm{O}_{3}, \mathrm{O}_{2}\right.$ and $\left.\mathrm{N}_{2}\right)$ and two ion species $\left(\mathrm{H}^{+}, \mathrm{O}^{+}\right)$for which chemistry, transport and energy are solved. In addition, there are ten minor neutral constituents $\left(\mathrm{N}\left({ }^{4} \mathrm{~S}\right), \mathrm{N}\left({ }^{2} \mathrm{D}\right), \mathrm{NO}_{\mathrm{x}}=\mathrm{NO}+\mathrm{NO}_{2}\right.$, $\mathrm{HO}_{\mathrm{x}}=\mathrm{OH}+\mathrm{HO}_{2}+\mathrm{H}, \mathrm{H}_{2} \mathrm{O}, \mathrm{H}_{2}, \mathrm{CO}, \mathrm{CO}_{2}, \mathrm{CH}_{4}$ and $\mathrm{He}$ ), for which chemistry and transport are solved. The photo-chemical reactions include radiative recombination and ionisation.

CMAT2 allows for variable lower boundary height (between $15-80 \mathrm{~km}$ ). These can be of different types-MSISE90, fixed $T$ and $p$ and GSWM tidal forcing, depending on the study being carried out [Yiğit et al., 2012]. For a boundary at $80 \mathrm{~km}$, usually fixed $T$ and $p$, or MSISE90 values are sufficient. For a lower boundary at $15 \mathrm{~km}$, the boundary can be represented in a number of ways-including MSISE90, fixed $T$ and $p$, or by inclusion of a reanalysis data set such as NCEP or ERS [UCL, 2006b]. It also includes hybrid Matsuo-Lindzen gravity wave drag parameterisation, but addition of tides 
Table 3. Summary of the FPI data available through the ESPAS service

\begin{tabular}{|l|l|}
\hline Observed properties & $\begin{array}{l}\text { Neutral Horizontal Wind Velocity (Vn-Horiz) } \\
\text { Optical Photon Flux (In) }\end{array}$ \\
\hline Platforms & Sodankylä, Kiruna and Svalbard \\
\hline Observations & 5383436 measurements \\
\hline Time covering & 23 November 1997 to 21 March 2013 \\
\hline Availability & $\begin{array}{l}\text { ASCII files } \\
\text { MySQL database (SOS service) }\end{array}$ \\
\hline
\end{tabular}

Table 4. Summary of the CMAT2 data available through the ESPAS service

\begin{tabular}{|l|l|}
\hline \multirow{5}{*}{ Observed properties } & $\begin{array}{l}\text { Altitude of Constant Atmospheric Pressure (Height) } \\
\text { Zonal Neutral Wind Velocity (Vn-zonal) } \\
\text { Meridional Neutral Wind Velocity (Vn-meridional) } \\
\text { Vertical Neutral Wind Velocity (Vn-vertical) } \\
\text { Neutral Temperature (Tn) }\end{array}$ \\
\hline Time covering & currently January 2011 \\
\hline Availability & individual netCDF files [NetCDF, 1989] \\
\hline
\end{tabular}

is possible expressed as Hough functions. Note that the use of gravity wave schemes only really applies if the lower boundary is less than $\sim 80 \mathrm{~km}$.

CMAT2 includes self-consistent dynamo calculations for the high latitude ionosphere.

Atomic oxygen $\mathrm{O}$ is critical to mesopause energetics and CMAT2 provides a proper modelling of downward transport from the thermosphere. $\mathrm{NO}_{\mathrm{x}}$ chemistry and dynamics are highly interlinked and auroral effects on global circulation and vertical mixing are accounted for in CMAT2 [Dobbin et al., 2006].

CMAT2 output consists of more than 120 thermospheric and ionospheric parameters. Standard diagnostics are automatically generated and available at the CMAT2 Model Page [UCL, 2006a]. The CMAT2 website also supports archives for run results.

\subsubsection{FPI and CMAT2 within ESPAS}

Tables 3 and 4 present a summary of the FPIs and CMAT2 observations available through the ESPAS system by the end of the ESPAS project in January 2016. More data should be made available as time allows. 


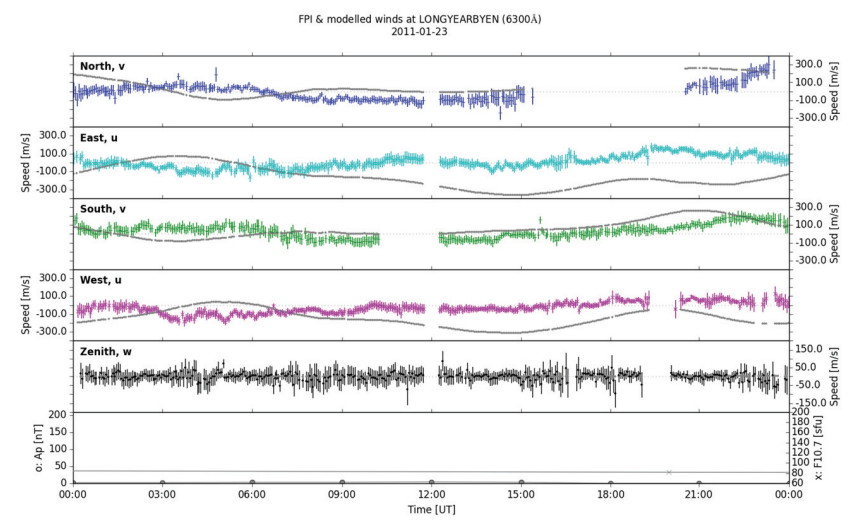

Fig. 3.1.8. Comparison of UCL FPI and CMAT2 thermospheric winds for 23 January 2011 for Svalbard red $(630.0 \mathrm{~nm})$ : epoch analysis of wind vectors (North: blue, East: cyan, South: green, West: magenta, Up: black) vs. CMAT2 (grey)

\subsubsection{Scientific use case (UC4C): suitability of FPI data for data assim- ilation into CMAT2}

An obvious application for ESPAS is its use as a test-bed for development of methodologies and standards for validation of near-Earth environment models. As part of their contribution to ESPAS, the Met Office developed a scientific use case (UC4c within work package WP8) to compare the neutral winds measured from FPIs and modelled by CMAT2 and evaluate the feasibility of assimilating FPI data into CMAT2 in the long term.

The use case covers the period between $1^{\text {st }}-31^{\text {st }}$ January 2011 , a period of rising solar activity. An extended CMAT2 simulation was run from the winter solstice 2010 to $2^{\text {nd }}$ February 2011, and used measured 3-hourly values of $A_{p}$ and daily $F 10.7 \mathrm{~cm}$ fluxes to act as external forcings to CMAT2, to ensure the simulation represented real conditions as well as possible. The neutral wind and height output files from the CMAT2 run were then used to derive horizontal wind as they would be observed by the FPIs, thus allowing direct comparison with any FPI data available for the time of run. It is worth emphasising that this implies making an assumption about the height of emission of the airglow observed by the FPIs, which is assumed to be $240 \mathrm{~km}$ [Aruliah et al., 2005].

Fig. 3.1.8 shows the results of the comparison for one day. A few interesting features emerge. There are a few data gaps - the period between $\sim 15-20$ UT for the North wind was a period of low intensity, when the noise was too large to fit the interference peaks reliably. The 6 min gap at noon for all winds however corresponds to when 10 consecutive 'dark images' are collected. This sequence of 10 dark images is taken every $24 \mathrm{~h}$ and the average ('BigDark') is subtracted from each of the sky images to remove camera noise. For 30 s exposure, a 'BigDark' image takes $10 \times 30$ s plus some dead time, i.e., a total of $\sim 6$ min.

Also apparent in Fig. 3.1.8 is that the red line (i.e., $\sim 240 \mathrm{~km}$ ) FPI observations at 


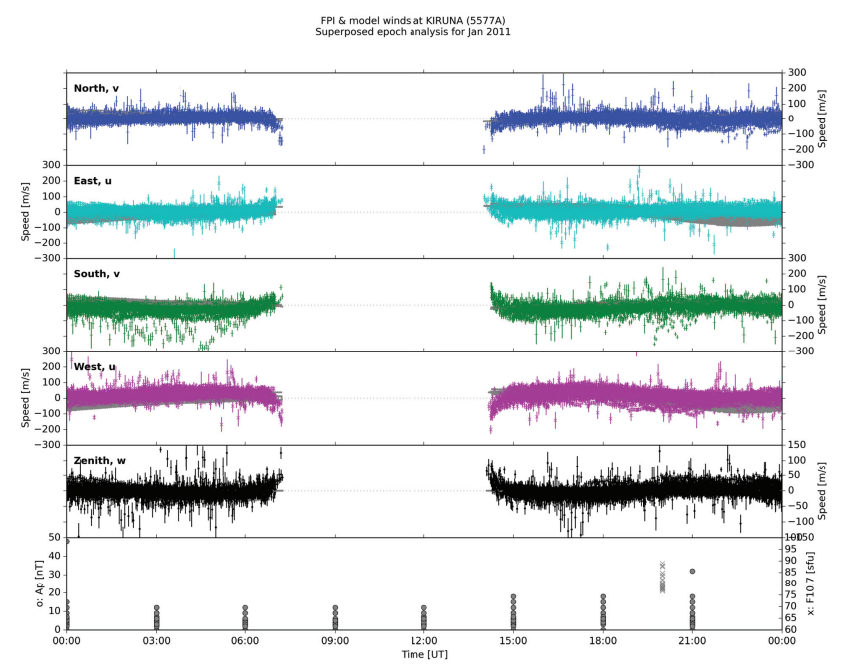

Fig. 3.1.9. Comparison of UCL FPI and CMAT2 thermospheric winds for January 2011 for Kiruna green $(557.7 \mathrm{~nm})$ : superimposed epoch analysis of wind vectors (North: blue, East: cyan, South: green, West: magenta, Up: black) vs. CMAT2 (grey)

Longyearbyen (inside the Arctic polar cap) show some large departures (up to $\sim 300 \mathrm{~m} / \mathrm{s}$ ) from the CMAT2 simulation results.

Fig. 3.1.9 shows a similar comparison, but for the green line (i.e., $\sim 120 \mathrm{~km}$ ) FPI observations at Kiruna (on the equatorward side of the auroral oval), and where a superposed epoch analysis is made for a month of data. Here, it is seen that the differences between FPI and CMAT2 winds are much smaller.

Fig.3.1.10 further illustrates this by presenting these data in histogram form-it is seen that the FPI observed wind distribution has a similar mean to the CMAT2 modelled wind distribution. This implies these data from Kiruna may be suitable for data assimilation into the CMAT2 model, as little bias correction is needed. This would however require suitable quality control, to reduce the larger variability of the FPI observations, which might cause numerical instabilities if assimilated as-is. Note that similar analysis (not shown) of the Longyearbyen data demonstrates that the situation seen in Fig. 3.1.8 is common-FPI and CMAT2 winds show much larger differences, seemingly due to large and variable model biases, probably precluding assimilation of Longyearbyen data. This is only the case at $\sim 240 \mathrm{~km}$ (red line) — the lower green line data ( $\sim 120 \mathrm{~km}$ ) shows much better agreement, suggesting this Longyearbyen green line data is also a suitable candidate for data assimilation.

As previously noted however, determining CMAT2 equivalents to FPI observations (required for quality control in any future assimilation scheme) requires assumptions about the emission height of the airglow observed by the FPIs.

Fig. 3.1.11 shows vertical profiles of the CMAT2 winds at Longyearbyen through the 


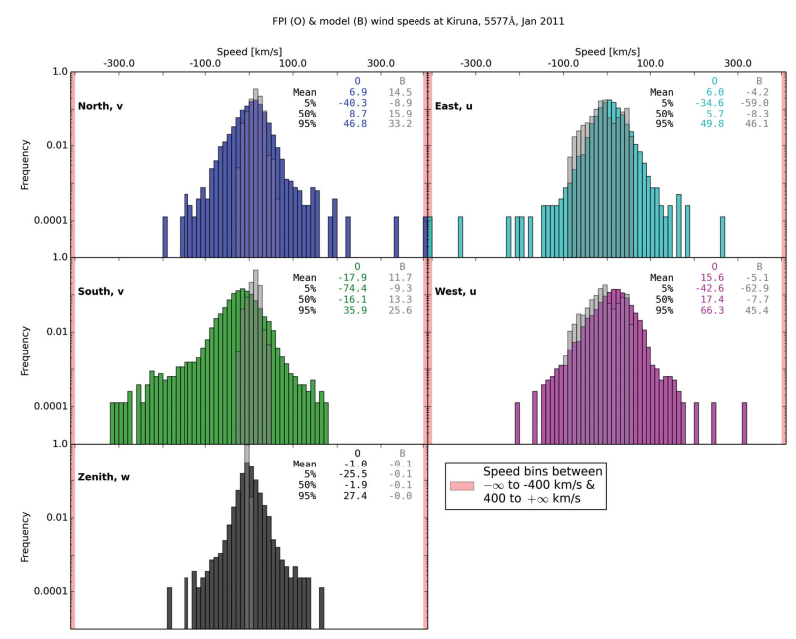

Fig. 3.1.10. Comparison of UCL FPI and CMAT2 thermospheric winds for January 2011 for Kiruna green $(557.7 \mathrm{~nm})$ : FPI vs. CMAT2 wind speed histograms with bins of $10 \mathrm{~m} \mathrm{~s}^{-1}$.

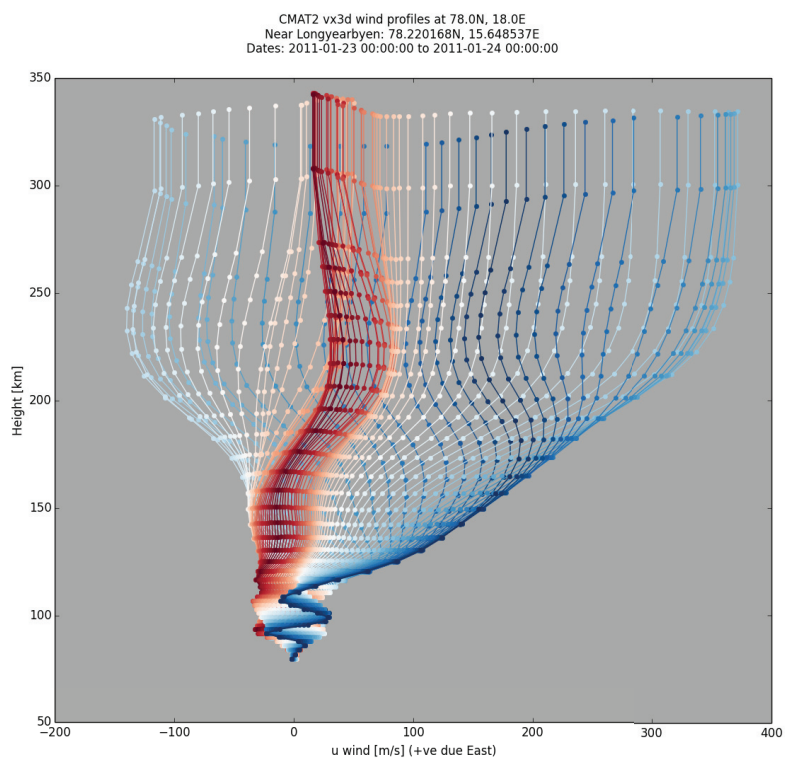

Fig. 3.1.11. Zonal wind profile from CMAT2 model at Kiruna location for 3 January 2011: nominal height of $557.7 \mathrm{~nm}$ (resp. $630.0 \mathrm{~nm}$ ) line is $120 \mathrm{~km}$ (resp. $240 \mathrm{~km}$ ). 
day. The results suggest that observation of the $630.0 \mathrm{~nm}$ red line will provide zonal wind subject to large diurnal variation but the small vertical gradient (large scale height) around $240 \mathrm{~km}$ suggests this assumed emission height will not be a significant source of error in any FPI-CMAT2 comparison. For observations with the $557.7 \mathrm{~nm}$ green line however, small diurnal variation is expected, but the large vertical gradient suggests errors in the assumed emission could propagate through into any errors in any FPI-CMAT2 comparison. Consequently, any future data assimilation scheme using FPI data will need to treat assumptions about the FPI emission height carefully since auroral activity introduces emissions in the region of $150 \mathrm{~km}$ [Bates, 1988]. Since the winds and temperatures increase steeply between $100-200 \mathrm{~km}$, it is important to know precisely what height is being measured by the $557.7 \mathrm{~nm}$ emission.

Preliminary work has also been conducted using EISCAT data—also available through ESPAS - to distinguish times where the FPI measurements are likely to be contaminated by auroral emissions at lower altitudes. This approach may help improve these comparisons, by ensuring that FPI measurements are only compared to model winds at the appropriate altitude.

\section{Acknowledgements}

We thank for their contribution Dr. Ian McWhirter and Dr. Andrew Charalambous for the design, construction, deployement and subsequent maintenance of the FPIs and SCANDI, and the photos and figures of the instruments.

\section{References}

UCL. CMAT2 Model Page @ONLINE. http://astroweb.projects.phys . ucl.ac.uk/cmat2/www/html, 2006a. [Online; accessed 29-March-2016].

UCL. CMAT2 User Guide @ONLINE. http://astroweb.projects. phys.ucl.ac.uk/cmat2/www/html/httpd/shared_docs/cmat2_ UserGuide.pdf, 2006b. [Online; V1-05beta; accessed 29-March-2016].

ESPAS. ESPAS Use Cases @ONLINE. http://www.espas-fp7.eu/index. php/overview/use-cases, 2012. [Online; accessed 29-March-2016].

A. L. Aruliah, E. M. Griffin, A. D. Aylward, E. A. K. Ford, M. J. Kosch, C. J. Davis, V. S. C. Howells, S. E. Pryse, H. R. Middleton, and J. Jussila. First direct evidence of meso-scale variability on ion-neutral dynamics using co-located tristatic FPIs and EISCAT radar in Northern Scandinavia. Ann. Geophysica, 23:147-162, January 2005.

A. L. Aruliah, E. M. Griffin, H.-C. I. Yiu, I. McWhirter, and A. Charalambous. SCANDI - an all-sky Doppler imager for studies of thermospheric spatial structure. Ann. Geophysica, 28:549-567, February 2010. .

D. R. Bates. Excitation of 557.7 nm O I line in nightglow. Planet. Space Sci., 36:883-889, September 1988. . 
C. J. Davis, A. D. Farmer, and A. Aruliah. An optimised method for calculating the $\mathrm{O}(+)-\mathrm{O}$ collision parameter from aeronautical measurements. Ann. Geophysica, 13: 541-550, May 1995. .

A. L. Dobbin, E. M. Griffin, A. D. Aylward, and G. H. Millward. 3-D GCM modelling of thermospheric nitric oxide during the 2003 Halloween storm. Ann. Geophysica, 24: 2403-2412, September 2006. .

E. A. K. Ford, A. L. Aruliah, E. M. Griffin, and I. McWhirter. High time resolution measurements of the thermosphere from Fabry-Perot Interferometer measurements of atomic oxygen. Ann. Geophysica, 25:1269-1278, June 2007. .

I. Galkin. ESPAS Space Physics Ontology @ONLINE. http: //www.espas-fp7. eu/trac/raw-attachment/wiki/PublicPages/ESPASDocs/ SpacePhysicsontology . pdf, 2015. [Online; accessed 29-March-2016].

E. Griffin, A. Aruliah, I. Müller-Wodarg, and A. Aylward. Comparison of high-latitude thermospheric meridionalwinds II: combined FPI, radar and model Climatologies. Ann. Geophysica, 22:863-876, March 2004. .

M. J. Harris. A new coupled middle atmosphere and thermosphere circulation model: Studies of dynamic, energetic and photochemical coupling in the middle and upper atmosphere. PhD thesis, Univ. of London, London, 2001.

M. J. Harris, N. F. Arnold, and A. D. Aylward. A study into the effect of the diurnal tide on the structure of the background mesosphere and thermosphere using the new coupled middle atmosphere and thermosphere (CMAT) general circulation model. Ann. Geophysica, 20:225-235, February 2002. .

F. A. Herrero and J. W. Meriwether, Jr. 6300-A airglow meridional intensity gradients. $J$. Geophys. Res., 85:4191-4204, August 1980. .

M. Z Jacobson. Fundamentals of Atmospheric Modeling. Cambridge University Press, Cambridge, UK, 2005. ISBN 978-0-521-54865-6.

NetCDF. Network Common Data Form @ONLINE. http: / / www . unidata.ucar. edu/software/netcdf, 1989. [Online; accessed 29-March-2016].

M. H. Rees. Physics and chemistry of the upper atmosphere. Cambridge University Press, Cambridge, 1989. ISBN 0-521-32305-3.

A. Ronksley. Optical remote sensing of mesoscale thermospheric dynamics above Svalbard and Kiruna. PhD thesis, Univ. of London, London, 2016.

W. Schunk, R, editor. Solar-Terrestrial Energy Program: Handbook of Ionospheric Models. Utah State University/SCOSTEP, 1996.

M. N. Vlasov, M. J. Nicolls, M. C. Kelley, S. M. Smith, N. Aponte, and S. A. GonzáLez. Modeling of airglow and ionospheric parameters at Arecibo during quiet and disturbed periods in October 2002. J. Geophys. Res., 110:A07303, July 2005. . 
O. Witasse, J. Lilensten, C. Lathuillère, and P.-L. Blelly. Modeling the OI 630.0 and $557.7 \mathrm{~nm}$ thermospheric dayglow during EISCAT-WINDII coordinated measurements. J. Geophys. Res., 104:24639-24656, November 1999. .

E. Yiğit, A. S. Medvedev, A. D. Aylward, A. J. Ridley, M. J. Harris, M. B. Moldwin, and P. Hartogh. Dynamical effects of internal gravity waves in the equinoctial thermosphere. J. Atmos. Sol.-Terr. Phys., 90:104-116, December 2012. . 



\title{
3.2 CLUSTER AND DEMETER SATELLITE DATA IN ESPAS
}

\author{
Fabien Darrouzet ${ }^{1}$, Johan De Keyser ${ }^{1}$ and Pierrette Décréau ${ }^{2}$
}

\begin{abstract}
The web portal of the FP7 ESPAS (Near-Earth Space Data Infrastructure for e-Science) project allows to retrieve electron density data from two European missions. The Cluster mission consists of four identical satellites (C1, C2, C3, C4) launched in 2000 on elliptical polar orbits with an initial perigee at $\sim 4 R_{E}$, an apogee at $\sim 19.6 R_{E}$ and an orbital period of $\sim 57$ hours. The spacecraft continue to investigate the Earth's magnetic environment and its interaction with the solar wind in three dimensions. The DEMETER (Detection of Electro-Magnetic Emissions Transmitted from Earthquake Regions) mission has been launched in June 2004 into a quasi sun-synchronous circular orbit (inclination of $98.3^{\circ}$ ) at $710 \mathrm{~km}$ altitude. The satellite operated until December 2010 and was devoted to the study of ionospheric disturbances related to seismic activity and pre- and post-seismic signatures, and to human-induced ionospheric effects. Both missions carried several scientific instruments, with some of them in particular allowing to determine some plasma parameters at the position of the satellite. On Cluster, the WHISPER (Waves of HIgh frequency and Sounder for Probing Electron density by Relaxation) instrument determined the electron density. On DEMETER, ISL (Instrument Sonde de Langmuir) measured the electron density and temperature. The missions, instruments and datasets are described in this paper.
\end{abstract}

\subsubsection{Introduction}

The European Commission FP7 ESPAS (Near-Earth Space Data Infrastructure for e-Science) project has been developed from November 2011 during 4 years (http://www.espas-fp7.eu/). Its main goal was to facilitate the access to archived observations and model-derived data of the near-Earth space environment, from

\footnotetext{
${ }^{1}$ Royal Belgian Institute for Space Aeronomy (IASB-BIRA), 3 Avenue Circulaire, 1180 Brussels, Belgium

${ }^{2}$ Laboratoire de Physique et Chimie de l'Environnement et de l'Espace (LPC2E), 3A Avenue de la Recherche Scientifique, 45071 Orléans, France
} 


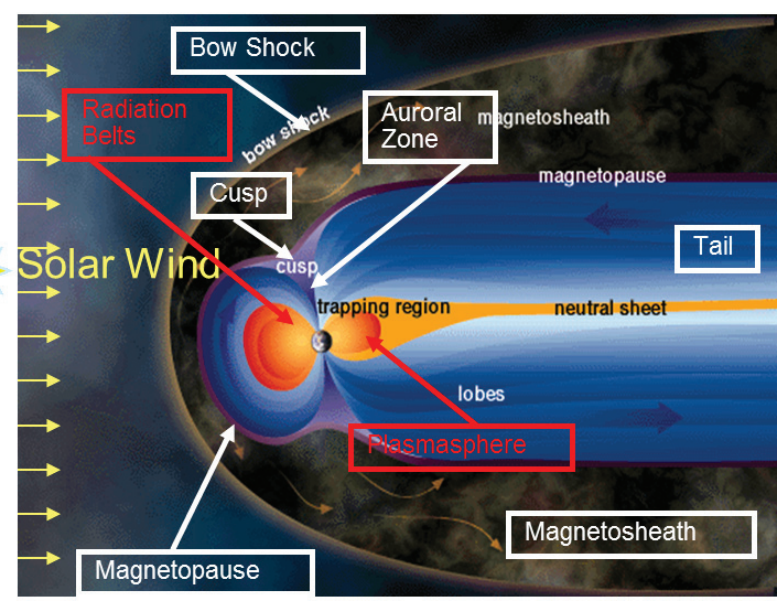

Fig. 3.2.1. Schematic representation of the magnetosphere of the Earth, its boundaries and sub-regions. (Courtesy of ESA)

the middle atmosphere up to the plasmasphere (Belehaki et al. 2014). The ESPAS web portal (https://www .espas-fp7.eu/portal/) offers an interoperable infrastructure to find, access and download data from various ground-based and spaceborne instruments. This enables the exploitation of multi-instrument, multi-point science data for analysis, model building, data assimilation into models, modelobservation comparison, space environment nowcast and forecast. This project ended in November 2015 and the ESPAS web portal is now fully operational.

The platform allows to access data from a variety of different sensors located on ground but also onboard satellites, and in particular Cluster and DEMETER (Detection of Electro-Magnetic Emissions Transmitted from Earthquake Regions). Cluster is a four-spacecraft mission still orbiting in the Earth's magnetosphere and solar wind, while DEMETER is an ionospheric mission that worked until end 2010.

This paper introduces the Earth's magnetosphere and one inner region, the plasmasphere in Sect. 3.2.2 and then the two missions and datasets in Sect. 3.2.3. The access to data through the ESPAS portal is described in the Chapter 5.1 and some conclusions are presented in Sect.3.2.4.

\subsubsection{Magnetosphere and plasmasphere}

\subsubsection{Magnetosphere}

The magnetic field of the Earth (similar to a dipole) and the solar wind from the Sun create a magnetic cavity around the Earth called the terrestrial magnetosphere (Gold 1959). As shown on Fig. 3.2.1, it is compressed in the direction of the Sun (dayside, 12:00 LT [local time], $\sim 10 R_{E}$ ) and elongated in the opposite direction (nightside, 00:00 LT, $\sim 100 R_{E}$ ). As the solar wind escapes the Sun and is directed 
towards the Earth, it is deflected around the Earth by the magnetosphere. There is an external boundary called the magnetopause, two boundary regions, the magnetosheath above and the ionosphere below, and several sub-regions including the plasmasphere.

\subsubsection{Plasmasphere}

The plasmasphere is a region of the inner magnetosphere with a toroidal shape. It is globally in co-rotation with the Earth and populated by cold plasma coming mainly from the ionosphere (Lemaire and Gringauz 1998), (Kotova 2007), (Darrouzet et al. 2009a), (Singh et al. 2011), (Darrouzet and De Keyser 2013). It has been discovered in the late 50's, early 60's, with the first results obtained from ground-based instruments (whistlers detectors) (Carpenter 1963), but also from satellites (Lunik 2) (Gringauz 1963).

The plasmasphere is composed of electrons and positive ions, with an energy of a few eV, a density between 10 and $10^{4} \mathrm{~cm}^{-3}$ and a temperature of about $10^{4} \mathrm{~K}$. Its outer boundary is called the plasmapause and is often characterized by a sharp decrease of the density. At the equator, it extends out to a radial distance of 2 to $8 R_{E}$, depending on the geomagnetic activity (indicated by the index $\mathrm{Kp}$ ). Figure 3.2.2 is a representation of the plasmasphere with its outer boundary and typical trajectories of the Cluster and DEMETER satellites.

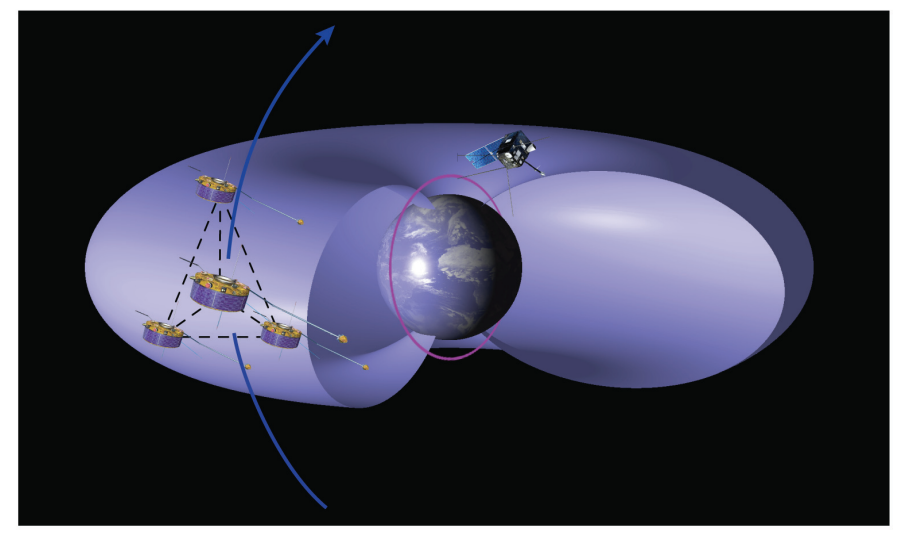

Fig. 3.2.2. Schematic representation of the plasmasphere around the Earth, with its outside boundary and typical trajectories of the 4 Cluster satellites and the DEMETER spacecraft. (Adapted from (Darrouzet et al. 2009a)) 


\subsubsection{Missions and datasets}

\subsubsection{Cluster/WHISPER}

The Cluster mission consists of 4 identical satellites: Rumba (C1), Salsa (C2), Samba (C3), Tango (C4) that have been launched in Summer 2000 (Escoubet et al. 1997). The satellites have a polar orbit (orbital time of 57 hours, initial perigee and apogee of about 4 and $19.6 R_{E}$ ) and traverse the inner magnetosphere during every orbit around perigee. The 4 satellites are in a tetrahedral configuration that changes along the orbit. The spacecraft separation distances have been modified almost every year (from 10 to $10^{4} \mathrm{~km}$ ).

Onboard, there are 11 well-calibrated instruments, including the WHISPER (Waves of HIgh frequency and Sounder for Probing Electron density by Relaxation) instrument (Décréau et al. 1997). It is a wave instrument using for reception one of the two long double sphere antennas (wire booms with a sphere-to-sphere separation of $88 \mathrm{~m}$ ) of the EFW (Electric Field and Wave) instrument (Gustafsson et al. 1997). Figure 3.2.3 shows one of the Cluster spacecraft with all the booms and antennas deployed. In particular the wire booms of the EFW instrument used by WHISPER are shown extending on both sides of the satellite.

The WHISPER instrument measures the electric field in the frequency range $2-80 \mathrm{kHz}$, with a frequency resolution of $0.163 \mathrm{kHz}$ and a time resolution of $2 \mathrm{~s}$ in normal mode (Décréau et al. 2001). WHISPER has 2 modes: (i) an active mode, in which the sounder analyses the pattern of resonances triggered in the medium by a radio pulse; (ii) a passive mode, in which the receiver monitors the natural plasma emissions.

Several methods can be used to determine the electron plasma frequency $F_{p e}$ from the data recorded by the WHISPER instrument: the identification of local wave cut-off properties (Canu et al. 2001), the observation of Bernstein modes

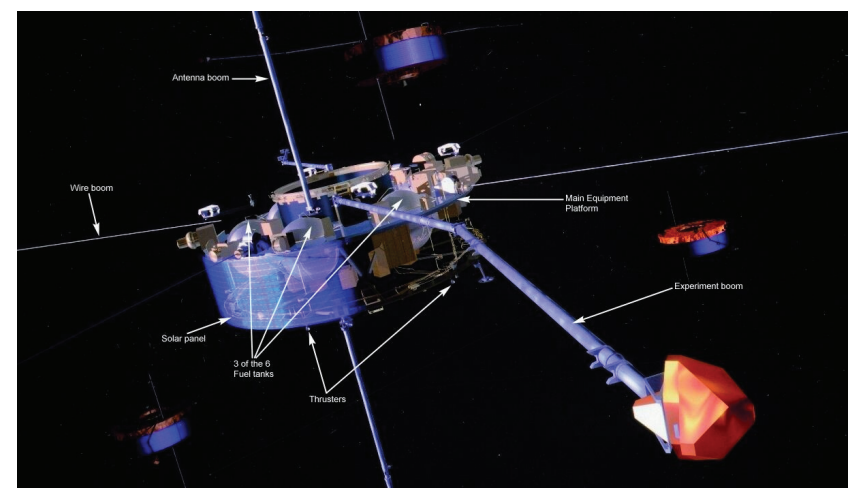

Fig. 3.2.3. Diagram of one of the Cluster spacecraft showing its main structural features. The wire booms of the EFW instrument used by WHISPER are shown extending on both sides of the satellite. (Courtesy of ESA) 
(Trotignon et al. 2003) or the use of lower hybrid resonances (Kougblénou et al. 2011). This analysis carries out a direct or indirect determination of the electron density $N_{e}$ related to $F_{p e}$ by the simple relation:

$$
N_{e}\left[\mathrm{~cm}^{-3}\right]=F_{p e}[k H z]^{2} / 81.0
$$

Figure 3.2.4 presents four time-frequency electric field spectrograms recorded by the WHISPER instrument onboard each Cluster spacecraft during a plasmasphere crossing on 11 April 2002 (Darrouzet et al. 2004). This shows clearly the crossing of a plume during the inbound and outbound passes, as well as many small density structures inside the plasmasphere (Darrouzet et al. 2009b). From those spectrograms, it is possible to determine $F_{p e}$ and then derive $N_{e}$ in the plasmasphere and also at the plasmapause (Darrouzet et al. 2013).

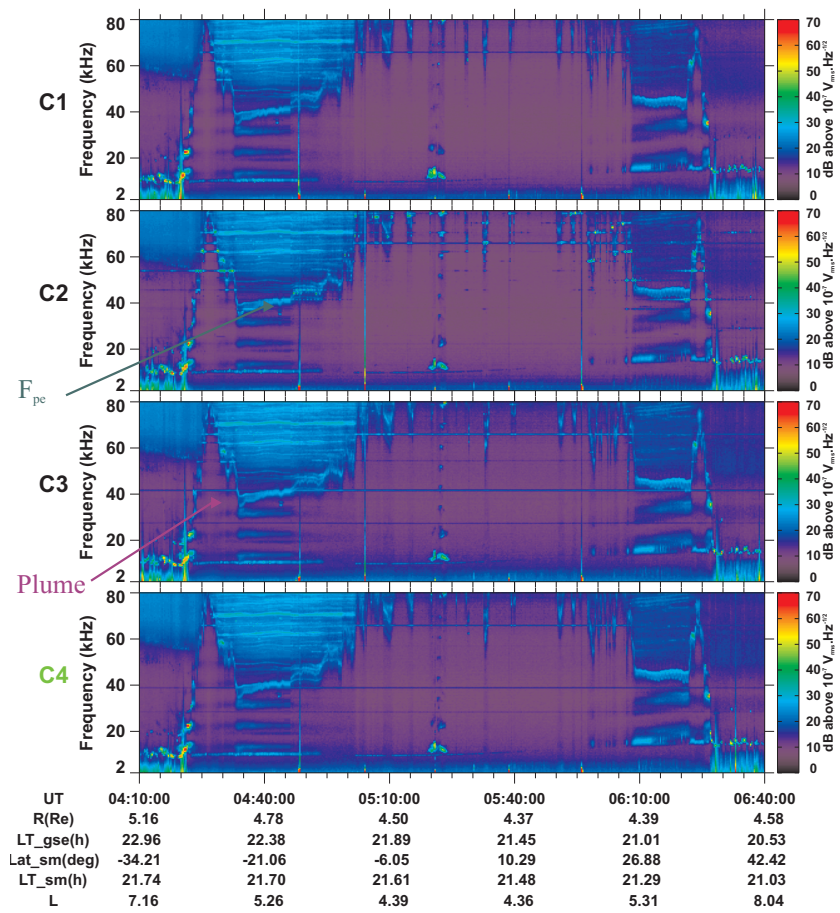

Fig. 3.2.4. Time-frequency electric field spectrograms measured by WHISPER onboard the four Cluster spacecraft on 11 April 2002 between 04:10 and 06:40 UT. The electron plasma frequency $F_{p e}$ line is indicated by a green arrow. A plume crossing is shown by a purple arrow. The orbital parameters of $\mathrm{C} 4$ are indicated at the bottom of the figure. (Adapted from (Darrouzet et al. 2006)) 


\subsubsection{DEMETER/ISL}

DEMETER (Detection of Electro-Magnetic Emissions Transmitted from Earthquake Regions) was a micro-satellite $(130 \mathrm{~kg})$ devoted to the investigation of Earth ionosphere disturbances due to seismic and volcanic activities (Cussac et al. 2006). It was a sun-synchronous satellite orbiting at $710 \mathrm{~km}$ altitude, with a $98.3^{\circ}$ inclination and was passing in almost the same local time everywhere during the day at 10:30 LT and during the night at 22:30 LT. It was launched in June 2004 and stopped working in December 2010.

DEMETER had two science modes of operation: (i) a survey mode collecting averaged data all around the Earth, with onboard processing to reduce the telemetry flow to $25 \mathrm{~kb} / \mathrm{s}$; (ii) a burst mode collecting data with a high bit rate of $1.7 \mathrm{Mb} / \mathrm{s}$ mainly activated above seismic regions.

Onboard, there were 6 instruments (see Fig. 3.2.5), including the ISL (Instrument Sonde de Langmuir) (Lebreton et al. 2006). ISL was a Langmuir probe comprised of two sensors: (i) a classical cylindrical sensor and (ii) a spherical sensor with its surface divided in seven segments. The two main observed properties measured by ISL were the electron density from $10^{2}$ to $5.10^{5} \mathrm{~cm}^{-3}$ and the electron temperature from 600 to $10000 \mathrm{~K}$. They were obtained with a $1 \mathrm{~s}$ time resolution.

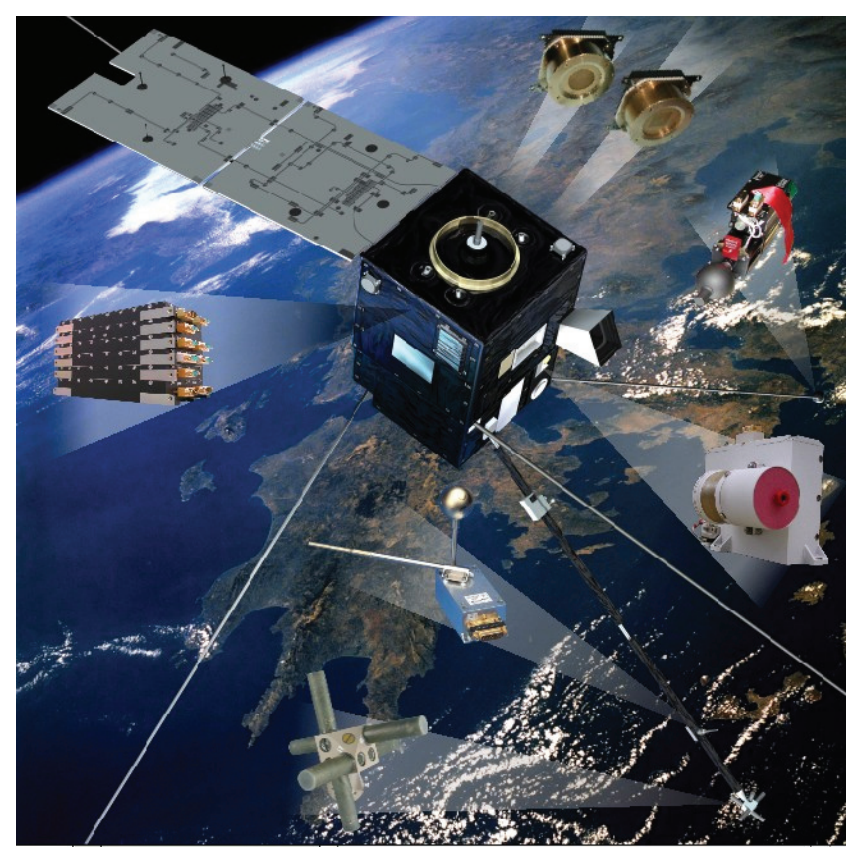

Fig. 3.2.5. Artistic representation of the DEMETER micro-satellite orbiting above the Earth, with the 6 instruments displayed around the satellite body. ISL is represented just below the satellite. (Courtesy of CNES) 


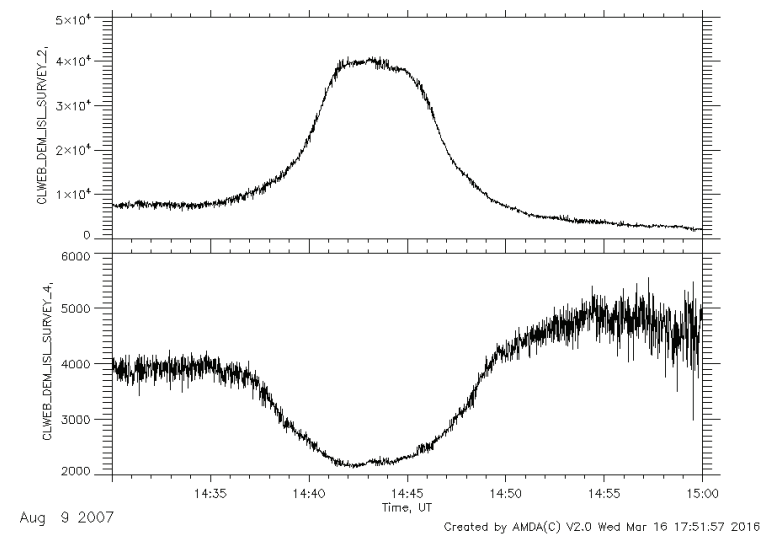

Fig. 3.2.6. Electron density in $\mathrm{cm}^{-3}$ (top) and electron temperature in $\mathrm{K}$ (bottom) measured by the ISL instrument on 9 August 2007 during 30 minutes. (Courtesy of AMDA/CDPP)

Figure 3.2.6 shows an example of the electron density and temperature measured by ISL on 9 August 2007 during 30 minutes, showing in particular an enhanced equatorial electron density between 14:38 and 14:48 UT, with a simultaneous electron temperature decrease.

The two datasets described in this section are available through the ESPAS web portal (https://www.espas-fp7.eu/portal/) and their access is described in the Chapter 5.1.

\subsubsection{Conclusion}

We describe in this paper two satellite datasets that can be downloaded through the ESPAS web portal. The first one is the electron density determined from the WHISPER instrument onboard the magnetospheric mission Cluster. The second one is the electron density and temperature measured by the ISL instrument onboard the ionospheric mission DEMETER. Both datasets are easy to use and interesting for combined ionospheric and magnetospheric research.

\subsubsection{Acknowledgements}

The ESPAS project is founded through EU-FP7 under grant agreement 283676. Analysis of DEMETER/ISL data was performed with the AMDA science analysis system provided by the CDPP (Centre de Données de la Physique des Plasmas) supported by CNRS, CNES, Observatoire de Paris and Université Paul Sabatier, Toulouse. FD thanks Anna Charisi and Yves Geunes for their kind help. 


\section{References}

Belehaki, A., M. Hapgood, N. Manola, S. Ventouras, S. James, G. Athanasopoulos, A. Lempesis, S. Marziou, J. Watermann, and the ESPAS team (2014), The ESPAS e-infrastructure: Access to data from near-Earth space, Proceeding of the 2014 conference on Big Data from Space (BiDS'14), pp. 350-353, doi:10.2788/1823.

Canu, P., P. M. E. Décréau, J.-G. Trotignon, J.-L. Rauch, H.-C. Séran, P. Fergeau, M. Lévêque, P. Martin, F.-X. Sené, E. Le Guirriec, H. Alleyne, and K. Yearby (2001), Identification of natural plasma emissions observed close to the plasmapause by the Cluster-Whisper relaxation sounder, Ann. Geophys., 19(10/12), 1697-1709, doi:10.5194/angeo-19-1697-2001.

Carpenter, D. L. (1963), Whistler evidence of a 'knee' in the magnetospheric ionization density profile, J. Geophys. Res., 68(6), 1675-1682, doi:10.1029/JZ068i006p01675.

Cussac, T., M. A. Clair, P. Ultré-Guerard, F. Buisson, G. Lassalle-Balier, M. Ledu, C. Elisabelar, X. Passot, and N. Rey (2006), The Demeter microsatellite and ground segment, Planet. Space Sci., 54(5), 413-427, doi:10.1016/j.pss.2005.10.013.

Darrouzet, F., and J. De Keyser (2013), The dynamics of the plasmasphere: Recent results, J. Atmos. Solar-Terr. Phys., 99 (7), 53-60, doi:10.1016/j.jastp.2012.07.004.

Darrouzet, F., P. M. E. Décréau, J. De Keyser, A. Masson, D. L. Gallagher, O. Santolík, B. R. Sandel, J.-G. Trotignon, J.-L. Rauch, E. Le Guirriec, P. Canu, F. Sedgemore, M. André, and J. F. Lemaire (2004), Density structures inside the plasmasphere: Cluster observations, Ann. Geophys., 22(7), 2577-2585, doi:10.5194/angeo-22-25772004 .

Darrouzet, F., J. De Keyser, P. M. E. Décréau, D. L. Gallagher, V. Pierrard, J. F. Lemaire, B. R. Sandel, I. Dandouras, H. Matsui, M. Dunlop, J. Cabrera, A. Masson, P. Canu, J.-G. Trotignon, J.-L. Rauch, and M. André (2006), Analysis of plasmaspheric plumes: CLUSTER and IMAGE observations, Ann. Geophys., 24(6), 17371758, doi:10.5194/angeo-24-1737-2006.

Darrouzet, F., J. De Keyser, and V. Pierrard (Eds.) (2009a), The Earth's Plasmasphere: A Cluster and Image Perspective, 296 pp., Springer, New York.

Darrouzet, F., D. L. Gallagher, N. André, D. L. Carpenter, I. Dandouras, P. M. E. Décréau, J. De Keyser, R. E. Denton, J. C. Foster, J. Goldstein, M. B. Moldwin, B. W. Reinisch, B. R. Sandel, and J. Tu (2009b), Plasmaspheric Density Structures and Dynamics: Properties Observed by the CLUSTER and IMAGE Missions, Space Sci. Rev., 145(1-2), 55-106, doi:10.1007/s11214-008-9438-9.

Darrouzet, F., V. Pierrard, S. Benck, G. Lointier, J. Cabrera, K. Borremans, N. Y. Ganushkina, and J. D. Keyser (2013), Links between the plasmapause and the radiation belt boundaries as observed by the instruments CIS, RAPID, and WHISPER onboard Cluster, J. Geophys. Res. Space Physics, 118(7), 4176-4188, doi:10.1002/jgra.50239.

Décréau, P. M. E., P. Fergeau, V. Krasnosels'kikh, M. Lévêque, P. Martin, O. Randriamboarison, F.-X. Sené, J.-G. Trotignon, P. Canu, P. B. Mögensen, and Whisper Investigators (1997), WHISPER, A Resonance Sounder and Wave Analyser: Performances and Perspectives for the Cluster Mission, Space Sci. Rev., 79(1-2), 157-193, doi:10.1023/A:1004931326404.

Décréau, P. M. E., P. Fergeau, V. Krasnosels'kikh, E. Le Guirriec, M. Lévêque, P. Martin, O. Randriamboarison, J.-L. Rauch, F.-X. Sené, H.-C. Séran, J.-G. Trotignon, 
P. Canu, N. Cornilleau, H. de Féraudy, H. Alleyne, K. Yearby, P. B. Mgensen, G. Gustafsson, M. André, D. A. Gurnett, F. Darrouzet, J. Lemaire, C. C. Harvey, P. Travnicek, and Whisper Experimenters (2001), Early results from the Whisper instrument on Cluster: an overview, Ann. Geophys., 19(10-12), 1241-1258, doi:10.5194/angeo-19-1241-2001.

Escoubet, C. P., C. T. Russell, and R. Schmidt (Eds.) (1997), The Cluster and Phoenix Missions, 658 pp., Kluwer Academic Publishers, Dordrecht.

Gold, T. (1959), Motions in the magnetosphere of the Earth, J. Geophys. Res., 64(9), 1219-1224, doi:10.1029/JZ064i009p01219.

Gringauz, K. I. (1963), The structure of the ionized gas envelope of Earth from direct measurements in the U.S.S.R. of local charged particle concentrations, Planet. Space Sci., 11(3), 281-296, doi:10.1016/0032-0633(63)90030-8.

Gustafsson, G., R. Boström, B. Holback, G. Holmgren, A. Lundgren, K. Stasiewicz, L. Åhlén, F. Mozer, D. Pankow, P. Harvey, P. Berg, R. Ulrich, A. Pedersen, R. Schmidt, A. Butler, A. W. C. Fransen, D. Klinge, M. Thomsen, C.-G. Fälthammar, P.-A. Lindqvist, S. Christenson, J. A. Holtet, B. Lybekk, T. A. Sten, P. Tanskanen, K. Lappalainen, and J. Wygant (1997), The Electric Field and Wave Experiment for the Cluster Mission, Space Sci. Rev., 79(1-2), 137-156, doi:10.1023/A:1004975108657.

Kotova, G. A. (2007), The Earth's Plasmasphere: State of Studies (a Review), Geomagn. Aeron., 47(4), 409-422, doi:10.1007/s11214-013-9993-6.

Kougblénou, S., G. Lointier, P. M. E. Décréau, J.-G. Trotignon, J.-L. Rauch, X. Vallières, P. Canu, A. Masson, and J. Pickett (2011), Lower hybrid resonances stimulated by the four Cluster relaxation sounders deep inside the plasmasphere: Observations and inferred plasma characteristics, Ann. Geophys., 29(11), 2003-2018, doi:10.5194/angeo29-2003-2011.

Lebreton, J.-P., S. Stverak, P. Travnicek, M. Maksimovic, D. Klinge, S. Merikallio, D. Lagoutte, B. Poirier, P.-L. Blelly, Z. Kozacek, and M. Salaquarda (2006), The ISL Langmuir probe experiment processing onboard DEMETER: Scientific objectives, description and first results, Planet. Space Sci., 54(5), 472-486, doi:10.1016/j.pss.2005.10.017.

Lemaire, J. F., and K. I. Gringauz (Eds.) (1998), The Earth's Plasmasphere, 372 pp., Cambridge University Press, New York.

Singh, A. K., R. P. Singh, and D. Siingh (2011), State studies of Earth's plasmasphere: A review, Planet. Space Sci., 59(9), 810-834, doi:10.1016/j.pss.2011.03.013.

Trotignon, J.-G., P. M. E. Décréau, J.-L. Rauch, E. Le Guirriec, P. Canu, and F. Darrouzet (2003), The Whisper Relaxation Sounder Onboard Cluster: A Powerful Tool for Space Plasma Diagnosis around the Earth, Cosmic Res., 41(4), 345-348, doi:10.1023/A:1025045308666. 



\title{
3.3 CALIBRATED AND CORRECTED POES/MEPED ENERGETIC PARTICLE OBSERVATIONS
}

\author{
Timo Asikainen ${ }^{1}$
}

\begin{abstract}
Low altitude NOAA/POES satellites have measured energetic particles with MEPED instrument from 1979 to present. However, these measurements have suffered from a variety of instrumental and data quality problems, but recent advances in detailed understanding of the MEPED instrument have allowed us to calibrate and correct the data. Currently, this database forms the longest systematically calibrated energetic particle dataset in space physics. It has now been made available though the ESPAS Data Portal in 1/4 satellite orbit time resolution. The offered data products include average energetic proton and electron fluxes in two directional telescopes at different energy channels from two opposite local time sectors and hemispheres. The data allow one to study the particle fluxes in a variety of time scales from space weather events to space climate time scales over several solar cycles. Here we review the work done to correct and recalibrate the MEPED database and describe in detail the data products published in ESPAS Data Portal.
\end{abstract}

\subsubsection{Introduction}

Energetic particles are an important part of space weather and space climate. They are a key element in generation of magnetic storms as they form the ring current and radiation belts around Earth. Energetic particles precipitating from these regions during and after geomagnetic storms also have atmospheric effects. In addition to causing auroras, they ionize the upper atmosphere, which also leads to complex chain of chemical reactions affecting atmospheric composition and thermal structure (e.g., Andersson et al., 2014). These changes can lead to changes in atmospheric dynamics which sometimes can even propagate down to surface level and affect regional climate (e.g. Baumgaertner et al., 2011; Maliniemi et al., 2013). To be able to study particle populations during storms and their effects in the atmosphere in space climate time scales over several solar cycles, direct long-term

\footnotetext{
1 Space Climate Research Unit, ReSoLVE Centre of Excellence, POBox 3000, FIN-90014, University of Oulu, Finland
} 
satellite measurements are needed. Although satellite measurements of energetic particles have been made since the dawn of space age in different satellites, systematic measurements with similar instrumentation and on similar orbits are needed for obtaining a consistent and homogeneous view of the changes in the particle populations. One of the longest running satellite programs is the NOAA/POES (Polar Orbiting Environmental Satellites) program, which has been operational since 1978. The POES satellites are mainly intended for Earth monitoring (e.g., atmospheric and weather monitoring instruments), but they also include MEPED (Medium Energy Proton and Electron Detector) energetic particle instrument as a part of their SEM (Space Environment Monitor) instrument package. A total of 14 satellites carrying the SEM package have been launched since 1978.

Despite the long temporal coverage of POES measurements, their use for longterm studies has been problematic due to several instrumental problems, which cause systematic errors and long-term drifts and inhomogeneities in the measurements. These problems are related to degradation of the proton detectors caused by radiation damage, noise problems introducing false counts in some detectors of some satellites, non-ideal instrument efficiencies, which differ between instrument versions and contamination of electron measurements by energetic protons. In addition to these instrumental problems, the archived POES auxiliary data, i.e., quantities calculated from satellite position (e.g., magnetic local time, magnetic coordinates etc.) are only rough first order approximations to more accurate values. Especially before mid 1990s also the archived satellite position data and consequently the auxiliary data as well contain spurious errors, sometimes significant, which makes the interpretation of the measurements problematic.

We have studied the NOAA/POES MEPED database meticulously and have corrected and recalibrated the entire database extending from 1979 to present. This dataset now forms the longest recalibrated set of energetic particle measurements to date and offers unique possibilities to study near-Earth particle populations in space weather and especially in space climate time scales. For the purpose of space climate studies, we have released the entire corrected MEPED dataset in $1 / 4$ of satellite orbit time resolution in the ESPAS Data Portal. Section 2 of this chapter presents a review of NOAA/POES satellites, the MEPED instrument. Section 3 reviews the different instrumental and data problems of the MEPED instrument and the procedures applied to the data in order to correct them. Section 4 discusses the NOAA/MEPED data products made available through the ESPAS system and Section 5 presents a short summary.

\subsubsection{NOAA satellites and MEPED instruments}

NOAA/POES satellites are low-altitude $(\sim 850 \mathrm{~km})$ satellites, which fly on nearly circular polar orbits with an orbital period of about $102 \mathrm{~min}$. The orbital planes relative to the Sun-Earth line stay relatively constant, i.e., the satellites are "Sun synchronous". However, the orbital planes of most satellites drift back and forth slowly with a period of typically about 25 years and an amplitude of a few local time hours (with the exception of NOAA-16 for which the drift is significant). This 


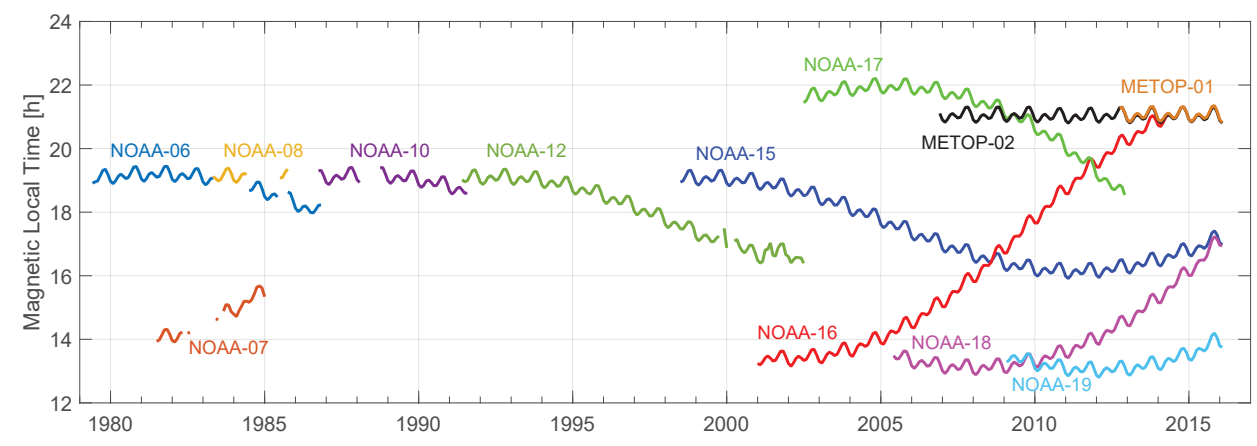

Fig. 3.3.1. Monthly averaged Magnetic Local Time (MLT) of the ascending node of all NOAA satellites as a function of time. Figure also indicates the operational period of the different satellites.

is demonstrated in Figure 3.3.1, which shows the magnetic local time (MLT) of the ascending node (measured at $40^{\circ} \mathrm{N}$ latitude) of the satellite orbit as a function of time for all POES satellites, which we have used. At the same time the figure indicates the operational period of the different satellites.

The MEPED instrument onboard the POES satellites consists of two sets of telescopes measuring energetic protons and electrons from $30 \mathrm{keV}$ upwards in two nearly orthogonal directions. MEPED also includes an omnidirectional detector measuring highly energetic $\mathrm{MeV}$ and $\mathrm{GeV}$ range protons and electrons, but this instrument is not discussed further here. Up to NOAA-14 (launched in 1995) the POES satellites carried an older, SEM-1, version of the MEPED instrument, while starting from NOAA-15 (launched in 1998) the satellites have carried an updated version called SEM-2. (Note that NOAA-14 has not been used here, since its MEPED data is mostly corrupted due to unknown reason. Also TIROS-N, the first SEM-1 satellite launched in 1978, has not been used since its instruments differ significantly from subsequent SEM-1 satellites). The energy channels of the SEM-1 and SEM-2 electron and proton detectors have been summarized in Table 3.3.1.

Protons and electrons are both measured with two telescopes, the $0^{\circ}$ and $90^{\circ}$ telescopes, with a sampling time of $2 \mathrm{~s}$ (the two directions are sampled on alternating seconds). In regions where the particle fluxes are very low, the $2 \mathrm{~s}$ sampling time can be too short to obtain meaningful counts for calibration. Because of this we have first resampled the data by computing $16 \mathrm{~s}$ averaged measurements (i.e., average of 8 consecutive measurements) in our calibrated MEPED dataset. In SEM-2 the $0^{\circ}$ (local vertical) telescope points roughly away from the Earth along the radial Earth-satellite line and the $90^{\circ}$ (local horizontal) telescope points almost antiparallel to spacecraft velocity vector. To ensure a clear field of view both of these telescopes have slightly been rotated from these directions (for more details see, e.g., Asikainen and Mursula, 2013). At high latitudes, where the magnetic field lines near the Earth are nearly radial, the $0^{\circ}$ telescope measures roughly 


\begin{tabular}{|c|c|c|}
\hline Proton channels & Nominal energy range of protons & $\begin{array}{l}\text { Nominal energy range of } \\
\text { contaminating electrons }\end{array}$ \\
\hline $\mathrm{P} 1$ & $30 \mathrm{keV}-80 \mathrm{keV}$ & $\gtrsim 6 \mathrm{MeV}^{(1}$ \\
\hline $\mathrm{P} 2$ & $80 \mathrm{keV}-250 \mathrm{keV}$ & $\approx 6 \mathrm{MeV}^{(1}$ \\
\hline P3 & $250 \mathrm{keV}-800 \mathrm{keV}$ & $-(1$ \\
\hline $\mathrm{P} 4$ & $800 \mathrm{keV}-2500 \mathrm{keV}$ & - $(1$ \\
\hline $\mathrm{P} 5$ & $2500 \mathrm{keV}-6900 \mathrm{keV}$ & $-\left(\gtrsim 800 \mathrm{keV}^{(2}\right.$ for SEM-1) \\
\hline P6 & $>6900 \mathrm{keV}$ (no P6 in SEM-1) & $\gtrsim 800 \mathrm{keV}^{(2}$ \\
\hline Electron channels & Nominal energy range of electrons & $\begin{array}{l}\text { Nominal energy range of } \\
\text { contaminating protons }\end{array}$ \\
\hline E1 & $>30 \mathrm{keV}$ & $\begin{array}{l}140-1000 \mathrm{keV} \text { in SEM-1 } \\
210-2600 \mathrm{keV} \text { in SEM-2 }\end{array}$ \\
\hline $\mathrm{E} 2$ & $>100 \mathrm{keV}$ & $\begin{array}{l}220-1000 \mathrm{keV} \text { in SEM-1 } \\
280-2600 \mathrm{keV} \text { in SEM-2 }\end{array}$ \\
\hline E3 & $>300 \mathrm{keV}$ & $\begin{array}{l}390-1000 \mathrm{keV} \text { in SEM-1 } \\
450-2600 \mathrm{keV} \text { in SEM-2 }\end{array}$ \\
\hline
\end{tabular}

Table 3.3.1. Nominal energy ranges of the proton and electron channels of the MEPED SEM-1 and SEM-2 instruments. Note that the exact response of the instrument (esp. electron detector) depends strongly on energy and nominal energy range of response only roughly describes the instrument response (Asikainen and Mursula, 2013; Yando et al., 2011). The energy ranges for SEM-1 and SEM-2 versions of the instrument are the same except when indicated otherwise. The P-channels refer to proton detector and E-channels to electron detector. Both detectors are sensitive to both particle species to some degree. The proton counting efficiency of the electron channels is 100\%. ${ }^{1)}$ MEPED modeling results by Yando et al. (2011) suggest that proton channels are also sensitive to electrons. Electron response in P1 and P2 channels starts to be significant only above some $6 \mathrm{MeV}$ energy. In P3 to P5 (SEM-2) there is no significant electron response. Typically electron fluxes at these energies are so small compared to proton fluxes that the contamination of P1-P5 (P4 in SEM-1) is not an issue. ${ }^{2)}$ In P6 (P5 in SEM-1) the electron response is significant above some $800 \mathrm{keV}$, where $100 \%$ of electrons are counted. This channel can be used as an indicator of relativistic electrons. ${ }^{3)}$ Based on MEPED modeling results by Asikainen and Mursula (2013).

field-aligned precipitating particles and the $90^{\circ}$ telescope measures roughly locally trapped particles. At low latitudes the situation is opposite so that the $90^{\circ}$ telescope measures roughly field-aligned particles (either precipitating or upflowing, depending on the direction of satellite motion and the hemisphere) and $0^{\circ}$ telescope locally trapped particles. However, since the field of view of the telescopes is $30^{\circ}$, the actual range of pitch angles that the telescopes measure can be quite large. In SEM-1 the detector orientations differ from those of the SEM-2 satellites so that the $0^{\circ}$ telescope is pointed precisely along the radial direction and the $90^{\circ}$ telescope is roughly perpendicular to the orbital plane and thus satellite velocity (for more details see, e.g., Asikainen and Mursula, 2013). A more detailed description of SEM-1 is given by Hill et al. (1985); Seale and Bushnell (1987); Raben et al. (1995), and of SEM-2 by Evans and Greer (2000). 


\subsubsection{Calibrations and corrections}

3.3.3.1 Proton dectectors Galand and Evans (2000) were the first to note that the MEPED proton detectors onboard the POES satellites degrade due to radiation damage. They noted that initially as satellites were launched the counts recorded by the $90^{\circ}$ telescope were typically larger than those in the $0^{\circ}$ telescope because of the anisotropic pitch angle distribution of energetic protons in the ring current. However, they also noted that after a few years the $90^{\circ} / 0^{\circ}$ flux ratio started decreasing and eventually became systematically smaller than 1 . They suggested that this decrease is due to radiation damage, which degrades the detectors and is more severe in the $90^{\circ}$ telescope, where the fluxes are higher. Obviously, without correction the radiation damage leads to erroneous fluxes and artificial long-term trends in the proton data.

Asikainen and Mursula (2011) and Asikainen et al. (2012) were the first studies that considered the effects of radiation damage to the MEPED proton detectors in detail. The MEPED proton (and also electron) detectors are essentially solid state silicon detectors, where the measurement of an incoming particle is based on measuring the amount of ionization produced by the incoming particle in the silicon detector. This ionization is proportional to the kinetic energy of the incoming particle. Solid state silicon detectors are generally well known to suffer from radiation damage caused by the particles that are being measured (Lutz, 1999; Grupen and Shwartz, 2008). The incoming particles affect the detector, e.g., by creating various defects in the solid state silicon lattice and by increasing the width of the so-called dead layer in front of the detector chip, where the produced ionization cannot be collected. These defects, among other things, reduce the mobility of free charge carriers and thus affect the detection of the energy of incoming particles. The reduced mobility of the free charges reduces the amount of collected charge and thus leads to underestimation of particle energy, which means that the energy required to produce a count in a given energy channel increases. Thus in effect, the radiation damage increases the energy thresholds of the instrument from their initial nominal values. Since the measured fluxes typically decrease as a function of energy, the radiation damage leads to underestimation of particle flux at a given energy channel. This underestimation becomes significant typically already 1-2 years after satellite launch and needs to be corrected before the data can be used for quantitative studies (Asikainen and Mursula, 2011).

Asikainen and Mursula (2011) developed a methodology to estimate the temporal development of the effective energy thresholds of the MEPED proton detectors and to use this information to correct the proton measurements. The first estimates were later refined by Asikainen et al. (2012). The overall process of proton data correction is summarized in Figure 3.3.2. As a new satellite is launched, an old satellite can be compared to it by finding satellite conjunctions, i.e., times where satellites are suitably close to each other spatially and temporally (step 1). The measured spectra can then be compared to find by which factors ( $\alpha$ factors) the energy thresholds in the old satellite have increased (step 2). Performing the comparison for multiple conjunctions each time a new satellite is launched allows 
us to estimate the temporal development of the $\alpha$ factors (step 3). The $\alpha$ factors can then be computed for any time and be used to compute the proton fluxes at nominal energy thresholds from the measured spectrum (step 4). However, as noted by Asikainen and Mursula (2011), computing the flux at any energy which is below the lowest energy measured by the instrument (defined by $\alpha$ factor of the P1 channel) is problematic because one has to extrapolate measured energy spectrum to lower energies. This typically leads to significant overestimation of the flux even when the $\alpha$ factors are still small. Accordingly, the highest value of the P1 $\alpha$ factor during a satellite's operational period essentially determines the lowest energy above which one is always able to get reliable estimates for the flux. When comparing several satellites it is the highest value of P1 $\alpha$ factors of all satellites that determines the lowest usable energy threshold.

Asikainen et al. (2012) also noted another problem present in NOAA-08 and NOAA-12, which is related to false counts introduced by electronic noise in the proton instrument. The proton instrument actually contains two separate detector chips, the front and the back detector. In SEM-1 the front detector measures energy channels P1-P4 and the back detector measures those high energy protons which penetrate through the front detector and deposit energy also into the back detector. These counts are recorded in the P5 channel. The front and back detectors operate in anti-coindicence logic so that if a count is registered in the back detector it is not recorded in the channels of the front detector. For some reason, the back detector of $0^{\circ}$ telescope in NOAA-12 began showing increased electronic noise in form of false counts in the P5 channel in mid 1996. This also erased real counts observed at the same time in the front detector channels P1P4 and led to artificial decrease of the count rate in these channels. Asikainen et al. (2012) found that comparing the $0^{\circ}$ counts to the counts of the unaffected $90^{\circ}$ telescope allowed one to correct the noise induced temporal change in the $0^{\circ}$ counts. This noise effect was corrected before determining and correcting the problems related to radiation damage. A similar noise effect was also seen in the $90^{\circ}$ telescope of NOAA-08 starting in late 1985 and was corrected with the same methodology as for NOAA-12.

3.3.3.2 Electron detectors The electron measurements from NOAA/POES electron detectors show no indication of radiation damage. This is because the electron telescopes have a shielding Ni-foil covering the aperture of the telescope. This foil stops most of the low energy protons, which would otherwise cause radiation damage. However, the foil allows higher energy protons to penetrate the instrument and be misidentified as electrons (proton contamination). It also scatters electrons entering the instrument and significantly affects the electron counting efficiency of the instrument. Asikainen and Mursula (2013) studied these problems in detail and also found that subtle differences in electron instrument construction between SEM-1 and SEM-2 versions of the instrument cause the proton contamination and instrument efficiencies to be different in SEM-1 and SEM-2 leading to inhomogeneous measurements. Most of the difference between SEM-1 and SEM-2 comes from the fact that SEM-2 has about $49 \%$ thicker Ni-foil than SEM-1. This 


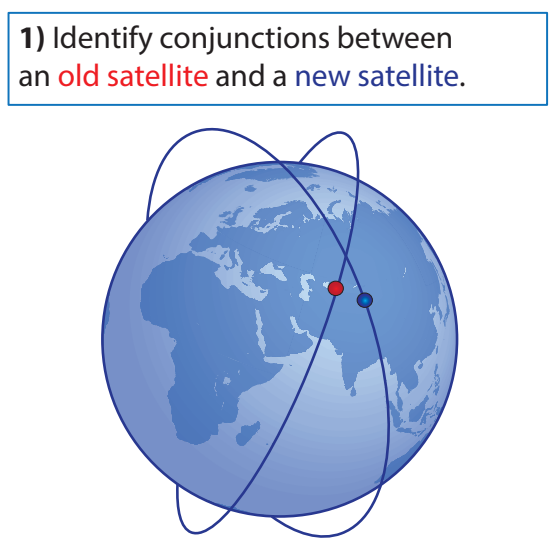

3) Repeat for many conjunctions each time a new satellite is launched to get the temporal development of $\alpha$ factors.

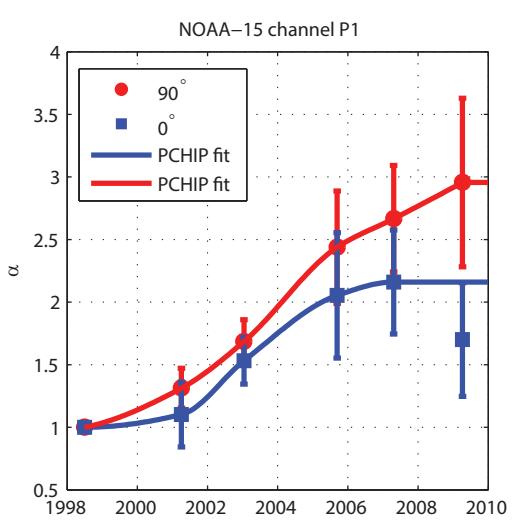

2) Compare spectra of old and new satellites and determine $\alpha$ factors.

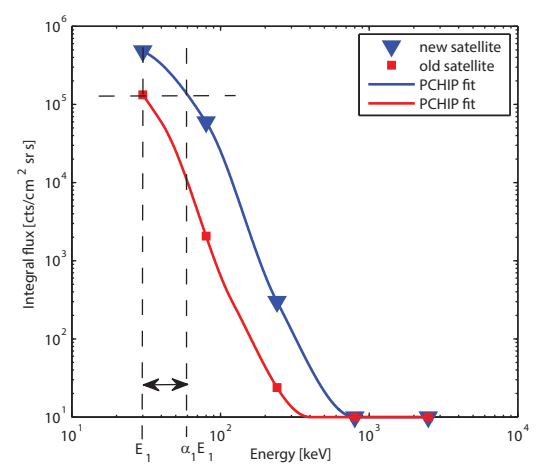

4) For each measurement fit an interpolant to the measured spectrum and use it to compute the fluxes at nominal energies.

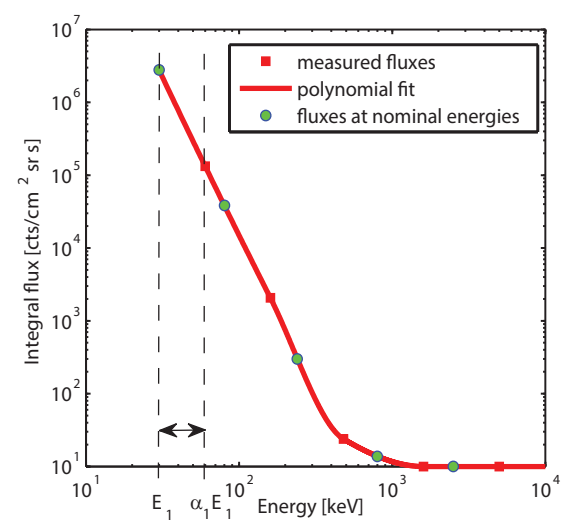

Fig. 3.3.2. Schematic illustrating the steps in correcting the proton measurements of one POES satellite (NOAA-15 used as an example).

means that SEM-1 detectors are sensitive to slightly lower energy protons than SEM-2 (see also Table 3.3.1) and the electron efficiencies are higher (less electron scattering) in SEM-1 than in SEM-2. Asikainen and Mursula (2013) used a Monte Carlo particle simulation to estimate the SEM-1 and SEM-2 electron instrument efficiencies for incoming electrons and protons. They also developed a method to use these efficiencies to remove proton contamination from the electron measurements and correct them for the non-ideal instrument efficiency. After these corrections the homogeneity of the entire MEPED electron dataset was shown to be much improved. 
3.3.3.3 Auxiliary data Satellite position in the NOAA/POES dataset is recorded by three parameters; geographic latitude, geographic longitude and altitude. In SEM-2 data, where an improved data archiving process was introduced, the satellite positions are relatively accurate, but in SEM-1 data the reported altitude of the satellite is constant and corresponds to the average altitude along the orbit. In addition the older SEM-1 data (especially for NOAA-06) contains spurious errors in satellite position, e.g., the reported longitude can sometimes be suddenly offset by several tens to more than 180 degrees for a long period of time (several days). The NOAA/POES dataset also contains a large set of different auxiliary parameters, which are calculated on the basis of satellite position. These parameters include geomagnetic coordinates, corrected geomagnetic latitude, Local Time/Magnetic Local Time and magnetic field components calculated at the satellite position and at the foot of the magnetic field line defined at $120 \mathrm{~km}$ altitude, pitch angles of the telescopes and L-value of the field line. Computation of all of these parameters is based on the IGRF magnetic field model and requires considerable amount of computational time. Because the archival procedures of NOAA/POES data date back to a time, when computational resources were quite limited, the archived data is based on interpolation of precalculated tables for these parameters. The tables have been computed assuming a constant satellite altitude and a constant IGRF magnetic field for each given year (Evans and Greer, 2000).

Since we are no longer limited by computational resources, we can compute more accurate auxiliary data for the POES dataset. We used the IRBEM library (International Radiation Belt Environment Modeling, https://craterre.onecert.fr/ prbem/irbem/description.html) to recalculate all the auxiliary parameters for all POES satellites using the accurate satellite position and IGRF magnetic field model interpolated to the time of each datapoint. The IRBEM library also allowed us to calculate additional auxiliary data not included in the original POES dataset (e.g., 2nd adiabatic invariant, corrected geomagnetic longitude etc.). For the SEM1 satellites we also needed to recalculate accurate position of the satellite, because of the spurious errors and because the accurate satellite altitude was not included in the archived data. The SEM-1 satellite positions were computed using the historical Two-Line Elements (parameter sets describing the satellite orbit) and the SGP4 orbit propagation model both obtained from https://celestrak.com/. Recalculation of SEM-1 satellite positions allowed us to correct the spurious errors in satellite position data, which obviously led to similar errors in all auxiliary parameters, and to obtain satellite positions also for those times when there were data gaps. Figure 3.3.3 shows an example of some recalculated and original parameters for NOAA-06 in 2-3 January 1986. One can see that the original data contains many data gaps and in the first half of the depicted time period the original data differs dramatically from the recalculated values because of erroneous satellite longitude. The original reported geographic longitude (top panel) is in opposite phase with the recalculated data and because of this the position dependent Magnetic Local Time (middle panel) and L-value (bottom panel) and also other parameters (not shown) differ significantly. In the latter half there is almost a perfect agreement in longitude and MLT, which indicates that the original position values 
were correct during this time and that using constant altitude with interpolation of tabulated values does not produce a large error. One can see that the L-values differ even in the latter period, because the original $\mathrm{L}$-values are capped at $\mathrm{L}=20$ and set to zero if they exceed this value. In the recalculated values there is no need for such a restriction.
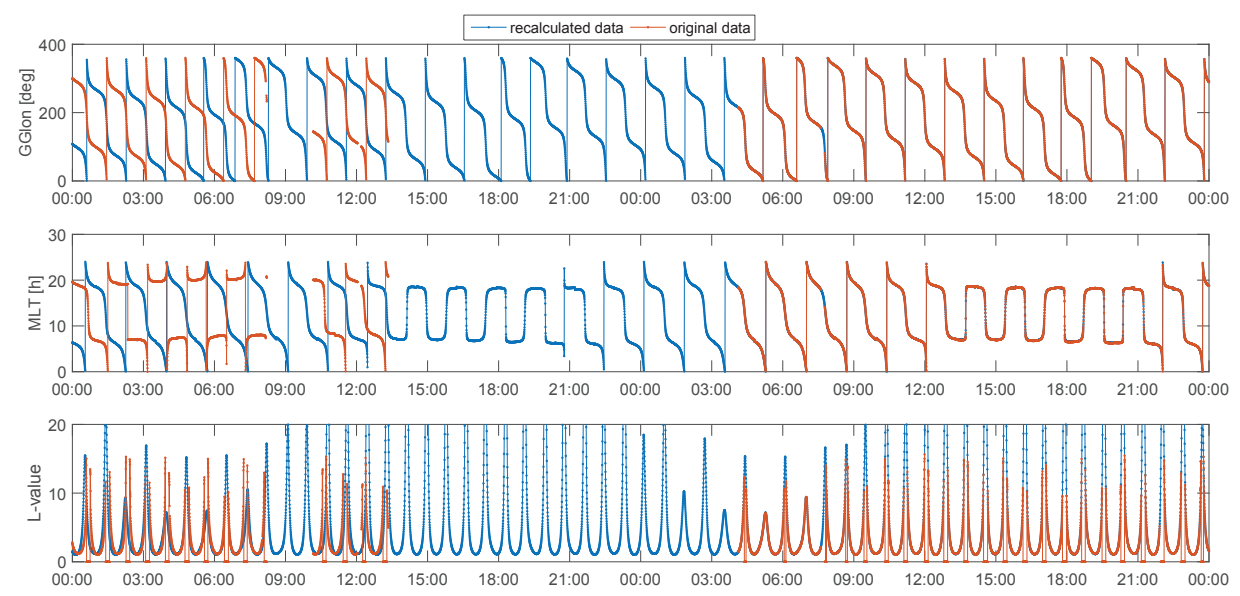

Fig. 3.3.3. Example of recalculation of satellite position and some auxiliary parameters for NOAA-06 in 2-3 January 1986. Top panel shows satellite geographic longitude, middle panel shows satellite Magnetic Local Time (MLT) and bottom panel shows L-value of the field line.

\subsubsection{Data products in ESPAS}

We have developed some specific data products based on the corrected and calibrated NOAA/POES dataset to be used especially in long-term studies of space climate. These products are available through the ESPAS Data Portal. To facilitate long-term studies we have computed energetic proton and electron fluxes conveniently averaged over $1 / 4$ of a satellite orbit. The four segments of satellite orbit are defined by the direction of satellite motion and the geographic hemisphere according to Table 3.3.2. Using this segmentation we have calculated the average energetic particle fluxes for the two telescopes in the different electron and proton energy channels (see Table 3.3.1) separately in two opposite local time sectors from north and south. Figure 3.3.4 shows a schematic of typical POES satellite orbit and the definitions of the four orbit segments in geographical coordinates (top) and 3D space (bottom). In all the four segments the data have been taken from L-shells above $\mathrm{L}=2$. This boundary was chosen because it provides a clear separation between locally trapped particles measured at the $90^{\circ}$ telescopes and locally precipitating particles measured at $0^{\circ}$ telescopes (Asikainen and Mursula, 2014). (At $\mathrm{L}<2$ the pitch angles of the two telescopes are significantly different 


\begin{tabular}{l|l|l} 
Orbit segment & Hemisphere & Direction of motion \\
\hline 1 & North & Northward \\
2 & North & Southward \\
3 & South & Southward \\
4 & South & Northward \\
\hline
\end{tabular}

Table 3.3.2. Definition of the four orbit segments for calculating the $1 / 4$ orbit averages.

and $0^{\circ}$ telescope measures mostly trapped particles, while $90^{\circ}$ telescope measures precipitating particles). Another reason for selecting only $\mathrm{L}>2$ is that it neglects most of the very high fluxes in South-Atlantic Anomaly region, which are mostly unrelated to energetic particles in the ring current and radiation belts.

The data products include the values calculated from the corrected and calibrated data as well as the uncorrected values based on original unmodified data for comparison. Note that because of the problems related to correcting the P1 proton channels (see discussion above in Section 3.1) it is not recommended to use the corrected P1 data after about 2 years from satellite launch. The orbital period of about 102 min allows one to study the energetic particle fluxes with these data from space weather to space climate time scales ranging from single storm events to solar cycle variation of energetic particles. In order to characterize the satellite position over the entire orbital segments, these data products include the satellite geographic latitude, longitude, altitude and Magnetic Local Time corresponding to the start and end times of the orbital segments (also included in the data) as well as the median of these quantities over the orbital segment. The data also includes an orbit segment indicator, a value between 1 and 4, corresponding to the orbital segment in question as defined in Table 3.3.2. Because the original 16 sec data often contains data gaps, we have also included for each orbital segment the data coverage (i.e., fraction of usable data), which can be used as a quality measure for the orbital segment average. The data products are offered as monthly ASCII files and the contents is described in Table 3.3.3.

\subsubsection{Summary}

Energetic particle measurements from the MEPED instruments onboard the low altitude NOAA/POES satellites can be used to study long-term changes of these particle fluxes from 1979 to present. The measurements have suffered from a variety of instrumental and data quality problems, but recent advances in detailed understanding of the MEPED instrument have allowed us to calibrate and correct the data. Currently, this database forms the longest systematically calibrated energetic particle dataset in space physics. These data have now been made available through the ESPAS Data Portal in 1/4 satellite orbit time resolution. The offered data products include average energetic proton and electron fluxes in two directional telescopes at different energy channels from two opposite local time sectors and hemispheres. They are well suited for long-term space climate studies but can also be used, e.g., to monitor changes in energetic particle fluxes driven by space weather events like geomagnetic storms. 

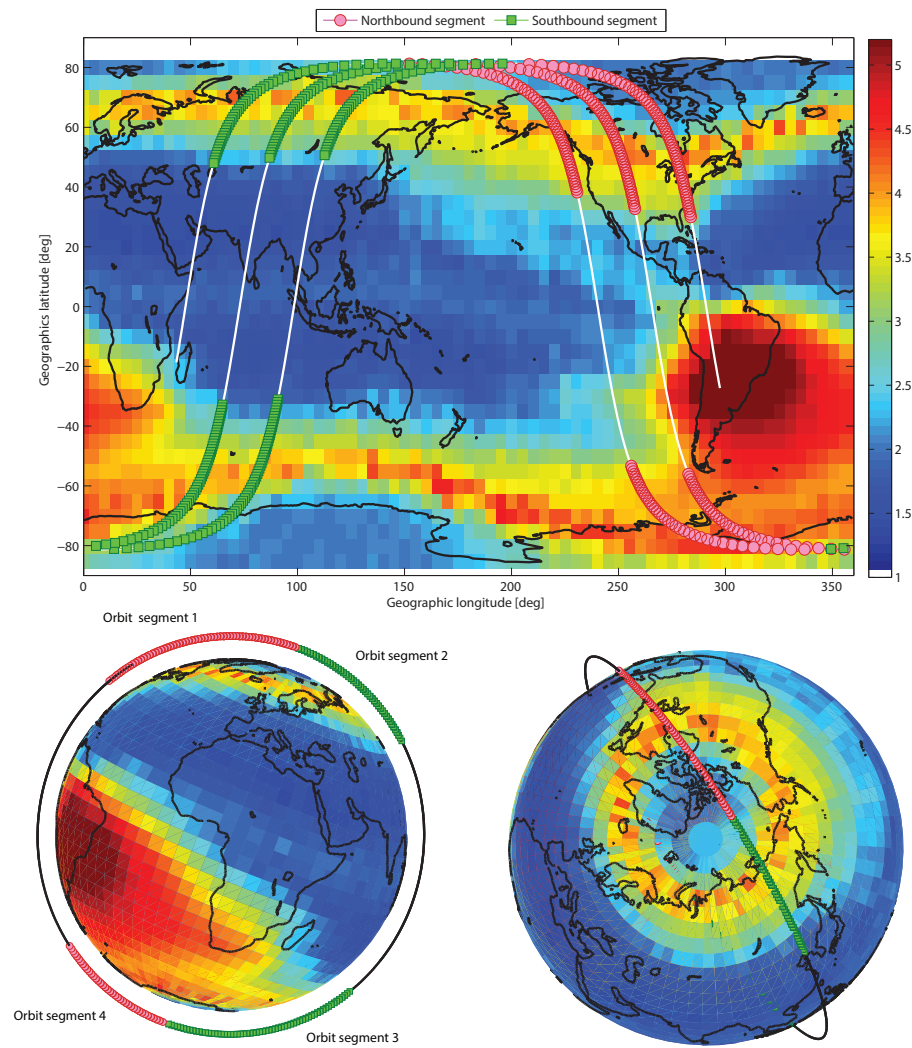

Fig. 3.3.4. A schematic of a typical POES satellite orbit and the definitions of the four orbit segments in geographical coordinates (top) and 3D space (bottom). For reference a typical pattern of energetic electron precipitation obtained from the corrected POES measurements is superposed on the globe. Colored markers indicate the range of L-values $(\mathrm{L}>2)$, where the data in each orbit segment was included into the averages.

\subsubsection{Acknowledgements}

We thank NOAA/NGDC (http://www.ngdc.noaa.gov/stp/satellite/poes/index.html) for providing the original MEPED energetic particle measurements from NOAA/POES satellites. We gratefully acknowledge support for this work via the Near-Earth Space Data Infrastructure for e-Science project (www.espas-fp7.eu), which is funded by the Research Infrastructures theme of the EU Framework 7 programme under Grant Agreement Number 283676. We acknowledge the financial support by the Academy of Finland to the ReSoLVE Center of Excellence (project No. 272157) and to project Nos. 257403, 264994 and 292712. 


\begin{tabular}{|c|c|c|}
\hline Column & Description & Units \\
\hline \multirow{2}{*}{$\begin{array}{l}\text { Auxiliary } \\
\text { data: } \\
1\end{array}$} & & \\
\hline & START time of the $1 / 4$ orbit segment & $\begin{array}{l}\text { yyyy-mm-dd- } \\
\text { Thh:mm:ssZ }\end{array}$ \\
\hline 2 & END time of the $1 / 4$ orbit segment & $\begin{array}{l}\text { yyyy-mm-dd- } \\
\text { Thh:mm:ssz }\end{array}$ \\
\hline 3 & orbit segment number & values $1,2,3,4$ \\
\hline 4 & fraction of usable data in the orbit segment, quality indicator & \\
\hline 5 & Satellite Geographic latitude median value during $1 / 4$ orbit & degrees \\
\hline 6 & Satellite Geographic latitude in $1 / 4$ orbit segment START & degrees \\
\hline 7 & Satellite Geographic latitude in $1 / 4$ orbit segment END & degrees \\
\hline 8 & Satellite Geographic longitude median value during $1 / 4$ orbit & degrees \\
\hline 9 & Satellite Geographic longitude in $1 / 4$ orbit segment START & degrees \\
\hline 10 & Satellite Geographic longitude in $1 / 4$ orbit segment END & degrees \\
\hline 11 & Satellite Altitude median value during $1 / 4$ orbit & $\mathrm{km}$ \\
\hline 12 & Satellite Altitude in $1 / 4$ orbit segment START & $\mathrm{km}$ \\
\hline 13 & Satellite Altitude in $1 / 4$ orbit segment END & $\mathrm{km}$ \\
\hline 14 & Satellite Magnetic Local Time median value during $1 / 4$ orbit & hours \\
\hline 15 & Satellite Magnetic Local Time in $1 / 4$ orbit segment START & hours \\
\hline & Satellite Magnetic Local Time in $1 / 4$ orbit segment END & hours \\
\hline \multirow{3}{*}{\multicolumn{3}{|c|}{$\begin{array}{l}\text { Energetic } \\
\text { Particle } \\
\text { fluxes: }\end{array}$}} \\
\hline & & \\
\hline & & \\
\hline 17 & $0^{\circ}$ telescope P1 channel PROTON fluxes, CORRECTED & $1 / \mathrm{cm}^{2} \mathrm{sr} \mathrm{s}$ \\
\hline 18 & $0^{\circ}$ telescope P2 channel PROTON fluxes, CORRECTED & $1 / \mathrm{cm}^{2} \mathrm{sr} \mathrm{s}$ \\
\hline 19 & $0^{\circ}$ telescope P 3 channel PROTON fluxes, CORRECTED & $1 / \mathrm{cm}^{2} \mathrm{sr} \mathrm{s}$ \\
\hline 20 & $0^{\circ}$ telescope P4 channel PROTON fluxes, CORRECTED & $1 / \mathrm{cm}^{2} \mathrm{sr} \mathrm{s}$ \\
\hline 21 & $0^{\circ}$ telescope P5 channel PROTON fluxes, CORRECTED & $1 / \mathrm{cm}^{2} \mathrm{sr} \mathrm{s}$ \\
\hline 22 & $90^{\circ}$ telescope P1 channel PROTON fluxes, CORRECTED & $1 / \mathrm{cm}^{2} \mathrm{sr} \mathrm{s}$ \\
\hline 23 & $90^{\circ}$ telescope P2 channel PROTON fluxes, CORRECTED & $1 / \mathrm{cm}^{2} \mathrm{sr} \mathrm{s}$ \\
\hline 24 & $90^{\circ}$ telescope P3 channel PROTON fluxes, CORRECTED & $1 / \mathrm{cm}^{2} \mathrm{sr} \mathrm{s}$ \\
\hline 25 & $90^{\circ}$ telescope $\mathrm{P} 4$ channel PROTON fluxes, CORRECTED & $1 / \mathrm{cm}^{2} \mathrm{sr} \mathrm{s}$ \\
\hline 26 & $90^{\circ}$ telescope P5 channel PROTON fluxes, CORRECTED & $1 / \mathrm{cm}^{2} \mathrm{sr} \mathrm{s}$ \\
\hline 27 & $0^{\circ}$ telescope P1 channel PROTON fluxes, UNCORRECTED & $1 / \mathrm{cm}^{2} \mathrm{sr} \mathrm{s}$ \\
\hline 28 & $0^{\circ}$ telescope P2 channel PROTON fluxes, UNCORRECTED & $1 / \mathrm{cm}^{2} \mathrm{sr} \mathrm{s}$ \\
\hline 29 & $0^{\circ}$ telescope P3 channel PROTON fluxes, UNCORRECTED & $1 / \mathrm{cm}^{2} \mathrm{sr} \mathrm{s}$ \\
\hline 30 & $0^{\circ}$ telescope P4 channel PROTON fluxes, UNCORRECTED & $1 / \mathrm{cm}^{2} \mathrm{sr} \mathrm{s}$ \\
\hline 31 & $0^{\circ}$ telescope P5 channel PROTON fluxes, UNCORRECTED & $1 / \mathrm{cm}^{2} \mathrm{sr} \mathrm{s}$ \\
\hline 32 & $0^{\circ}$ telescope P6 channel PROTON fluxes, UNCORRECTED ${ }^{(*)}$ & $1 / \mathrm{cm}^{2} \mathrm{sr} \mathrm{s}$ \\
\hline 33 & $90^{\circ}$ telescope $\mathrm{P} 1$ channel PROTON fluxes, UNCORRECTED & $1 / \mathrm{cm}^{2} \mathrm{sr} \mathrm{s}$ \\
\hline 34 & $90^{\circ}$ telescope P2 channel PROTON fluxes, UNCORRECTED & $1 / \mathrm{cm}^{2} \mathrm{sr} \mathrm{s}$ \\
\hline 35 & $90^{\circ}$ telescope P3 channel PROTON fluxes, UNCORRECTED & $1 / \mathrm{cm}^{2} \mathrm{sr} \mathrm{s}$ \\
\hline 36 & $90^{\circ}$ telescope P4 channel PROTON fluxes, UNCORRECTED & $1 / \mathrm{cm}^{2} \mathrm{sr} \mathrm{s}$ \\
\hline 37 & $90^{\circ}$ telescope P5 channel PROTON fluxes, UNCORRECTED & $1 / \mathrm{cm}^{2} \mathrm{sr} \mathrm{s}$ \\
\hline 38 & $90^{\circ}$ telescope P6 channel PROTON fluxes, UNCORRECTED ${ }^{(*)}$ & $1 / \mathrm{cm}^{2} \mathrm{sr} \mathrm{s}$ \\
\hline 39 & $0^{\circ}$ telescope PROTON fluxes $120-250 \mathrm{keV}$, CORRECTED & $1 / \mathrm{cm}^{2} \mathrm{sr} \mathrm{s}$ \\
\hline 40 & $90^{\circ}$ telescope PROTON fluxes $120-250 \mathrm{keV}$, CORRECTED & $1 / \mathrm{cm}^{2} \mathrm{sr} \mathrm{s}$ \\
\hline 41 & $0^{\circ}$ telescope E1 channel ELECTRON fluxes, CORRECTED & $1 / \mathrm{cm}^{2} \mathrm{sr} \mathrm{s}$ \\
\hline 42 & $0^{\circ}$ telescope E2 channel ELECTRON fluxes, CORRECTED & $1 / \mathrm{cm}^{2} \mathrm{sr} \mathrm{s}$ \\
\hline 43 & $0^{\circ}$ telescope E3 channel ELECTRON fluxes, CORRECTED & $1 / \mathrm{cm}^{2} \mathrm{sr} \mathrm{s}$ \\
\hline 44 & $90^{\circ}$ telescope E1 channel ELECTRON fluxes, CORRECTED & $1 / \mathrm{cm}^{2} \mathrm{sr} \mathrm{s}$ \\
\hline 45 & $90^{\circ}$ telescope E2 channel ELECTRON fluxes, CORRECTED & $1 / \mathrm{cm}^{2} \mathrm{sr} \mathrm{s}$ \\
\hline 46 & $90^{\circ}$ telescope E3 channel ELECTRON fluxes, CORRECTED & $1 / \mathrm{cm}^{2} \mathrm{sr} \mathrm{s}$ \\
\hline 47 & $0^{\circ}$ telescope E1 channel ELECTRON fluxes, UNCORRECTED & $1 / \mathrm{cm}^{2} \mathrm{sr} \mathrm{s}$ \\
\hline 48 & $0^{\circ}$ telescope E2 channel ELECTRON fluxes, UNCORRECTED & $1 / \mathrm{cm}^{2} \mathrm{sr} \mathrm{s}$ \\
\hline 49 & $0^{\circ}$ telescope E3 channel ELECTRON fluxes, UNCORRECTED & $1 / \mathrm{cm}^{2} \mathrm{sr} \mathrm{s}$ \\
\hline 50 & $90^{\circ}$ telescope E1 channel ELECTRON fluxes, UNCORRECTED & $1 / \mathrm{cm}^{2} \mathrm{sr} \mathrm{s}$ \\
\hline 51 & $90^{\circ}$ telescope E2 channel ELECTRON fluxes, UNCORRECTED & $1 / \mathrm{cm}^{2} \mathrm{sr} \mathrm{s}$ \\
\hline 52 & $90^{\circ}$ telescope E3 channel ELECTRON fluxes, UNCORRECTED & $1 / \mathrm{cm}^{2} \mathrm{sr} \mathrm{s}$ \\
\hline
\end{tabular}

Table 3.3.3. Contents of NOAA/POES data files available in ESPAS data portal. $(*)$ Only available for SEM-2 satellites.

\section{References}

Andersson, M. E., Verronen, P. T., Rodger, C. J., Clilverd, M. A., and Seppälä, A.: 2014, Nature Com. 5, 5197

Asikainen, T. and Mursula, K.: 2011, J. Atmos. Solar-Terrestrial Phys. 73, 335

Asikainen, T. and Mursula, K.: 2013, J. Geophys. Res. 118, 6500 
Asikainen, T. and Mursula, K.: 2014, Journal of Atmospheric and SolarTerrestrial Physics 113(0), 29

Asikainen, T., Mursula, K., and Maliniemi, V.: 2012, J. Geophys. Res. 117, A09204, doi:10.1029/2012JA017593

Baumgaertner, A. J. G., Seppälä, A., Jöckel, P., and Clilverd, M. A.: 2011, Atmos. Chem. Phys. 11, 4521

Evans, D. S. and Greer, M. S.: 2000, NOAA Technical Memorandum, Boulder, Colorado OAR SEC-93

Galand, M. and Evans, D.: 2000, NOAA Technical Memorandum, Boulder, Colorado OAR 456-SEC 42

Grupen, C. and Shwartz, B.: 2008, Particle Detectors, Vol. 26 of Cambridge monographs on particle physics, nuclear physics and cosmology, Cambridge University Press, second edition

Hill, V. J., Evans, D. S., and Sauer, H. H.: 1985, NOAA Technical Memorandum, Boulder, Colorado ERL SEL-71

Lutz, G.: 1999, Semiconductor Radiation Detectors, Springer, first edition

Maliniemi, V., Asikainen, T., Mursula, K., and Seppälä, A.: 2013, J. Geophys. Res. 118

Raben, V. J., Evans, D. S., Sauer, H. H., Sahm, S. R., and Huynh, M.: 1995, NOAA Technical Memorandum, Boulder, Colorado ERL SEL-86

Seale, R. A. and Bushnell, R. H.: 1987, NOAA Technical Memorandum, Boulder, Colorado ERL SEL-75

Yando, K., Millan, R., Green, J., and Evans, D.: 2011, J. Geophys. Res. 116, A10231, doi:10.1029/2011JA016671 



\title{
3.4 GROUND AND SPACE BASED GNSS IONOSPHERE MONITORING DATA IN ESPAS
}

\author{
Jens Berdermann ${ }^{1}$, Mainul Hoque ${ }^{1}$, Martin Kriegel $^{1}$ and Norbert \\ Jakowski $^{1}$ for the ESPAS consortium
}

\begin{abstract}
Radio signals transmitted by modern communication, navigation and Earth observation systems are influenced during propagation through the ionosphere. The ionosphere is an ionoized layer ranging from about $50 \mathrm{~km}$ till $1000 \mathrm{~km}$ around the earth and is mainly generated by the solar irradiance. The strong dependence on geographical, diurnal, seasonal, solar cycle and space weather effects lead to strong dynamical ionospheric variations and causes problems for reliable modelling and related applications. During the past decades a growing number of observations are available with the potential to significanly improve monitoring and modelling of the ionosphere. Especially ground- and space-based Global Navigation Satellite System (GNSS) data provide a significant contribution for our understanding of the ionosphere, but also for improving operations and performance of telecommunication and navigation systems. GNSS based ionospheric products provided via ESPAS help to understand the ionosphere and its interaction with extreme space weather conditions.
\end{abstract}

\subsubsection{Introduction}

Well established ground- and space-based GNSS measurements offer a unique chance to permanently monitor the electron density and the structure of the ionosphere-plasmasphere system. Ionospheric key parameters such as electron density, ion composition and plasma temperature are highly variable during a solar cycle, season, daytime and with geographic/geomagnetic location due to permanently changing solar irradiation conditions that are closely related to space weather. Severe space weather events modify the magnetosphere, ionosphere and thermosphere systems at quite different spatial and temporal scales. The GNSS technique is well suited to monitor medium to large-scale effects in time and space.

1 German Aerospace Center, Institute of Communication and Navigation, Kalkhorstweg 53, 17235 Neustrelitz 
Thus storm-induced changes of the ionospheric plasma developing at characteristic times of a few days and scale lengths of up to several thousand kilometres can be monitored complementary by ground- and space-based GNSS measurements. Space-based data for example can provide information about the ionosphere over the ocean and regions where ground-based data are not available and allow to estimate ionospheric key parameters for the different ionospheric layers. In ESPAS, ionospheric data products based on GNSS reference networks as well as from ionosonde station, such as TEC maps, scintillation plots, slab thickness plots and ionograms are available. The ESPAS space-based ionosphere data products like radio occultation profiles and sounding profiles of the topside ionosphere and plasmasphere are from Low Earth Orbit (LEO) satellites. The ionosphere data and products are disseminated by several ESPAS data providers. Ground- as well as space-based GNSS data, such as GPS, Galileo and GLONASS measurements, and non-GNSS data such as vertical sounding data of ionosonde stations providing relevant information which are of great interest for the scientific community, but are also important to users in the area of telecommunication, navigation and radar systems. Radio signals transmitted by modern communication, navigation and earth observation systems may be heavily disturbed by space weather hazards, where the ionospheric range errors at slant ray paths may reach up to $100 \mathrm{~m}$ and must be corrected even for mass market applications. Therefore, service provider needs to be trained in understanding GNSS measurements and related ionospheric monitoring products in order to take space weather events seriously into account while providing satellite-based navigation and telecommunication services. This can be done by using ESPAS reference data sets in order to rate and improve operational service systems. In the following section, we will give a short introduction into relevant ground- and space-based GNSS data products related to the ionosphere, which are availabe via ESPAS.

\subsubsection{Ground-Based GNSS data as part of ESPAS}

Trans-ionospheric signals using radio frequencies below $10 \mathrm{GHz}$ propagate through the ionosphere and are influenced by refraction, diffraction and scattering of radio waves causing a propagation delay. Therefore, ionospheric effects are relevant for technical systems in the navigation domain resulting in an enlarged distance estimation between the satellite and the receiver. The GNSS radio signals are operated at frequencies affected by the ionosphere, which is classified as the dominant error source for modern satellite-based navigation services. The GNSS observables are range measurements deduced from time and phase differences of received and receiver-generated signals. The measured carrier phase $\Phi$ and code $\Psi$ ranges

$$
\begin{aligned}
& \Phi=\rho+c(d t-d T)-d_{I}+d_{A}+\left(d_{M P}\right)_{\Phi}+d q+d Q+N \lambda+\epsilon_{\Phi} \\
& \Psi=\rho+c(d t-d T)+d_{I g r}+d_{A}+\left(d_{M P}\right)_{\Psi}+d q+d Q+\epsilon_{\Psi}
\end{aligned}
$$

are called pseudo ranges due to several errors affecting the signal propagation time accuracy and therefore the calculated range. They are biased due to satellite clock 
errors $d t$, receiver clock errors $d T$, satellite instrumental biases $d q$, the receiver instrumental biases $d Q$, random errors $\epsilon_{\Phi}, \epsilon_{\Psi}$ and along the signal propagation path by the ionospheric phase delay $d_{I}$, the ionospheric group delay $d_{I g r}$, the atmospheric delay $d_{A}$ as well as from multipath effects $\left(d_{M P}\right)_{\Phi}$ and $\left(d_{M P}\right)_{\Psi}$. In the equations $\rho$ is given as the geometrical distance between satellite and receiver, $\lambda$ is the carrier wavelength and $N$ is the integer carrier phase ambiguity. Information about the ionosphere can be deduced from the signal time delay (TEC maps) or amplitude and phase measurements (scintillations). In the following we are interested in the ionospheric effects, as the dominant part within the whole error budget for single frequency GNSS applications.

\subsubsection{TEC maps}

The Total Electron Content (TEC) is derived from the ionospheric delay in dual frequency code and carrier phase GNSS measurements and can be calculated by integration over all electrons along the slant ray path between satellite and receiver

$$
d_{I}=\frac{40.3}{f^{2}} \int n_{e} d s=\frac{40.3}{f^{2}} T E C^{s \ln t},
$$

with the electron density $n_{e}$, the used GNSS frequency $f$ and $T E C^{\text {slnt }}$ is the slant TEC value along the raypath. TEC provides the number of electrons per square meter and the most frequently used unit is 1 TECU $=10^{16}$ electrons $/ \mathrm{m}^{2}$. In a first approximation the ionospheric range error in GNSS is proportional to TEC. Therefore, a single frequency GNSS user could directly derive the dominant first order ionospheric range error when knowing the Total Electron Content along the signal ray path. Calculation of TEC values over certain regions can be done using a multitude of GNSS measurements provided from GNSS networks like the International GNSS Service (IGS) and EUREF [Jakowski et al., 1996]. Global TEC maps in the Space Weather Application Center Ionosphere (SWACI) and its successor the Ionosphere Monitoring and Prediction Center (IMPC) are mainly based on $1 \mathrm{~Hz}$ data streams provided by the International GNSS Service RealTime Pilot Project (IGS-RTPP). In order to generate 2-dimensional TEC maps, the slant TEC measurements have to be converted into vertical TEC by using the single layer mapping function

$$
M(\epsilon)=\frac{T E C^{\text {slant }}}{T E C^{\text {vert }}}=\left(1-\left(\frac{R_{E} \cos \varepsilon}{R_{E}+h_{s p}}\right)^{2}\right)^{-1 / 2},
$$

where $h_{s p}$ is the height of the ionosphere single-layer approximation, $T E C^{\text {vert }}$ is the vertical TEC at the ionospheric pierce point, $R_{E}$ is the Earth radius and $\varepsilon$ is the elevation angle. The measured and calibrated TEC data needs to be assimilated into a background model in order to extrapolate measurement information to regions outside the observation area. Such background models are usually based on physical approaches taking into account the natural behaviour of the ionosphere as e.g. diurnal and seasonal variations, geographic/geomagnetic dependence and 


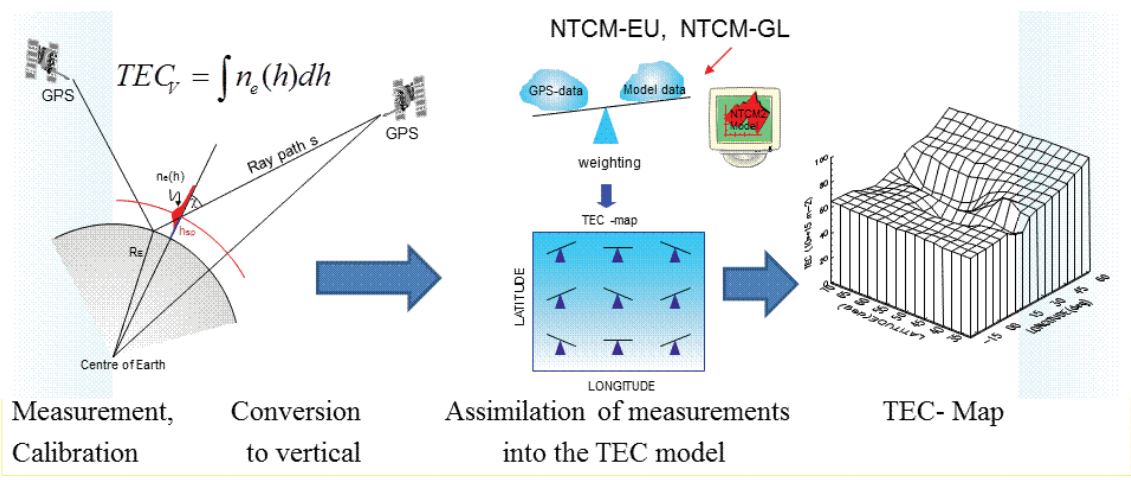

Fig. 3.4.1. Processing chain to generate TEC maps.

dependence from solar activity [Jakowski et al., 2011]. Figure 3.4.1 shows a graphical representation of the TEC map processing chain. SWACI TEC maps are based on a $1 \mathrm{~Hz}$ sampled GNSS data model-assisted TEC reconstruction using the Neustrelitz TEC model (NTCM) as background model [Jakowski et al., 2005]. The assimilated TEC maps are generated in near real time with 5 minutes latency and are further processed to derive latitudinal and zonal gradients, rate of change of TEC as well as 27 days medians and TEC rates. The SWACI TEC products provided via ESPAS to researchers and interested users are given in Figure 3.4.2. The SWACI TEC map ASCII data files available in ESPAS specify in the header

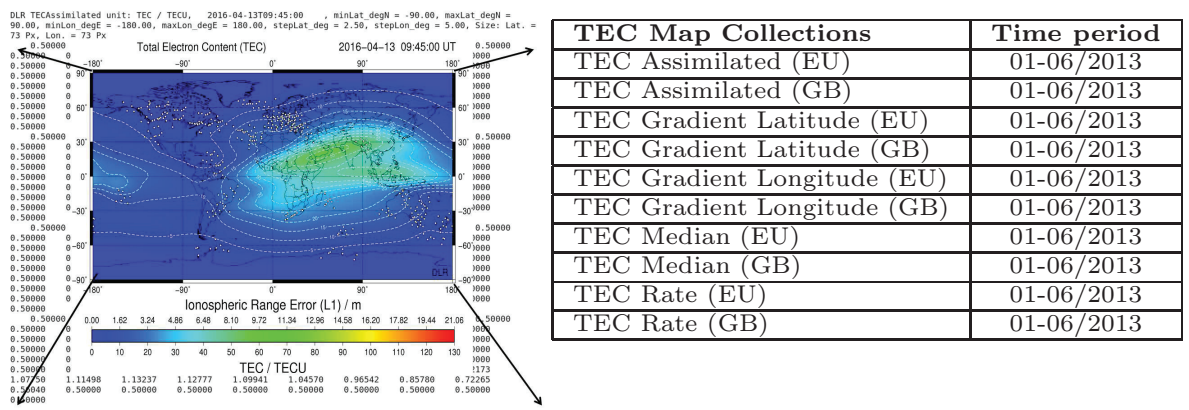

Fig. 3.4.2. Left: Global SWACI TEC map and underlying ASCII data format as provided via the ESPAS system. Right: Table of GNSS TEC Map products provided with ESPAS.

line product type, unit, product date, minimal and maximal latitude, minimal and maximal longitude, grid size, pixel size. As highligted in Figure 3.4.2, the data lines are a top view numerical representation of the grid map, starting with value of the first cell (North-West) down to the value of the last cell (South-East). In order to get GNSS TEC map data via the ESPAS portal click on assets, select GNSS Receiver, click Observed Properties, select Total Electron Content (I), click 
on Time Period and select the wished time interval. SWACI TEC data downloaded via ESPAS can be further analysed using the TEC time series plotter, a valueadded service prototype designed for the ESPAS project. It provides a simple but functional user interface to extract time series data from global TEC maps and enables the user to do rapid analysis of the TEC based on selected locations and time ranges without knowing the data format of SWACI TEC maps in detail. The ESPAS user can download an executable of this service from the ESPAS system under "VALUE ADDED SERVICES".

\subsubsection{Scintillation}

Small scale irregularities of the ionospheric plasma may cause fluctuations of the signal strength of radio waves. These signal scintillations usually decrease the positioning quality or can even lead to loss of lock to the satellites on a receiver level [Hlubek et al., 2014]. To quantify the severity of scintillation events the scintillation indices

$$
S_{4}=\sqrt{\frac{\left\langle A^{4}\right\rangle-\left\langle A^{2}\right\rangle^{2}}{\left\langle A^{2}\right\rangle^{2}}}=\sqrt{\frac{\left\langle I^{2}\right\rangle-\langle I\rangle^{2}}{\langle I\rangle^{2}}} \text { and } \sigma_{\phi}=\sqrt{\frac{1}{n-1} \sum_{i=1}^{n}\left(\phi_{i}-\langle\phi\rangle\right)^{2}}
$$

are widely used as statistical measures. The index $S_{4}$ describes the signal amplitude $A$ or intensity $I=A^{2} / 2$ fluctuation of the radio signal, whereas the index $\sigma_{\phi}$ is a measue of the standard deviation of the phase $\phi$ noise, where the mean is usually computed over one minute. There exist a strong spatial and temporal dependence of scintillation occurence. In the polar region, scintillation events can occur at any time in connection with geomagnetic storms caused by strong solar wind condition due to a coronal mass ejection. In the equatorial region, scintillation events are more frequent due to flow inversion of the equatorial plasma during evening hours. Scintillation events can last from several minutes up to several hours and are classified in different intensity levels. In ESPAS available stations Neustrelitz

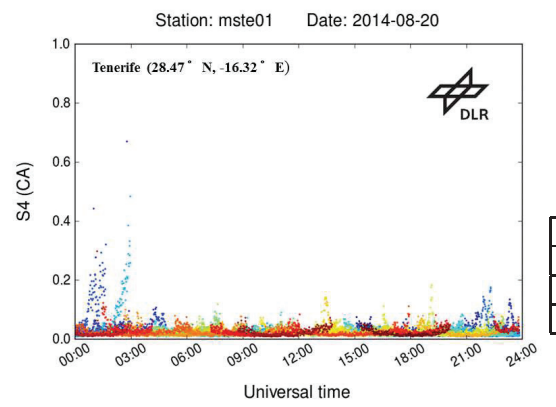

\begin{tabular}{|c|c|}
\hline Value of $S_{4}$ & Classification \\
\hline $0.2<S_{4} \leq 0.4$ & Weak \\
\hline $0.4<S_{4} \leq 0.6$ & Moderate \\
\hline $0.6<S_{4} \leq 1.0$ & Strong \\
\hline
\end{tabular}

\begin{tabular}{|l|c|}
\hline Collection name & Time period \\
\hline Scintillation Plots Neustrelitz & $02 / 2011-11 / 2014$ \\
\hline Scintillation Plots Tenerife & $02 / 2011-11 / 2014$ \\
\hline Scintillation Plots Toulouse & $02 / 2011-11 / 2014$ \\
\hline
\end{tabular}

Fig. 3.4.3. Left: Index $S_{4}$ showing a scintillation event at the high rate GNSS station in Tenerife. Right Top: Table of scintillation intensity levels according to [Gwal et al., 2004]. Right Bottom: Table of scintillation products provided with ESPAS. 
(Germany, mid latitudes), Toulouse (France, mid latitudes) and Teneriffa (Spain, low latitudes) belong to a network of high rate GNSS receiver stations $(20,50 \mathrm{~Hz})$ distributed in North-South direction to monitor ionospheric scintillation in real time. The ASCII file consists of a headerline specifying the columns $G P S_{W e e k}$, $G P S_{T O W}, \mathrm{PRN}, S_{4}(\mathrm{CA})$ and Sigma(L1,60Sec)/radian. Starting with the second line, the data values for the above-specified column are written, having the number -999.99 in case of an invalid value.

\subsubsection{Slab Thickness}

The equivalent slab thickness is a measure of the width of the shape of the vertical electron density profile of the ionosphere. The equivalent slab thickness $\tau$ is defined by the ratio of the total electron content (TEC) and the peak electron density of the local ionosphere

$$
T E C=\tau \cdot N m F 2 .
$$

To compute the peak electron density, vertical sounding data from ionosonde stations Juliusruh of the Institut of Atmospheric Physics (IAP) in Kuehlungsborn and the Tromsoe Geophysical Observatory (TGO) are used, which are provided every 15 minutes. The corresponding TEC data are extracted from TEC maps generated in DLR. The shape of the vertical electron density profile reflects the complexity of production, loss and transportation of plasma in the Earths ionosphere. A first order measure of the profile shape is the equivalent slab thickness, which is defined as the ratio of the total electron content TEC and the ionospheric peak density NmF2. This ratio is very sensitive to the competition of plasma driving forces such as thermospheric winds and electric fields and therefore very helpful in exploring perturbation processes in the ionosphere [Jakowski et al., 2008; Gerzen et al., 2013]. The slab thickness is well correlated with thermospheric heating at daytime but
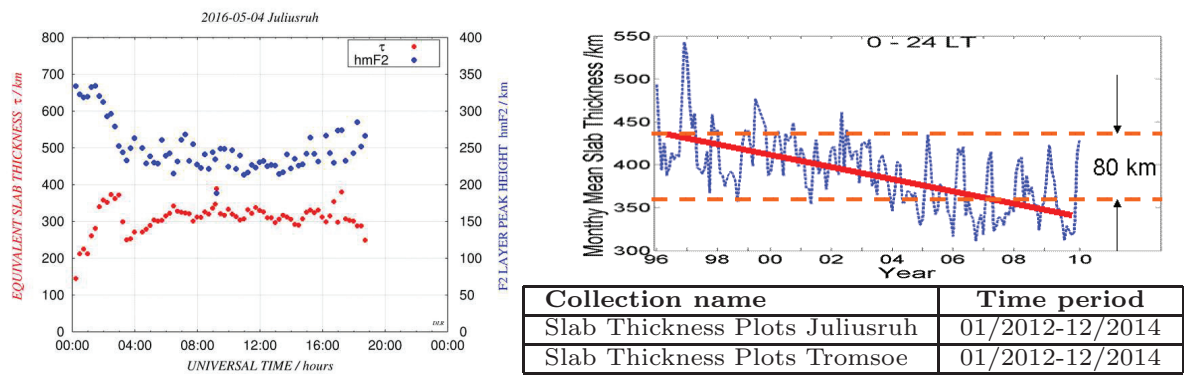

Fig. 3.4.4. Left: Equivalent slab thickness (red) and peak electron density height hmF2 (blue). Right Top: Long-term trend of the change in slab thickness over Juliusruh. Right Bottom: Table of slab thickness products provided with ESPAS.

increases significantly due to the enhanced contribution of the plasmasphere to TEC in the night. The data provided with ESPAS allow correlation studies of the 
equivalent slab thickness with extreme space weather events but also with longterm climatological and solar cycle trend studies. Slab thickness changes indicate deformation of the electron density profile and are important for estimating the driving forces of ionospheric perturbations.

\subsubsection{Space Based GNSS data as part of ESPAS}

ESPAS space-based GNSS data for ionospheric research can be separated into two main product branches: Radio Occultation (RO) data and GNSS-based topside ionosphere measurements. Space-based GNSS data are important to fill the gap of ionospheric ground-based measurements over the ocean or regions difficult to access. The general idea of the Radio Occultation (RO) method is that a spacecraft will track radio signal transmitted from another spacecraft while it passes through the planetary atmosphere. The geometry of RO requires at least one transmitting spacecraft and one receiving spacecraft for sounding the Earths atmosphere. The GNSS signals from GPS, GLONASS, Galileo, BeiDou are routinely tracked by several LEO satellites for sounding Earths ionosphere and neutral atmosphere. RO measurement can be used to derive information on ionospheric parameters like the Total Electron Content, the electron density profile, the topside electron density and the bottomside slab thickness. In Figure 3.4.5, an example plot for a radio occultation profile derived from differential TEC measurements onboard CHAMP is given. The radio occultation technique has a large potential for mea-
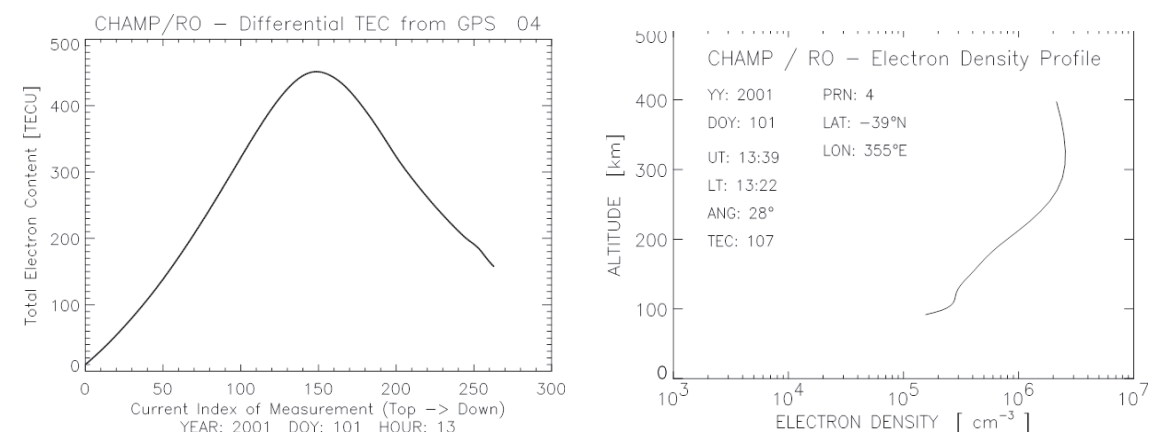

Fig. 3.4.5. Left: Differential TEC from GNSS measurement onboard CHAMP. Right: Electron density profile from differential TEC under assumption of spherical symmetry and an orbit height of CHAMP near F2 layer peak $(350 \mathrm{~km})$.

suring the vertical electron density structure of the ionosphere with high data coverage on global scale. Hence, RO data products can essentially contribute to the establishment of operational data sets of the global electron density distribution for developing and improving global ionospheric models and to provide operational space weather information [Jakowski et al., 2002]. The future science mission FORMOSAT-7/COSMIC-2 will consist of 6 LEO satellites lunched in 2017 and another 6 satellites in 2020 (US-Taiwan) with the potential to allow 
high resolution ionospheric tomography based on RO measurements. Beside the GPS radio occultation measurements of the ionosphere, satellites like CHAMP (CHAllenging Minisatellite Payload) and GRACE can track several satellites simultaneously for navigation. The received dual frequency GPS signals provide additional information on the ionization state of the topside ionosphere and plasmasphere [Heise et al., 2002]. Thus, with its space-based GNSS data, ESPAS provides a valuable database for the improvement of ionospheric/plasmaspheric models [Hoque and Jakowski, 2011, 2012].

\section{References}

Jakowski, N., Hoque, M.M., Mayer, C. (2011), A new global TEC model for estimating transionospheric radio wave propagation errors Journal of Geodesy, 85 (12), pp. 965974, Springer, ISSN 0949-7714.

Hlubek, N., Berdermann, J., Wilken, V., Gewies, S., Jakowski, N., Wassaie, M., Damtie, B. (2014), Scintillations of the GPS, GLONASS, and Galileo signals at equatorial latitude J. Space Weather Space Clim. 4 A22 DOI: 10.1051/swsc/2014020.

Gwal, A. K., S. Dubey, and R. Wahi (2004), A study of L-band scintillations at equatorial latitudes, Adv. Space Res., 34, 20922095, doi:10.1016/j.asr.2004.08.005.

Jakowski, N., Stankov, S. M., Klaehn, D., (2005), Operational space weather service for GNSS precise positioning Annales Geophysicae 23 3071-3079.

Jakowski, N. (1996), TEC Monitoring by Using Satellite Positioning Systems Book: Modern Ionospheric Science, Eds. Kohl, H., Ruester, R. Schlegel, K., ISBN3-9804862-1-4.

Jakowski,N., Stankov, S.M., Wilken, V., Borries, C., Altadill, D., Chum, J., Buresova, D., Boska, J., Sauli, P., Hruska, F., Cander, Lj. R., (2008), Ionospheric behavior over Europe during the solar eclipse of 3 October 2005, Journal of Atmospheric and Solar-Terrestrial Physics, 70, Issue 6, 836-853, ISSN 1364-6826.

Gerzen, T., Jakowski, N., Wilken, V., and Hoque, M. M., (2013), Reconstruction of F2 layer peak electron density based on operational vertical total electron content maps, Ann. Geophys., 31, 1241-1249.

Jakowski, N., Wehrenpfennig, A., Heise, S., Reigber, Ch., Luhr, H., Grunwaldt, L. and Meehan, T. K., (2002), GPS radio occultation measurements of the ionosphere from CHAMP: Early results GRL, 29, No.10, (2002), 95-1.

Heise, S., Jakowski, N., Wehrenpfennig, A., Reigber, CH., and Luhr, H., (2002), Sounding of the topside ionosphere/plasmasphere based on GPS measurements from CHAMP: Initial results GRL; 29, NO. 14, (2002).

Hoque, M. M., Jakowski, N., (2011), A new global empirical NmF2 model for operational use in radio systems, Radio Science, 46, Issue 6, RS6015, doi:10.1029/2011RS004807.

Hoque, M. M., Jakowski, N. (2012), A new global model for the ionospheric F2 peak height for radio wave propagation, Ann. Geophys., 30, 797-809.

We acknowledge the cooperation with the German Federal Agency for Cartography and Geodesy (BKG), the International GNSS Service (IGS), the German Research Centre for Geosciences (GFZ), the Leibniz-Institute of Atmospheric Physics (IAP) and the University of Tromsø. We thank the Universidad de La Laguna and the University of Toulouse for hosting our high rate GNSS stations. ESPAS project is funded through EU-FP7 under grant agreement 283676. 


\subsection{GROUND BASE IONOSPHERIC RADIO SOUNDING: BASIC PRINCIPLES AND APPLICATION}

Bruno Zolesi ${ }^{1}$

1. Istituto Nazionale di Geofisica e Vulcanologia, Roma, Italia

\subsubsection{Introduction}

The importance and the actuality of the ground base ionospheric measurements are here considered. Some historical notes on the first studies and experiments and the evolution of vertical ionospheric radio sounding are reported taking into account the role of the international radio communication organizations like CCIR (International Radio Consultative Committee) and ITU-R (International Telecommunication Union - Radio-Communication Sector) as well as the scientific associations like URSI (International Union of Radio Science) and COSPAR (Committee on Space Research). The basic physical principles of the ionospheric vertical soundings are also shown and then the significance of the ionospheric measurements, their interpretation according the international conventions used for a common morphological description of the ionosphere. Finally the application of the ionospheric radio soundings to the ionospheric mapping and modelling for ionospheric prediction and forecasting of $\mathrm{HF}$ radio communication and space weather tools are shortly described.

\subsubsection{Historical notes}

The story of the exploration and the experimental investigation of the terrestrial ionosphere starts when Guglielmo Marconi, Nobel prize in 1909 for his contribution to the development of wireless telegraphy, realized on 12th December 1901 a transoceanic radio link, that may be considered the first to provide the experimental proof of the existence of the ionosphere, postulated during the nineteenth century by various scientists like Balfour Stewart and Arthur Schuster. Then the vertical structure of the ionosphere was described during the $1920 \mathrm{~s}$ by the systematic experiments and theoretical studies of Edward V. Appleton, winning him the Nobel Prize in 1947. This was possible thanks to the technological developments of the Americans Gregory Breit and Merle A. Tuve. In the same period, the name "ionosphere" was coined during a discussion between another British scientist Robert Watson Watt and Appleton.

The ionosphere is that part of the terrestrial atmosphere, above $50 \mathrm{~km}$ of altitude, characterized by a high density of free electrons and free ions. It is also defined as 
the region where the ion and electron density reaches values as to influence the refraction index of the radio waves $(3 \mathrm{kHz}-30 \mathrm{MHz})$. The ionospheric plasma is mainly due to the photoionization of atmospheric gases caused by the UV and X electromagnetic radiations coming from the Sun. It is a very low-density plasma immersed in the geomagnetic field called magneto-plasma (Fig. 3.5.1).

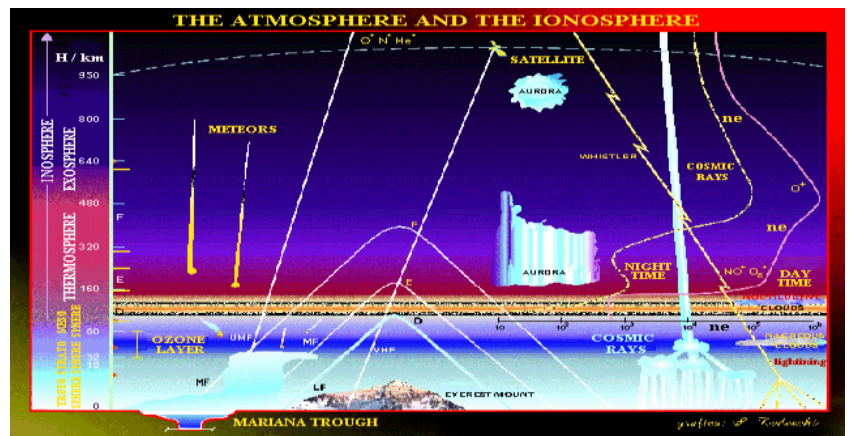

Fig. 3.5.1. The Atmosphere and Ionosphere: a picture of principal physical phenomena.

The principal and traditional method to investigate the terrestrial ionosphere was the ionospheric vertical sounding that uses basic radar techniques to detect electron density of ionospheric plasma as a function of the height by scanning the transmitting HF frequency and measuring the time delay of any echoes. Starting from about 1930, the network of ionospheric vertical stations expanded considerably and their data contributed to a better knowledge of the ionospheric phenomena. While the first routine ionospheric sounding stations were set primarily for scientific purposes, the great expansion was during the Second World War due to the need to make predictions on long distance radio links. Finally the maximum expansion was reached during the International Geophysical Year in 1958.

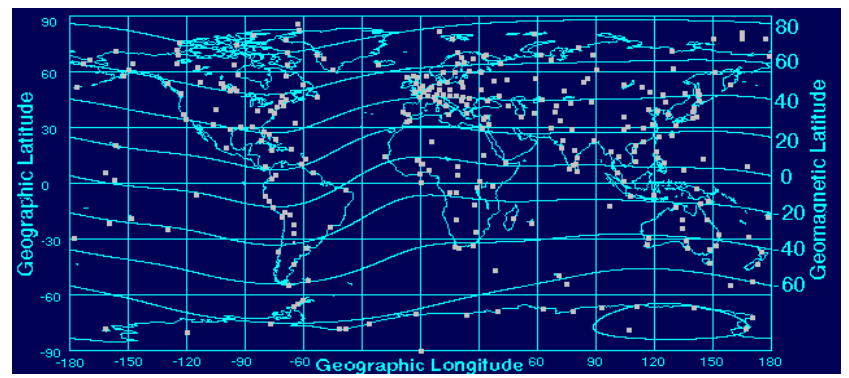

Fig. 3.5.2. Map of the ionospheric vertical sounding stations operating during the International Geophysical Year.

Considering that the maintenance of an adequate network of stations for 
scientific and practical purposes depends on the cooperation of organizations involved in geophysical studies of the ionosphere or involved in studies concerning radio propagation problems, some international organizations such as URSI and ITU, the former CCIR, encouraged investigations and observations on ionosphere and the exchange of the data through the World data Centres (Fig. 3.5.2).

\subsubsection{Ionospheric measurements by vertical radio soundings}

The method and the instrumentation used for electronic density measurements are based on the principle that when an electromagnetic wave penetrates vertically in the ionospheric plasma, the reflection occurs at the level where the refractive index becomes zero. According to the magneto-ionic theory, the refractive index:

$$
n^{2}=1-\left(f_{N} / f\right)^{2}
$$

is dependent on the plasma frequency $f_{N}$; given by:

$$
f_{N}=\sqrt{\frac{N q^{2}}{4 \pi^{2} \varepsilon_{0} m}}
$$

where $N$ is electron density, $q$ and $m$ the charge and the mass of the electron and $f$ the incident frequency. Reflection in the ionosphere occurs when the incident frequency $f$ is equal to $f_{N}$. A vertical ionospheric sounder emits radio impulses with increasing frequency from $1 \mathrm{MHz}$ to $20 \mathrm{MHz}$, measuring the time delay of radio signals received back from the different ionospheric layers (Fig. 3.5.3).

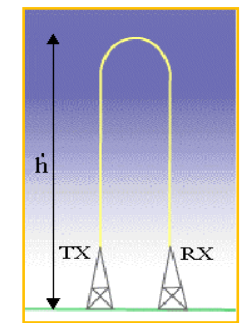

Fig. 3.5.3. A vertical ionospheric sounder emits radio impulses with increasing frequency from $1 \mathrm{MHz}$ to $20 \mathrm{MHz}$, measuring the time delay of radio signals received back from the different ionospheric layers.

The maximum electron density $N_{M}$ corresponds to the maximum reflected incidence frequency, called the critical frequency $f_{o}$

$$
N_{M}=1.2410^{10} \mathrm{fo}^{2}
$$

where $N_{M}$ and fo are expressed in $\mathrm{el} / \mathrm{m} 3$ and in $\mathrm{MHz}$ respectively. 


\subsubsection{1 lonograms and their interpretation}

The ionogram is the record produced by the ionosonde which shows the time delay between the transmission time and the received echo from the ionospheric layer, proportional to the altitude, as function of the radio frequency according to the relation:

$$
\Delta t=\frac{2}{c} h
$$

Since the signal travels more slowly in the ionosphere than in the free space, the heights observed $h$ ' exceed the true height reflections and are so called virtual heights (Fig. 3.5.4).

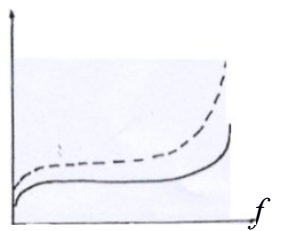

Fig. 3.5.4. The times delay recorded and then the heights observed, dotted line, exceed the true height, continuous line, because the signal travels more slowly in the ionosphere than in the free space.

Then the ionogram is a plot of the virtual height of reflection vs the transmitted frequency. According the magneto-ionic theory we have two or, more rarely, even three traces in the ionogram. They are called ordinary and extraordinary traces. They are caused by a different value of the refraction index due to the effect of the geomagnetic field (Fig. 3.5.5).

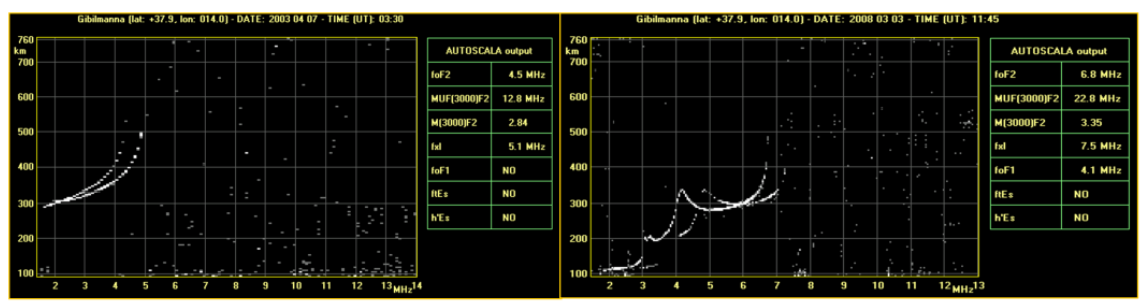

Fig. 3.5.5. Typical ionograms with ordinary and extraordinary traces; during the night, left, and during the daytime, right.

From the analysis of one ionogram, several important characteristics, like the critical frequencies and the heights of the different ionospheric layers, can be found that have a significant role in the studies concerning ionospheric physics, space weather and related phenomena (Fig. 3.5.6). 

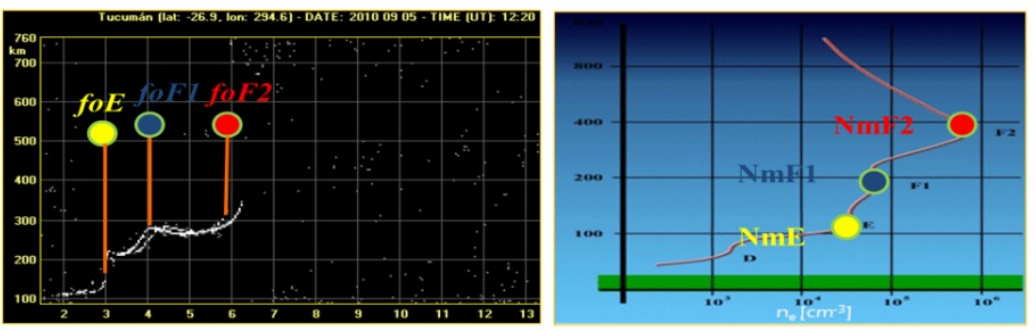

Fig. 3.5.6. From the ionogram, left, to the electron density profile, right: the important ionospheric characteristics.

The routine tasks of every standard ionospheric station, as defined in the URSI handbook of ionogram interpretation and reduction edited by W.R. Piggot and K. Rawer, are: 1) Monitor the ionosphere above the station, 2) Obtain significant median data to evaluate long-term changes, 3) Study phenomena peculiar to the region, 4) Study the global morphology of the ionosphere. These objectives require a set of standard techniques and conventions applicable for the general interpretation of ionospheric measurements in order to achieve a more phenomenological description of the ionogram, as well as providing a simplified description of the ionosphere above the station (Fig. 3.5.7). This set of conventions and rules for scaling ionograms are exhaustively described in the handbook mentioned above and more recently in the Manual of Ionogram scaling, edited by the Japanese Ministry of Post and Telecommunications, Radio Research Laboratory. For a simple description of the ionosphere by vertical sounding, it is convenient to consider the ionosphere as schematically divided into the conventional regions D, E, F, and the sporadic E.

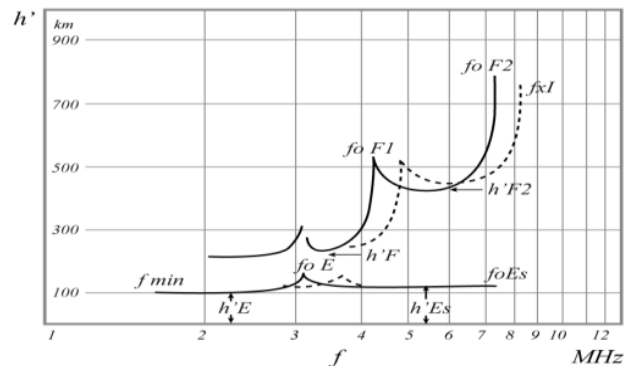

Fig. 3.5.7. Ideal daytime ionogram with routinely scaled parameters.

F region. $f_{0} F 2$ : critical frequency of the ordinary trace of the highest layer of the $\mathrm{F}$ region; $f x I$ : highest frequency recorded by a reflection from the $\mathrm{F}$ region ; foF 1 : critical frequency of the ordinary trace of the $\mathrm{F} 1$ layer; $h^{\prime} F 2$ : minimum virtual 
height of the ordinary trace of the $\mathrm{F} 2$ layer; $h^{\prime} F$ : lowest virtual height of the ordinary trace of the F region. E Region. $f o E$ : critical frequency of the ordinary trace of the $\mathrm{E}$ region; $h^{\prime} E$ : minimum virtual height of the ordinary trace of the $\mathrm{E}$ region; Es Sporadic E layer; foEs: highest frequency of the ordinary trace of the continuous sporadic E layer; $h$ 'Es: minimum virtual height of the ordinary trace of the Es layer; $f b E s$ : blanketing frequency of the Es layer. fmin: lowest frequency recorded in the ionogram.

Today they contribute to ionospheric databases on the internet, like well-known: SPIDR (Space Physics Interactive Data Resource): http://spidr.ngdc.noaa.gov/spidr/; SWUA (Electronic pace Weather Upper Atmosphere): http://www.eswua.ingv.it/; DIAS (Digital Ionospheric Upper Atmosphere Service): http://dias.space.noa.gr and UMass (Lowell Center for Atmospheric Research): http://umlcar.uml.edu/.
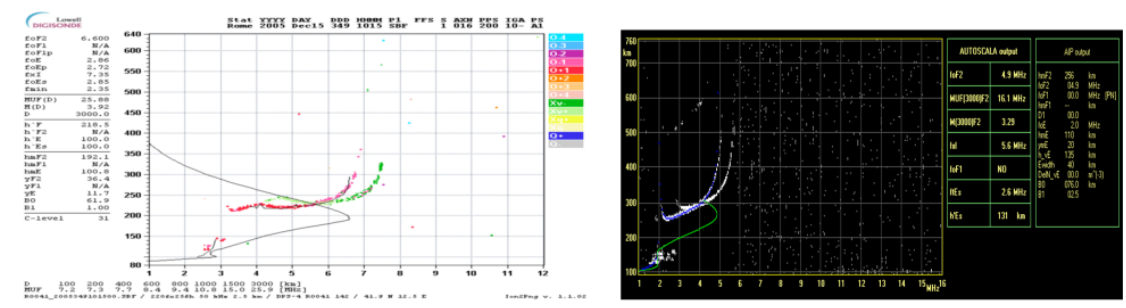

Fig. 3.5.8. Examples of ionograms autoscaled by ARTIST method, left, and AUTOSCALA method, right.

During the second half of the previous century, the ionosondes had an important technological evolution and consequently the accuracy and efficiency of the ionograms recorded; from the first ones analogical recorded on film, to the digital one. However, the most important development in the last years is the automatic scaling of the ionograms; they are essential for monitoring the ionospheric plasma in real time for Space Weather purposes and to better understand the ionospheric storm dynamics. In Fig. 3.5.8 are shown two examples of two different methods of autoscaling: ARTIST and AUTOSCALA.

\subsection{4. lonospheric radio sounding application}

\subsubsection{Models of the electron density profile}

These ground-based routine measurements constituted the basis for the global models of ionospheric plasma. They were so important for any future ionospheric 
investigations that some international organizations concerned with establishing internationally agreed global propagation models, like URSI, COSPAR, and in particular the CCIR, the forerunner of the ITU-R, a United Nations Specialised Agency, strongly encouraged this kind of ionospheric observation with international data exchange through the World Data Centres. The concept of electron density profile, or in another definition, electron concentration versus altitude was introduced considering its importance for both theoretical studies and practical applications. So, the routine ionospheric vertical incidence measurements were used in the first historical models, like the T. Shimazaki formula published in 1955 and still in use,

$$
h m F 2=\frac{1490}{M(3000) F 2}-176 k m
$$

where $h m F 2$ is the height of maximum electron density and $M(3000) F 2$ is the transmission factor, one of the routinely scaled characteristics in an ionogram; or in the simple model of P.A. Bradley and J.R. Dudeney that introduced an important improvement.

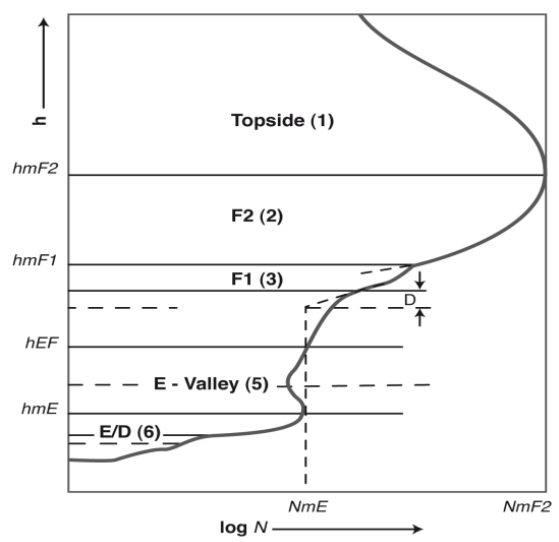

Fig. 3.5.9. Scheme of the IRI electron density profile divided into six regions (from Bilitza 1990).

Then, in the last decades, the International Reference Ionosphere has been a very important result that joined the efforts of a group of the international scientific community, who over the last sixty years have worked to improve and upgrade a standard model of the ionosphere. IRI is a complex model that describes for a given coordinate, time, and date not only the electron density in the range from roughly 50 $\mathrm{km}$ to $2000 \mathrm{~km}$, but also the ion composition together with the electron and ion temperatures (http://iri.gsfc.nasa.gov/) (Fig. 3.5.9). 


\subsubsection{Ionospheric mapping and prediction for HF communication}

A numerical method developed at the ITS (Institute of Telecommunication Sciences) at the Boulder Laboratories of the U.S. Department of Commerce by W.B. Jones and R.M. Gallet in 1958 was applied to the basic input data of the median monthly hourly values of $f o F 2$ and $M(3000) F 2$, obtained from ionograms of the worldwide network of ionosondes, as in the Fig. 3.5.2. This method significantly improved in the following years was able to globally map the two key ionospheric characteristics, extremely important for long distance HF communications. In Fig. 3.5.10 is shown an example of predicted median $M U F(0) F 2$ map.

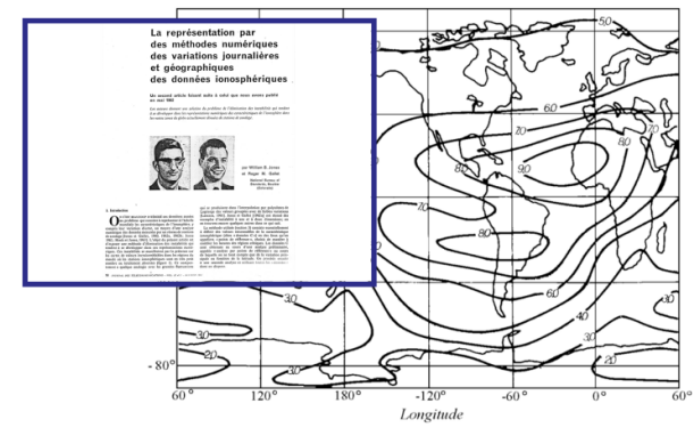

Fig. 3.5.10. An example of predicted median $M U F(0) F 2$ map and the first page of the paper by W.B. Jones and R.M. Gallet.

In fact, the $\mathrm{HF}$ electromagnetic spectrum of 3-30 $\mathrm{MHz}$ became the principal waveband for long distance radio communications during the 20th century. Then to predict the status of the ionosphere and assessing which parameters should be used for HF radio communication resulted in the development of geophysical and empirical models as well as statistical methods for collecting ionospheric measurements. In order to satisfy the needs of HF radio frequency planners, the prediction of hourly monthly medians for a given geophysical observation was implemented. Ionospheric prediction services are then able to produce point to point diagrams of the predicted Maximum and Lower Usable Frequency for a given distance, Fig. 3.5.11, left; as well as the area covered by a given radio frequency, Fig. 3.5.11, right. 

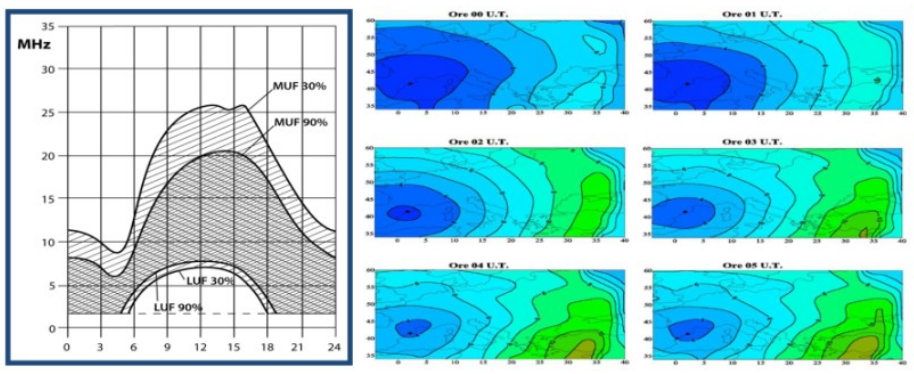

Fig. 3.5.11. Examples of a diagram of the predicted Maximum and Lower Usable Frequency for a given point to point radio link, left, and area covered by a given radio frequency, right.

\subsubsection{Projects on Space Weather Tools}

During the last years, important international projects have been developed where the ionospheric vertical sounding is active and gives an important contribution to the understanding of the Space around the Earth. Beside of course ESPAS, it is worth to mention DIAS (European Digital Upper Atmosphere Server), preceded by the ESA pilot project GIFINT (Geomagnetic Indices Forecasting and Ionospheric Nowcasting Tools) and more recently the GIRO (Global Ionospheric Radio Observatory ). DIAS is a European service for the specification and the prediction of the state of the upper atmosphere based on historical data collections and on the realtime information provided by several European ionospheric stations developing added-value products and services for ionospheric specification and forecasting. In Fig. 3.5.12 are shown two products of DIAS: a regional map of the predicted ionospheric characteristics $f_{o F}$, right, and the $\mathrm{f}$ plots at different ionospheric stations in Europe provided by the DIAS service, left.
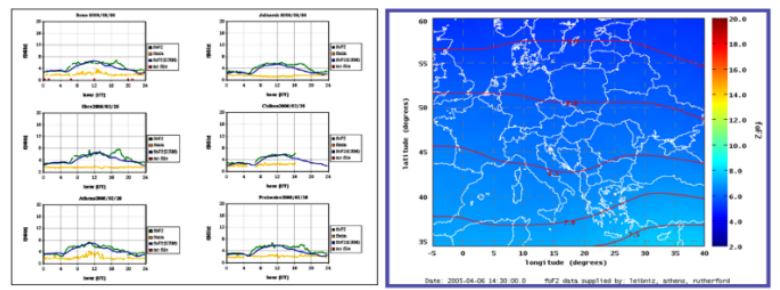

Fig. 3.5.12. Regional map of the predicted ionospheric characteristics foF2, right, and the f plots at different ionospheric stations in Europe provided by the DIAS service, left. 
GIRO provides accurate specification of electron density in the Earth's ionosphere at $>60$ locations in the world. Thirty-seven GIRO locations provide realtime ionospheric data to the central server in Lowell, Massachusetts; in Fig. 3.5.13 the map of the GIRO network. GIRO sites are equipped by Digisonde instruments Real-time and retrospective data from GIRO locations are ingested in Lowell Digital Ionogram DataBase (DIDBase). GIRO data are opened for public access via DIDBase and DriftBase Web Portals, and custom software tools for digisonde data analysis, $\underline{\text { SAO Explorer and Drift Explorer. }}$

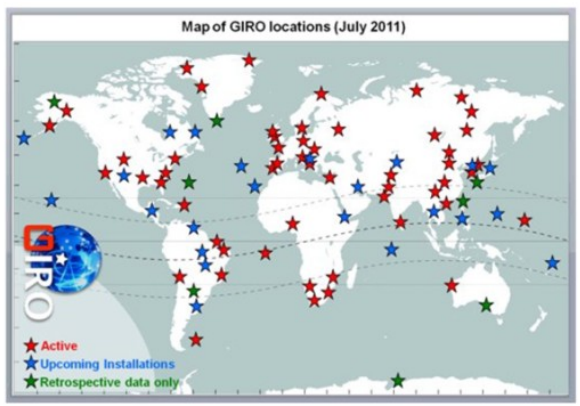

Fig. 3.5.13. The map of the GIRO network.

\subsubsection{Other applications of ionospheric vertical sounding: ionospheric long trend studies and lithosphere and ionosphere coupling}

Rishbeth and Roble, in their paper published on Planet Space Sci in 1992, considered the possibility that a cooling of the Upper Atmosphere could be caused by an enhanced greenhouse effect in the lower atmosphere. In fact, the accuracy of the estimation of $\mathrm{hmF} 2$ could be sufficient to detect a long trend of $-14 \mathrm{~km} /$ century considering taking into account temporal series longer than 35 years that were considered. During the last two decades, many other papers tried to solve this dilemma; there are still opposite opinions that take alternatively into account the different control of the geomagnetic field.

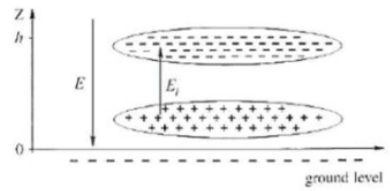

Fig. 3.5.14. Lithosphere and ionosphere coupling: a simple schematic picture of the electric field generated by the emanation from the ground of various chemical substances. 
Ionospheric effects of lithospheric phenomena could be considered together with a larger class of studies defined as electromagnetic effects of seismic events. S. Pulinets and K. Bordachuk developed a physical model to explain some anomalous variations in the ionosphere, taking into account and correlating ionospheric measurements and gas emission over the ground in a seismogenetic area. The emanation from the ground of various chemical substances like radon, and light gases including helium and hydrogenous as well as submicron and metallic aerosols, changes the electrodynamic properties of the atmosphere over a region originating an earthquake. The radon released from the crust is an important source of ionization and clusters of heavy ions in the atmospheric layer close to the ground produce an additional electric field overlapping the total (ionosphere-ground) electric field (Fig. 3.5.14).

\subsubsection{Conclusion}

In conclusion, we could still affirm the importance of the ground base ionospheric vertical sounding not only for the validation of satellite measurements but for their intrinsic importance to maintain an important monitoring of the terrestrial ionosphere. A constant and systematic monitoring along many solar cycles as well real-time monitoring for space weathers tools. Good experimental observations will never be obsolete: they could be used by other scientists in the future; good data are like an excellent wine: year after year is much better.

\section{References (and suggested readings)}

Belehaki A, Cander LjR, Zolesi B, Bremer J, Juren C, Stanislawska I, Dialetis D, Hatzopoulos M, (2005) DIAS Project: The establishment of a European digital upper atmosphere server. J Atmos Sol-Terr Phys 67:1092-1099

Bilitza D (2001) International Reference Ionosphere 2000. Radio Sci 36:261-275

Bilitza D, Reinisch BW (2008) International Reference Ionosphere: Improvements and new parameters. Adv Space Res 42:599-609

Budden KG (1961) Radio waves in the ionosphere. Cambridge Univ. Press, CambridgeDavies K (1990) Ionospheric Radio. IEE Electromagnetic Waves Series 31, Peter Peregrinus Ltd, London

Hargreaves JK (1992) The Solar Terrestrial environment. Cambridge Atmospheric and Space Science series 5, Cambridge University Press, Cambridge

Jones WB, Gallet RM (1960) Ionospheric mapping by numerical methods. Telecommun J 12: 260-264

McNamara LF (1991) The Ionosphere: Communications, Surveillance, and 
Direction Finding. Krieger Publishing Company, Malabar

Piggot WR, Rawer K (1972) U.R.S.I Handbook of Ionogram Interpretation and Reduction. World Data Center A for Solar Terrestrial Physics- Report UAG-23, NOAA, Environmental Data Service, Asheville

Pulinets S, Boyarchuk K (2004) Ionospheric Precursors of Earthquakes, SpringerVerlaig, Heidelberg

Rishbeth H, Roble RG (1992) Cooling of the Upper Atmosphere by enhanced greenhouse gases:modeling of the ionospheric and termospheric effects. Planet Space Sci 40:1011-1026

Ractliffe JA (1962) The Magneto-Ionic Theory and its Applications to the Ionosphere. Cambridge University Press, Cambridge

Reinisch BW, Galkin IA, Khmyrov GM, Kozlov AV, Bibl K, Lisysyan IA, Cheney GP, Huang X, Kitrosser DF, Paznukhov VV, Luo Y, Jones W, Stelmash S, Hamel R, Grochmal J (2009) The New Digisonde for Research and Monitoring Applications. Radio Sci. doi: 10.1029/2008RS004115

Zolesi,B and L. R. Cander. Ionospheric Prediction and Forecasting, Springer, Geophysics,DOI:101007/978-3-642-38430-1Springer Verlag Berlin Heidelberg, 2014 pp 240 


\title{
3.6 IONOSPHERIC MODELING RESULTS IN ESPAS
}

\author{
I. Tsagouri ${ }^{1}$
}

\begin{abstract}
To facilitate advances in near-Earth space science and applications, the ESPAS portal offers access to the output from a number of ionospheric prediction models including: i) the International Reference Ionosphere (IRI), ii) the Simplified Ionospheric Regional Model (SIRM), iii) the real-time UPdating of the Simplified Ionospheric Regional Model (SIRMUP) and iv) the Topside Sounder Model Profilerassisted Digisonde (TaD). This chapter aims to introduce the relevant data to the user of the system in support of their effective exploitation. The discussion includes a brief outline of the models, a description of the models' output that is available through ESPAS, as well as a short demonstration of their potential use in scientific investigations.
\end{abstract}

\subsubsection{Introduction}

The Earth's ionosphere holds a central role in the near-Earth space environment: it poses a transition region from the fully ionized magnetospheric plasma to the neutral atmosphere, being subject of many influences from above (i.e., solar and magnetospheric influences) and below (i.e., meteorological influences) and an interesting challenge for the reliable performance of many technological systems that operate within or through the medium. In this context, ionospheric prediction models are relevant to a variety of needs, including research purposes and therefore, they are valuable tools for ionospheric developments.

The ionospheric prediction models that are presented here assume semi-empirical or empirical formulations to reproduce the electron density profile (i.e., the variation of the electron density with height) or the values of particular observed properties (e.g., foF2, M(3000)F2 and MUF) at a given time and location. Relevant modeling challenges include the long-term ionospheric variability and the transient disturbances imposed by external forcing.

The long-term ionospheric variability. The formation of the ionosphere is primarily driven by the solar radiation that ionizes the major atmospheric constituents. It contains a regular component with a period of about 11 years, the

1 National Observatory of Athens, Metaxa and Vas. Pavlou, 15236, Penteli, Greece 
11-year sunspot cycle, a component that has a quasi-period of about a year and fluctuations with periods of less than a month. The general trends are clearly seen in long ionospheric data records and therefore, long-term ionospheric variations can be efficiently reproduced by climatological models through the exploitation of solar indices (e.g., the sunspot number R, the radio flux at $10.7 \mathrm{~cm}$ wavelength (F10.7) and their smoothed values). Relevant modeling examples include the IRI model (e.g., Bilitza 2001; Bilitza and Reinisch 2008; Bilitza et al. 2014) and the SIRM model (Zolesi et al. 1993, 1996).

The transient disturbances imposed by external forcing (e.g., space weather effects) on the Earth's ionosphere. Their prediction has been proven to be a high demanding task that requests sophisticated treatments. The update of the climatological estimates to the actual conditions has been invoked as an option for real-time applications. This approach is based on the exploitation of actual measurements and the development of model-oriented indices to work with particular empirical models. An example of this approach is the SIRMUP model (Zolesi et al. 2004; Tsagouri et al. 2005) with the introduction of the effective R12 index (Reff). However, the correlation between this type of indices and the ionospheric variation is only an evidence of associated phenomena (Bradley 1993). From the physics point of view, a more promising alternative that opens also the window to future time predictions comes from the accommodation of geomagnetic activity indices (e.g., Kp and Ap) into empirical formulations. These indices aim to drive the ionospheric response to geomagnetic storm force. A hybrid combination of the ingestion of actual observations into empirical formulations that are driven by activity indices has been adopted by the TaD model (Kutiev et al. 2012; Belehaki et al. 2012; Marinov et al. 2015).

\subsubsection{Models and modeling results}

\subsubsection{The International Reference lonosphere (IRI)}

The International Reference Ionosphere (IRI) is the international standard for the climatological specification of the plasma properties in the ionosphere (e.g., Bilitza 2001; Bilitza and Reinisch, 2008; Bilitza et al. 2014). IRI builds up the electron density profile by separation into different regions. It is able to describe monthly averages of the electron density, electron temperature, ion temperature, ion composition, and several additional observed properties in the altitude range from 60 to $2000 \mathrm{~km}$. Over time, as new data became available and new modeling techniques emerged, a series of steadily improved editions of the IRI model have been published (i.e., IRI 75, IRI-79, IRI-86, IRI-90, IRI-95, IRI-2001, IRI-2007, IRI-2012).

The ESPAS makes available the global grids $\left(0^{\circ}\right.$ to $360^{\circ}$ in longitude and $-90^{\circ}$ to $90^{\circ}$ in latitude) of the foF 2 predictions that were obtained from the IRI-2012 version of the model (available at http://iri.gsfc.nasa.gov/). To obtain the grids, they were adopted the default specifications for the model's input parameters with the following exceptions: the foF2 STORM model (Fuller-Rowell et al. 2000) and 
the foE STORM model (Mertens et al. 2013) are set off. The grids are available in ASCII format (see Fig. 3.6.1) in two versions, following the two options that are available for the F peak model: the CCIR (Comité Consultatif International des Radiocommunications) and the URSI model.

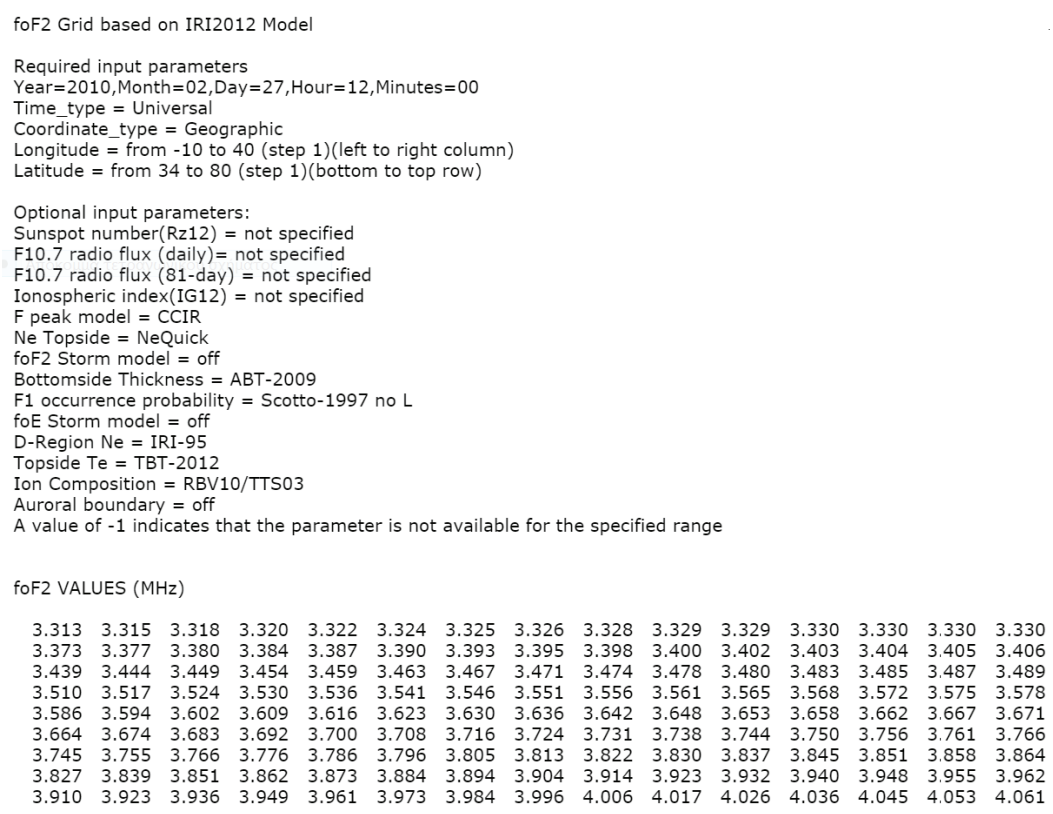

Fig. 3.6. 1. An example of the IRI-generated grids for the foF 2 that are available via ESPAS. The input parameters used for the generation of the grid are listed in the header of each file.

\subsubsection{The Simplified lonospheric Regional Model (SIRM)}

The SIRM model belongs to the group of ionospheric models that exploit analytical spatial distribution to oversimplify a number of ionospheric phenomena of real significance for radio communication applications. It represents monthly median values of key ionospheric characteristics measured by the vertical incidence sounding, such as the foF 2, M(3000)F2, h'F, foF1 and foE in a restricted area in middle latitudes. It is based upon a Fourier analysis of their monthly median values obtained from a number of ionospheric stations operating for several years in Europe assuming: i) a linear variation of the given characteristics with 12-monthly smoothed sunspot number R12, ii) a linear variation of the model coefficients with the geographical latitude within the limited area of Europe, iii) no longitudinal changes at constant local time, and iv) the use of a limited number of Fourier coefficients in the model description that are sufficient for portraying the main features of the middle latitude ionosphere under median conditions. The 


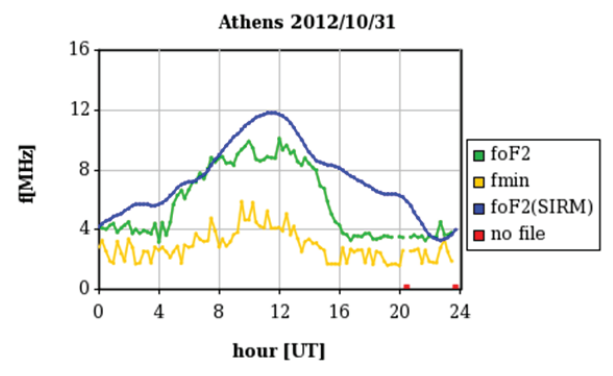

foF 2 at Athens for $2012 / 10 / 31$

\begin{tabular}{|c|c|c|c|c|}
\hline DATE & Hour & F & & $M$ \\
\hline $2 / 10 / 31$ & $\theta \theta: \theta \theta$ & 4.2 & 2.9 & 4.2 \\
\hline $12 / 10 / 31$ & $00: 15$ & 4.1 & 3.3 & 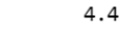 \\
\hline $12 / 10 / 31$ & $00: 30$ & 4.1 & 2.6 & 4.6 \\
\hline $2012 / 10 / 31$ & $00: 45$ & 4.3 & 1.9 & 4. \\
\hline $2012 / 10 / 31$ & $\theta 1: \theta \theta$ & 4.4 & 1.8 & 4.9 \\
\hline $2012 / 10 / 31$ & $01: 15$ & 3.8 & 3.3 & 5. \\
\hline $2012 / 10 / 31$ & $01: 30$ & 4.1 & 2.4 & 5. \\
\hline $2012 / 10 / 31$ & $01: 45$ & 4.3 & 1.9 & \\
\hline $2012 / 10 / 31$ & $\theta 2: \theta \theta$ & 4.6 & 3.4 & 5.4 \\
\hline $2012 / 10 / 31$ & $02: 15$ & 3.8 & 2.8 & 5. \\
\hline $2012 / 10 / 31$ & $02: 30$ & 4.0 & 1.8 & - \\
\hline $2012 / 10 / 31$ & $02: 45$ & 3.8 & 1.8 & 5. \\
\hline $2012 / 10 / 31$ & $\theta 3: \theta \theta$ & 4.0 & 2.6 & 5.7 \\
\hline $2012 / 10 / 31$ & $03: 15$ & 3.9 & 2.6 & 3. \\
\hline $2012 / 10 / 31$ & $03: 30$ & 3.7 & 1.8 & 5.6 \\
\hline $2012 / 10 / 31$ & $03: 45$ & 4.4 & 2.9 & 5.6 \\
\hline $2012 / 10 / 31$ & $\theta 4: \theta \theta$ & 3.2 & 2.7 & \\
\hline $2012 / 10 / 31$ & $04: 15$ & 4.5 & 2.9 & 5. \\
\hline $2012 / 10 / 31$ & $04: 30$ & 3.7 & 2.6 & 6 \\
\hline $2012 / 10 / 31$ & $04: 45$ & 4.5 & 2.2 & 6. \\
\hline $2012 / 10 / 31$ & $05: 00$ & 5.7 & 2.6 & s. \\
\hline $2012 / 10 / 31$ & $05: 15$ & 6.3 & 2.9 & 6. \\
\hline $2012 / 10 / 31$ & $05: 30$ & 6.6 & 1.8 & 7. \\
\hline $2012 / 10 / 31$ & $05: 45$ & 6.1 & 3.0 & \\
\hline $2012 / 10 / 31$ & $06: \theta 0$ & 6.7 & 2.9 & 7. \\
\hline $2012 / 10 / 31$ & $06: 15$ & 7.2 & 2.9 & \\
\hline $2012 / 10 / 31$ & $06: 30$ & 7.2 & 3.8 & 7. \\
\hline $2012 / 10 / 31$ & $06: 45$ & 7.8 & 3.4 & \\
\hline $2012 / 10 / 31$ & $\theta 7: 00$ & 7.4 & 3.3 & \\
\hline $2012 / 10 / 31$ & $07: 15$ & 8.1 & 3.3 & 8. \\
\hline $2012 / 10 / 31$ & $07: 30$ & 8.8 & 4.8 & \\
\hline $2012 / 10 / 31$ & $07: 45$ & 8.5 & 3.9 & 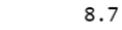 \\
\hline $2012 / 10 / 31$ & $08: 00$ & 8.8 & 2.9 & \\
\hline
\end{tabular}

Fig. 3.6. 2. SIRM-related output available via ESPAS includes the plots of observed and modeled foF 2 produced by the DIAS system for Athens location. The results are presented together with the minimum frequency of ionogram echoes, fmin and they are available in PNG and ASCII formats.

SIRM has been implemented in the European Digital Upper Atmosphere Server (DIAS) to provide predictions for the European region for long-term planning purposes (http://dias.space.noa.gr). An example of the SIRM related output that is registered in ESPAS is presented in Fig. 3.6.2.

\subsubsection{The real-time UPdating of the Simplified lonospheric Regional Model (SIRMUP)}

The SIRMUP is an ionospheric mapping technique developed to support ionospheric nowcasting applications. It is designed to update SIRM's monthly median estimates to real-time conditions based on the idea that the real time values of the ionospheric properties are determined from the SIRM model by using the effective sunspot number, Reff, instead of R12. The Reff is calculated through the comparison of SIRM estimates with actual measurements and it is chosen to give the best fit between model calculations and actual measurements obtained from a grid of ionosondes located in the mapping area (Zolesi et al. 2004; Tsagouri et al. 2005). SIRMUP has been also implemented in DIAS system to produce 
nowcasting maps for the European region (from $-5^{\circ} \mathrm{W}$ to $40^{\circ} \mathrm{E}$ in longitude and from $34^{\circ} \mathrm{N}$ to $60^{\circ} \mathrm{N}$ in latitude) through the exploitation of automatically scaled observations obtained by DIAS Digisondes. SIRMUP related results available via ESPAS include estimates of the foF2 critical frequency, the M(3000)F2 and the MUF (Maximum Usable Frequency) for ionospheric links considering Athens as the transmission point. The results are available in map (PNG) and grid (ASCII) format. Fig. 3.6.3 presents an example of the results available for the foF2.

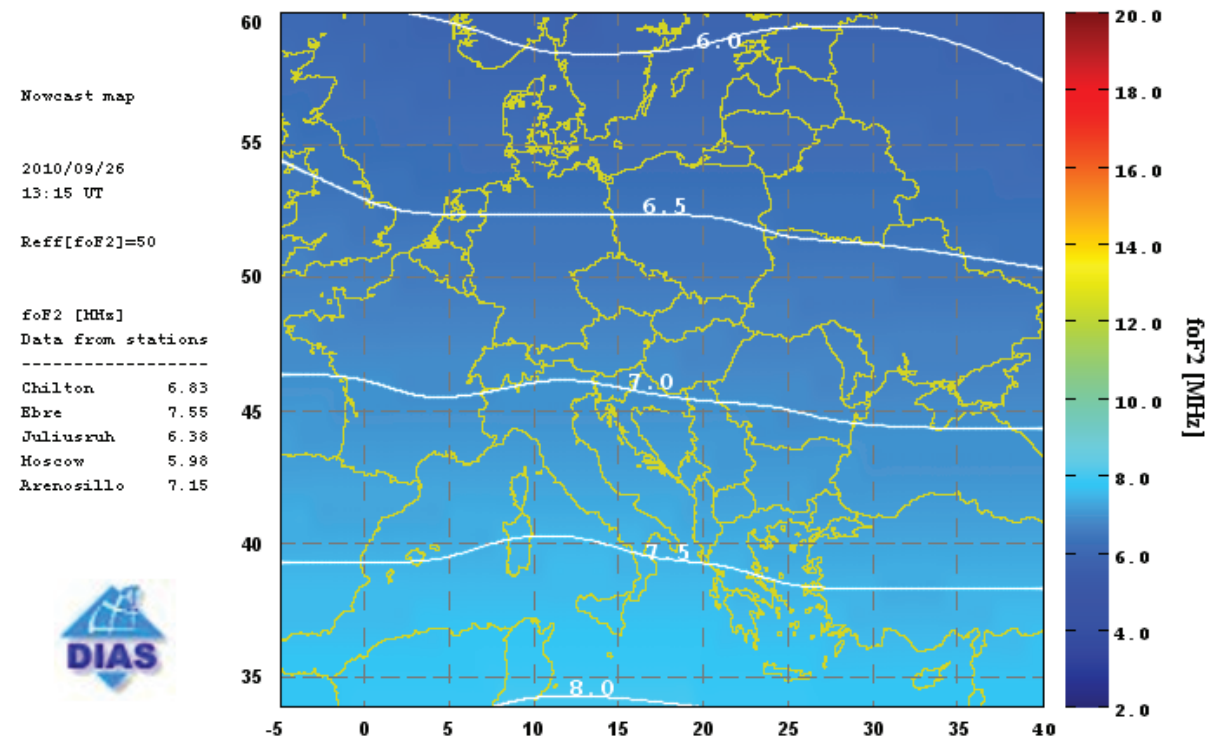

Fig. 3.6. 3. An example of the foF2-SIRMUP maps available via ESPAS in PNG format. On the left of the map, apart from the date and time, the value of the Reff and the list of stations contributing with data to the generation of the map are also reported.

\subsubsection{The Topside Sounder Model Profiler-assisted Digisonde ( $T a D)$}

TaD belongs to the group of models developed by utilizing data from topside sounders aboard Alouette and ISIS satellites to reconstruct the electron density profile in the topside ionosphere. It is built on the cooperation of three components (Kutiev et al. 2012; Belehaki et al. 2012; Marinov et al. 2015 and references therein): i) The Topside Sounder Model (TSM), which reproduces the topside electron density scale height $(\mathrm{HT})$, the $\mathrm{O}^{+}-\mathrm{H}^{+}$(upper) transition height (hT) and their ratio (RT). The results are expressed as functions of month, geomagnetic latitude, local time, solar flux (F10.7) and geomagnetic index (Kp). ii) The Topside Sounder Model Profiler (TSMP), which provides the shape of the vertical plasma distribution in the topside ionosphere and plasmasphere by introducing the TSM parameters into well-known formulas describing the vertical plasma distribution. 
To obtain the density distribution, the F2 layer peak density (NmF2) and height hmF2 are required to be specified at its lower boundary. iii) The TaD, which uses the TSM ratio RT to link the TSMP to the Digisonde topside profiling technique: the F2 layer peak density $\mathrm{NmF}$, the peak height hmF2, and the scale height $\mathrm{Hm}$, all provided by the Digisonde software are adopted for the reconstruction of the electron density profile up to $20,000 \mathrm{~km}$ in height. TaD has been implemented in the DIAS system to map the ionospheric conditions in the topside ionosphere. Among others, the results include European maps (from $-10^{\circ}$ to $40^{\circ} \mathrm{E}$ in longitude and from $35^{\circ}$ to $55^{\circ} \mathrm{N}$ in latitude) of the electron density at predefined heights. Relevant results available via ESPAS apply to ionospheric heights of 500, 750 and $1000 \mathrm{~km}$ (see Fig. 3.6.4).
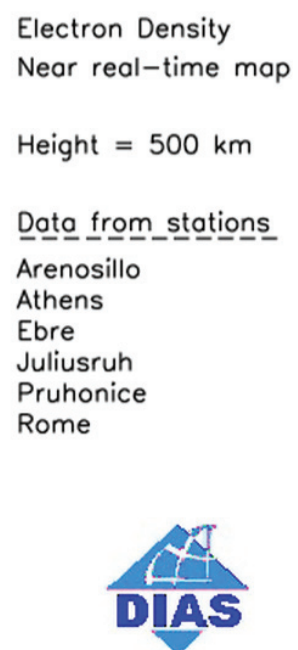

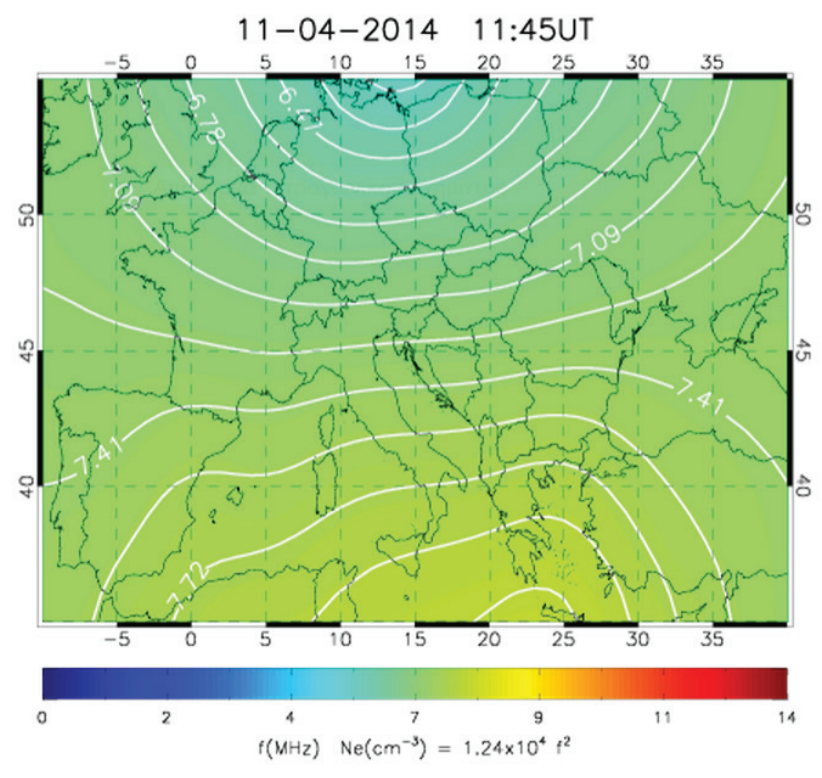

Fig. 3.6. 4. An example of the TaD-generated maps available via ESPAS for the electron density at $500 \mathrm{~km}$. The map includes also information on the distribution of the stations that contribute with data to its generation (on the left).

\subsubsection{Overview of the data available}

Table 3.6.1 attemps to provide a comprehensive overview of the ionospheric modeling results available through ESPAS. Relative information includes the observed properies, spatial and temporal resolutions and file formats. Table 3.6.2 presents the observed properties with respect to the phenomenon, measurand and qualifier. All data were made available by the National Observatory of Athens. 
Table 3.6. 1. A comprehensive overview of ionospheric modeling results available through ESPAS.

\begin{tabular}{|c|c|c|c|c|c|}
\hline Project & $\begin{array}{c}\text { Model/ } \\
\text { Asset }\end{array}$ & $\begin{array}{c}\text { Observed } \\
\text { properties }\end{array}$ & $\begin{array}{c}\text { Spatial } \\
\text { coverage }\end{array}$ & $\begin{array}{c}\text { Time } \\
\text { resolution }\end{array}$ & Format \\
\hline - & $\begin{array}{c}\text { IRI } \\
(C C I R, \\
U R S I)\end{array}$ & foF2 & $\begin{array}{c}\text { Global } \\
\left(0 \text { to } 360^{\circ} \mathrm{E},\right. \\
\left.-90 \text { to } 90^{\circ} \mathrm{N}\right)\end{array}$ & $1 \mathrm{hr}$ & ASCII \\
\hline DIAS & SIRM & foF 2 & Athens & Daily plots & $\begin{array}{l}\text { PNG } \\
\text { ASCII }\end{array}$ \\
\hline \multirow[t]{2}{*}{ DIAS } & SIRMUP & $\begin{array}{c}\text { foF } 2 \\
\mathrm{M}(3000) \mathrm{F} 2\end{array}$ & $\begin{array}{l}\text { Regional } \\
\left(-5 \text { to } 40^{\circ} \mathrm{E},\right. \\
\left.34 \text { to } 60^{\circ} \mathrm{N}\right)\end{array}$ & $15 \mathrm{~min}$ & $\begin{array}{l}\text { PNG } \\
\text { ASCII }\end{array}$ \\
\hline & & MUF & $\begin{array}{l}\text { Regional } \\
\text { Transmission } \\
\text { point Athens } \\
\left(-5 \text { to } 40^{\circ} \mathrm{E}\right. \\
\left.34 \text { to } 60^{\circ} \mathrm{N}\right)\end{array}$ & & \\
\hline DIAS & $\mathrm{TaD}$ & $\begin{array}{c}\mathrm{Ne} \\
\text { (electron } \\
\text { (density) }\end{array}$ & $\begin{array}{c}\text { Regional/Topside } \\
\left(-10 \text { to } 40^{\circ} \mathrm{E},\right. \\
\left.35 \text { to } 55^{\circ} \mathrm{N}\right) \\
\text { Heights: } \\
500,750,1000 \mathrm{~km}\end{array}$ & $15 \mathrm{~min}$ & $\begin{array}{l}\text { PNG } \\
\text { ASCII }\end{array}$ \\
\hline
\end{tabular}

Table 3.6. 2. Observed properties with respect to the phenomenon, the measurand and the qualifier.

\begin{tabular}{lllc}
\hline $\begin{array}{l}\text { Observed Property } \\
\text { (full and short name) }\end{array}$ & Phenomenon & Measurand & Qualifier \\
\hline F2 layer critical & Wave/ & Critical Frequency & - \\
frequency (foF2) & Electromagnetic Wave & (f) & \\
\hline Standard MUF & Wave/ & Maximum Usable & - \\
at $3000 \mathrm{~km}$ & Electromagnetic Wave & Frequency (f) & \\
$(\mathrm{MUF}(3000) \mathrm{F} 2)$ & & & Ratio \\
\hline M-Factor of F2 layer & Wave/ & Critical Frequency & \\
at 3000 km & Electromagnetic Wave & $(\mathrm{f})$ & \\
$(\mathrm{M}(3000)$ F2) & Maximum Usable & Frequency (f) & \\
& & Number Density (N) & - \\
\hline Electron Density (Ne) & Particle/ & & \\
& Charged Particle/ & & \\
& Electron & & \\
\hline
\end{tabular}

\subsubsection{Scientific use cases}

\subsubsection{Monitoring of the ionospheric disturbances}

Recently, the ESPAS-IRI grids were incorporated in the DIAS system to help the user of the system to monitor the level of the ionospheric activity at regional scale. 
This is possible through the comparison between the SIRMUP and IRI predictions. As an example, we present in Fig. 3.6.5 the SIRMUP- and IRI-generated grids for October 7, 2015 16:00 UT in a map format. The visual inspection of the two maps indicates strong ionospheric depletion with respect to the climatological predictions (i.e., IRI estimates) over Europe. Indeed, the variation of observed and monthly median foF2 over four European locations presented in Fig. 3.6.6, verifies that the ionosphere over Europe experiences a deep negative phase (i.e., reduction of the ionospheric ionization with respect to normal conditions) on October, 7 as a response to the geomagnetic storm event occurred in the time interval $6-9$ October 2015.

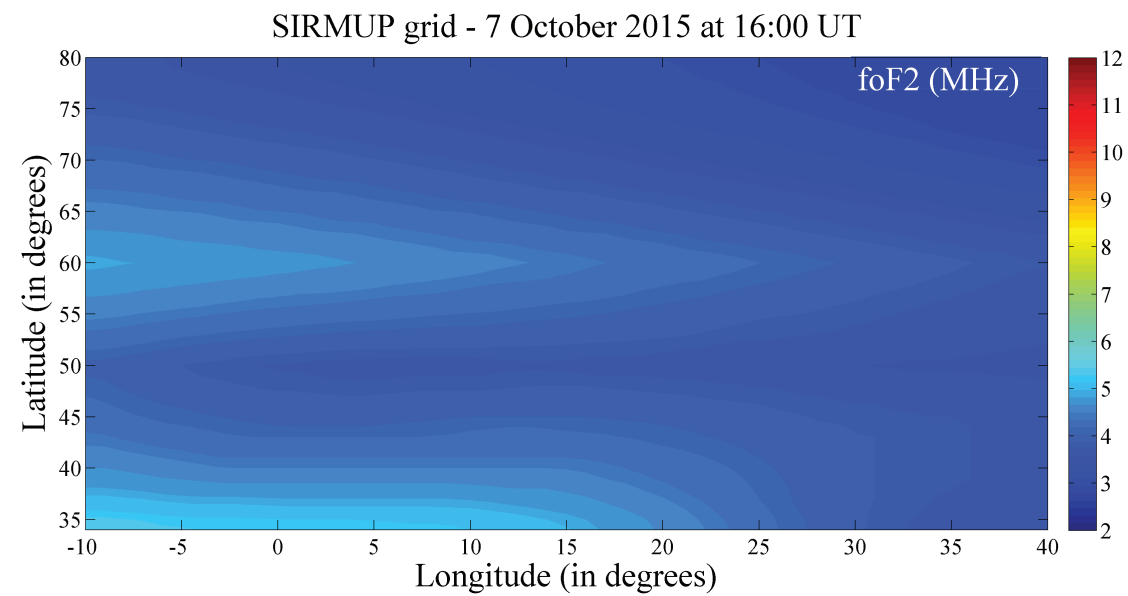

IRI grid - 7 October 2015 at 16:00 UT

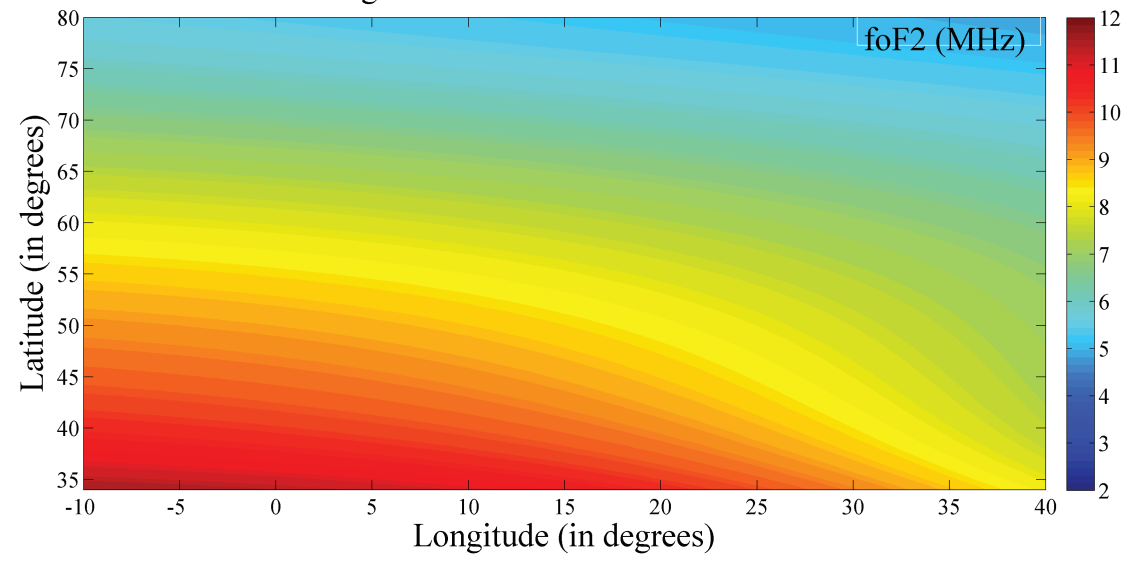

Fig. 3.6. 5. The SIRMUP- (top) and IRI- (bottom) generated maps for 7 October 2015 16:00 UT. 

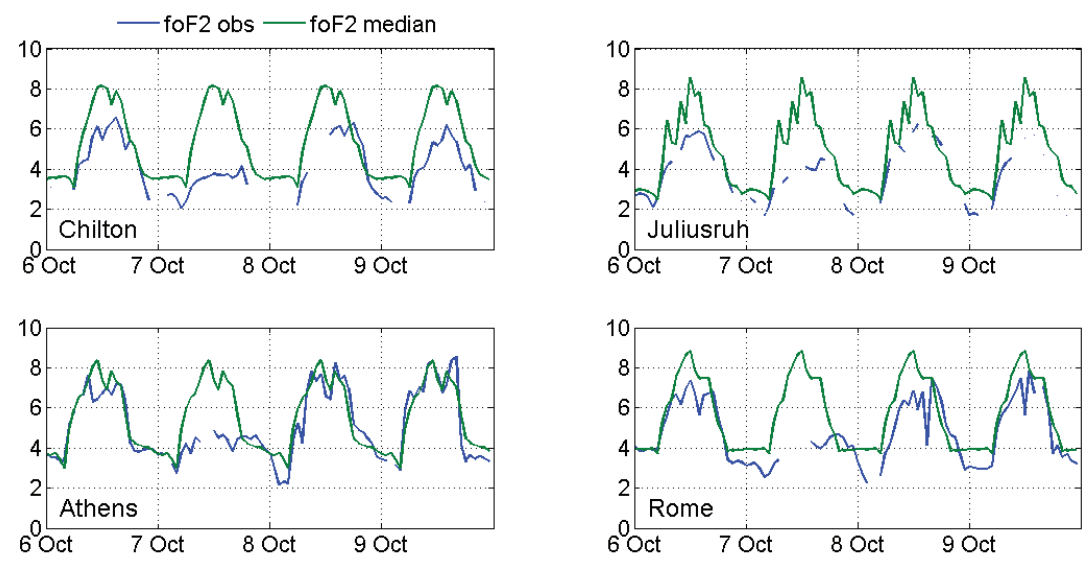

Fig. 3.6. 6. The observed and monthly median foF 2 over four European locations for the time interval 6 - 9 October 2015.

\subsubsection{Validation of models}

The systematic evaluation of any space weather model's performance is a strong requirement for scientific and operational applications. It is recommended to include comparison with actual measurements, but also comparison with standard prediction methods to ensure improvement over existing capabilities. The role of the baseline model for the validation of ionospheric prediction models is usually given to IRI (e.g., Spence at al. 2004).

\subsubsection{3-D analysis of ionospheric disturbances}

The 3-D electron density distribution estimated by electron density profilers may expand current capabilities in the detailed study of the ionospheric behaviour under the occurrence of both large and small scale disturbances. As an example, the TaD results were exploited by Belehaki et al. (2015) in conjunction with ground-based ionograms and GPS-TEC estimates for the identification of large scale travelling ionospheric disturbances (LSTIDs) (see Fig. 3.6.7).

\section{References}

Belehaki, A., Tsagouri, I., Kutiev, I., Marinov, P. and Fidanova, S. Upgrades to the topside sounders model assisted by Digisonde ( $\mathrm{TaD})$ and its validation at the topside ionosphere. J. Space Weather Space Clim., 2, A20, 2012.

Belehaki A., I. Tsagouri, I. Kutiev, and P. Marinov, Characteristics of Large Scale Travelling Ionospheric Disturbances Exploiting Ground-Based Ionograms, GPS-TEC and 3D Electron Density Distribution Maps, Proceedings of the 14th International Iono- 


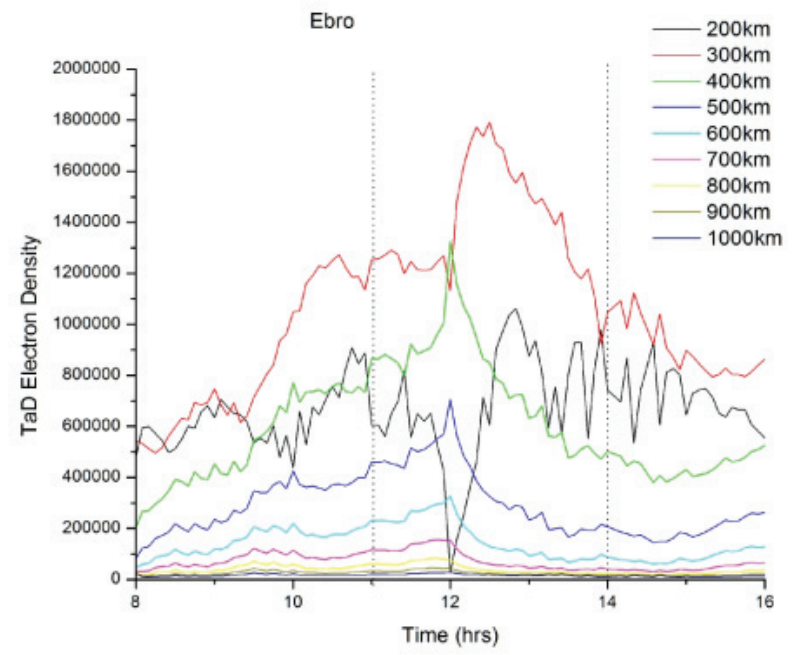

Fig. 3.6. 7. The electron density modeled by $\mathrm{TaD}$ for heights ranging from 200 to $1000 \mathrm{~km}$ over Ebro on March 7, 2012. This analysis indicates strong electron density disturbances in the bottomside ionosphere assosciated with LSTIDs signatures (after Belehaki et al., 2015).

spheric Effects Symposium, Editor in Chief: Keith M. Groves, Crowne Plaza Hotel Alexandria, Virginia, USA, 12-14 May 2015.

Bilitza, D., International Reference Ionosphere 2000, Radio Sci. 36, 2, 261-275, DOI: 10.1029/2000RS002432, 2001.

Bilitza, D., and Reinisch, B. W., International reference ionosphere 2007: improvements and new parameters. Advances in Space Research, 42(4), 599-609, 2008.

Bilitza, D., Altadill, D., Zhang, Y., Mertens, C., Truhlik, V., Richards, P., ... and Reinisch, B., The International Reference Ionosphere 2012a model of international collaboration, Journal of Space Weather and Space Climate, 4, A07, 2014.

Bradley, P.A., Indices of ionospheric response to solar-cycle epoch, Adv. Space Res. 13, 3, 25-28, DOI: 10.1016/0273-1177(93)90242-4, 1993.

Fuller-Rowell, T. J., E. Araujo-Pradere, and M. V. Codrescu. "An empirical ionospheric storm-time correction model." Advances in Space Research 25.1: 139-146, 2000.

Kutiev I, Marinov P, Fidanova S, Belehaki A and Tsagouri I: Adjustments of the TaD electron density reconstruction model with GNSS-TEC parameters for operational application purposes. J. Space Weather Space Clim., 2, A21, 2012.

Marinov, P., Kutiev, I., Belehaki, A., and Tsagouri, I., Modeling the plasmasphere to topside ionosphere scale height ratio, Journal of Space Weather and Space Climate, 5, A27, 2015.

Mertens, C. J., Xu, X., Bilitza, D., Mlynczak, M. G., and Russell, J. M., Empirical 
STORM-E model: I. Theoretical and observational basis. Advances in Space Research, 51(4), 554-574, 2013.

Spence, H., D. Baker, A. Burns, T. Guild, C.-L. Huang, G. Siscoe and R. Weigel, Center for Integrated Space Weather Modeling Metrics Plan and Initial Model Validation, J. Atmos. Solar-Terr. Phys., 66/15-16, 1499, 2004.

Tsagouri, I., B. Zolesi, A. Belehaki, and L.R. Cander, Evaluation of the performance of the real-time updated simplified ionospheric regional model for the European area, J. Atmos. Sol.-Terr. Phys. 67, 12, 1137-1146, DOI:10.1016/j.jastp.2005.01.012, 2005.

Zolesi, B., L.R. Cander, and G. De Franceschi (1993), Simplified ionospheric regional model for telecommunication applications, Radio Sci. 28, 4, 603- 612, DOI: 10.1029/93RS00276, 1993.

Zolesi, B., L.R. Cander, and G. De Franceschi, On the potential applicability of the simplified ionospheric regional model to different midlatitude areas, Radio Sci. 31, 3, 547-552, DOI: 10.1029/95RS03817, 1996.

Zolesi, B., A. Belehaki, I. Tsagouri, and L.R. Cander, Real-time updating of the Simplified Ionospheric Regional Model for operational applications, Radio Sci. 39, RS2011, DOI: 10.1029/2003RS002936, 2004. 



\title{
3.7. Ionospheric Data assimilation in ESPAS
}

\author{
M. J. Angling ${ }^{1}$, S. Elvidge ${ }^{1}$, N. Jackson-Booth ${ }^{2}$, R. W. Penney ${ }^{2}$ \\ 1. Space Environment and Radio Engineering Group, University of Birmingham, UK \\ 2. QinetiQ Ltd, Malvern, UK
}

\subsubsection{Introduction}

Even though the ionosphere has been studied for many years, ionospheric modelling remains an active area of research. This is because ionospheric models support the successful operation, planning and management of RF systems [Goodman and Aarons, 1990]. There are three main approaches to modelling the ionosphere: empirical, physics-based and data assimilation.

\subsubsection{Empirical Models}

Empirical models (also often referred to as 'statistical models' or 'median models') are based upon observations. Relationships between the variables in the model are usually determined via curve fitting techniques. Although empirical models can be used to reproduce observed relationships between model variables, they cannot directly be used to determine whether one physical parameter affects another. Also, without accounting for any of the underlying physical processes, they only allow for simple extrapolation into areas where there are no available observations.

Many ionospheric empirical models have been developed. These include the International Reference Ionosphere (IRI) [Bilitza and Reinisch, 2008] which can be accessed by the ESPAS portal. Others include NeQuick [Nava et al., 2008], the Parameterized Ionospheric Model (PIM) developed by the Air Force Research Laboratory (AFRL) [Daniell et al., 1995] and the Bent Ionospheric Model [Llewellyn and Bent, 1973]. IRI and the Bent model have previously been compared by [Bilitza et al., 1988]. 


\subsubsection{Physics-Based Models}

Physics-based models solve the equations which describe the physical processes in the ionosphere/thermosphere [Schunk, 1996]. To model atmospheric density the models generally use empirical models (such as NRLMSISE-00) to generate an initial condition. Neutral and ion species production is then calculated via chemical reaction equations and using solar X-rays and EUV conditions. Ion transportation and recombination are also considered. The initial and boundary conditions, as well as proxies for solar activity, are the main drivers for the models. There are a number of approaches to modelling the physics of the ionosphere, which rely on different numerical methods [Purnell, 1976; Augenbaum, 1984; Bott, 1989], and thus exhibit different levels of complexity and use a variety of inputs.

Physics models have the potential to provide ionospheric forecasts since, in principle, the physics can be used to propagate the model densities from one time step to the next. However, [Shim et al., 2012] suggested that errors in electron density can be very large due to errors in initialization and boundary conditions.

Well-known physics models include the Thermosphere Ionosphere Exosphere General Circulation Model (TIE-GCM) developed by NCAR [Richmond, 1992]; the Global Ionosphere Thermosphere Model (GITM) [Ridley et al., 2006]; the Coupled Thermosphere Ionosphere Plasmasphere Electrodynamics Model (CTIPe) developed at the Space Weather Prediction Center [Codrescu et al., 2012]; and the Coupled Middle Atmosphere and Thermosphere (CMAT) model from University College London [Harris, 2011].

\subsubsection{Data assimilation models}

As discussed elsewhere in this ebook, there is a wide range of datasets providing near real-time measurements of the state of the ionosphere. This data enables a further modelling approach - data assimilation. Data assimilation models aim to optimally combine disparate measurements with a background model.

There are many techniques for data assimilation (some of which are described in Section 3.7.0). Similarly, there is a wide range of models which are based upon assimilative routines. These include the Electron Density Assimilative Model (EDAM, see Section 3.7.3.4.) [Angling and Jackson-Booth, 2009], the GPS Ionospheric Inversion (GPSII) model [Fridman et al., 2006] and the data ingestion version of NeQuick [Nava et al., 2011], which all use an empirical background model. Other data assimilation models, including the Utah State University Global Assimilation of Ionospheric Measurements (USU-GAIM) model [McNamara et al., 2008] and the Jet Propulsion Laboratory's Global Assimilative Ionospheric Model (GAIM) [Mandrake et al., 2005], use data assimilation techniques in conjunction with physics-based background models. Data assimilation is also used in $3 \mathrm{D}$ 
tomography schemes such as the Multi-Instrument Data Analysis System (MIDAS) [Mitchell and Spencer, 2003; Spencer and Mitchell, 2007]. A review of data assimilation models can be found in [Bust and Mitchell, 2008]. Ionospheric data assimilation models are usually not truly real-time, since there is generally some latency between the data being retrieved and it being assimilated. However, they can work in 'near-real-time' [Angling and Khattatov, 2006].

\subsubsection{Data Assimilation}

\subsubsection{Introduction}

In many systems there are fewer observations than the number of unknowns, i.e. the system is mathematically underdetermined. The observations which are available are subject to experimental uncertainty, and often the observed characteristic is not the variable that is directly modelled. Therefore an observation operator $(\boldsymbol{H})$ is used to transform the state space to the observation space. For a linear observation process, this can be represented as

$$
\boldsymbol{y}_{0}=\boldsymbol{H} \boldsymbol{x}+\boldsymbol{\epsilon}_{0}
$$

Equation 1

Where $\boldsymbol{y}_{0}$ is a vector of observations, $\boldsymbol{x}$ the true state and $\boldsymbol{\epsilon}_{0}$ the observation error.

It is common to want to estimate the state of a system from some measurements which only indirectly relate to that state. For example, one might want to estimate the (vertical) TEC above a given ground location, given (slant) measurements of TEC from some GPS satellites.

The first approach is to just use data from the nearest satellite/receiver pair to the region of interest. Secondly, if more than one satellite/receiver pair exists, then both can be used to estimate the TEC. This estimation can be improved by using more satellite/receiver data. However, depending on a number of factors, including the distance of the data from the point of interest and the quality of the data, each new piece of information should be individually weighted. Data assimilation is the art of optimally combining various sources of information to estimate the true state of the system.

A wide range of assimilation methods have been developed; e.g. weighted least squares (WLS) [Plackett, 1950], Kalman filters [Kalman, 1960; Houtekamer and Mitchell, 2005], Optimal Interpolation (OI) [Gandin, 1963; Eddy, 1967] and variational methods [Le Dimet and Talagrand, 1986]. The short introduction in this chapter merely serves to highlight the essence of the field (and focusses on Kalman filters). There are a number of books on the subject that are recommended for further 
reading: [Rodgers, 2000], [Kalnay, 2003] and [Evensen, 2009].

\subsubsection{Least Squares}

A simple approach to data assimilation is to use the method of least squares [Legendre, 1805]. The method requires the estimation of the state to be a value that minimises the sum of the squares of the error of each term. That is, for $N$ observations, $\Omega_{i}$, a solution (often called the analysis) $x_{a}$ is found that minimises:

$$
\sum_{i=1}^{N}\left(x_{a}-\Omega_{i}\right)^{2}
$$

Equation 2

This approach is often used for data fitting (constructing curves of best fit to a series of data). It is not used in data assimilation models since, in its classic form, does not allow for differently weighted data. This means that the result can easily be skewed by outliers.

\subsubsection{Weighted Least Squares}

To overcome the problem with least squares, weighted least squares (WLS) can be used. Assuming the data is unbiased, the WLS is formed from a linear combination of observations and has the minimum variance of all such combinations. To derive the WLS consider a linear combination of a background vector $\left(\boldsymbol{x}_{b}\right)$ and an observation vector $\left(\boldsymbol{y}_{0}\right)$ to produce an analysis $\left(\boldsymbol{x}_{a}\right)$ :

$$
x_{a}=x_{b}+K\left(y_{0}-x_{b}\right)
$$

Equation 3

where $\boldsymbol{K}$ is a weighting matrix, and $\boldsymbol{x}_{a}, \boldsymbol{x}_{b}$ and $\boldsymbol{y}_{o}$ have associated error covariance matrices $\boldsymbol{A}, \boldsymbol{B}$ and $\boldsymbol{O}$. To find the WLS, a $\boldsymbol{K}$ must be found which minimises the expected analysis error covariance matrix $(\boldsymbol{A})$. This is equivalent to minimising the trace of $\boldsymbol{K}$ [Park and $X u, 2013]$, and is given by:

$$
\boldsymbol{K}=\boldsymbol{B}(\boldsymbol{B}+\boldsymbol{O})^{-1}
$$

Equation 4

A detailed description of the derivation of Equation 4 can be found in Kelly [2013]. If an observation operator is required to transform between the observation space to the state space, the WLS for vector equations can be extended so that:

$$
\boldsymbol{K}=\boldsymbol{B} \boldsymbol{H}^{T}\left(\boldsymbol{H} \boldsymbol{B} \boldsymbol{H}^{T}+\boldsymbol{O}\right)^{-1}
$$

Equation 5 


\subsubsection{Kalman Filters}

Finding the WLS for a variable can be further developed by replacing the unique state $\boldsymbol{x}$ with a series of states $\boldsymbol{x}^{t}$, where $t$ is a time index. There are then a number of methods which one can use to solve these equations and create the best analysis. This includes variational assimilation, which avoids the inversion required to compute $\boldsymbol{K}$ by considering the analysis as an approximate solution to the equivalent minimization problem [Le Dimet and Talagrand, 1986]. An alternative to variational assimilation is the Kalman filter which is an extension of the leastsquares analysis [Kalman, 1960].

The Kalman filter is a technique used to perform data assimilation, where each background state is provided by an "update" step, which starts from the previous analysis [Kalman, 1960]. There are a number of conditions and assumptions which are required before using a Kalman filter. First, an initial background state is required to start the procedure $\left(\boldsymbol{x}_{b}^{0}\right)$. A (linear) model which describes the evolution of the state, i.e. an approximation of how the state which is being modelled changes over time, is also required $\left(\boldsymbol{M}^{t}\right)$. It needs not be a perfect description of the evolution of the state, since it is combined with data. Finally, the errors (model and observation) are assumed to have no bias, i.e. $E\left[\boldsymbol{\eta}^{t}\right]=0$ and $E\left[\boldsymbol{\epsilon}_{i}^{t}\right]=0$, where $\boldsymbol{\eta}^{t}$ and $\boldsymbol{\epsilon}_{i}^{t}$ are the model and observation errors respectively. Also, it is assumed that different types of errors, such as the model and observation errors, are independent of each other, $E\left[\boldsymbol{\eta}^{t} \boldsymbol{\epsilon}_{i}^{t}\right]=0$.

Given a series of states, $\boldsymbol{x}^{t}$, the Kalman filter will give the optimal (i.e. the minimum mean square error) estimate of the state, $\boldsymbol{x}_{a}^{t}$, using observations $\boldsymbol{y}_{o}^{1}, \boldsymbol{y}_{o}^{2}, \ldots, \boldsymbol{y}_{o}^{t}$. The initial conditions, $\boldsymbol{x}_{b}^{0}$ and $\boldsymbol{B}^{0}$, are the starting state and its corresponding error covariance matrix. These are then used to perform the analysis step:

Analysis step. This uses the vector equations for the WLS with the observation operator as well as the error covariance matrix [Kelly, 2013] giving:

$$
\begin{aligned}
\boldsymbol{K}^{t} & =\boldsymbol{B}^{t} \boldsymbol{H}^{T}\left(\boldsymbol{H} \boldsymbol{B}^{t} \boldsymbol{H}^{T}+\boldsymbol{O}\right)^{-1}, & & \text { Equation 6 } \\
\boldsymbol{x}_{a}^{t} & =\boldsymbol{x}_{b}^{t}+\boldsymbol{K}\left(\boldsymbol{y}_{o}^{t}-\boldsymbol{H} \boldsymbol{x}_{b}^{t}\right), & & \text { Equation 7 } \\
\boldsymbol{A}^{t} & =\left(I-\boldsymbol{K}^{t} \boldsymbol{H}\right) \boldsymbol{B}^{t} . & & \text { Equation 8 }
\end{aligned}
$$

Where $I$ is the identity matrix.

Update step. Using the values from the analysis step, the update step is used to find the background values $\boldsymbol{x}_{b}^{t+1}$ and $\boldsymbol{B}^{t+1}$ for use in the next analysis step.

$$
\begin{aligned}
& \boldsymbol{x}_{b}^{t+1}=\boldsymbol{M}^{t, t+1} \boldsymbol{x}_{a}^{t}, \\
& \boldsymbol{B}^{t+1}=\boldsymbol{M}^{t, t+1} \boldsymbol{A}\left(\boldsymbol{M}^{t, t+1)}\right)^{T}+\boldsymbol{Q}^{t} .
\end{aligned}
$$

Where $\boldsymbol{Q}^{t}$ is the model error covariance matrix. This process is repeated $t$ times, 
until the assimilation is complete.

When using a Kalman filter storage for the error covariance matrices scale with the square of the size of the state. Therefore, although it provides the best combination of the model and data it is computationally expensive. To overcome this, and other problems (such as the propagation model needing to be linear), a number of variants of the Kalman filter have been proposed. Such variants include: the band limited Kalman filter, which only saves part of the covariance matrix based on physical correlation lengths [Hajj et al., 2004]; the extended Kalman filter, which allows the use of non-linear models in the Kalman filter [Julier and Uhlmann, 2004]; the ensemble Kalman filter, which replaces the covariance matrix by the sample covariance [Evensen, 1994] and the local ensemble Kalman filter which performs the analysis around each model grid point [Ott et al., 2004].

\subsubsection{Using ESPAS for data assimilation}

\subsubsection{ESPAS as a data source}

ESPAS exposes a wide range of ionospheric measurements that may be used in a ionospheric data assimilation system (Table 3.7.1).

Table 3.7.1. Ionospheric measurements that may be found in ESPAS

\begin{tabular}{|c|c|c|}
\hline Data type & Measurement type & Instruments \\
\hline \multirow{4}{*}{$\begin{array}{c}\text { Electron Density } \\
\text { profiles }\end{array}$} & Vertical ionosondes & Digisonde \\
\cline { 2 - 3 } & Top-side ionosondes & AIS \\
\cline { 2 - 3 } & $\begin{array}{c}\text { Incoherent scatter } \\
\text { radar }\end{array}$ & ISIS \\
\cline { 2 - 3 } & $\begin{array}{c}\text { Space based GPS } \\
\text { radio occultation }\end{array}$ & EISCAT \\
\cline { 2 - 3 } & $\begin{array}{c}\text { In-situ Langmuir } \\
\text { probe }\end{array}$ & CHAMP \\
\cline { 2 - 3 } Electron densities & GPACE \\
\hline \multirow{2}{*}{$\begin{array}{c}\text { Total electron } \\
\text { content }\end{array}$} & GPS & CHAMPTER \\
\cline { 2 - 3 } & & CHAMP \\
\cline { 2 - 3 } & & GRACE \\
\hline
\end{tabular}

\subsubsection{Data assimilation models in ESPAS}

ESPAS makes available a number of data assimilation models. EDAM will be 
described in more detail in the following section (Table 3.7.2).

Table 3.7.2. Assimilative models in ESPAS

\begin{tabular}{|l|l|}
\hline \multicolumn{1}{|c|}{ Model } & \multicolumn{1}{c|}{ Provider } \\
\hline Electron Density Assimilative Model & QinetiQ, University of Birmingham \\
\hline $\begin{array}{l}\text { CHAMP/GRACE Topside Ionosphere } \\
\text { / Plasmasphere Reconstruction }\end{array}$ & DLR \\
\hline DIAS maps & National Observatory of Athens \\
\hline SWACI maps & DLR \\
\hline
\end{tabular}

\subsubsection{Electron Density Assimilative Model (EDAM)}

The Electron Density Assimilative Model (EDAM) has been developed at QinetiQ, UK, to assimilate ionospheric measurements into a background ionospheric model [Angling and Khattatov, 2006; Angling et al., 2009]. The background model is provided by IRI-2007 (the 2007 version of IRI) [Bilitza and Reinisch, 2008]. The EDAM assimilation is based on the weighted least squares described in Section 3.7.0.

A magnetic coordinate system (tilted dipole) is used in EDAM and a time step of 15 minutes. The electron density differences between the voxels of the analysis and the background model are propagated from one time step to the next by assuming persistence combined with an exponential decay. The time constant for this decay is set at four hours. Thus if the data feed is interrupted, the analysis will decay back to the background model.

EDAM assimilates GNSS slant TEC observations as well as ionosonde information in the form of the ionogram virtual height traces [Angling and JacksonBooth, 2011] (Figure 3.7.1). It can also assimilate radio occultation (RO) observations of slant TEC [Angling and Cannon, 2004; Angling, 2008] and in situ electron densities, but these capabilities are not used in the implementation that provides data to ESPAS. 


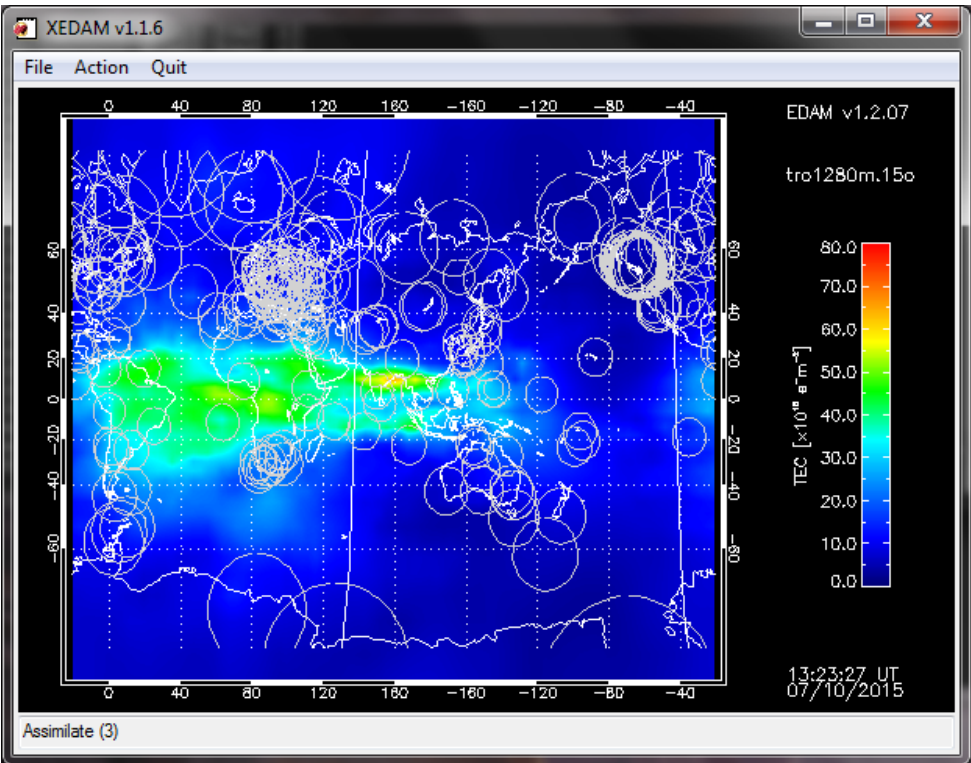

Figure 3.7.1. Screengrab from EDAM while it is assimilating data. The grey circles indicate each input data point's region of influence.

Internally, EDAM stores the ionospheric grids as differences from the IRI grid. However, in order to provide data to ESPAS, a processing system (EMMENTAL) is used to convert the EDAM difference files into full grids, images, and associated metadata (Table 3.7.3). Data is provided at 15-minute time intervals and with approximately 100 minutes latency.

Table 3.7.3. EDAM file types held by ESPAS

\begin{tabular}{|c|c|l|l|}
\hline File type & $\begin{array}{c}\text { File } \\
\text { format }\end{array}$ & \multicolumn{1}{|c|}{ Contains } & Example \\
\hline Images & PNG & $\begin{array}{l}\text { Vertical total electron content } \\
\text { (VTEC) map } \\
\text { Peak electron density (NmF2) } \\
\text { map }\end{array}$ & $\begin{array}{l}\text { Figure 3.7.2 } \\
\text { Figure 3.7.3 }\end{array}$ \\
\hline Data & $\begin{array}{l}\text { gzip } \\
\text { EONEX }\end{array}$ & 3D electron density grid & Figure 3.7.4 \\
\hline Metadata & XML & $\begin{array}{l}\text { Metadata describing the EDAM } \\
\text { data }\end{array}$ & \\
\hline
\end{tabular}




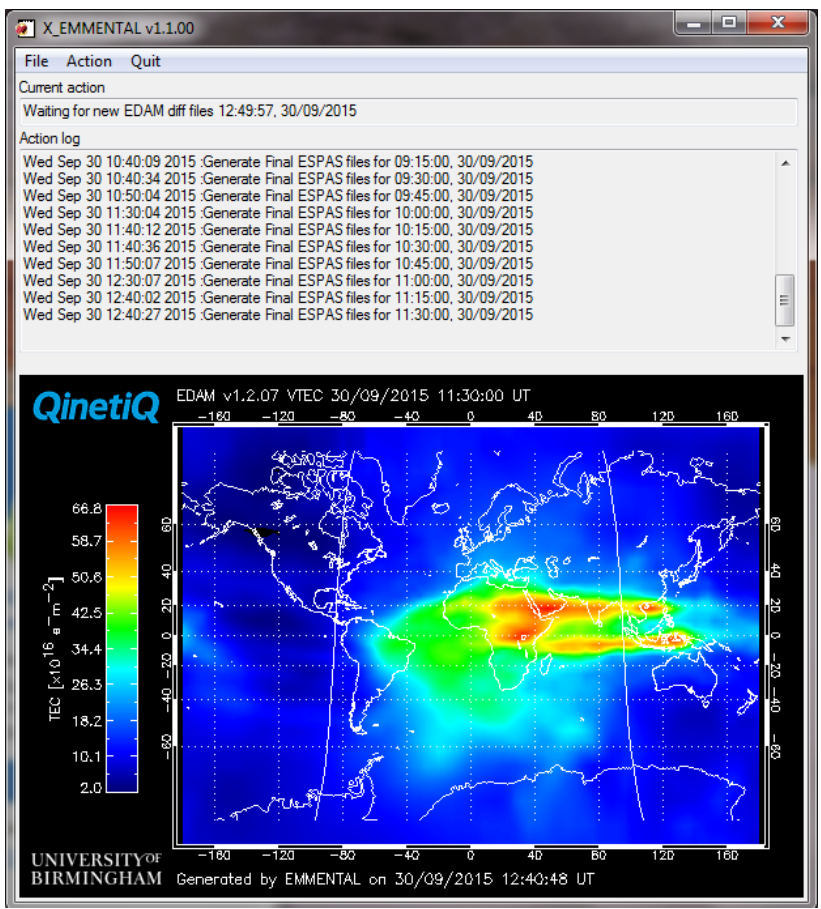

Figure 3.7.2. Example EDAM vertical TEC. Here it is shown as it is displayed by the EMMENTAL processor.

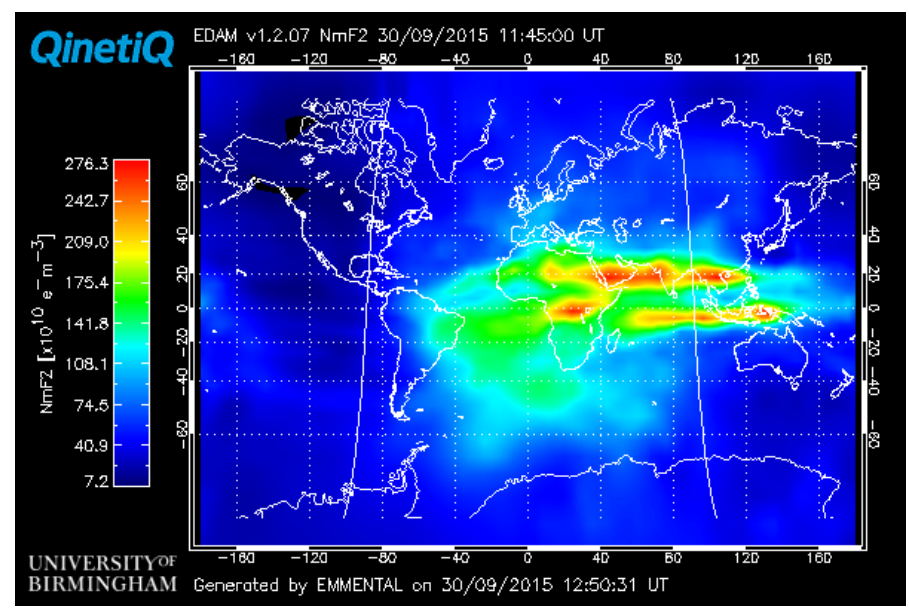

Figure 3.7.3. Example EDAM NmF2 map as stored by ESPAS. 


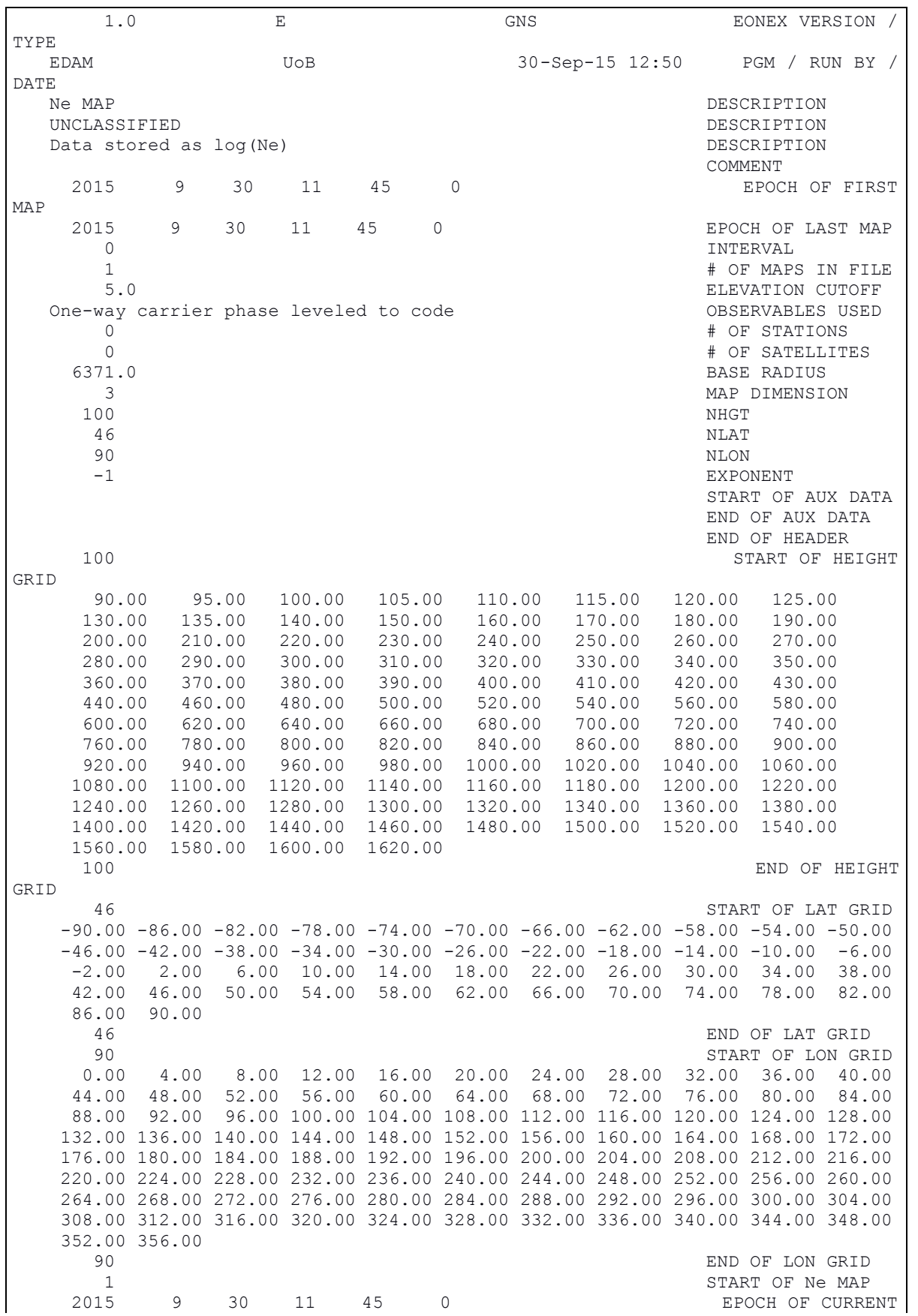




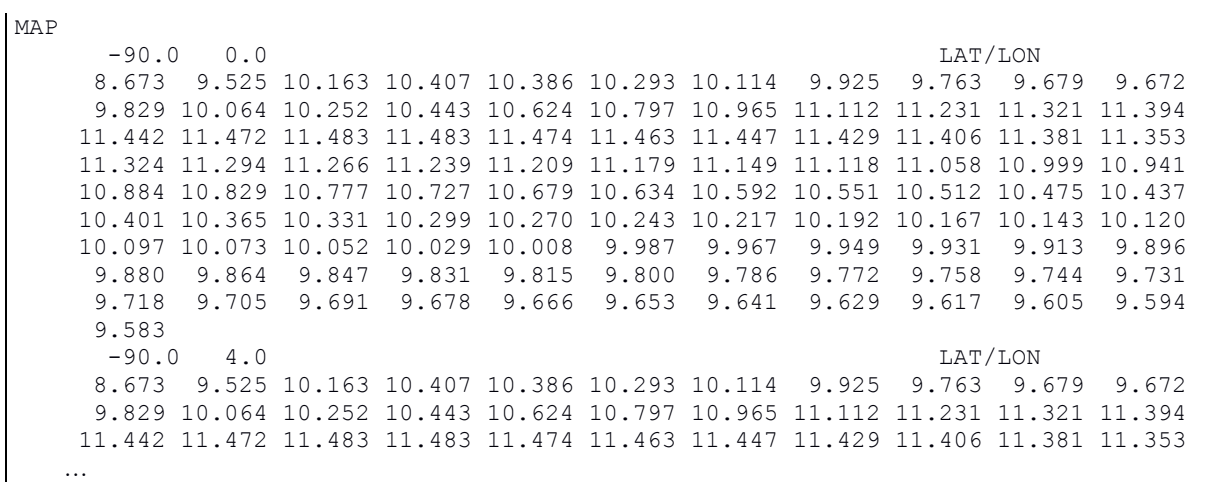

Figure 3.7.4. Example header and start of data from EDAM EONEX file.

\section{Acknowledgements}

EDAM is developed by QinetiQ as part of the Dstl Space programme via the Cyber and Information Systems division.

\section{References}

Angling, M. J. (2008), First assimilations of COSMIC radio occultation data into the Electron Density Assimilative Model (EDAM), Ann. Geophys., 26(2), 353-359.

Angling, M. J., and P. S. Cannon (2004), Assimilation of radio occultation measurements into background ionospheric models, edited by J. Goodman, Radio Sci., 39(RS1S08), 100-106, doi:doi:10.1029/2002RS002819.

Angling, M. J., and N. Jackson-Booth (2009), On the use of Ground and Space Based GPS Measurements in the Electron Density Assimilative Model (EDAM), in Institute of Navigation, International Technical Meeting, Anaheim, USA.

Angling, M. J., and N. K. Jackson-Booth (2011), A short note on the assimilation of collocated and concurrent GPS and ionosonde data into the Electron Density Assimilative Model, Radio Sci., 46(4).

Angling, M. J., and B. Khattatov (2006), Comparative study of two assimilative models of the ionosphere, Radio Sci., 41(RS5S20), doi:10.1029/2005RS003372.

Angling, M. J., J. Shaw, A. K. Shukla, and P. S. Cannon (2009), Development of an HF frequency selection tool based on the EDAM real time ionosphere, Radio Sci., 44(RS0A13), n/a-n/a, doi:10.1029/2008RS004022. 
Augenbaum, J. M. (1984), A Lagrangian Method for the Shallow Water Equations Based on a Voronoi Mesh - One Dimensional Results, J. Comput. Phys., 53, 240265.

Bilitza, D., and B. W. Reinisch (2008), International Reference Ionosphere 2007: Improvements and new parameters, J. Adv. Sp. Res., 42(4), 599-609, doi:10.1016/j.asr.2007.07.048.

Bilitza, D., K. Rawer, and S. Pallaschke (1988), Study of Ionospheric Models for Satellite Orbit Determination, Radio Sci., 23(3), 223-232.

Bott, A. (1989), A Positive Definite Advection Scheme Obtained by Nonlinear Renormalization of the Advective Fluxes, Mon. Weather Rev., 117, 1006-1015.

Bust, G. S., and C. N. Mitchell (2008), History, current state, and future directions of ionospheric imaging, Rev. Geophys., 46(RG1003), 1-23, doi:10.1029/2006RG000212.

Codrescu, M., C. Negrea, M. Fedrizzi, T. Fuller-Rowell, A. Dobin, N. Jakowski, H. Khalsa, T. Matsuo, and N. Maruyama (2012), A Real-Time Run of the Coupled Thermosphere Ionosphere Plasmasphere Elecetrodynamics (CTIPe) Model, $S p$. Weather, 10(2), doi:10.1029/2011SW000736.

Daniell, R. E., L. D. Brown, D. N. Anderson, M. W. Fox, P. H. Doherty, D. T. Decker, J. J. Sojka, and R. W. Schunk (1995), PRISM: A global ionospheric parameterisation based on first principles models, Radio Sci., 30(5), 1499.

Le Dimet, F.-X., and O. Talagrand (1986), Variational algorithms for analysis and assimilation of meteorological observations: theoretical aspects, Tellus, 38A, 97110.

Eddy, A. (1967), The Statistical Objective Analysis of Scalar Data Fields, J. Appl. Meteorol., 6, 597-609.

Evensen, G. (1994), Sequential data assimilation with a nonlinear quasi-geostrophic model using Monte Carlo methods to forecast error statistics, J. Geophys. Res., 99(C5), 10143, doi:10.1029/94JC00572.

Evensen, G. (2009), Data Assimilation, the Ensemble Kalman Filter, 2nd ed., Springer-Verlag Berline Heidelberg.

Fridman, S. V, L. J. Nickisch, M. Aiello, and M. Hausman (2006), Real-time reconstruction of the three-dimensional ionosphere using data from a network of GPS receivers, Radio Sci., 41(RS5S12), doi:10.1029/2005RS003341.

Gandin, L. (1963), Objective analysis of meteorological fields (Leningrad: Gridromet). English translation (Jerusalem: Israel Program for Scientific Translation), 1965. 
Goodman, J. M., and J. Aarons (1990), Ionospheric effects on modern electronic systems, Proc. IEEE, 78(3), 512-528.

Hajj, G. A., B. D. Wilson, C. Wang, X. Pi, and G. Rosen (2004), Data assimilation of ground GPS total electron content into a physics-based ionospheric model by use of the Kalman filter, Radio Sci., 39(RS1S05), doi:doi:10.1029/2002RS002859.

Harris, M. J. (2011), A New Coupled Middle Atmosphere and Thermosphere General Circulation Model: Studies of Dynamic, Energetic and Photochemical Coupling in the Middle and Upper Atmosphere, Universtiy College London.

Houtekamer, P. L., and H. L. Mitchell (2005), Ensemble Kalman Filtering, Q. J. R. Meteorol. Soc., 131, 3269-3289, doi:10.1256/qj.05.135.

Julier, S. J., and J. K. Uhlmann (2004), Unscented filtering and nonlinear estimation, Proc. IEEE, 92(3), 401-422.

Kalman, R. E. (1960), A New Approach to Linear Filtering and Prediction Problems, Trans. ASME-Journal Basic Eng., 82, 34-45.

Kalnay, E. (2003), Atmospheric Modeling, Data Assimilation and Predictability, Cambridge University Press, Cambridge.

Kelly, A. (2013), Mobile Robotics: Mathematics, Models, and Methods, Cambridge University Press.

Legendre, A. M. (1805), Nouvelles méthodes pour la détermination des orbites des cometes, F. Didot.

Llewellyn, S. K., and R. B. Bent (1973), Documentation and Description of the Bent Ionospheric Model, Hanscom AFB, MA, USA.

Mandrake, L., B. Wilson, C. Wang, G. A. Hajj, A. J. Mannucci, and X. Pi (2005), A performance evaluation of the operational Jet Propulsion Laboratory/University of Southern California Global Assimilation Ionospheric Model (JPL/USC GAIM), $J$. Geophys. Res., 110(A12306), doi:doi:10.1029/2005JA011170.

McNamara, L. F., C. R. Baker, and D. T. Decker (2008), Accuracy of USU-GAIM Specifications of foF2 and M(3000)F2 for a World-Wide Distribution of Ionosonde Locations, Radio Sci., 43(RS1011), doi:doi:10.1029/2007RS003754.

Mitchell, C. N., and P. S. J. Spencer (2003), A three-dimensional time-dependent algorithm for ionospheric imaging using GPS, Ann. Geophys., 46(4), 687-696.

Nava, B., P. Coisson, and S. Radicella (2008), A new version of the neQuick ionosphere electron density model, J. Atmos. Solar-Terr. Phys., doi:10.1016/j.jatsp.2008.01.015.

Nava, B., S. Radicella, and F. Azpilicueta (2011), Data Ingestion into NeQuick 2, Radio Sci, 46, doi:10.1029/2010RS004635. 
Ott, E., B. Hunt, I. Szunyogh, A. Zimin, E. Kostelich, M. Corrazza, E. Kalnay, and J. Yorke (2004), A local ensemble Kalman filter for atmospheric data assimilation, Tellus, 56, 415-428.

Park, S. K., and L. Xu (2013), Data Assimilation for Atmospheric, Oceanic and Hydrologic Applications (Vol. II), SpringerLink : B $\{\ddot{\mathrm{u}}\}$ cher, Springer.

Plackett, R. L. (1950), Some theorems in least squares, Biometrika, 37(1-2), 149-57.

Purnell, D. K. (1976), Solution of the Advective Equation by Upstream Interpolation with a Cubic Spline, Mon. Weather Rev., 104, 42-48.

Richmond, A. D. (1992), Assimilative mapping of ionospheric electrodynamics, Adv. Space. Res., 12(6), 59-68.

Ridley, A. J., Y. Deng, and G. Toth (2006), The Global Ionosphere-Thermosphere Model (GITM), J. Atmos. Solar-Terr. Phys., 68, 839-864.

Rodgers, C. D. (2000), Inverse methods for atmospheric sounding: theory and practice, Atmospheric, Oceanic and Planetary Physics, World Scientific Publishing, Singapore.

Schunk, R. W. (1996), Solar Terrestrial Energy Program (STEP). Handbook of Ionospheric Models. Schunk.pdf, SCOSTEP, Boulder, Colorado, USA.

Shim, J. S. et al. (2012), CEDAR Electrodynamics Thermosphere Ionosphere (ETI) Challenge for systematic assessment of ionosphere/thermosphere models: Electron density, neutral density, $\mathrm{NmF}$, and hmF2 using space based observations, $S p$. Weather, 10, doi:10.1029/2012SW000851.

Spencer, P. S. J., and C. N. Mitchell (2007), Imaging of fast moving electron-density structures in the polar cap, Ann. Geophys., 50(3), 427-434. 


\title{
3.8. Incoherent and coherent scatter radars
}

\author{
Ingemar Häggström \\ EISCAT Scientific Association, Sweden
}

Figure 3.8.1 illustrates how incoherent and coherent scatter radars works. The main difference is how the signal is scattered and detected. Echoes for both radars come from collective scattering, or plasma irregularities. Incoherent scatter radars see weak ion-acoustic structures in any direction whereas coherent scatter radars only see large amplitude structures aligned with the magnetic field. These HF radars use refraction to bend the rays so as to hit perpendicularity to $\mathrm{B}$ in the $\mathrm{F}$ region. $\mathrm{F}$ region magnetic field-aligned echoes should drift at $\mathrm{ExB}$ since ions and electrons both ExB drift. Table 3.8.1 below shows some key differences between the two radar types.

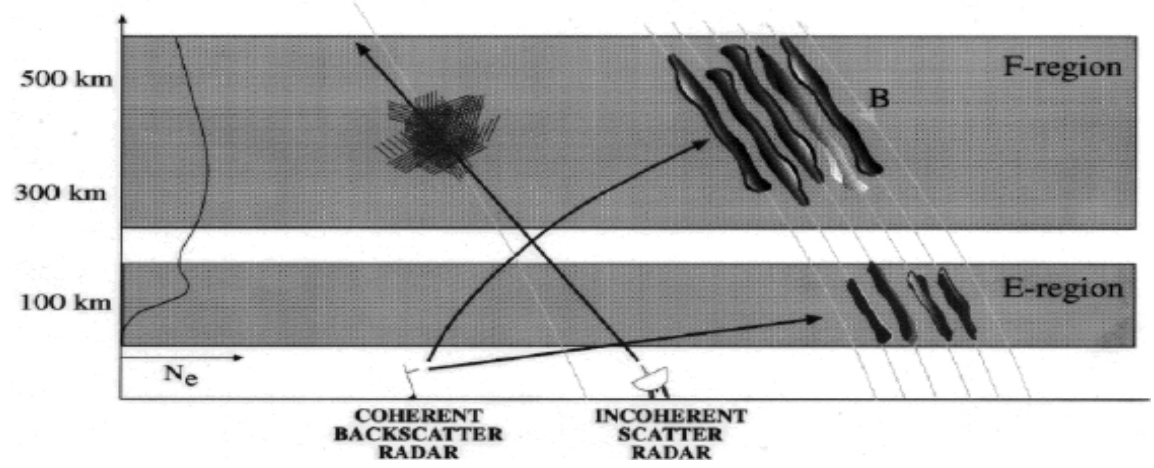

Figure 3.8.1 Schematic picture of coherent and incoherent scatter radars

Table 3.8.1 Key properties of coherent and incoherent scatter radars.

\section{Radar}

Power

Frequency

Range resolution

Temporal resolution

Field of View

Parameters

Radar operations

\section{Incoherent}

$\sim 1 \mathrm{MW}$

Fixed (UHF/VHF)

100 's m-10s km

$\mathrm{ms}$

Narrow

$\mathrm{N}_{\mathrm{e}}, \mathrm{T}_{\mathrm{e}}, \mathrm{T}_{\mathrm{i}}, \mathrm{V}_{\mathrm{i}}$

Coded pulses
Coherent

$\sim 10 \mathrm{~s} \mathrm{~kW}$

Variable (HF)

$15-45 \mathrm{~km}$

mins

Wide

$\mathrm{V}_{\text {los }}$, power, spectral width

Multi-pulse 


\subsubsection{Incoherent scatter radars}

This technique is the most powerful ground-based tool for these research applications. The basic data measured with the incoherent scatter radar technique are profiles of electron density, electron and ion temperature, and ion velocity. Subsequent processing allows a wealth of further parameters, describing the ionosphere and neutral atmosphere, to be derived. A selection of well-designed radar pulse schemes are available to adapt the data-taking routines to many particular phenomena, occurring at altitudes between about $50 \mathrm{~km}$ and more than $2000 \mathrm{~km}$. Depending on geophysical conditions, a best time resolution of less than one second and an altitude resolution of a few hundred meters can be achieved.

There currently exist some 10 incoherent scatter radars in world. The first radars built are the $0.1 \mathrm{~km}^{2}$ radars in Jicamarca (1962) and Arecibo (1963). However, as it turned out, the received signals were much more narrowband than expected and subsequently the radars built since are somewhat smaller in size and many of them are steerable. These kinds of radars are also called HPLA-radars (High Power Large Aperture) and are used for incoherent scatter measurement as well as all sorts of space objects from micro-meteors to planets.

\subsubsection{The EISCAT Incoherent Scatter Radars}

The European installations are run by EISCAT, the European Incoherent Scatter Scientific Association. EISCAT is also being used as a coherent scatter radar for studying instabilities in the ionosphere, as well as for investigating the structure and dynamics of the middle atmosphere and as a diagnostic instrument in ionospheric modification experiments with the Heating facility. The experimental sites of EISCAT are located in the Scandinavian sector, north of the Arctic Circle. They consist of two independent radar systems on the mainland, together with a further radar constructed on the island of Spitzbergen in the Svalbard archipelago - the EISCAT Svalbard Radar - Scandinavia.

The EISCAT UHF radar operates in the $931 \mathrm{MHz}$ band with a peak transmitter power of more than $2.0 \mathrm{MW}$ and $32 \mathrm{~m}$, fully steerable parabolic dish antenna located in Tromsø (Norway).

The monostatic VHF radar in Tromsø operates in the $224 \mathrm{MHz}$ band with a peak transmitter power of $1.5 \mathrm{MW}$ and a $120 \mathrm{~m} \times 40 \mathrm{~m}$ parabolic cylinder antenna, which is subdivided into four sectors. It can be steered mechanically in the meridional plane from vertical to $60^{\circ}$ north of the zenith; limited east-west steering is also possible using alternative phasing cables. Receiving sites are also located near Kiruna (Sweden) and Sodankylä (Finland), allowing continuous tri-static measurements to be made.

The EISCAT Svalbard radar (ESR), located near Longyearbyen, operates in the 
$500 \mathrm{MHz}$ band with a peak transmitter power of $1.0 \mathrm{MW}$, a fully steerable parabolic dish antenna of $32 \mathrm{~m}$ diameter, and a fixed field aligned antenna of $42 \mathrm{~m}$ diameter. The high latitude location of this facility is particularly aimed at studies of the cusp and polar cap region.

\subsubsection{Incoherent Scatter}

Thomson scatter is re-radiation by free electrons of incident electro-magnetic wave energy. The radar cross-section per electron,

\section{$\sigma_{\mathrm{R}}=4 \pi\left(\mathrm{q}^{2} / 4 \pi \varepsilon_{0} \mathrm{~m}_{\mathrm{e}} \mathrm{c}^{2}\right)^{2}=10^{-28} \mathrm{~m}^{2}$ is extremely small.}

The collective echo power is typically equivalent to $1 \mathrm{~cm}^{2}$ at $400 \mathrm{~km}$ range. The scattering electrons are electrostatically bound to the heavy ions, within the Debye length, giving a typical spectrum of ion motion with a Doppler shift relative to the line-of-sight bulk drift: $\left.\mathrm{V}_{\text {los }} / \mathrm{c}=\Delta \lambda / \lambda_{0}\right)$. The total width is related to the ion distribution function:

$$
\begin{gathered}
f(v)=\sqrt{\left(\frac{m}{2 \pi k T}\right)^{3}} 4 \pi v^{2} \exp \left(-\frac{m v^{2}}{2 k T}\right) \\
v_{p}=\sqrt{\frac{2 k T}{m}}
\end{gathered}
$$

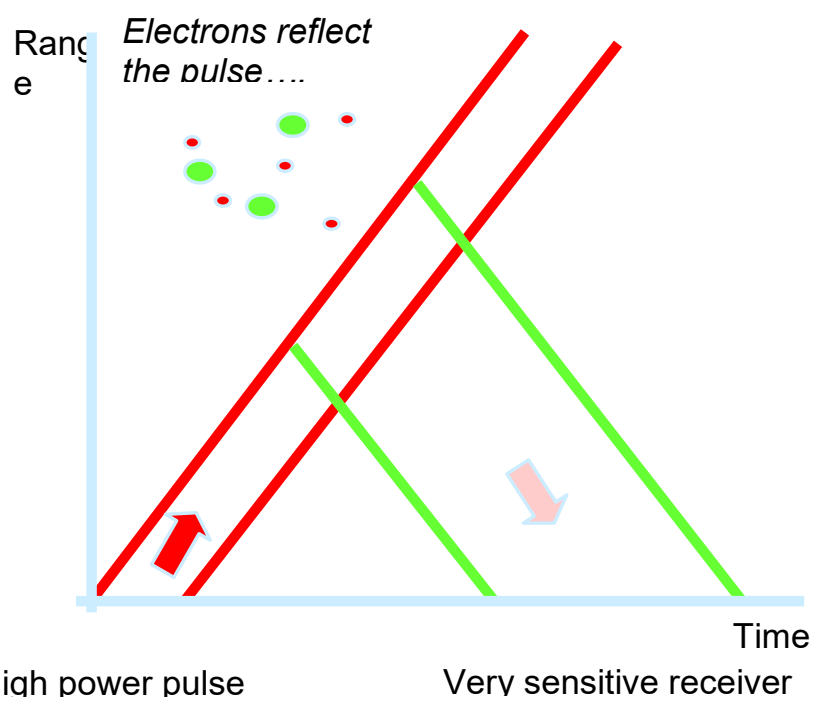

Figure 3.8.2 Range-time diagram of an incoherent scatter radar 
The process how the radar works is illustrated in Figure 3.8.2 in a so-called range/time diagram. A high radiowave of high power is transmitted, the wave goes virtually unattended through the ionosphere. At any height the electrons scatter the signal isotropically. The amount of scatter is very small compared to the transmission power, with a factor of roughly $10^{-19}$. The amount of signal received is proportional to the total area of the antenna. As the transmission is often modulated in several respects, the received signal has to go through rather complicated decoding processes. As an example, to get high range resolution one needs to transmit a relativity short pulse, but to get high spectral resolution, the pulse has to be rather long. These conflicting requirements vary for different ionospheric layers, so complicated modulation principles are often used to satisfy this. After forming the spectral components for all range interval, the signal goes into a fitting procedure and iteratively compared to theoretical spectra. As the incoherent scatter theory is so exact, the result gives a very detailed information on the ionosphere via the parameters derived. There are primarily profiles of four parameters derived: the electron density, electron and ion temperature and the ion bulk flow velocity.

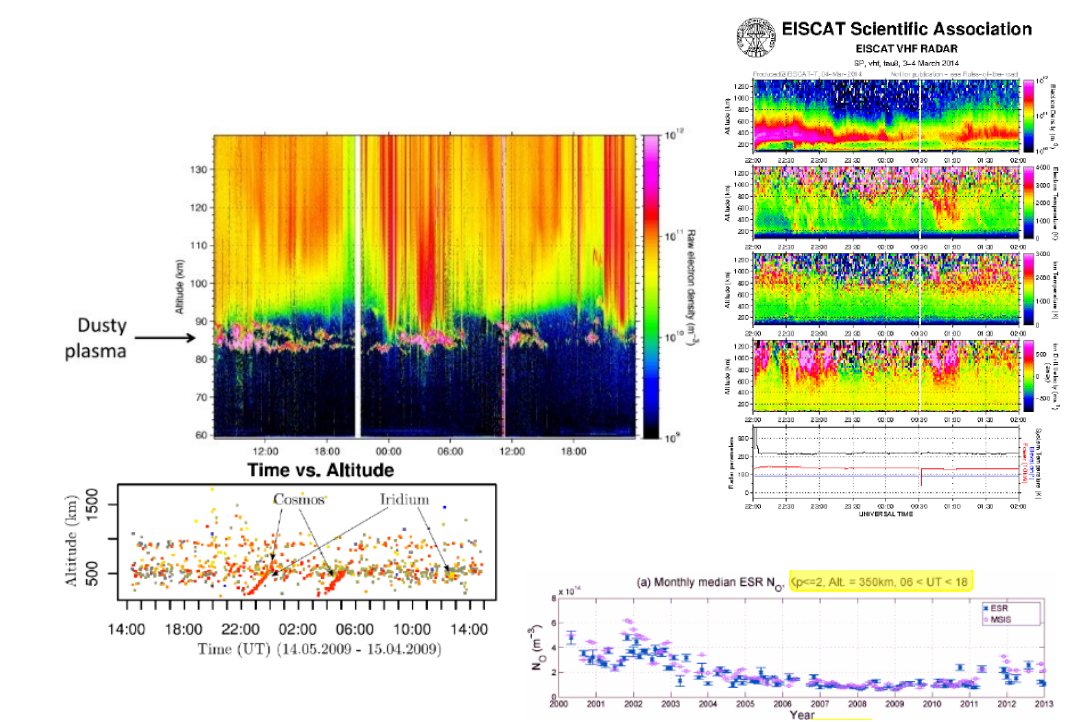

Figure 3.8.3 Examples of data and parameters that can be derived from an incoherent scatter radar

However, depending on how the analysis is done and altitude region, one can fit for other parameters such as collision frequency, ion composition, negative and cluster ions and so on. One can also set constraints on parameters or vary the integration in time and/or space to increase the accuracy. Combining the derived parameters with other data or models gives a wealth of further physical quantities 
describing ionosphere and neutral atmosphere like neutral wind, electric field or currents in various directions. Figure 3.8.3 shows different sets of parameters derived: a summertime E-region with additional coherent echoes, PMSE (polar mesospheric summer echoes); the four basic parameters over a 4-hour period; coherent echoes from space debris; and a statistical study over long-term ion temperatures.

A selection of well-designed radar pulse schemes is available to adapt the datataking routines to many particular phenomena, occurring at altitudes between about $50 \mathrm{~km}$ and more than $2000 \mathrm{~km}$. Depending on geophysical conditions, a best time resolution of less than one second and an altitude resolution of a few hundred meters can be achieved.

\subsubsection{Some cautions}

Using data from an incoherent scatter radar sometimes needs some cautions, and having a data plot is not the same as knowing what is going on. What you see depends on where and how the antenna is directed and there can be ambiguous variations in the data. For most cases, it is needed to know some physics to help making sense of the data and sometimes combining with data from other instruments will give a better context.

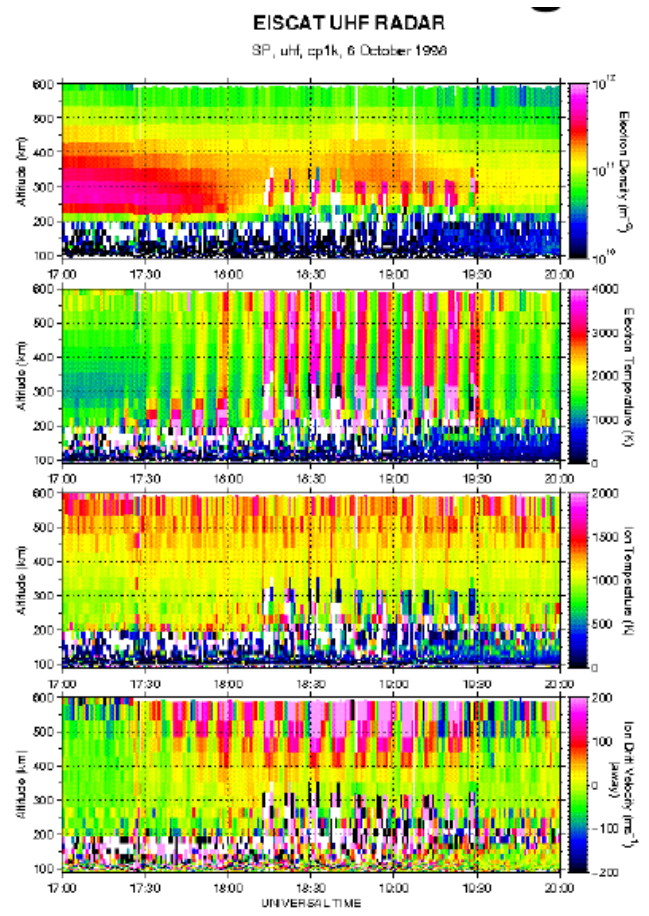




\section{Figure 3.8.4 Effects caused by ionosperic modification}

EISCAT has a co-located large HF transmitter to locally modify the ionosphere. With this, one can excite the plasma and use the ionosphere as a plasma laboratory. Depending on transmitter frequency and power, the effects cause, among others, variations in plasma density, temperature and also light emissions at heights with matching plasma frequency. These are probed by the incoherent scatter radar, and figure 3.8.4 shows an example how it can appear. These data do not show a natural behavior and should be used with care.

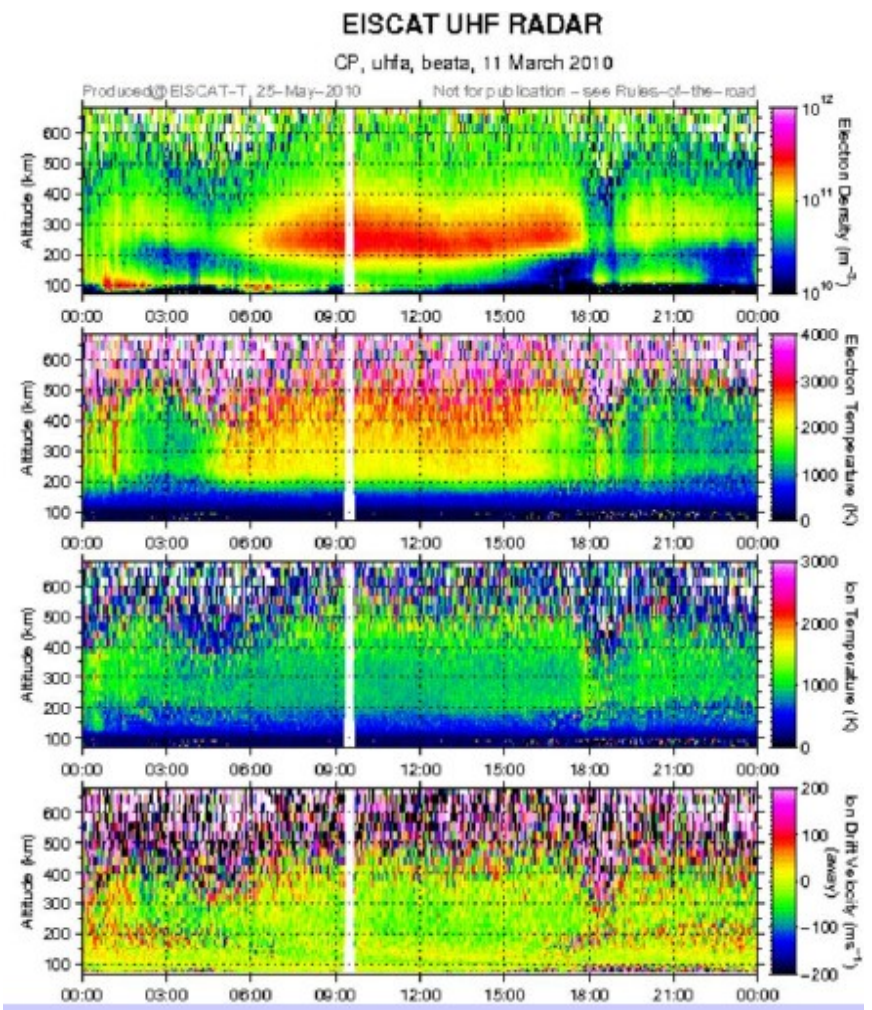

Figure 3.8.5 Field-aligned measurements over 24 hours at equinox.

Next figure (Fig. 3.8.5) shows a simple data set. The plot shows the height structure of the $\mathrm{E}$ and $\mathrm{F}$ regions, and the diurnal variation of the ionosphere is clearly visible. There is an enhancement of electron density in the E-region at morning and evening which is a signature of aurora arcs passing the radar beam. The depletion at 1800 of $\mathrm{F}$ region electron density shows the main ionospheric trough passing overhead, or as the radar follows the earth rotation, the radar is moving under the 
trough. There are also signatures of tides with different periods as well as nighttime $\mathrm{F}$ region density enhancements caused by transport from the dayside due to ionospheric convection.
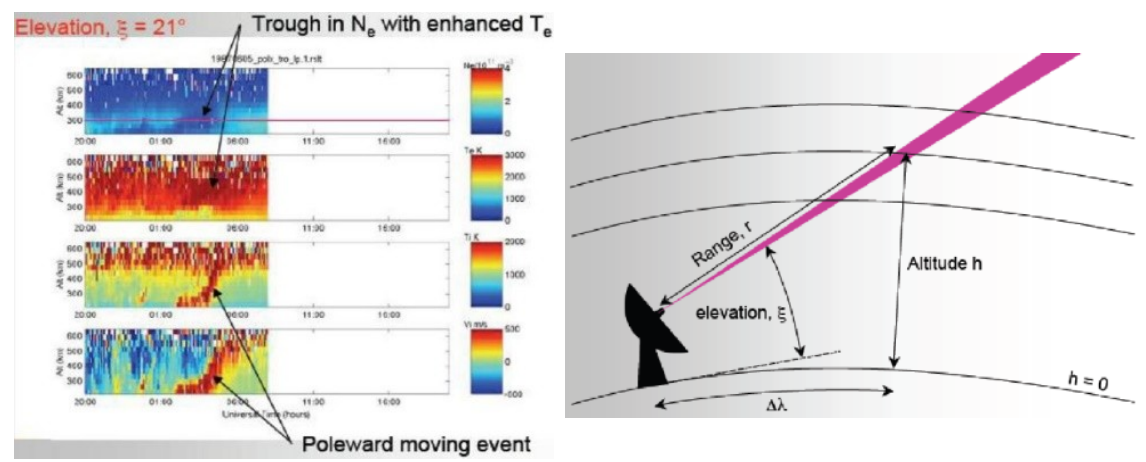

Figure 3.8.6 Measurements along a low elevation direction.

One should always remember that the data can depend strongly on the design of the experiment. The ISR technique can be prone to both systematic and random errors and if the data look unusual - be suspicious! Always try to eliminate possible sources of error before publishing a new discovery. One example is illustrated in figure 3.8.6, where structure appears to start at low altitudes and moving upward. This is not true. The antenna is pointing northward at low elevation, and as the latitude increases, so does the altitude of the radar beam. A field-aligned structure moving north will thus show up in the plot as increased altitude.

\subsubsection{Coherent scatter radars}

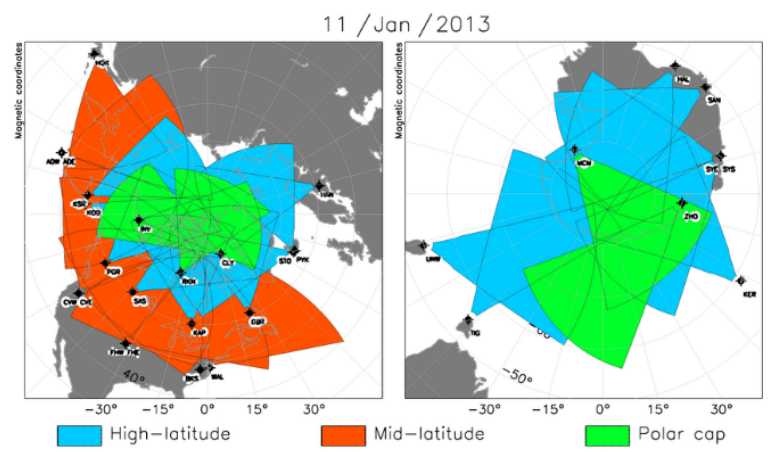

Figure 3.8.7 Existing and planned coverage of the SuperDARN network. 
One example of coherent radar is the SuperDARN radar. SuperDARN is global network of ionospheric radars working at $\mathrm{HF}$ frequencies, 8-20 $\mathrm{MHz}$. The parameters these provide are line of sight velocity, or ExB drifts in the F-region, spectral width and backscatter power. Due to the BraggScatter condition, signal is only backscattered when beam is perpendicular to B-field and this is from density structures along the B-field. The radars have large field of views, and give global convection maps. As the radars are global, also inter-hemispheric studies can be made. Figure 3.8.7 shows current and planned SuperDARN radars.

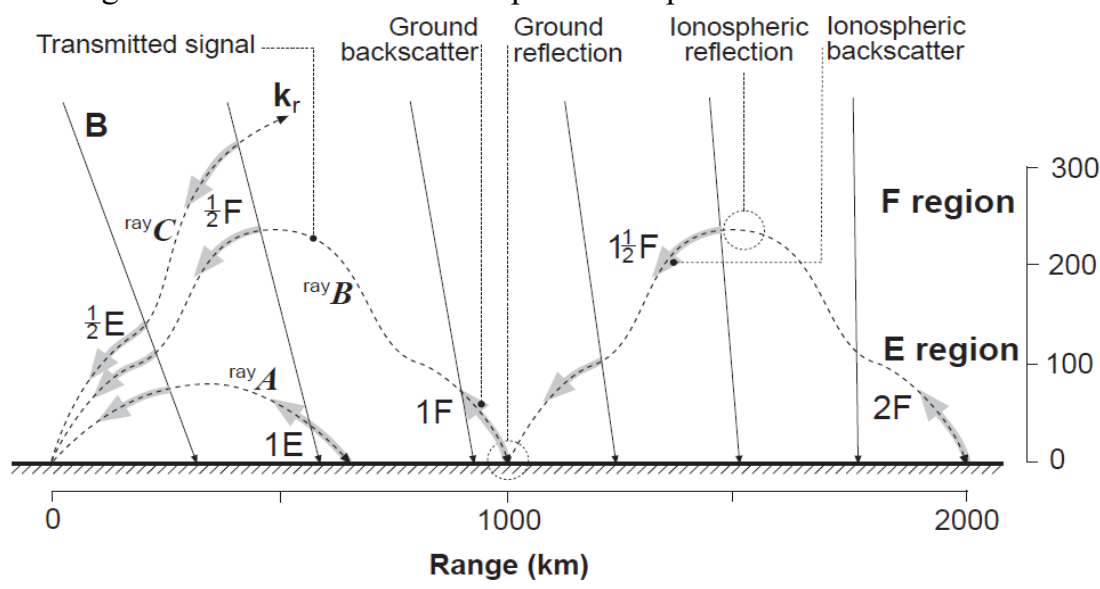

Figure 3.8.8. HF radar beam refractions and reflections in the ionosphere

As the radar beams get bent in the ionosphere, the beams might go through several bounces between the ionosphere and ground. Figure 3.8.8 illustrates this, showing how a beam of the right frequency is bent down to the ground and up again, giving reflection at larger distance. The ground reflection will also give an echo, but this can be easily recognized from the zero Doppler and spectral width. The signal can undergo several hops, extending the measurement ranges considerably.
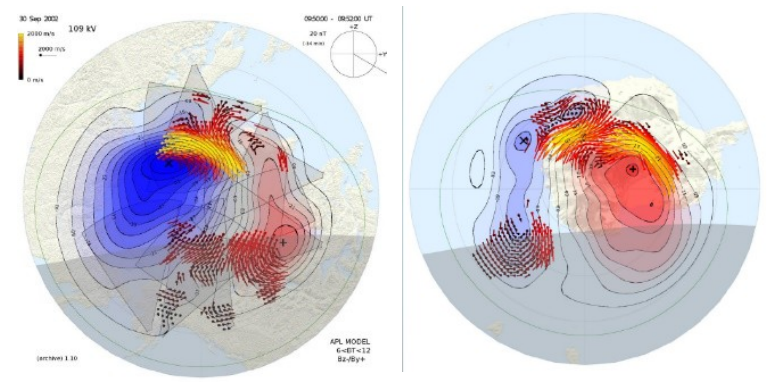

Figure 3.8.9 Global maps of ionospheric convection fitted to SuperDARN drift measurements. 
Combining data from two or more radars, global convection drifts can be derived. Figure 3.8.9 shows SuperDARN measurements of ion drifts from both hemispheres being fitted to a convection model. This is one of the regular products from the network.
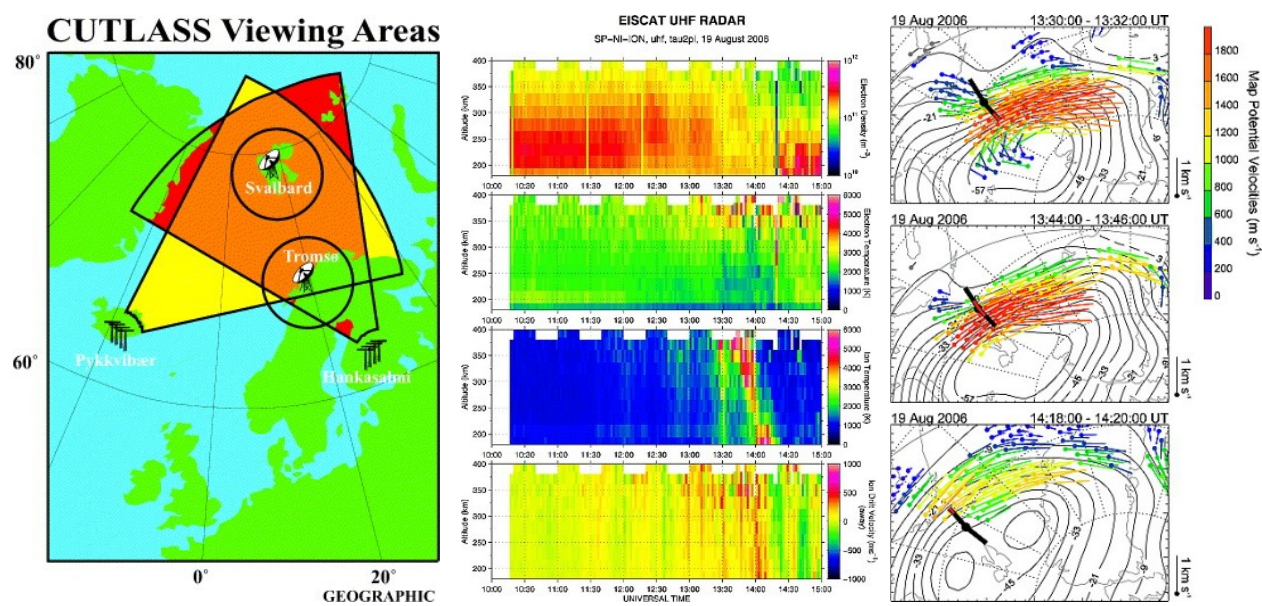

Figure 3.8.10 Combined measurements of incoherent and coherent radars

Many studies combine the data from both coherent and incoherent scatter radars. One example below (Fig. 3.8.10) shows the Cutlass SuperDARN pair and EISCAT in a combined effort. The region of high ion temperatures sweeping over the EISCAT data is well explained by the fast plasma flow measured by SuperDARN. 



\title{
4. ESPAS interoperability
}

\author{
Anna Belehaki ${ }^{1}$, Natalia Manola ${ }^{2}$, Mike Hapgood ${ }^{3}$ \\ 1. National Observatory of Athens, Greece \\ 2. ATHENA Research Center, Greece \\ 3. RAL Space, Rutherford Appleton Laboratory, STFC, UK
}

Through the ESPAS portal, the user can have access to a large number of repositories with heterogeneous data from ground and space, in situ and remote sensors. The user can perform searches for observations using specific criteria (e.g. time, instrument) and then download data files or data values.

From its inception, ESPAS was designed to meet the following requirements:

- Integrate heterogeneous data from multiple providers, ranging from groundbased observations acquired with multiple instruments to data from spaceborne sensors. To do so, specific policies were established on identification, access, availability, quality, sharing and re-use of the data (or metadata) of the participating content providers.

- Enable metadata/data search and access across multiple data sources through a central platform. This was made possible through the establishment of a variety of workflows (data flows) initiated on the ESPAS platform.

- Provide value-added services to explore metadata, visualize or manipulate the integrated data, and eventually mine metadata.

- Serve as a test-bed for proposed methodologies and standards for validation and optimization of metadata of a specific data collection.

- Allow for extensive testing through several test and use cases, designed to serve the needs of the wide and interdisciplinary user and provider communities for computationally intense science carried out in a highly distributed data environment.

- Integrate into the wider European scientific infrastructures. To do so, it carries on and extends the policies and procedures issued at its participating data providers on data openness, quality, identification, etc.

ESPAS uses and adapts well-established techniques from related data eInfrastructures disciplines and from the Digital Libraries domain to provide the required semantic integration of the participating data sources. Main elements towards building interoperability are: the data model, which is compatible with and encapsulates all underlying data formats; the definition and employment of XML schemas for metadata exchange format; the domain-specific vocabularies used to describe the near-earth science data and phenomena; the services (wrappers) installed at the data nodes to support metadata publishing and data exposition; the 
central coordinating platform that showcases the metadata aggregation and data access through a portal that provides tools for data registration and validation and customized search workflows for more complex queries. An illustration of ESPAS architecture is given in Figure 4.1. The ESPAS platform adopts the principles of the Service Oriented Architecture (SOA), based on the D-NET system (Manghi et al., 2014), and it is structured in the following layers:

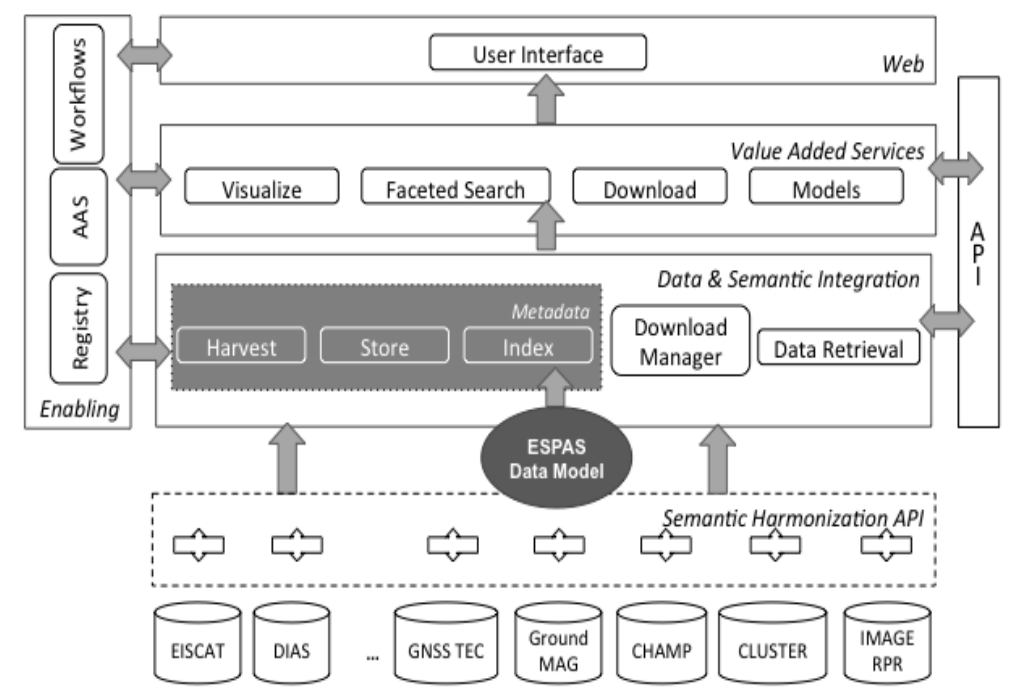

Figure 4.1: A high level representation of the ESPAS architecture

Enabling Layer: provides the necessary components that glue, manage and organize all the services in an SOA. It implements service registration and a notification based communication system, making the overall system extensible and extendible.

Data Management Layer: focuses on the metadata harvesting and the basic data management services of the ESPAS system: storage, database, index.

Access and Value-added Services Layers: include advanced search, statistics capabilities, and enable the development of models and visualizations tools.

Web Layer: provides the User Interface service, i.e., the ESPAS portal.

\section{Reference}

Manghi P. et al., (2014) "The D-NET software toolkit: A framework for the realization, maintenance, and operation of aggregative infrastructures", Program: electronic library and information systems, Vol. 48 Issue: 4, pp.322 - 354 


\title{
4.1 THE ESPAS DATA MODEL
}

\author{
Sarah James ${ }^{1}$, Spiros Ventouras ${ }^{1}$ and Anna Charisi ${ }^{2}$
}

\begin{abstract}
The ESPAS Data Model models the data description and so makes heterogeneous data sets discoverable through the ESPAS system. The concepts defined and used in the data model are described and examples of their application are given.
\end{abstract}

\subsubsection{Introduction}

In order for scientific data to be discoverable in ESPAS and to be comprehensible and valuable to the end user, those data must be fully described so that it is clear what they are and how they were created. This description of the data is called metadata.

The ESPAS Data Model allows us to have a common understanding of the metadata content and structure, and provides for a computer readable schema. The Data Model defines a series of concepts which allow a data provider to answer key questions about their data.

The ESPAS Data Model is built strictly and entirely on the 19100 series of Geographic Information Standards, in particular the Observations and Measurements (O \& M) standard, ISO 19156.

\subsubsection{Data Model Overview}

A high level overview of the ESPAS Data Model concepts and their relationships is shown here.

\footnotetext{
${ }^{1}$ RAL Space, Science and Technology Research Council, Rutherford Appleton Laboratory, Didcot, OX11 0QX, UK

2 National Observatory of Athens, Athens, Greece
} 


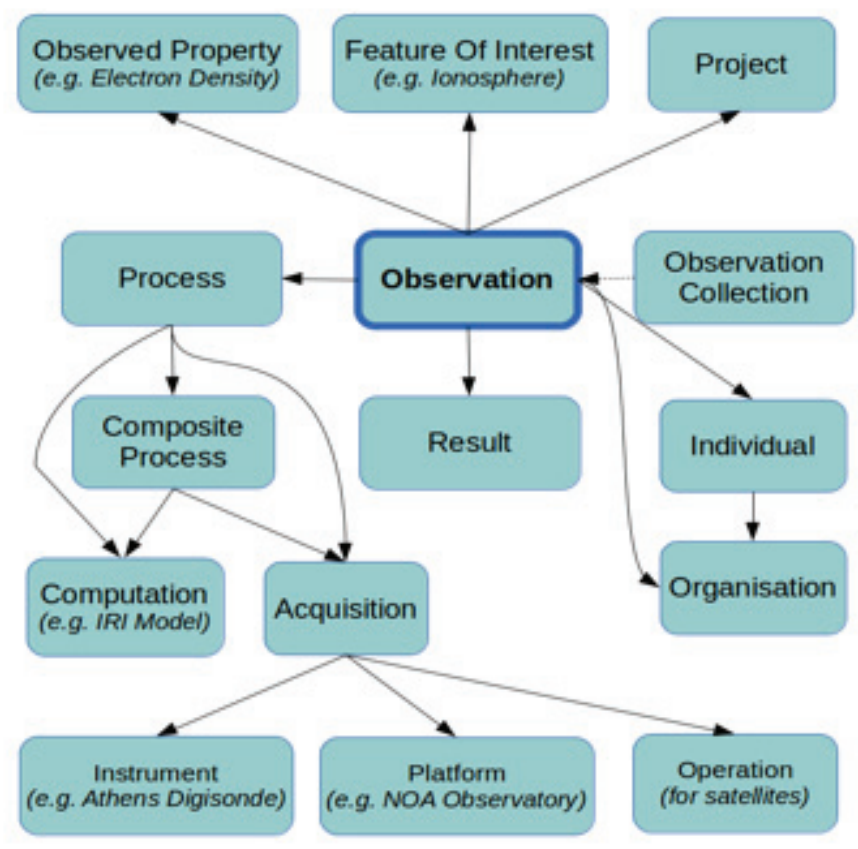

\subsubsection{ESPAS Data Model - Key Concepts}

\subsection{Observation}

The central concept of the ESPAS Data Model is that of the observation. This is taken from the 19156 Observations and Measurements standard. The observation is the act that results in the estimation of the value of a property of a feature of interest. That is the act that results in the data (the observation result). It uses a process to get the data, which might make use of a sensor to take measurements, or an algorithm, or a process chain of more than one of these. An observation is associated with a discrete time instant or period.

\subsection{Feature of Interest}

A feature of interest is a real world object, a feature, carrying the properties which are under observation. The feature of interest is the subject of the observation.

\subsection{Observed Property}

The observed property is a phenomenon associated with the feature of interest for which the observation result gives an estimate of its value. 


\subsection{Observation Result}

The observation result is the value of the observed property obtained by the act of observation.

\subsection{Process}

The process is a designated procedure used to generate the result. A procedure can have one or more components. The components can be acquisitions or computations. An acquisition process interacts with the feature of interest by means of a sensor. A computation process is a pure computation with no instrument involved, for example a model or processing software.

The concept of a composite process describes a process chain of acquisitions, computations or both.

\subsubsection{Further Data Model Concepts}

An instrument is defined as a measuring instrument or sensor that interacts with the feature of interest to estimate a value for an observed property.

A platform is defined as the object on which an instrument is located. It can be a stationary observatory or a moving platform such as a spacecraft. The concept of an operation defines the movement of non-stationary platforms, for example the orbit of a spacecraft platform.

A project is defined as an identifiable activity or project intended to achieve a set of objectives in order to produce datasets.

An observation collection can be any existing set of observations. An observation collection shares a set of criteria, for example they could be produced by the same project, or arise from the same instrument.

The definition of an organisation is a body or institute or organisation that has a particular role associated with a real world object. An organisation can be associated with many sorts of ESPAS objects, for example with instruments, projects or collections. An organisation can be identified as having various roles, for example the role of data provider, or operator. Likewise, the Data Model defines an individual as a person who has a responsibility regarding a real world object. Like an organisation, an individual can be associated with many sorts of ESPAS objects, and an individual can be identified as having various roles.

\subsubsection{Examples}

Let's take a look at some examples to illustrate how the ESPAS Data Model can be used to describe some data.

\subsubsection{A Very Simple Example}

The temperature in a room is measured. "Temperature in the room" is our observation. The procedure is an acquisition using an instrument, a thermometer. The 
result is, say, $20^{\circ} \mathrm{C}$.

\subsubsection{An Example with a Composite Process}

This example looks at how the description of data plots from a project using an instrument and some software to generate results can be modelled in the ESPAS Data Model.

The actual data, the observation result, that we need to describe is a 24-hour plot which plots three things: the critical frequency of the F2 layer (foF2) of the ionosphere as measured by the Athens Digisonde instrument and processed from the raw data with ARTIST software; the same observed property, foF2, as computed by a model called SIRM; and the minimum frequency of reflections from the ionosphere as measured by the Athens Digisonde instrument and processed from the raw data with ARTIST software.

Here are the data described in terms of the ESPAS Data Model.

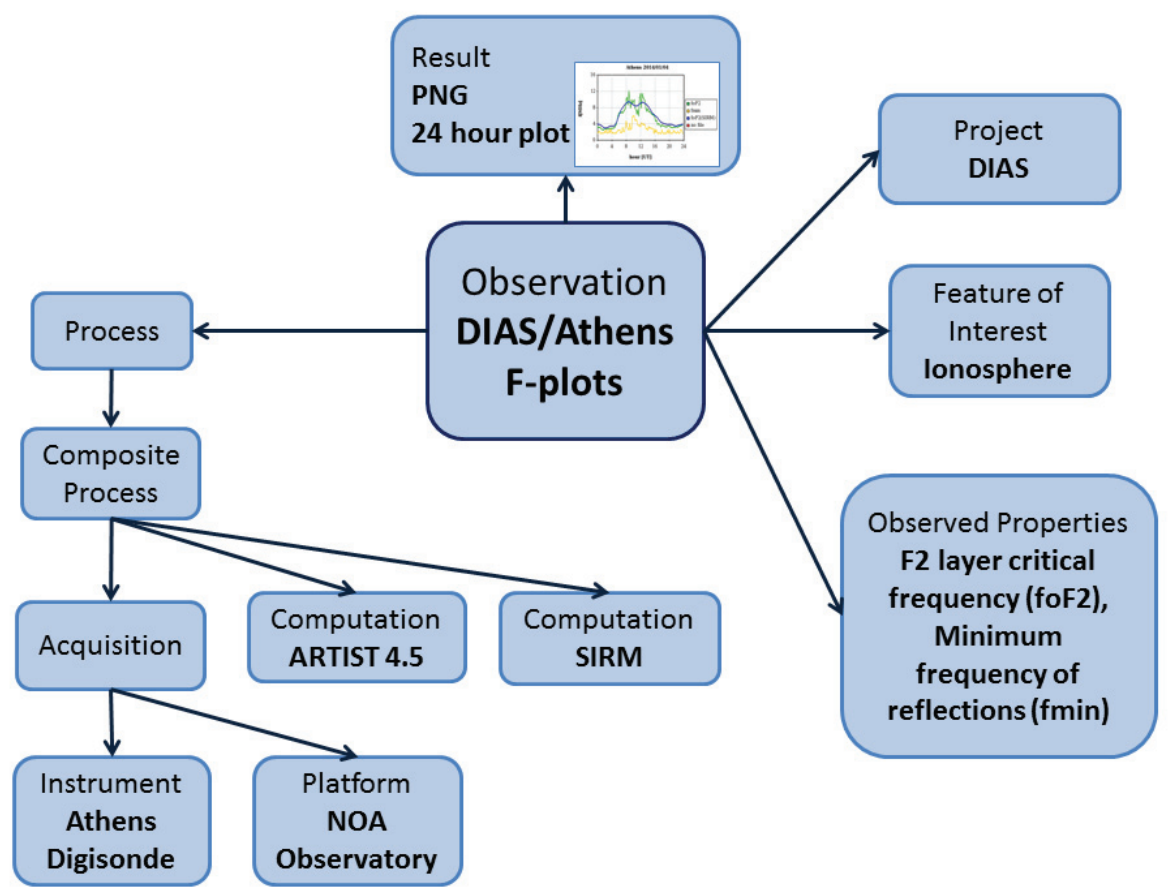

\subsubsection{Making Use of the Data Model}

\subsubsection{Realised in XML}

In practice metadata in ESPAS is realised in XML format records that implement the ESPAS Data Model. Data providers creating ESPAS metadata can make 
use of a web based data registration tool to generate the necessary XML records through a series of web forms.

\subsubsection{Controlled Vocabulary}

The ESPAS Data Model provides a means to structure the data description that is not specific to the ESPAS domain. It must be used together with vocabularies specific to the science domain to provide an interoperable, consistent means to describe data sets. The ESPAS Ontology has been developed to provide the required vocabularies and is described in its own right elsewhere in this book.

\subsubsection{How ESPAS Uses the Data Model}

The flexible ESPAS Data Model allows the data user to search ESPAS for data in many ways: the time period of the data, the phenomenon described by the data, the data's observed properties, the instrument or computation used to get the data, the location of an instrument, or the data collection.

Once the user has identified and requested data for download, the ESPAS system is able to use the structured Data Model of metadata to identify how to download the data from the data provider. 



\section{Appendix: 2}

\section{Controlled vocabularies used in ESPAS Data Model}

Many of the properties of the concepts of ESPAS Data Model use values from controlled vocabularies. A list of these controlled vocabularies used in ESPAS Data Model is given, along with a short definition:

Component: For vector properties, it describes which of the three components is provided in the data only in those cases when observation does not specify the vector property in full. Typical components are X, Y, Z. The Component has to be accompanied by a suitable description of the Coordinate Reference System (Crs).

Compressed Representation: Describes the formalism of compressed representation of voluminous or complex 3D, 2D, and 1D data. Typical examples are spherical harmonics for $2 \mathrm{D}$ maps on the sphere, truncated Fourier transforms (harmonics) for diurnal time series, Empirical Orthogonal Functions (EOF).

Crs: Corresponds to the Coordinate Reference Systems (e.g. GSE, GSM...) used to describe a vector Component (observed property definition), the location of a Platform and the geographic extent of an Observation.

Dimensionality Instance: Dimensionality is a compact description of the domain $\mathrm{X}$ spanned by the independent (input) variables $\mathrm{x} 1, \mathrm{x} 2, \mathrm{x} 3 \ldots$ of the Observation result (output dependent variable $\mathrm{Y}$ ):

$$
\mathrm{Y}=f(\mathrm{x} 1, \mathrm{x} 2, \mathrm{x} 3 \ldots)
$$

The independent variables $\mathrm{x} 1, \mathrm{x} 2, \mathrm{x} 3 \ldots$ are tested in the course of the Observation to acquire values of the dependent variable Y. For example, an Observed Property "NeutralWindVelocity" is a vector field variable with a natural presentation as a Vector (magnitude and direction) defined in 3D space (latitude, longitude, altitude).

The Dimensionality Instance describes the Single instance of the acquired $\mathrm{Y}$ values of the observed property in time (time is not included in the list of independent variables) (e.g.

1D.point, 1D.Profile, 2D.Map, 2D.image).

Dimensionality Timeline: Dimensionality is a compact description of the domain $\mathrm{X}$ spanned by the independent (input) variables $\mathrm{x} 1, \mathrm{x} 2, \mathrm{x} 3 \ldots$ of the Observation result (output dependent variable $\mathrm{Y}$ ):

$$
\mathrm{Y}=f(\mathrm{x} 1, \mathrm{x} 2, \mathrm{x} 3 \ldots)
$$

The independent variables $\mathrm{x} 1, \mathrm{x} 2, \mathrm{x} 3 \ldots$ are tested in the course of the Observation to acquire values of the dependent variable Y. For example, an Observed Property "NeutralWindVelocity" is a vector field variable with a natural presentation as a Vector (magnitude and direction) defined in 3D space (latitude, longitude, altitude). The Dimensionality Timeline describes the timeline of 
the acquired $\mathrm{Y}$ values of the observed property (time is one of the independent variables) (e.g. Timeseries, Animation).

Licence: It is the element of an agreement describing the terms under which data registered in ESPAS can be used.

Platform Type: Describes the type of a Platform (e.g. ground-based station, satellite).

Projection: For vector properties, it describes a plane or a line on which the vector projection is observed by the Instrument. The Projection is provided in the data only in those cases when Observation does not specify the vector property in full. Typical projections are horizontal, line of sight, orbital, perpendicular. The Projection has to be accompanied by a suitable description of the Coordinate Reference System (crs).

Related Observation Role: Describes the role of the related Observation (e.g. location information...).

Related Party Role: Describes the role (owner, principal investigator, researcher, etc.) of a related party for an object (Project, Observation Collection, Instrument, etc.).

Result Accumulation: Describes the frequency with which additions are/were made to the Observation's result (e.g. daily, monthly, hourly...).

Result Data Format: Describes the data format of a resulting file of an Observation.

Service Function: Describes the function of a service offered by a Data Provider at the Observation Result level. So, it specifies whether the Observation Result files (data files) are available for download or for view only from the end user.

Status: Describes the status of a Project, an Observation, an Operation of a Platform (e.g. historical, ongoing...).

Unit: Describes the unit of the Observed Property as measured in a specific process (e.g. Km, MHz).

For a detailed view of the vocabularies, one should visit the ESPAS portal help pages:

Browse $\rightarrow$ ESPAS Supplementary Vocabularies of the ESPAS Portal (https://www.espas-fp7.eu/portal/) 


\subsection{ESPAS Services}

Anna Charisi (1), Antonis Lebesis (2), Natalia Manola (2)

(1) National and Kapodistrian University of Athens, Greece

(2) ATHENA Research Center, Greece

To facilitate access to heterogeneous data offered by data providers, a set of basic supporting services has been defined and implemented by ESPAS. Each of these services essentially implements a client-server protocol, with the server part residing at the data provider side (in the Semantic Harmonization Layer, bundled within the ESPAS wrapper) and the client side at the ESPAS platform Data Management Layer:

An OGC compliant Catalogue Service (CSW), which supports the identification of ESPAS resources offered by each data provider.

A Download Service, that facilitates the download of data bundles in terms of data collections offered by each provider.

An OGC Compliant Sensor Observation Service (SOS), which facilitates the collection of selected data parameters or values from the observations of each data provider.

The visualization of the internal workflows for different user queries is given in Figure 4.2.1.

\subsubsection{Harvesting metadata : OGC Catalogue Service}

OGC Web services (OWS) are the prevailing types of services in the geospatial application domain (Doyle et al., 2001). Based on the OGC Catalogue Service for the Web (CSW), i.e., a profile of the catalogue service with the goal to expose the catalogue functionality over the web (Nebert et al., 2007), ESPAS has partially implemented the specified CSW interface specification to accommodate the getRecords operation. Through the getRecords operation, clients are able to submit queries for the discovery of metadata records for each of the major metadata entities specified by the ESPAS model. Constraints on the expected results are expressed as Contextual Query Language - CQL queries over a list of specific properties, which include the type and the modification date of the expected metadata entity. The supported binding includes HTTP Key Value Pair (KVPs). 


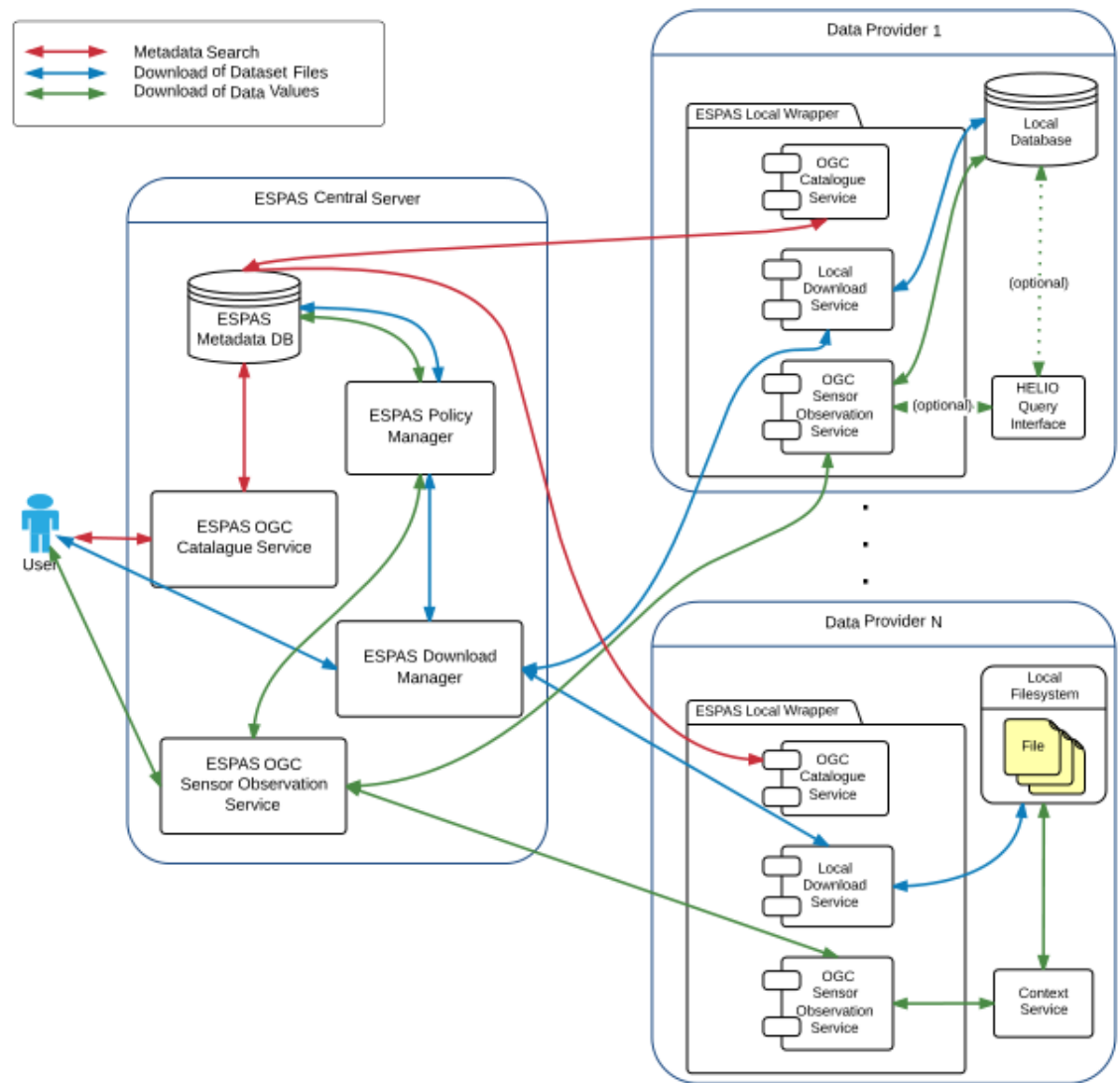

Figure 4.2.1.: A visualization of the internal workflows for different user queries

\subsubsection{Retrieving datasets: Download Service}

The download service is an ESPAS proprietary service that enables ESPAS clients to retrieve data collections in formats defined by the data providers and specified in the metadata descriptions. It is implemented on top of basic D-NET services (Manghi et al., 2014), which provide subscribe-notify and database interaction operations, as well as on other services that facilitate policy enforcement functionality. The download service operates in an asynchronous manner so as to avoid blocking clients from performing other activities while the download request 
is submitted and processed by the associated data providers. In terms of architecture, the download service may be logically split into three distinct components, namely the Central Download Manager, local Download Service and Policy Manager. The Central Download Manager component is responsible for checking conformance of each request against the policies defined in the Policy Manager and coordinating the interaction with the local Download Services. The Policy Manager is an XACML v3.0 (Rissanen, 2013) based policy server, responsible for maintaining the policies defined by the data providers and validating each request against related policies. Local Download Services are deployed on each provider and are responsible for processing the download requests related to each distinct provider.

\subsubsection{Retrieving data values: OGC Sensor Observation Service}

One of the well-known types of OGC Web services is the Sensor Observation Service (SOS). SOS is a web service that is used to query real-time sensor data and sensor data time series and is part of the Sensor Web vision. The offered sensor data comprises descriptions of sensors themselves, which are encoded in the Sensor Model Language (SensorML) and the measured values in the Observations and Measurements (O\&M) encoding format (Cox, 2006).

The preliminary implementation offered by ESPAS is supporting partially the specified SOS service interface (Bröring et al., 2012). It includes a customized implementation of the getResult and getResultTemplate operations, which facilitate the retrieval of specific observed property values and value templates respectively, for observations performed by data providers. Among the set of optional query criteria defined for the getResult operation, the provided implementation supports only time-related ones, whereas in terms of bindings only HTTP Key Value Pair (KVPs) based requests.

Moreover, the actual implementation requires a layer that retrieves data from the data providers, whether this might reside in databases or files. Using the HELIO approach, and bundled in the ESPAS wrapper, the ESPAS implementation of the SOS service is able to do one of the following through the use of generic services that rely on configuration: convert standard SQL queries, HELIO-compliant databases, or retrieve from files through the CSX generic services.

\section{References}

Bröring A. et al., OGC Sensor Observation Service Interface Standard v2.0.0, Open Geospatial Consortium Standard, OGC 12-006, 2012 
Cox, Simon, "Observations and measurements." Open Geospatial Consortium Best Practices Document. OGC, 2006.

Doyle A. et al., "Introduction to OGC Web Services," OGC- Open Geospatial Consortium, OGC White Paper 2001.

Manghi P. et al., (2014) "The D-NET software toolkit: A framework for the realization, maintenance, and operation of aggregative infrastructures", Program: electronic library and information systems, Vol. 48 Issue: 4, pp.322 - 354

Nebert D. et al., OpenGIS ${ }^{\circledR}$ Catalogue Services Specification v2.0.2, Open Geospatial Consortium Standard, OGC 07-006r1, 2007

Rissanen, E. (2013). eXtensible Access Control Markup Language (XACML) v3.0. OASIS standard, Available at: http://docs.oasis-open.org/ xacml/3.0/xacml-3.0-corespec-en.html. 


\title{
5. ESPAS functionalities for the end- user
}

\author{
Anna Belehaki ${ }^{1}$, Anna Charisi ${ }^{2}$, Sarah James ${ }^{3}$, Mike Hapgood ${ }^{3}$, \\ Spiros Ventouras ${ }^{3}$, Ivan Galkin ${ }^{4}$, Antonis Lembesis ${ }^{5}$, Jens Berdermann ${ }^{6}$ \\ 1. National Observatory of Athens, Greece \\ 2. National and Kapodistrian University of Athens, Greece \\ 3. RAL Space, STFC Rutherford Appleton Laboratory, UK \\ 4. University of Massachusetts Lowell, USA \\ 5. ATHENA Research Center, Greece \\ 6. Deutsches Zentrum für Luft- und Raumfahrt e.V., Germany
}

The basic functionalities provided by ESPAS can be grouped into five main categories:

1. Metadata search for observations that satisfy the following specific criteria:

- Time period: the time period when the observations were acquired

- Assets: the Instruments and Models that were used for the generation of the observations

- Observed properties: the observed properties that were measured in the observations

- Observation collections: the collections that the observations belong to

- Location: the location of the platforms (ground-based observatories or satellites) on which the instruments are mounted and used for the generation of the observations

2. Download of data files: The result of a metadata search is a list of the observation collections (that contain the observations) that satisfy the query criteria. Then, the user can proceed to download data files residing in the ESPAS data providers nodes. The data files are provided in the original format as defined by each ESPAS data provider.

3. Download of data values (extracted parameters): Following the metadata search, the user can request to download data values of specific observed properties, as extracted from the data files. A subset of the observed properties is available for download as extracted data values. After a data value download request, the user gets as a result a text file (csv or XML format) that contains the values of the selected observed properties. 
4. Plotting tools: Downloaded data values can be plotted using either the quick plot of the ESPAS platform or the most advanced IDL-based plotting tool for OGC data files.

5. Registration and validation of data: Data collections from space missions and ground-based instruments can be registered in ESPAS following the standards of the ESPAS data model and domain ontology. The service is available to the scientific community upon request.

The search for metadata is the fundamental service based on which the user can proceed to the data queries. This service is available to all and no registration is required. However, in order for the user to proceed with the use of more advanced functionalities provided by the system, registration is required. The search for metadata is based on the execution of workflows whose design is dynamic and depends on the user needs. The user can start its query for any of the criteria: time, asset, observed properties or observed collections, and finish its workflow design at any criterion. If for example it is supposed that the chosen criterion is "observed properties", a list of all the observed properties (in alphabetical order) that are associated with observations appears on the right side of the screen (see Figure 5.1.a). The filters (Phenomenon, Measurand, Qualifier) which appear on the left side serve to narrow down or facilitate the selection of observed properties presented in the right part. A hierarchical view of each filter is provided. The filters provide an alternative search option based on the ESPAS space physics ontology definition. It should be noted that the "OR" relationship is implied among the options of the same filter, and an "AND" relationship is implied between the filters. If one selects the "ion" and "electron" as phenomenon (see Figure 5.1.b), then the observed properties with phenomenon "ion" OR "electron" are presented on the right. A high level query could be represented as: phenomenon="ion" OR phenomenon="electron". However, if also the "density" is selected at the "measurand" filter, then the observed properties with phenomenon "ion" OR "electron" AND measurand equal to "density" are presented. A high level query could be represented as: measurand="density" AND (phenomenon="ion" OR phenomenon="electron").

Contrary to the progressive search described above which is progressive and non-ordered, the Metadata Search by Location is ordered. In this case, the search is using as criteria the time period (up to a maximum of 30 days) and the location of the instrument (ground-based observatories and/or satellites).

In the framework of the ESPAS project, various kinds of possible Value Added Services (VAS) have been discussed in order to support the user in identifying interesting time periods or via additional high-level operations on the data. In general, one can identify two fundamental different types of value-added services depending on the availability of real data or only metadata within a data infrastructure system. Both VAS on meta-data level, like data annotation, 
dissemination or information services, as well as VAS based on real time data, like validation, comparison, scaling or combining services, can significantly improve the user benefit and therefore the usage of the whole system.

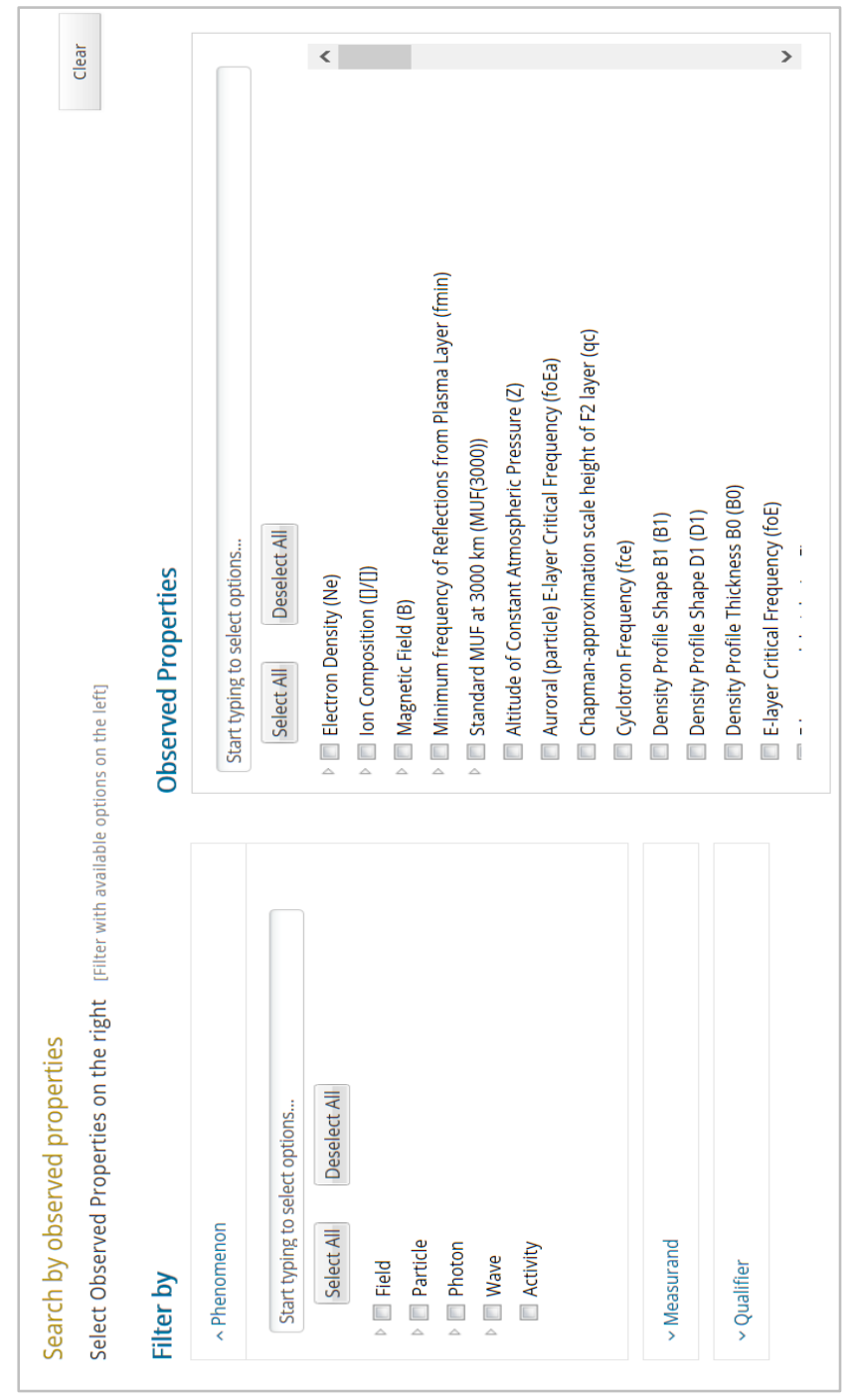

Figure 5.1.a: A screenshot from the ESPAS Platform User Interface showing the response of the "Metadata search query" when the user is searching by "Observed Properties". Without any further filtering. 


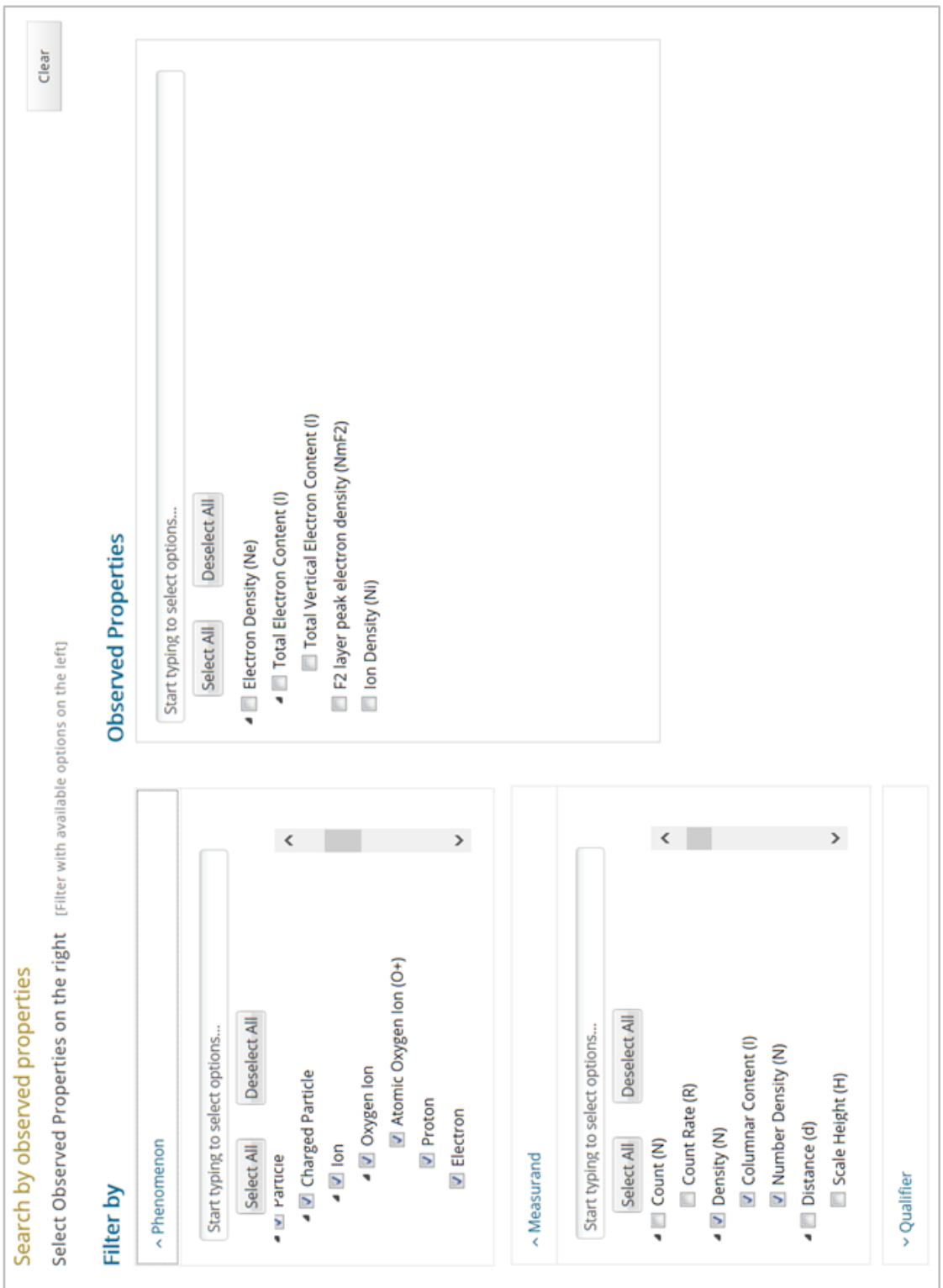

Figure 5.1.b: A screenshot from the ESPAS Platform User Interface showing the response of the "Metadata search query" when the user is searching by "Observed Properties", but further filtered by "Phenomenon" and "Measurand" components. 
However, two VAS types are based on entirely different system requirements. VAS using metadata stored within the ESPAS system can be accessed very fast and are stable since no further dependencies on data provider platforms with special access requirements and/or safety policies have to be taken into account. The complexity of VAS operations using metadata is low and once established, easy to maintain, but these services are limited in their capabilities.

Value Added Services based on real data are flexible and allow a broad range of possible supporting operations, but are difficult to maintain if the data operations are executed remotely at the different external data provider sites via the ESPAS infrastructure system as interface. This remote access will be especially slow when applied on large datasets due to time-consuming search operations inside the data files. A solution could be to circumvent the time-consuming operations at provider sites by storing the needed data temporally within the ESPAS system. However, this would increase storage and maintenance cost with the consequence to needlessly complicate a provision of the ESPAS service after the project lifetime. Therefore, the consortium discussed several possibilities to realize real time VAS within ESPAS with minimal maintenance and service efforts. The following two preferred concepts have been identified and demonstrated within the project. One concept is to retain the measuring values at least partially within a meta-data format using the sensor observation service (SOS), which allows to query real-time sensor data. Another concept demonstrated here in detail is a web-application tool written in JavaScript, which allows to run the service client based and is therefore independent from system requirements. In the ESPAS VAS demonstrator "TEC Time Series Plotter (TTSP)", a combination of extraction, scaling and comparison service is given using real data provided via the ESPAS platform.

The TTSP is a demonstrator for an ESPAS value-added service generated by the ESPAS data provider DLR. It allows to plot, analyse and download the time series of Total Electron Content (TEC) values and the corresponding range errors for different radio frequencies at selected locations worldwide for a given time period from 2D TEC maps provided by SWACI. The temporal resolution of the plotted time series can be selected too, but depends on the maximal temporal resolution of the data downloaded via ESPAS. The path to the downloaded data has to be given in the data location field. One click at the progress bar starts the processor. The progress of the VAS data processing is visible via the progress bar. The generated time series plots can be downloaded as PNG and the corresponding data in JSON data file format.

Figure 5.2. shows the graphical interface of the demonstrator, where the GPS L2 frequency range error at different locations during the time period from $23^{\text {rd }}$ February till $1^{\text {st }}$ March 2014 is plotted in 5 minutes resolution. The time series shows the benefit of the VAS for data analysis. It supports the detection of space weather effects since the latitude dependent influence of a moderate geomagnetic storm on the ionosphere during $27-28^{\text {th }}$ February is clearly visible. 


\section{• ерРар TEC Time Series Plotter A Deutuches Zentrum An ESPAS valustrelitz.}

Which locations on Earth do you want to analyse?

Simply add some locations to your time series plot by clicking the map or by entering the coordinates or address in the form below the map. You can remove locations by using a right click on the previously selected locations or delete all locations al once by just using the appropriate button below the map. Feel free to readjust the color of the selected grid cells, which will correspond to the color in the time series plot, by clicking muttiple times on the same cell.
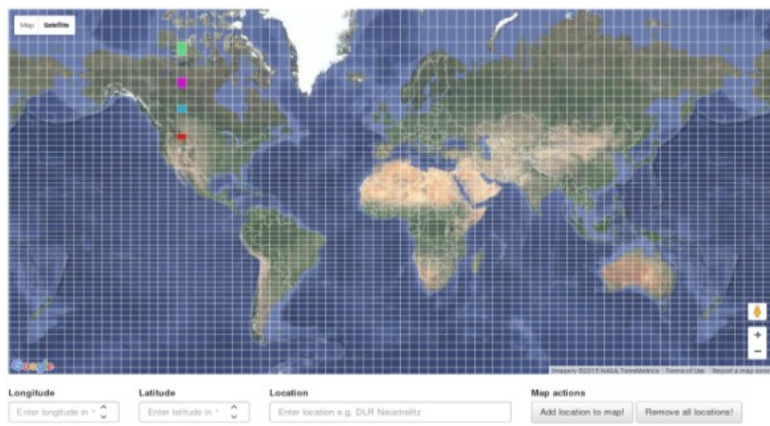

Which time period, time interval or GNSS frequency do you want to analyse?

Please specily the start and the end time of the time series according to your downloaded ESPAS data. You can also limit the data processing time by setting a time interval of interest. Select a GNSS frequency, if you are interested in the corresponding range error instead of TEC.

Stert Time

$$
\text { End Tin }
$$
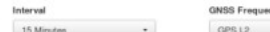

You already downloaded SWACI TEC maps from ESPAS?

Fine, then you only need to specily the location of your downloaded ESPAS data and click the progress bar to start generating the time series plot, otherwise please visit the ESPAS data portal first and download some SWACI TEC maps.

The data is plotted right after the import of your ESPAS data was successful. Feel free to readjust your fiter settings to retresh your time series plot. You can pan and zoom the time series and also temporary deactivate several graphs by clicking the legend without reprocessing.

After processing you may download the data in JSON format or as PNG flle for further investigations by using the menu on the right top of the plot.

Path to Deme
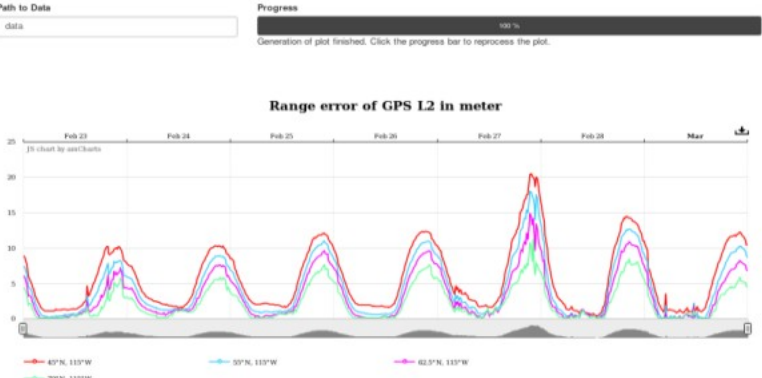

Figure 5.2. Graphical interface of the TEC Time Series Plotter VAS showing the range error for the L2 GPS frequency during the time period from 23.02 - 01.03.2014 in 5 minutes resolution. 
The ESPAS user can download TEC map data and the latest version of the service tool from the ESPAS portal. Since the service uses only HTML and JavaScript technology, it is straightforward to integrate it into existing web services. The caveat is the implementation of data provision for this service. The easiest solution is a static data hosting next to the application. A standalone version of this service was built by using node-webkit, an app runtime based on Chromium browser and node.js, which enables writing and distributing native applications with the common web technologies supporting Windows and Linux. Finally, the ESPAS user will have the opportunity to download an executable of this service next to the SWACI TEC maps which he can acquire from the ESPAS system. Since the app contains the web browser and all required HTML and JavaScript files, no installation is needed. The maintenance of such services in case of a data format change can be done directly at the data provider site, where the VAS was generated. Therefore, no cost intensive and time consuming changes at the ESPAS system or communications with the administrators are needed. New real data service tools can be easily made available by data providers at the ESPAS portal. 



\title{
5.1 HOW TO ACCESS DATA THROUGH ESPAS
}

\author{
I. Tsagouri ${ }^{1}$, A. Charisi $^{1}$ and F. Darrouzet ${ }^{2}$
}

\begin{abstract}
The homogenized access to data from the near-Earth space environment that are archived in different data repositories is the fundamental use case of the ESPAS platform. The access is provided through the ESPAS portal at https://www.espas-fp7.eu/portal, which was carefully designed in accordance to the users requirements. This chapter introduces the main functionalities of the system and elaborates examples of relevant data requests. The aim is to provide a brief guidance on how the end-user can search and download data by exploiting the platform's capabilities.
\end{abstract}

\subsubsection{Introduction}

The access to the data starts with the submission of metadata search requests. The compilation of a search query is supported by dynamic workflows that help the end-user to refine the search request based on a set of criteria that includes the following options:

- Time period: the time period when the observations were acquired

- Assets: the instruments and models that were used for the generation of the observations

- Observed properties: the observed properties that were measured in the observations

- Observation collections: the collections that the observations belong to

The end-user is able to initiate a metadata/data search query by any of these criteria and to complete the query through any combination of them. Each of them filters the previous one helping the user to conclude on the desirable set of data. The metadata search is open to all users with no registration required, while the data download service is available to registered users.

\footnotetext{
${ }^{1}$ National Observatory of Athens, Metaxa and Vas. Pavlou, 15236, Penteli, Greece

${ }^{2}$ Royal Belgian Institute for Space Aeronomy (IASB-BIRA), 3 Avenue Circulaire, 1180 Brussels, Belgium
} 


\subsubsection{Search and Download}

To initiate the metadata/data search, the user should reach the Search and Download page of the portal (see Fig. 5.1.1) in order to select one of the available options reported in the previous section, i.e. time period, assets, observed properties or observation collections.

\section{○)}

Search \& Download

Welcome to the ESPAS metadata/data search facility. You can contact us if you have questions or encounter a problem. Please follow one of the two search paths available to perform your query:

Progressive Search

Filter your search with different options as you go along (real-time)

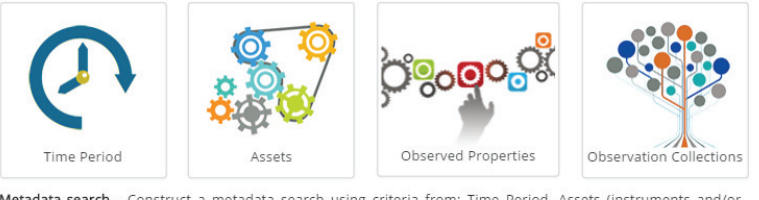

Metadata search - Construct a metadata search using criteria from: Time Period, Assets (instruments and/or models), Observed Properties and Observation Collections (visit our ESPAS Data Model and ESPAS Space Physics Ontology pages for more information) to search our metadata. Start with any of these criteria by clicking one of the buttons above and then continue with any other to filter further your results. You can submit your query at any stage of the progressive search.

Spatial/temporal Search Filter your search by time and location (off-line)

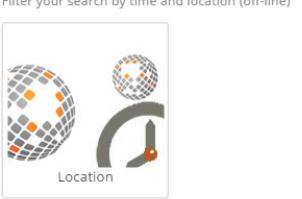

Metadata search - The Spatial / temporal Search allows you to select a restricted time period ( 30 days maximum) and then search the ESPAS metadata by platform (ground-based observatories and / or satellites) location.

(Click here to see a video tutorial)

Data download - You can download selected datafiles or values that are extracted from the data files (you will be required to log in as a registered user). Choose to save your results locally or plot them through the system.

NOTE - for the location search and for the download of extracted data values, a maximum of 30 days can be selected.

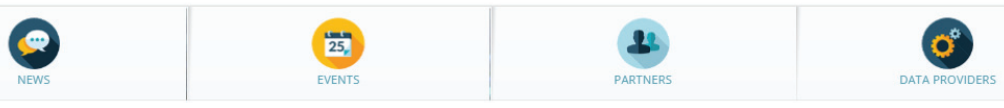

Fig. 5.1. 1. The Search and Download starting page. The end-user can start the query by clicking on any of the available search options/criteria.

In each of the steps one may follow, the selected criteria will be recorded in the top part of the pages, in the Current Selections area in order to help the users keep track of their preferences.

\subsubsection{Time period}

In the From date and To date fields the user may define the time period of interest in UTC timezone. Moreover, one may specify the subset of day in UTC (this will apply for all days in the selected time period) by using the fields Subset start and Subset end (see Fig. 5.1.2). 

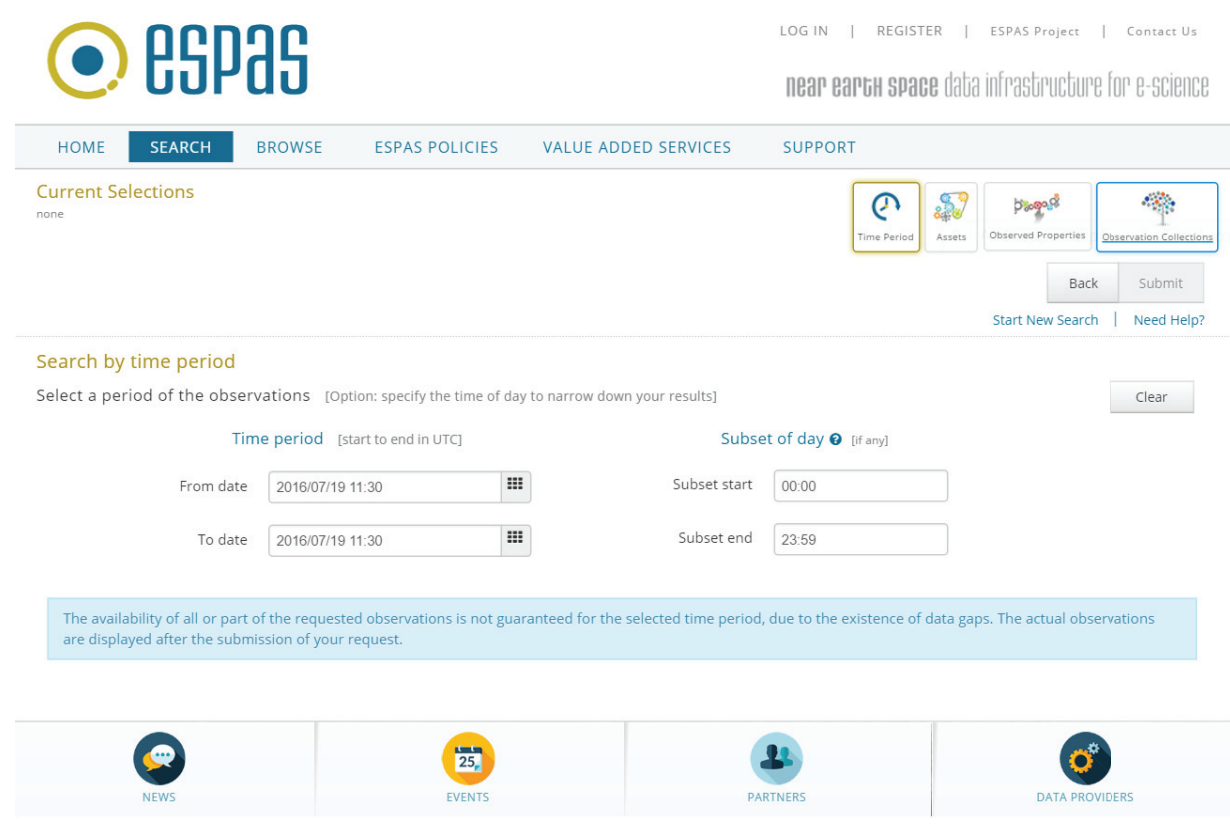

Fig. 5.1. 2. Selecting the Time Period.

\subsubsection{Assets}

Within ESPAS, an asset corresponds to an Instrument or a Model or a software package that was used to generate an observation. Entering the corresponding page, there is a list of all the assets (in alphabetical order) that are associated with observations grouped as Instruments and Models. The user may scroll down this list and select the assets to be included in the metadata query. The buttons Select All or Deselect All are able to select and deselect all the options respectively. In the left part of the page there are also some filters (Instrument type, Platform, Project) that the user may use to narrow down or facilitate the selection of assets presented in the right part. A hierarchical view of each filter is provided. Note also that the selection of an option automatically selects all its siblings in the hierarchy (see Fig. 5.1.3).

\subsubsection{Observed Properties}

Entering the Observed Properties page, in the right part there is a list of all the observed properties (in alphabetical order) that are associated with observations. The user may scroll down this list and select the observed properties to be included in the metadata query. The buttons Select All or Deselect All are able to select and deselect all the options, respectively. In the left part there are some filters 


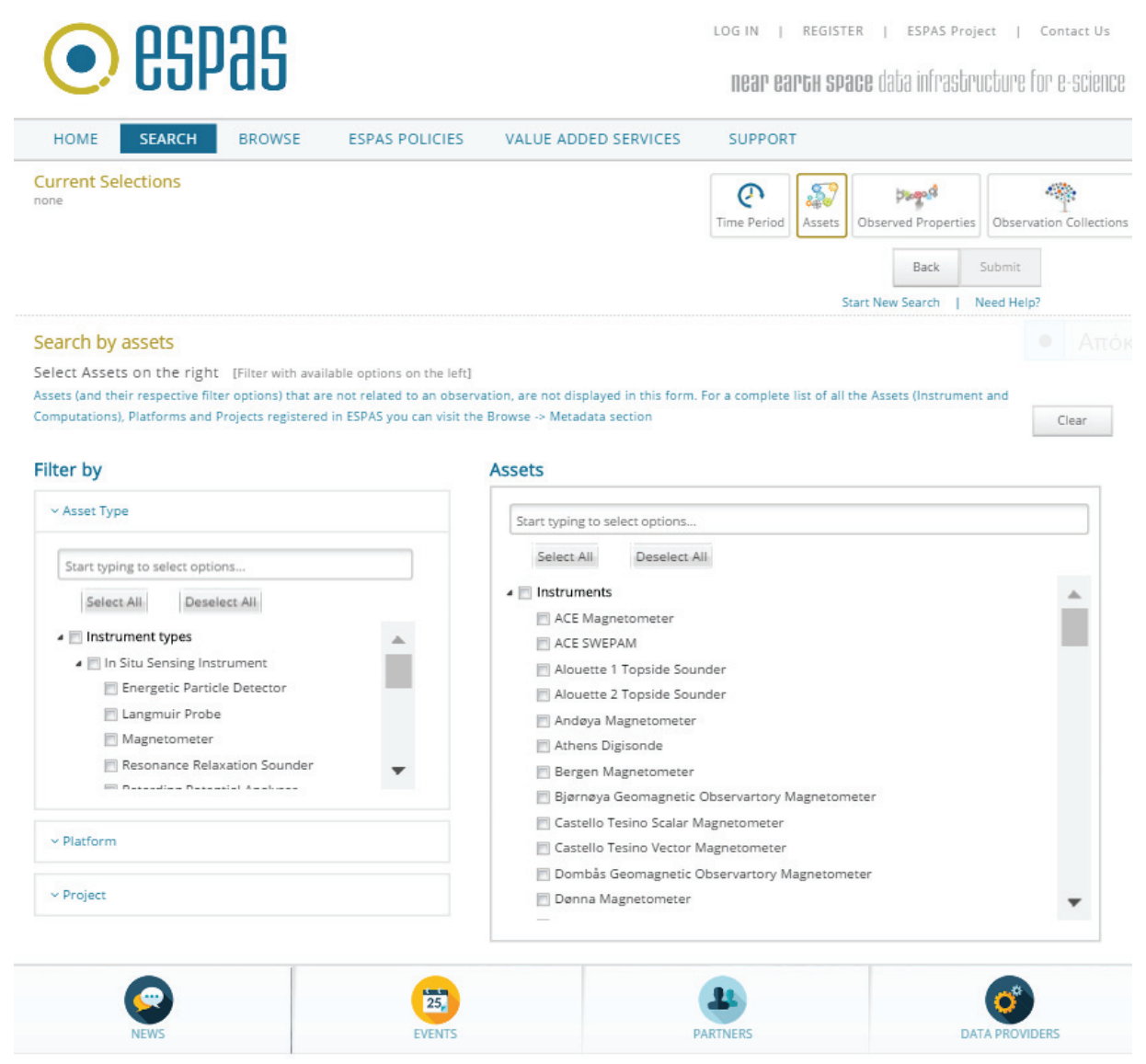

Fig. 5.1. 3. Selecting the Assets.

(Phenomenon, Measurand, Qualifier) that the user may use to narrow down or facilitate the selection of observed properties presented in the right part. A hierarchical view of each filter is provided. Note also that the selection of an option automatically selects all its siblings in the hierarchy (see Fig. 5.1.4).

\subsubsection{Observation Collections}

By entering the Observation Collections page, in the right part there is a list of all the observation collections (in alphabetical order) that are associated with at least one observation. The user may scroll down this list and select the observation collections to be included in the metadata query. The buttons Select All or Deselect All are able to select and deselect all the options, respectively. In the left part there are some filters (Region of Space, Dimensionality) that the user may use to 


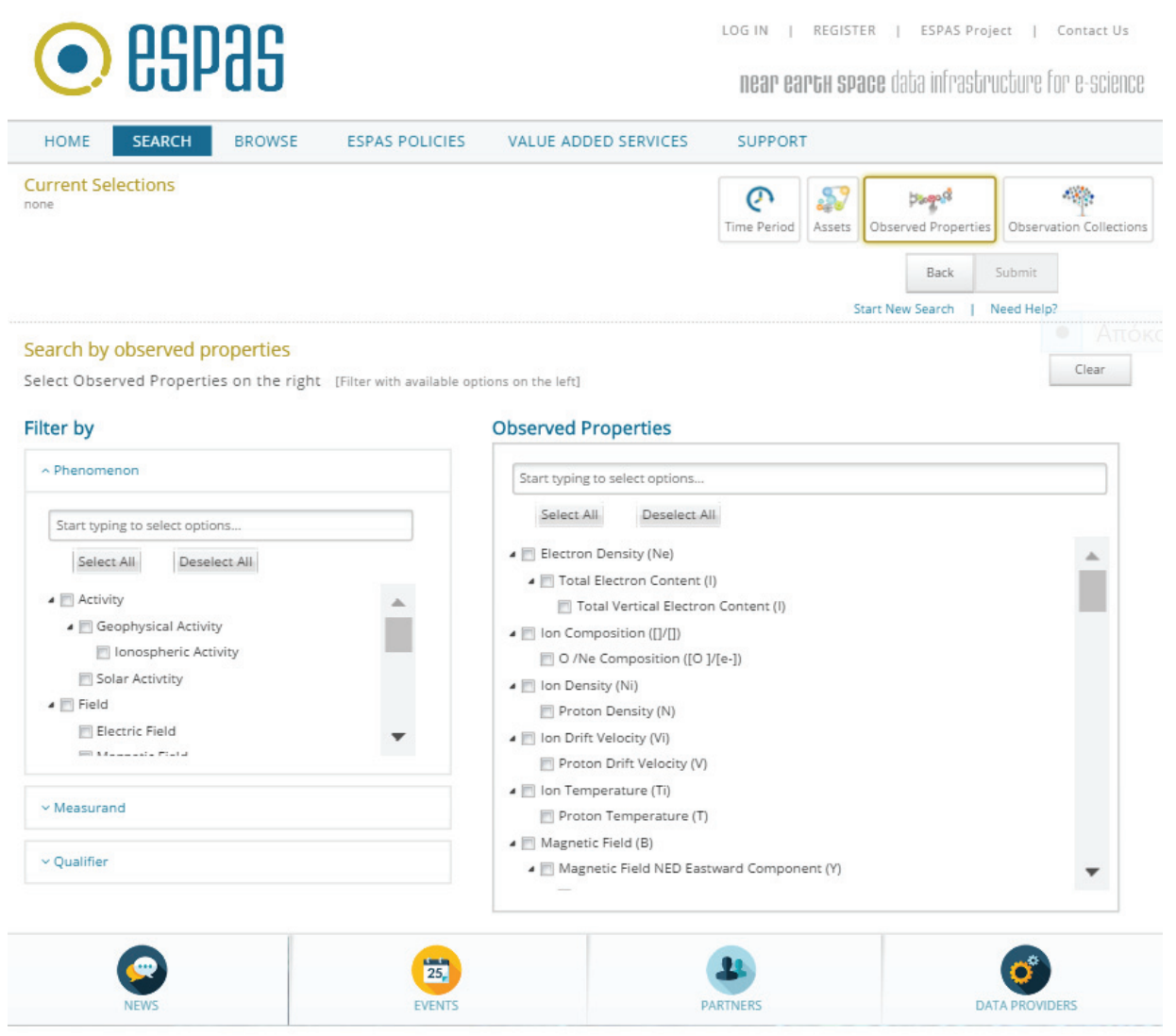

Fig. 5.1. 4. Selecting the Observed Properties.

narrow down or facilitate the selection of the observation collections presented in the right part. A hierarchical view of each filter is provided. Note also that the selection of an option automatically selects all its siblings in the hierarchy (see Fig. 5.1.5).

\subsubsection{Data Download}

The download of data (files or values) is a service that is available only from the Results page that is reached after the submission of a metadata search request. This service requires registration and log in the ESPAS portal. To be able to exploit the Download option, the user should select a time period up to 30 consistent days in a specific request. 


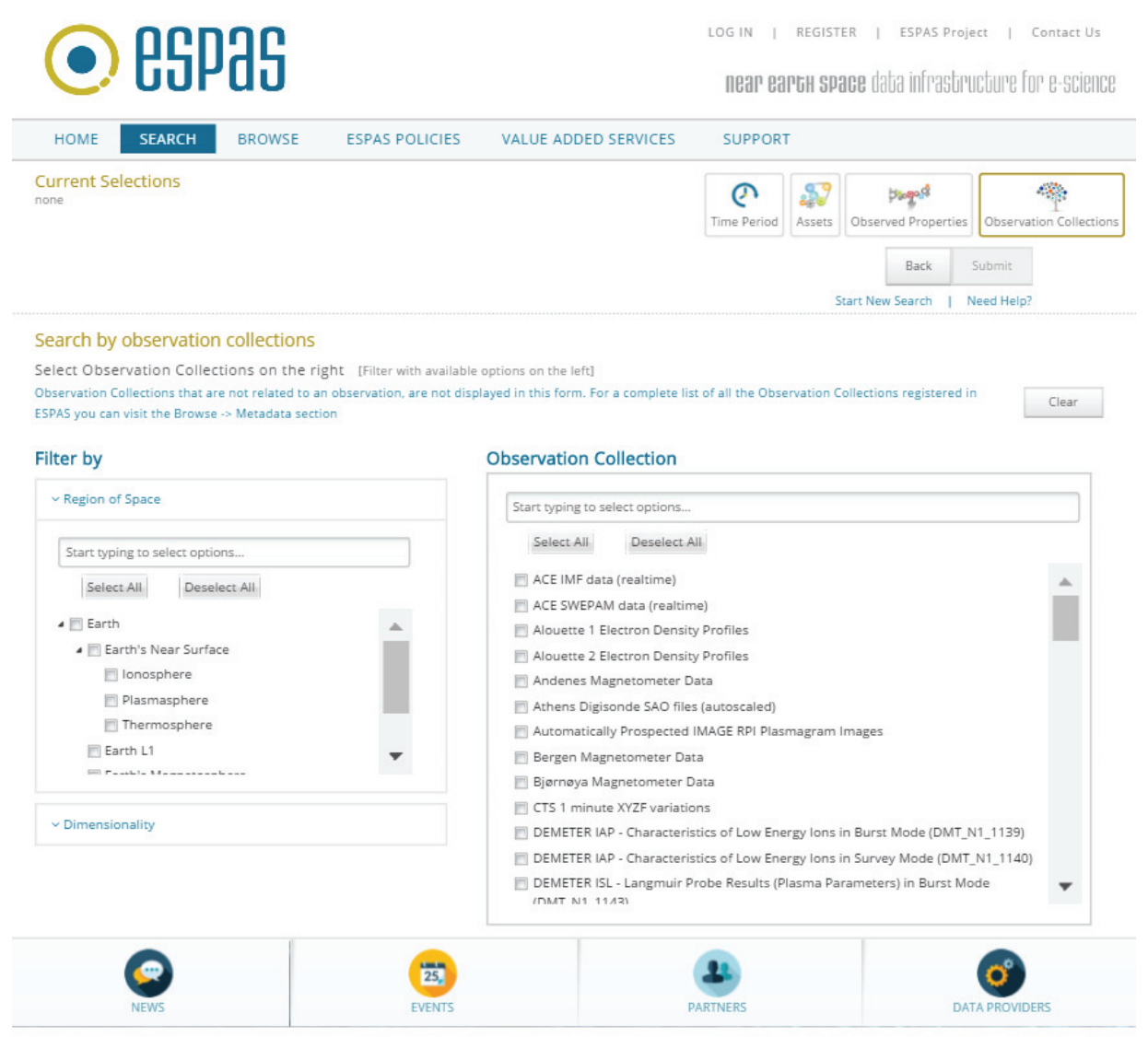

Fig. 5.1. 5. Selecting the Observation Collections.

\subsubsection{Examples}

\subsubsection{1 lonospheric data: observed and modeled foF2}

The screen shots that appear in Fig. 6 to 11 aim to describe how the end user can search and download modeled and observed values of the foF 2 critical frequency. In favor of simplicity, we assume that one is looking for foF 2 values obtained over Athens and Rome for a specific time interval, e.g. June 2006. The proposed workflow is:

1. Select the time interval (see Fig. 5.1.6)

2. Select the observed property (see Fig. 5.1.7)

3. Select the assets: Instruments and Models (see Fig. 5.1.8 and Fig. 5.1.9)

4. Select the observation collections and submit (see Fig. 5.1.10)

5. Download data (see Fig. 5.1.11) 
I. Tsagouri et al.: How to access data through ESPAS

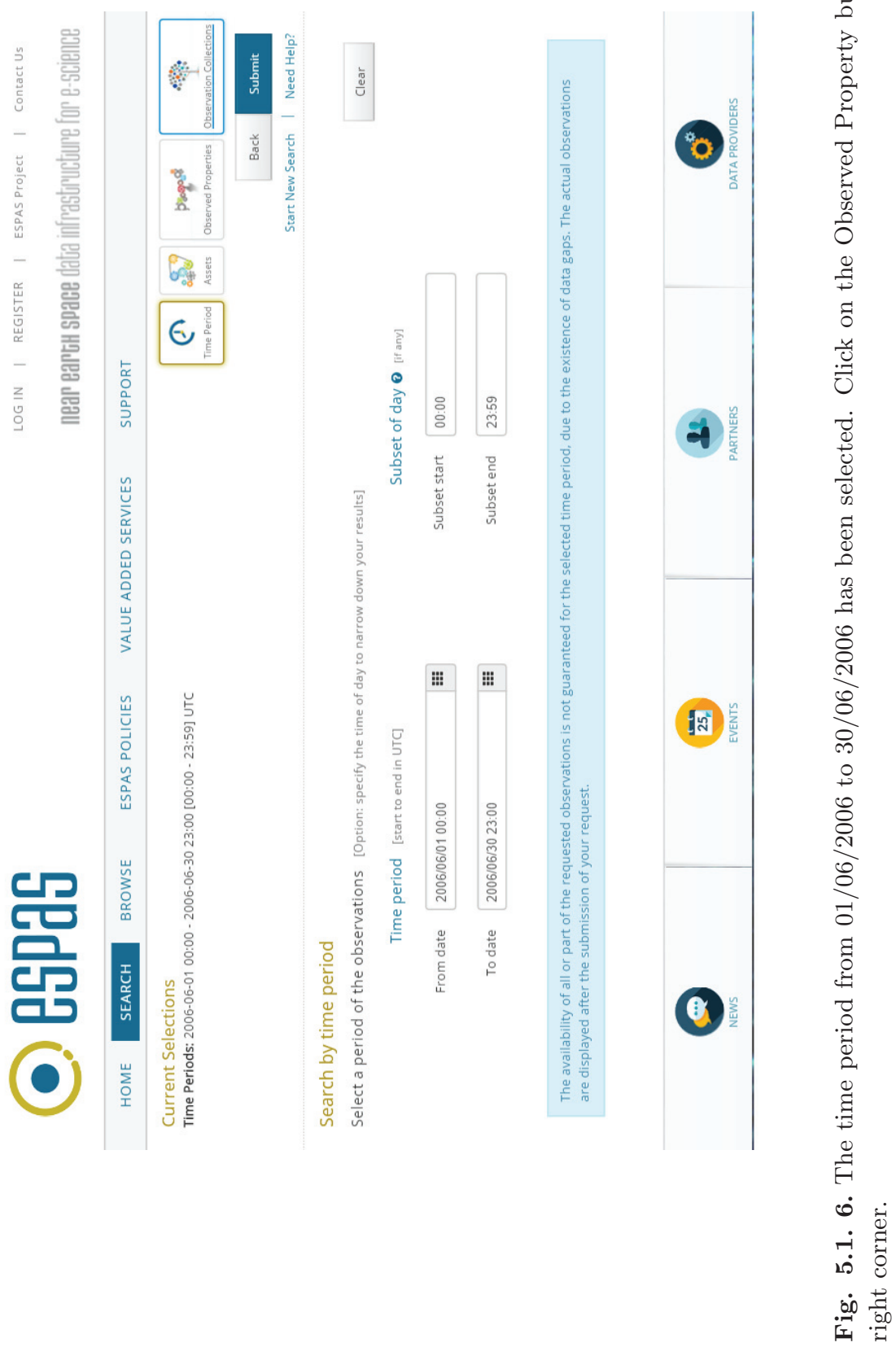



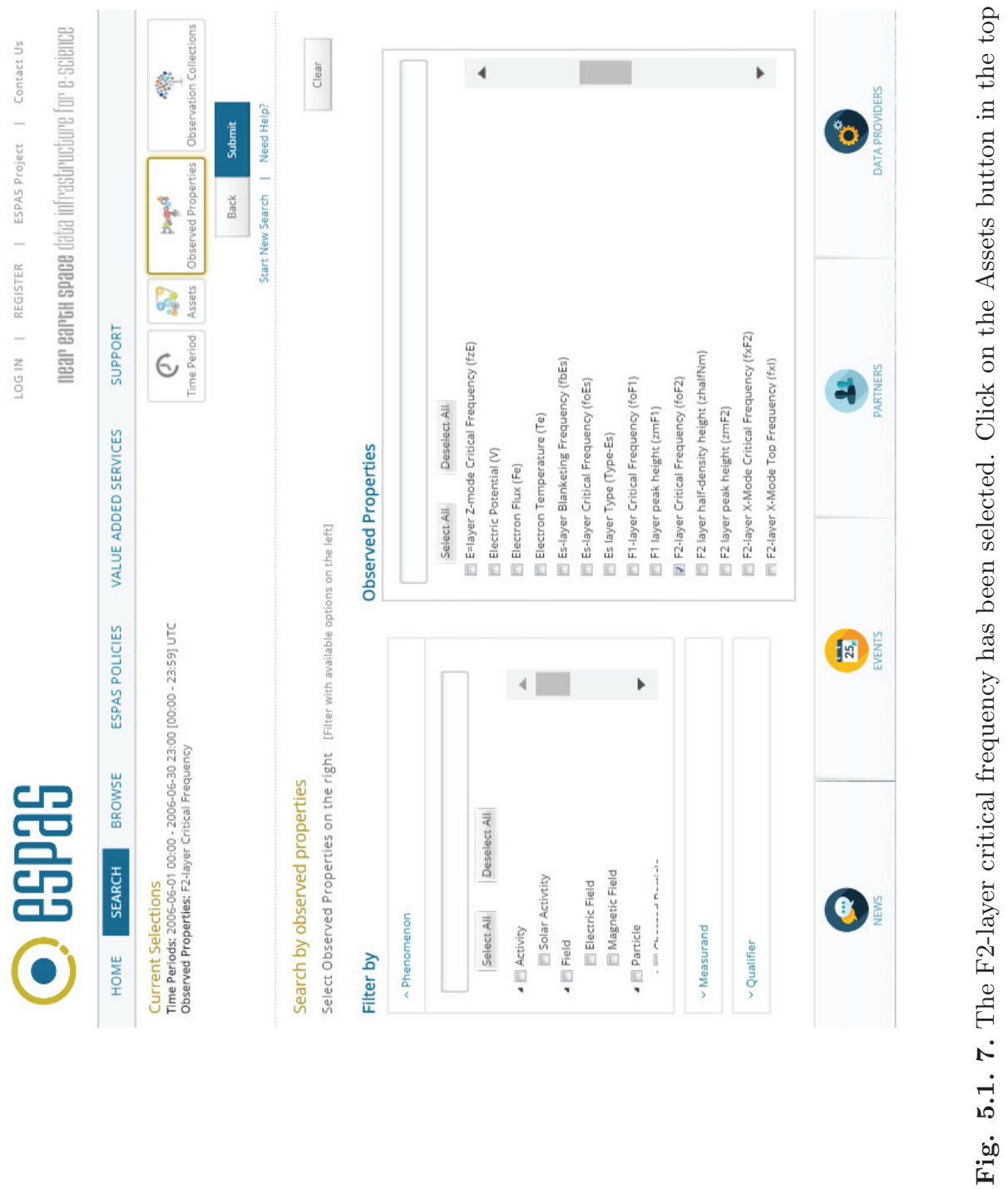
I. Tsagouri et al.: How to access data through ESPAS
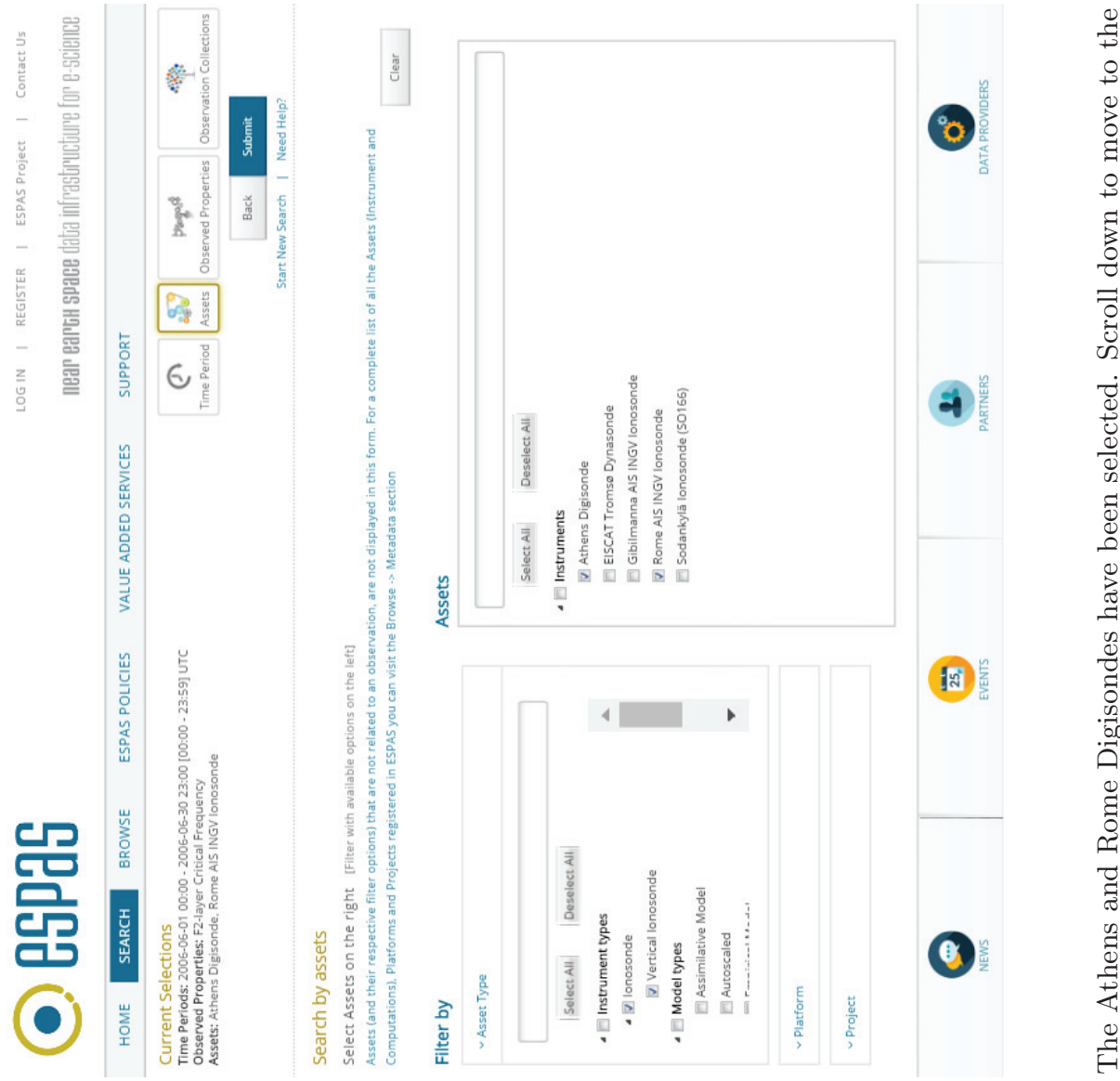

9)

范

$\underset{8}{8}$

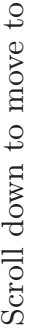

迅

ฐ

(

(iii)

(9) 莬

E

$\infty$

में

$\stackrel{\infty}{i}$ 

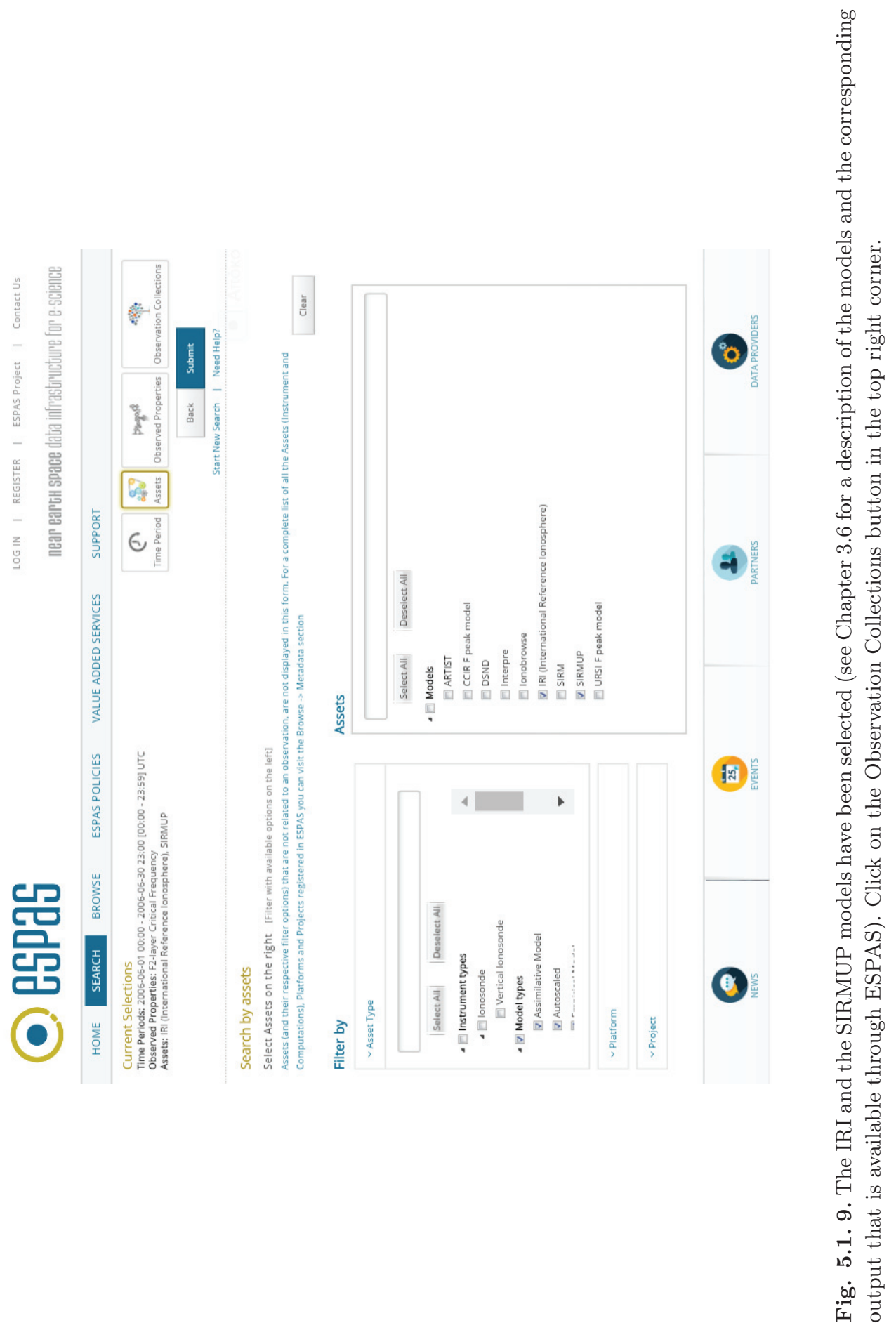
I. Tsagouri et al.: How to access data through ESPAS

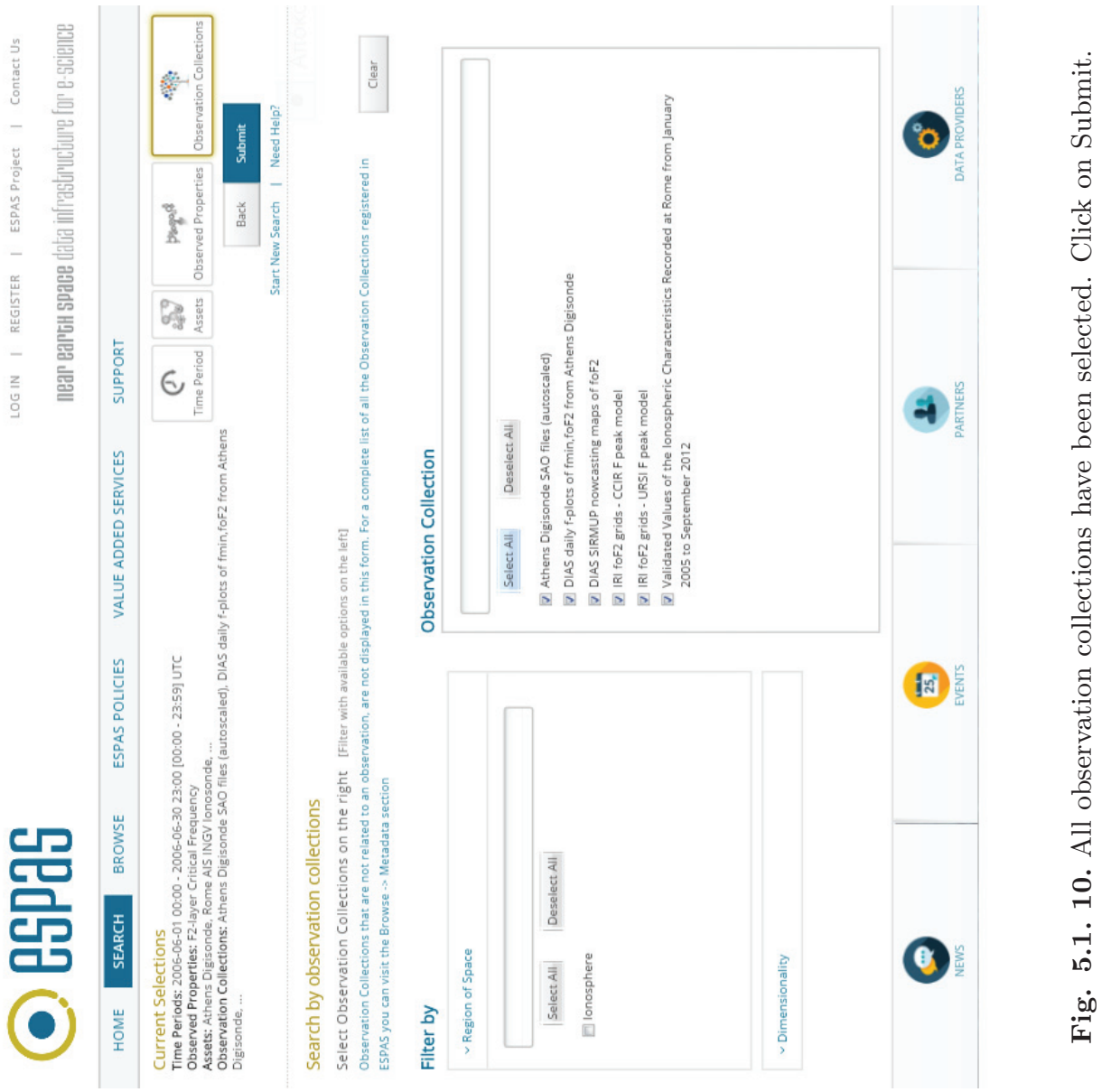




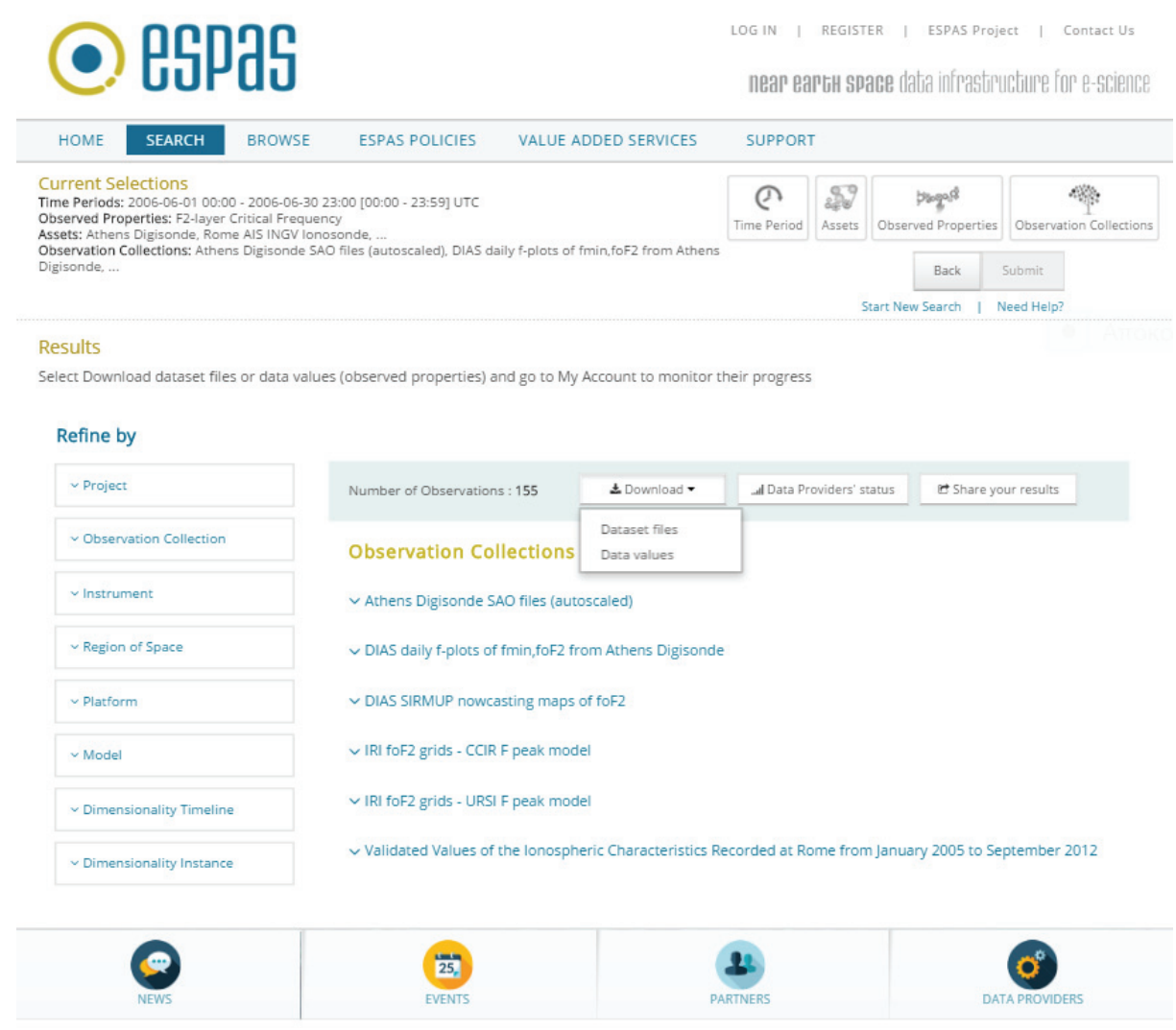

Fig. 5.1. 11. In the Results page and through the Download option the user is able to download the requested datasets either as raw files provided by each data provider by selecting the Dataset files option or as extracted data values in ASCII or XML formats by selecting the option Data values. Following the Data values option, the user may be able to plot the data directly on the web portal (see the example that follows in Section 5.1.3.2 of this chapter).

\subsubsection{Cluster and DEMETER satellite data}

The Cluster and DEMETER satellite datasets are described in Chapter 3.2. For the WHISPER instrument onboard Cluster, the data are directly downloaded from the Cluster Science Archive (CSA: http://www . cosmos .esa.int/web/csa/access) through the ESPAS wrapper installed at IASB-BIRA in Belgium. For the ISL instrument, the data have been first downloaded from the "Centre de Données de la Physique des Plasmas" (CDPP: https://sipad-cdpp.cnes.fr) and then stored on a server at NOA (National Observatory of Athens), where they are accessed 
through the ESPAS wrapper installed at NOA in Greece.

On the ESPAS web portal, both datasets can be accessed through the

- "Observation Collections" search: Select "DEMETER ISL - Langmuir Probe Results" and "WHISPER Electron Density", or

- "Observed Properties" search: select "Electron Density" and "Electron Temperature", or

- "Assets" search: select "ISL Langmuir probe on board DEMETER" and "WHISPER Instrument Onboard Cluster".

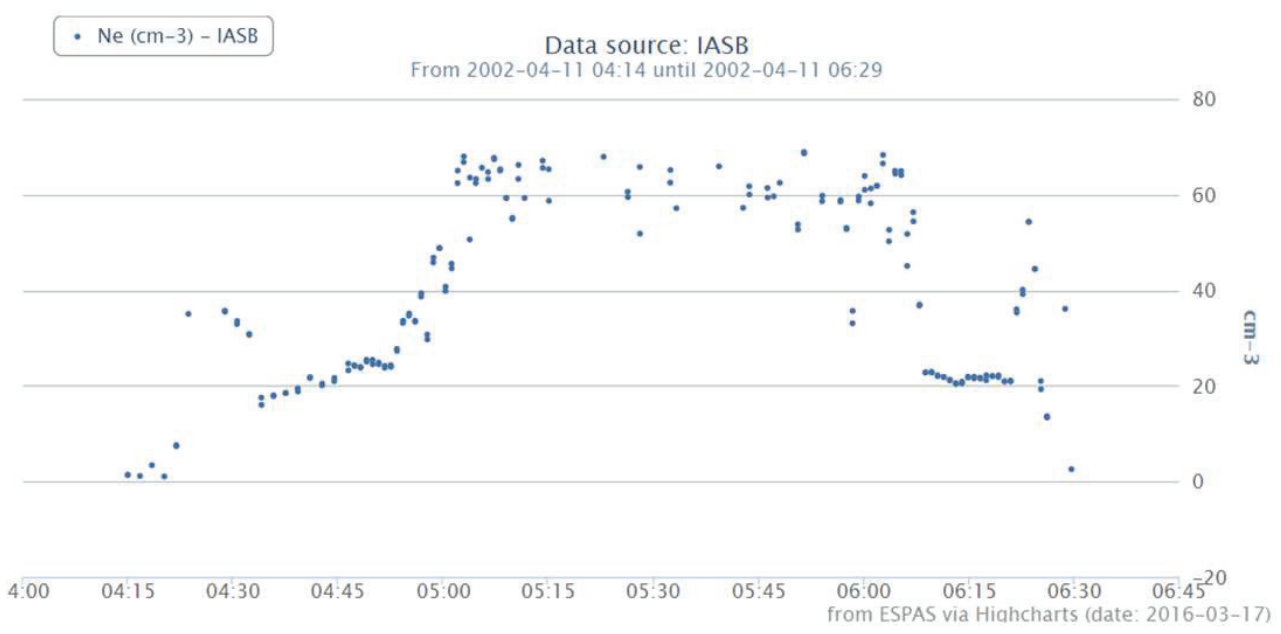

Fig. 5.1. 12. Electron density in $\mathrm{cm}^{-3}$ determined from WHISPER onboard $\mathrm{C} 1$ on 11 April 2002 during 2 hours and 45 minutes and plotted via the ESPAS user interface. (Courtesy of ESPAS)

After selecting the time period of the desired data, it is then possible to download the datafiles with the data in the format given by the data providers (ASCII file for WHISPER and binary file for ISL). For the WHISPER dataset, it is also possible to download data values with the extracted observed properties (in ASCII or XML format). Following the procedure visualized in Fig. 5.1.11, it is possible to plot directly the extracted values on the web portal. An example is shown on Fig. 5.1.12 with the electron density determined from WHISPER onboard C1 during the plasmasphere crossing of the event shown in Fig. 3.2.4 of Chapter 3.2 and plotted as a function of time. The plume crossings during the inbound and outbound passes are clearly seen on this density plot, as well as the higher density inside the main plasmasphere during perigee crossing near the equator. 



\section{Summary}

Mike Hapgood ${ }^{1}$, Anna Belehaki ${ }^{2}$ and the ESPAS consortium ${ }^{3}$

1. RAL Space, STFC Rutherford Appleton Laboratory, UK

2. National Observatory of Athens, Greece

3. https://www.espas-fp7.eu/trac/wiki/PublicPages/ESPASConsortium

The ESPAS project was funded under the EU/FP7 Programme with the goal of making Europe a foremost player in the efficient use and dissemination of comprehensive information about the near-Earth space environment. Europe has a long heritage of academic research on this environment, but the need for that research has gained a new significance in this decade because of growing awareness that variations in this environment (a key part of "space weather") have adverse impacts on technologies that underpin many infrastructures now critical to the functioning of those societies. Thus we need to better understand the physical processes in near-Earth space which lead to those impacts and how those processes are driven by the energy flowing from the Sun, e.g. via the solar wind.

ESPAS has contributed to advances in this science by establishing a platform that integrates the heterogeneous data available from instruments that monitor conditions in near-Earth space (a mixture of satellite-borne sensors and groundbased instruments). This great variety of datasets gives us diverse views of the physical processes operating in near-Earth space. This is a marvellous opportunity to challenge theoretical understanding of those processes, since those diverse views will provide strong constraints on theory. Thus this science needs facilities, such as ESPAS, that enable scientists to systematically explore and exploit multi-point measurements made across near-Earth space.

\subsection{ESPAS innovation}

To deliver this integration of heterogeneous datasets, the ESPAS Consortium has established a generic approach to handling data from the near-Earth domain, exploiting existing e-Science standards and tools for geospatial data. This innovative approach includes the following aspects: (a) an ESPAS "Data Model" that provides a standard and consistent way to describe an archive of data on conditions in nearEarth space, (b) an ESPAS Space Physics Ontology that provides a structured set of concepts and relationships that supports these descriptions and embodies them within a controlled vocabulary.

The ESPAS system built on this approach now provides powerful tools for searching diverse data archives. For example, a "progressive search" allows a scientist to apply a series of selection criteria in whichever order they prefer. Thus scientists can customise searches to their personal interests and their knowledge of the existing data. When they have found data of interest they can download those data, either as raw files, or, where available, as a timetagged set of values of selected 
parameters in the discovered data. The user can then manipulate and display the data as they wish.

Although the primary focus of ESPAS has been on helping scientists to discover data that can support research about the near-Earth space environment, we have sought to also facilitate access to the discovered data and to add some value to these data. In general the core ESPAS system will download these data in the native format of the archive, which is often specific to the type of measurement. Thus it is ultimately the user's responsibility to read those data into whatever analysis tools he or she wishes to use. In many ways this is unavoidable since the choice of those tools is very much a matter for individual groups and even individual users. There is no dominant standard for analysis tools in this area of science, e.g. several high-level programming languages are popular including IDL and Matlab. And as noted above, there is also no dominant standard for data exchange, for the very good reason that the data types are very diverse. This is a very different situation to much of astronomy where images are the dominant form of data and hence standards for wider data exchange have developed, e.g. based around the original FITS standard for digital transport of images.

Thus ESPAS has recognised that for many scientists in our area the critical issue is access to useful data, and that, once they have that data, they will be happy to work hard to read the data into their own analysis systems. Our core task has been to help them find and download those data, and, most important, to provide information on data formats and on potential tools to read those data (e.g. the TEC Time Series Plotter tool described in section 5). However, we recognised that there was value in providing a service that would allow user to download selected time series data in a common format. The selection would extract a subset of the data, covering a user-defined time period and a user-defined subset of the available parameters. The focus on time series reflects the central importance of time series measurements in the study of the near-Earth space environment (mirroring the importance of images in astronomy). We have implemented this download option for a number of datasets, focusing on those datasets where it was straightforward to implement methods for subsetting the data. This has proved to be a valuable addition to the ESPAS services, enabling users to download and analyse selected data. It has also enabled us to deliver a generic service for plotting the time series data that are ubiquitous in our area of science (and to make a plotting tool available to our users).

\subsection{Impact to the scientific developments and applications}

The ESPAS project has sought to address a number of audiences. The primary audience is, of course, the scientific community engaged in the study of the space environment in near-Earth space. But we have also sought to address some wider audiences including an applications community comprised of scientists and 
engineers working on technological systems whose performance is influenced by this environment. We have also addressed the wider data science community, learning from how they have solved problems in other science areas, but also providing them with a challenge in terms of the complexity of our data.

The science audience for ESPAS is diverse. It encompasses scientists involved in a huge variety of different measurement techniques and locations. These measurements include instruments on satellites and on the ground, and in both cases, a mixture of techniques including radio and optical remote sensing, in-situ measurements of energetic particles and electromagnetic fields. There is also a growing emphasis on development of models of the near-Earth space environment, both numerical and physics-based models. Thus we have a very diverse science audience, most of whom will be expert in their own niche areas, but not the whole field covered by ESPAS. Hence, ESPAS will help them by facilitating access to relevant data outside these niche areas.

The applications audience for ESPAS is in some ways simpler in that it is comprised of scientists and engineers who are not experts in the science of the nearEarth space environment and who do not seek to become experts. They simply require targeted information, data and advice that are relevant to their applications work. One key applications area is the development and operation of radio-based technologies that pass signals through Earth's ionosphere; this may be a transmission through the ionosphere between a satellite and the surface of the Earth, or a reflection off the ionosphere between two points on the surface of the Earth, or even a transmission between two satellites passing through the ionosphere. There is a huge, and ever growing, number of applications of such transionospheric radio propagation, e.g. the growing use of satellite applications, and most are affected by the ionosphere (with the precise effect dependent on the frequency). Other important applications areas include the generation of quasi-DC electric currents in electrically-grounded infrastructures (e.g. power grid, railway signals, pipelines) and the atmospheric radiation environment produced by radiation from space.

This applications audience reflects the potential of ESPAS to address the science and impact of space weather, i.e. the disturbances in near-Earth space and the upper atmosphere that can disrupt technologies critical to the smooth functioning of modern societies (as noted in the previous paragraph). These disturbances are driven by energy from the Sun, particularly via the tenuous outflow of hot plasma that we call the solar wind, but the near-Earth space environment plays a critical role in focusing (many thousand-fold) that energy in ways that greatly enhance the risk posed to critical technologies. Thus, ESPAS has significant potential to assist scientists and engineers working on space weather problems.

\subsection{Outlook}

ESPAS now has a Technology Readiness Level (TRL) 6, showing that it is a prototype system whose functionality has been verified in the academic 
environment and it is close to the expected performance. It should also be considered that due to its standardized tools (ISO data model), ESPAS has the potential to be integrated to a global e-infrastructure ecosystem for Earth, space and environmental data (see for example Ritschel et al., 2016). This integration will support studies of a number of key issues such as studies of long-term trends in the solar activity, the Earth's geomagnetic field and the upper atmosphere since it involves the exploitation of long time series of data from various regions in geospace (see for example Tsagouri et al., 2016).

Thus, an immediate future activity to exploit the system is to attract new data providers and encourage the existing data providers to update registered collections with new observations. This requires continuing efforts to raise awareness by dissemination activities among the relevant communities, including efforts to engage more strongly with the applications community. In this respect, the ESPAS consortium has to continue the training activities for both users of the system and for the data providers on the use of the tools offered by ESPAS and by other e-science systems that could be used together with ESPAS to maximize the benefits for the end-user work.

The already-existing population of ESPAS with a diverse range of data from the near-Earth space environment provides an excellent potential to support user-driven design and prototyping of innovative e-infrastructure services and applications to meet the needs of operators of critical infrastructures affected by space weather or other disturbances in geospace. The development of such innovative services (i.e. services workflows, software codes, and synthetic data products to support risk management) will promote multi-domain community-driven approaches (aviation, radio-systems, navigation, satellite operations, maritime and land transport, drilling, financial services) to fully exploit core e-infrastructure services with high economic innovation potential.

The intensity of all these activities depends on the available funding at national and EU level. The ESPAS community together with international partners works already towards this direction, seeking at the same time the support from the broader community of stakeholders.

\section{References}

Tsagouri, I., I. Galkin, T. Asikainen, Long-term changes in space weather effects on the Earth's ionosphere (2016), Advances in Space Research, http://dx.doi.org/10.1016/j.asr.2016.10.004

Ritschel, B., Borchert, F., Kneitschel, G.,Neher G., Schildbach, S.,Iyemori T., Koyama Y., Yatagai A., Hori, T., Hapgood M., Belehaki A., Galkin I., King T. (2016) Experiments using Semantic Web Technologies to connect IUGONET, ESPAS and GFZ ISDC data portals, Earth Planets Space, 68:181. doi:10.1186/s40623-016-0542-x 
Edited by:

Anna Belehaki, Mike Hapgood

and Juergen Watermann

\section{The ESPAS e-infrastructure:}

Access to data from near-Earth space

\section{Editors:}

Anna Belehaki, IAASARS, National Observatory of Athens, Greece Mike Hapgood, RAL Space, STFC Rutherford Appleton Laboratory, UK Juergen Watermann, jfwConsult, France

ESPAS provides an e-Infrastructure to support access to a wide range of archived observations and model derived data for the near-Earth space environment, extending from the Earth's middle atmosphere up to the outer radiation belts. To this end, ESPAS will serve as a central access hub for researchers who wish to exploit multi-instrument multipoint data for scientific discovery, model development and validation, and data assimilation, among others. Observation based and model enhanced scientific understanding of the physical state of the Earth's space environment and its evolution is critical to advancing space weather and space climate studies, two very active branches of current scientific research.

ESPAS offers an interoperable data infrastructure that enables users to find, access, and exploit near-Earth space environment observations from ground-based and spaceborne instruments and data from relevant models, obtained from distributed repositories. In order to facilitate efficient user queries ESPAS allows a highly flexible workflow scheme to select and request the desired data sets.

ESPAS has the strategic goal of making Europe a leading player in the efficient use and dissemination of near-Earth space environment information offered by institutions, laboratories and research teams in Europe and worldwide, that are active in collecting, processing and distributing scientific data. Therefore, ESPAS is committed to support and foster new data providers who wish to promote the easy use of their data and models by the research community via a central access framework. ESPAS is open to all potential users interested in near-Earth space environment data, including those who are active in basic scientific research, technical or operational development and commercial applications.

ISBN : 978-2-7598-1949-2

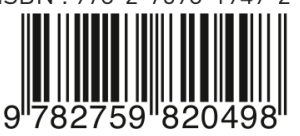

